\title{
The relevance, variability, and malleability of personality traits
}

Citation for published version (APA):

Prevoo, T. (2013). The relevance, variability, and malleability of personality traits. [Doctoral Thesis,

Maastricht University]. Datawyse / Universitaire Pers Maastricht. https://doi.org/10.26481/dis.20130524tp

Document status and date:

Published: 01/01/2013

DOI:

10.26481/dis.20130524tp

Document Version:

Publisher's PDF, also known as Version of record

\section{Please check the document version of this publication:}

- A submitted manuscript is the version of the article upon submission and before peer-review. There can be important differences between the submitted version and the official published version of record.

People interested in the research are advised to contact the author for the final version of the publication, or visit the DOI to the publisher's website.

- The final author version and the galley proof are versions of the publication after peer review.

- The final published version features the final layout of the paper including the volume, issue and page numbers.

Link to publication

\footnotetext{
General rights rights.

- You may freely distribute the URL identifying the publication in the public portal. please follow below link for the End User Agreement:

www.umlib.nl/taverne-license

Take down policy

If you believe that this document breaches copyright please contact us at:

repository@maastrichtuniversity.nl

providing details and we will investigate your claim.
}

Copyright and moral rights for the publications made accessible in the public portal are retained by the authors and/or other copyright owners and it is a condition of accessing publications that users recognise and abide by the legal requirements associated with these

- Users may download and print one copy of any publication from the public portal for the purpose of private study or research.

- You may not further distribute the material or use it for any profit-making activity or commercial gain

If the publication is distributed under the terms of Article $25 \mathrm{fa}$ of the Dutch Copyright Act, indicated by the "Taverne" license above, 


\title{
The Relevance, Variability, and Malleability of Personality Traits
}

\author{
Tyas Prevoo
}


Copyright (C)Tyas Prevoo, Maastricht 2013

All rights reserved. No part of this publication may be reproduced, stored in a retrieval system, or transmitted, in any form, or by any means, electronic, or mechanical, including photocopying, recording or otherwise, without prior permission in writing from the author.

This book was typeset by the author using $\mathrm{AT}_{\mathrm{E}} \mathrm{X}$.

Cover by a shy $\mathscr{G}$ aBsEnT art

Published by Datawyse - Universitaire Pers Maastricht ISBN 9789461592255 


\title{
The Relevance, Variability, and Malleability of Personality Traits
}

\author{
DISSERTATION \\ to obtain the degree of Doctor at \\ Maastricht University, \\ on the authority of the Rector Magnificus, Prof. dr. L.L.G. Soete \\ in accordance with the decision of the Board of Deans, \\ to be defended in public \\ on Friday May 24, 2013, at 10:00 hours
}

by

\section{Mathias Hubert Gerard Prevoo}

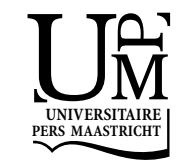




\section{Supervisors:}

Prof. dr. Lex Borghans

Prof. dr. Bas ter Weel

\section{Assessment Committee:}

Prof. dr. Andries de Grip (chairman)

Prof. dr. Thomas Dohmen

Prof. dr. Dinand Webbink (Erasmus University Rotterdam) 


\section{Acknowledgements}

The motto work hard, play hard(er) seems to imply a dichotomy of life, hinting towards a work-world, and a play-world. Such a view is flawed, in the same way as the dichotomization of skills into a cognitive and a noncognitive component. The introduction mentions that although there is a conceptual distinction between cognitive and noncognitive skills, these two sets of skills are highly complementary, and one cannot function without the other. The two can be substitutes to a certain extent - a high on one making up for a low on the other -, but the complementarity of the two results in the fact that the best performance can only be achieved in the case of high-high's.

I have found this to hold true also for the two worlds of work and play. While the quality of this dissertation is largely shaped by the quality of my work-world, and my play-world largely determines overall enjoyment of life, the complementarity of the two dictate that performance in one 'world' depends on the quality of the other 'world'. Frustration with a project or paper (i.e. a low work-world quality) is easily forgotten after an afternoon playing with my nephews (i.e. a high play-world quality), and to a lesser extent, a good day at work might also put a positive twist on an otherwise bad day. However, enjoyment of both playtime and worktime are maximized when both worlds meet. High high's in this setting provide the most productive work environment and also result in the best life memories, such as sharing slack(line) sessions or climbing trees with office mates or chilling on the beach in Malaga with a former roommate and colleagues after presenting work together at a conference.

Over the last few years, many people have contributed in varying ways to the development of this dissertation and it's author. The work presented in the following chapters would not have been accomplished without the academic, social, and moral support of a large group of people. Due to a lack of printing space, as well as incomplete memories, it is not possible to honor all contributions. Nevertheless, certain key players should be mentioned.

First of all, much gratitude goes out to my supervisors. Lex, you gave me a lot of freedom to dig into topics and details that I found interesting. This allowed me to explore several datasets and the problems they confronted me with. Your comments and remarks led me solutions I had not come up with myself. Bas, as tutor and supervisor during my master studies you already taught me valuable lessons regarding structuring my work and keeping the goal in mind. This guidance also proved essential during my PhD career, particularly towards the end, when it was time to finish up and bring everything together. Thank you both for your efforts throughout the years. 
Next, I would like to thank the members of the assessment committee (Andries de Grip, Thomas Dohmen, Dinand Webbink) for their efforts and comments. Where the assessment committee evaluated my final manuscript, the education-economics-clan made important contributions to earlier versions of chapters, mostly through interesting talks and discussions during the weekly lunch-meetings. On the administration side of things, Fleur, Silvana, and Sylvia have been invaluable in helping out with and organizing many small things that without their help would have been impossible to arrange.

Many of the skills used during my PhD were developed in my role as visiting research scholar at the University of Chicago in 2008. Bas, thank you very much for opening up this opportunity. Much gratitude also to Professor Jim Heckman for the invitation to be part of his research team. I thank my former Chicago colleagues for sharing their statistical, programming, and editing knowledge with me. This experience has proven to be of great value in producing and presenting my research results.

Many colleagues at FdEWB/SBE have made the years at TS53 very enjoyable. The Q\&A sessions with office mates Bart and Ulf, and neighbours Ron, Norbert, and Ehsan, provided quick and easy answers to small work-related questions, but often turned out to be less formal in-office soccer or basketball sessions. Many thanks for this laidback work atmosphere. Bart, thanks for letting me appoint you as my paranymph. Additional hallway coffee breaks and the pünktlich $12 \mathrm{pm}$ lunch meetings brought together friends and colleagues from a larger range of offices, including Mona, Thomas and Bas. Thanks for sharing and dragging me out of office.

Thanks not only to my friends at work, but also to those from in and around Maastricht and hometown Heerlen. Many thanks to all m-town slacklining members, friends, and likers for the many afternoons slack(lin)ing in the park. My old roomies at the Stationsstraat provided indoor fun on rainy days, ranging from dinners to wii-sessions. Paul and Jordi, thanks for the company and fun times and my apologies for slacking on house chores. Tuulia, our division of housework at the Tongerseweg was more effective, but your company, support and listening ear were most valuable to me, allowing me to clear my mind. The Parkstad clan (aka Sjappies) deserves special respect, including members from Heerlen- and Weltenghetto, as well as a Landgraaf-chapter. Sjappies - F, M\&E, R\&M, R, S\&A, T\&P - thanks for all the memories from numerous bday parties, NYE's, day- and weekendtrips, and a variety of nights out.

Last, but certainly not least, is the gratitude I owe to my family. Mom, thanks for investing in me throughout the years. You have made me who I am today. You are always there to help me in any way you possibly can. Reint, voor jou geldt hetzelfde. Je staat altijd klaar om te helpen of om gewoon gezellig te gaan touren. Bedankt voor je liefde voor mam, en voor mijn twee zussen. Maarten, I'm proud to have you as my (little) brother, and of course as my paranymph. Many thanks goes to the Prevoo family, including those from around the corner, and those from afar, but of course also to those who are no longer among us. You all helped shape me and therefore also this work.

\section{Tyas Prevoo, Maastricht, March 2013}




\section{Contents}

1 Introduction $\quad 1$

1.1 Motivation . . . . . . . . . . . . . . . . . . 1

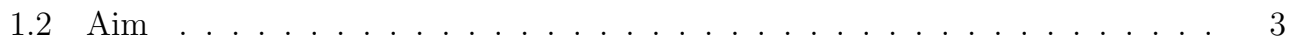

1.3 Outline and Results . . . . . . . . . . . . . . . . . . 4

2 The Investment Potential of Noncognitive Skills $\quad 7$

2.1 Introduction . . . . . . . . . . . . . . . . . . 8

2.2 Relevance . . . . . . . . . . . . . . . . . . . . . 10

2.2.1 Evidence from the Netherlands and Germany . . . . . . . . . . . . 13

2.2 .2 Discussion ............................ 15

2.3 Variability . . . . . . . . . . . . . . . . . . . . . . 19

2.3.1 Evidence from the Netherlands and Germany . . . . . . . . . . . . 25

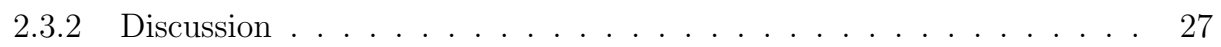

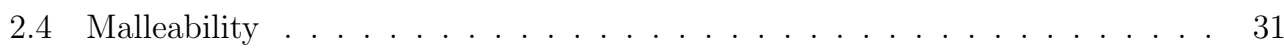

2.5 Conclusion . . . . . . . . . . . . . . . . . . . . 34

Appendix 2.A Big Five Traits . . . . . . . . . . . . . . . . . . . . 37

2.A.1 DNB Household Survey (DHS) . . . . . . . . . . . . . . . . . . 37

2.A.2 German Socio-Economic Panel (GSOEP) . . . . . . . . . . . . . 37

Appendix 2.B Outcome Measures . . . . . . . . . . . . . . . . . . . . . . . 40 
3 The Importance of Early Conscientiousness 43

3.1 Introduction . . . . . . . . . . . . . . . . . . . 44

3.2 Data . . . . . . . . . . . . . . . . . . . . . . . . . . . . . .

3.2.1 Personality Measures . . . . . . . . . . . . . . . . . . . 48

3.2.2 Outcome Measures . . . . . . . . . . . . . . . . . . . . 49

3.2 .3 Other Measures . . . . . . . . . . . . . . . . . . . . 51

3.2 .4 Selection . . . . . . . . . . . . . . . . . . 51

3.2 .5 Descriptive Statistics . . . . . . . . . . . . . . . . . . 52

3.3 Personality Traits and Outcomes . . . . . . . . . . . . . . . . 54

3.3.1 Basic Estimates . . . . . . . . . . . . . . . . . . . . . . . . . . . . . . . . . . 54

3.3 .2 Extensions . . . . . . . . . . . . . . . 56

3.4 Measurement Error . . . . . . . . . . . . . . . . . . . 6 61

3.5 Decomposing Conscientiousness . . . . . . . . . . . . . . . . 63

3.5.1 Lower-Order Structure . . . . . . . . . . . . . . . . . . . 63

3.5.2 Returns to Different Items . . . . . . . . . . . . . . . . 66

3.6 Policy Perspective . . . . . . . . . . . . . . . . . . . . 69

3.7 Conclusion . . . . . . . . . . . . . . . . . . . . . . 73

Appendix 3.A Personality Measures . . . . . . . . . . . . . . . . 75

Appendix 3.B Rutter, Self-esteem, and Locus of control . . . . . . . . . . . . . 77

Appendix 3.C Supporting Tables . . . . . . . . . . . . . . . . . . . . . . 81

4 Change of Personality Traits During Childhood 93

4.1 Introduction . . . . . . . . . . . . . . . . . . . . 94

4.2 Data and Approach . . . . . . . . . . . . . . . . . . . . . . . . . . . . . . . . . . . . .

4.2 .1 Personality measures . . . . . . . . . . . . . . . . . . . . . . . . . . . . . . . . . 96

4.2.2 Loss of parent . . . . . . . . . . . . . . . . . . . . . 97

4.2 .3 Family characteristics . . . . . . . . . . . . . . . . . . . . . . . . . . . 98

4.2 .4 Estimation . . . . . . . . . . . . . . . . . . 99

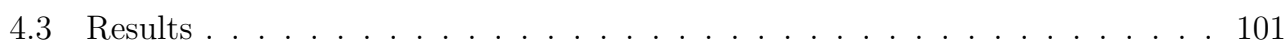

4.3.1 Baseline results . . . . . . . . . . . . . . . . . . . 101

4.3 .2 Selectivity . . . . . . . . . . . . . . . . . 102

4.4 Heterogeneous Effects . . . . . . . . . . . . . . . . . . . . . . . . . . . 104

4.4 Reasons for Loss . . . . . . . . . . . . . . . . . . . . . . . . 104

4.4 Age at Loss . . . . . . . . . . . . . . . . . . . . . . . . . . . . . . . . . . . . . . . . . . . . . . . . . .

4.4 .3 Gender Differences . . . . . . . . . . . . . . . . . . 108

4.5 Endogeneity and Sample Selection . . . . . . . . . . . . . . . . . 110

4.5.1 Placebo Effects of Losing a Parent . . . . . . . . . . . . . . . . . . 110

4.5.2 Sample Selection . . . . . . . . . . . . . . . . 112

4.6 Conclusion . . . . . . . . . . . . . . . . . . . . . 116

Appendix 4.A Regression Tables . . . . . . . . . . . . . . . . . 119

Appendix 4.B Results for Big Five Personality Traits . . . . . . . . . . . . . . 125

4.B.1 Baseline results and Selectivity . . . . . . . . . . . . . . . 125

4.B.2 Heterogeneous effects . . . . . . . . . . . . . . . . 127 
5 Stimulating Effective Habits in Teenagers 131

5.1 Introduction . . . . . . . . . . . . . . . . . . . . . 132

5.2 Treatment and Hypotheses . . . . . . . . . . . . . . . . . . . 134

5.3 Data and Approach . . . . . . . . . . . . . . . . . . 136

5.4 Results . . . . . . . . . . . . . . . . . . . . . . . . . . . . 140

5.4.1 High School Performance . . . . . . . . . . . . . . . . . . . 140

5.4 .2 Satisfaction with Study Choice . . . . . . . . . . . . . . . . . . 142

5.4 .3 Performance in Tertiary Education . . . . . . . . . . . . . . . . . 142

5.4.4 Personality . . . . . . . . . . . . . . . . . . . . . 143

5.4.5 Robustness Checks . . . . . . . . . . . . . . . 146

5.5 Conclusion . . . . . . . . . . . . . . . . . . . . . . . . . . 147

Appendix 5.A Big Five Traits . . . . . . . . . . . . . . . . . . . . 149

Appendix 5.B Attribution Style . . . . . . . . . . . . . . . 153

Appendix 5.C Regression Tables . . . . . . . . . . . . . . . . . . . 155

$\begin{array}{ll}\text { Bibliography } & 161\end{array}$

$\begin{array}{ll}\text { Samenvatting (Summary in Dutch) } & 167\end{array}$

$\begin{array}{lr}\text { Curriculum Vitae } & 175\end{array}$ 



\section{List of Figures}

2.1 Big Five Traits and Outcomes . . . . . . . . . . . . . . . . . 14

2.2 Big Five Traits, Controlling for Cognitive Ability . . . . . . . . . . . . . . 16

2.3 Big Five Traits and Outcomes, by Gender . . . . . . . . . . . . . . . . 17

2.4 Stability of Big Five Traits . . . . . . . . . . . . . . . . . . . . . . . . . . . . . . . . . . . . . . . .

2.5 Levels of Big Five Traits . . . . . . . . . . . . . . . . . . . . . . . . . . . . . . . . . . . . . . . . . . .

2.6 Change of Big Five Traits . . . . . . . . . . . . . . . . . . . . 29

3.1 Socio-Economic Outcomes by Deciles of Conscientiousness . . . . . . . . . 53

3.A.1 Clustering of Age-16 Personality Items into Four Big Five Traits . . . . . . 76

4.1 Loss of Parent on Personality . . . . . . . . . . . . . . . . . . . 103

4.2 Reasons for Loss of Parent on Personality . . . . . . . . . . . . . . . . . 105

4.3 Age at Loss of Parent on Personality . . . . . . . . . . . . . . . . . . 107

4.4 Loss of Parent on Personality, by Gender . . . . . . . . . . . . . . . . . 108

4.5 Reasons for Loss of Parent on Personality, by Gender . . . . . . . . . . . . 109

4.6 Placebo Effects: Loss of Parent . . . . . . . . . . . . . . . . . 111

4.7 Placebo Effects: Reason for Loss of Parent . . . . . . . . . . . . . . . . . . 112

4.8 Loss of Parent on Personality, Restricted Sample . . . . . . . . . . . . . . . 116

4.B.1 Loss of Parent on Big Five Traits . . . . . . . . . . . . . . . . . 126

4.B.2 Reasons for Loss of Parent on Big Five Traits . . . . . . . . . . . . . . . . 128

4.B.3 Loss of Parent on Big Five Traits, by Gender . . . . . . . . . . . . . . . . . 129

5.1 Treatment effects on Grade Averages . . . . . . . . . . . . . . . . . . . . 141

5.2 Treatment effects on Subject Specific Grades . . . . . . . . . . . . . . . . 141

5.3 Treatment effects on Tertiary Education . . . . . . . . . . . . . . . . 143

5.4 Treatment effects on Big Five Personality Traits . . . . . . . . . . . . . . 144

5.5 Treatment effects on Attribution Style . . . . . . . . . . . . . 145 



\section{List of Tables}

2.A.1 Big Five Items and Scales (DHS) . . . . . . . . . . . . . . . . . . . . . . . . . . 38

2.A.2 Big Five Items and Scales (GSOEP) . . . . . . . . . . . . . . . . . . . . . . 39

2.B.1 Outcome Measures for DHS and GSOEP . . . . . . . . . . . . . . . 41

3.1 Personality Items and Constructs . . . . . . . . . . . . . . . 50

3.2 Correlations of Personality with Outcomes . . . . . . . . . . . . . . 52

3.3 Returns to Personality, Main Specification . . . . . . . . . . . . . 55

3.4 Returns to Conscientiousness, All Specifications . . . . . . . . . . . . 57

3.5 Returns to Personality, Controlling for Occupational Sorting . . . . . . . . 60

3.6 Adjusting for Measurement Error: 2SLS, EIV regression and SEM . . . . . 62

3.7 Correlations of Conscientiousness Items with Personality and Outcomes . . 65

3.8 Returns to Conscientiousness Items on Wages, All Specifications . . . . . . 67

3.9 Returns to Conscientiousness Items on Outcomes, Main Specification . . . 68

3.10 Effects of Change in Personality Traits on Outcomes . . . . . . . . . . . . . 70

3.11 Effects of Large Decreases and Increases in Personality Traits on Outcomes 72

3.B.1 Correlations and Covariances of Rutter Items . . . . . . . . . . . . . . . 78

3.B.2 Correlations and Covariances of Self-esteem and Locus of Control Items . . 79

4.1 Distribution of Raw Personality Scores . . . . . . . . . . . . . . . . . 97

4.2 Descriptives by Loss of Parent . . . . . . . . . . . . . . . . . . . . . . . . . . . . . . . . . . . . . . .

4.3 Differences in Personality from Loss of Parent . . . . . . . . . . . . . . 101

4.4 Means for Selective Samples . . . . . . . . . . . . . . . . . . . . . 114

4.A.1 Effect of Loss of Parent on Personality Level at Age 16 . . . . . . . . . . . 120

4.A.2 Effect of Loss of Parent on Personality Change Between Ages 10 and 16 . . 121

4.A.3 Effect of Reason for Loss of Parent on Personality Development . . . . . . 122

4.A.4 Effect of Age at Loss of Parent on Personality Development . . . . . . . . . 123

5.1 Bias in Questionnaire Response . . . . . . . . . . . . . . . . 137

5.A.1 Inter-item Correlations and Covariances of Big Five Items . . . . . . . . . . 150

5.C.1 High School Performance: Average Exam Grades . . . . . . . . . . . . . . 155

5.C.2 High School Performance: Subject Specific Exam Grades . . . . . . . . . . 156

5.C.3 Study Choice and Performance in Tertiary Education . . . . . . . . . . 157

5.C.4 Big 5 Personality Traits . . . . . . . . . . . . . . . . . . . 158

5.C.5 Attribution Style: Positive and Negative Events . . . . . . . . . . . 159 



\section{Introduction}

\subsection{Motivation}

Cognitive ability is an important determinant of socio-economic success. In general, people with a higher level of cognitive ability earn higher wages, have better jobs, are more healthy and happy, and less prone to make mistakes. But there is more. We also know that the people with the highest levels of cognitive ability have a hard time. Malcolm Gladwell describes one such individual in his book Outliers. His name is Christopher Langan and he obtained higher scores on an IQ test than Albert Einstein did. Nevertheless, he did not become a successful scientist or entrepreneur. It turns out that he is unable to speak up for himself, and does not know how to reason and negotiate with those in positions of authority. Another example are the Termites, a group of incredibly smart children selected by psychologist Terman in the 1920s. Of the 730 selected children, about a third dropped out of college. Recent studies, such as How Children Succeed by Paul Tough and Willpower: Rediscovering the Greatest Human Strength by Roy Baumeister and John Tierney also point at capacities other than cognitive ability to explain success in life.

In the economic literature, Gary Becker (1964) developed the concept of human capital. He argued that people can invest in themselves by improving their cognitive abilities, skills, health, character and personality, to improve future outcomes, similar to the investments in physical capital that also serve to increase future productivity. Human capital theory stresses that abilities are valuable assets and explains the economic role of education as a way to change these abilities. Although Becker's description covered a broad spectrum of facets of human capital, such as cognitive ability, health, character and personality, the economic literature interpreted human capital as cognitive abilities for a long time.

However, the anecdotal evidence mentioned above and the findings from a number of recent studies have changed the weight put on cognitive ability in explaining socio-economic outcomes. Perhaps the most stunning evidence is presented in a series of papers by James Heckman on the children selected into the Perry Preschool Program in the United States (e.g. Heckman, Moon, Pinto, Savelyev \& Yavitz, 2010; Heckman, Malofeeva, Pinto \& Savelyev, 
2008, 2012). A group of 123 3-year olds from Ypsilanti, Michigan, were divided into two groups: a control group and a treatment group. The children in the treatment group received intensive treatment for two years, to foster their skills. The short run results demonstrated that children from the treatment group showed much larger increases in IQ scores during treatment than their peers from the control group. However, these initial increases in cognitive skills faded away, and by the age of 8 , children from both groups no longer differed in IQ. Follow-ups up until age 40, however, still revealed economically and statistically significant effects in terms of employment, educational performance, and criminal behavior. The authors find that these effects are mediated by changes in noncognitive skills (Heckman et al., 2012), with children from the treatment group showing higher scores on measures of noncognitive skills.

These insights have contributed to a new and mounting body of research on the importance of noncognitive skills in explaining socio-economic outcomes. Although the literature shows that there is no clear empirical distinction between cognitive and noncognitive skills, the term noncognitive generally refers to those skills not part of what we usually think of when defining cognitive ability or pure intelligence (such a general intelligence $g$, as defined in Herrnstein \& Murray, 1994). The new body of literature benefits from its multidisciplinary focus involving knowledge about brain development from the neurosciences, insights from (personality) psychology and from the economics literature, but also from the child development literature. The integration of scientific disciplines has been a tremendous boost for the body of knowledge on noncognitive skills (e.g. Borghans, Duckworth, Heckman \& Ter Weel, 2008a). Both cognitive and noncognitive skills have value in the production function, and the technology of skill formation postulates that the development of both cognitive and noncognitive skills depends on innate ability as well as investments (e.g. Cunha \& Heckman, 2007; Cunha, Heckman, Lochner \& Masterov, 2006).

While the advances in recent years have led to further development of human capital theory, they have also raised some additional questions. With noncognitive skills as an additional factor in the production function, we need to address the issue of how to measure these skills, or personality traits. Having addressed the issue of measurement, the relevance of different personality traits for varying outcome domains needs to be mapped. Do all traits matter equally for wages, education, health, and social outcomes? Or are the effects heterogeneous across traits and individuals? Given that individuals mature in terms of cognitive skills in childhood, the question arises to what extent this also applies to personality. Does personality mature early in life, or do personality traits vary throughout the life cycle? Lastly, to what extent is personality malleable, and can desirable personality traits be developed or improved by social policy or education programs?

Policymakers place great emphasis on developing cognitive skills and focus on achievement test scores to assess the performance of children and to evaluate education systems. Later on, universities like to admit those students with the highest cognitive test scores in high school, and employers use IQ tests to select workers. Despite the widespread use, the skills that they measure are not well-understood. It turns out that programs that enhance noncognitive skills have an important place in a successful policy portfolio. Relying only on curricula that foster cognitive skills is likely to overlook crucial opportunities to develop noncognitive skills (e.g. Borghans, Diris, Heckman, Kautz, \& Ter Weel, 2012). 


\section{$1.2 \quad \operatorname{Aim}$}

The aim of this dissertation is to contribute to the discussion on the relevance, variability, and malleability of personality. From an economic point of view, in line with the view on the productivity of human capital, the question is what the returns to personality traits are, and whether or not these traits are subject to change within an individual, and therefore also whether or not they are susceptible to investments directed at their development.

Within the framework of human capital theory, for individuals to be able to make wellinformed investment decisions, several pieces of information are needed. People need to be aware of what human capital is, which aspects of it are valued, how to invest in these different traits, and what the potential returns of such investments would be. An individual looking to maximize his income, needs to know what his employer values in an employee. He will then need to determine how he scores on these characteristics and figure out whether or not he could improve on some of these aspects. With general education being mandatory up until the age of sixteen in most developed countries, the choice of investing in higher cognitive skills and a broader knowledge base has already been forced upon us. The next determinant is then to what extent individuals reap the benefits of these investments, and if there are other investment decisions left for the individual to enhance his human capital, and thus his value in the labor market.

While individuals attend schooling at different levels or tracks, depending on (innate) ability, success in school is also largely determined by other factors, such as motivation and concentration and the ability to pay attention and behave in class. These behavioral factors are likely to be correlated, and are hard to measure, but are all arguably part of what we would call an individual's personality. Historically, personality and personality development has been the domain of psychologists. While there are competing taxonomies of personality ${ }^{1}$, the most widely used classification of personality traits is the Big Five, which concludes that the full dimensionality of an individual's personality can be captured by five constructs, namely openness to experience, conscientiousness, extraversion, agreeableness, and emotional stability. ${ }^{2}$ With the inclusion of personality items in many panel surveys and other datasets, personality measures are now used more and more by other fields, including sociology, health sciences, neurosciences, and economics. It is for this reason that in the remainder of this dissertation noncognitive skills are defined along the lines of the Big Five personality inventory and a number of measures of motivation, self-control and other behaviors.

The growing use of personality in research, both as input for later outcomes, and as an outcome in its own right, comes with some challenges. The first issue is related to the measurement of personality traits. While researchers are limited to using measures available in the data, it is important to provide a base for comparison with other findings. It is for this reason that for the analyses presented in this dissertation, the Big Five taxonomy of personality is used. Personality psychologist Brent Roberts (2009, p. 140) validates the use of such measures as follows: "personality skills are the relatively enduring patterns of thoughts, feelings, and behaviors that reflect the tendency to respond in certain ways under uncertain circumstances." This is an important notion, because to measure relevance, variability and malleability of skills, we need measures of enduring patterns of behavior across different circumstances.

\footnotetext{
${ }^{1}$ See for example Borghans et al. (2008a) for a discussion of the competing taxonomies of personality.

${ }^{2}$ See Section 2.1 for a description of these constructs.
} 
In estimating the relevance of personality traits for outcomes, results can only be compared if personality measures, outcome measures, and model specifications are comparable. Simple correlations lend themselves particularly well for meta-analysis, but do not provide information on the mechanisms behind the correlation. In order to address the issue of causality, it is crucial to account for confounding factors and mediators. For these reasons, all analyses presented here use multiple outcome measures, as well as multiple sets of covariates. In analyzing the correlation between life changes and events on the variability of personality, it is equally important to account for mediators. Causal interpretations of correlations that are driven by mediators might lead to ineffective and costly social policy. When it comes to the malleability of personality, the results of various early childhood interventions are difficult to compare, due to the very specific nature of each intervention. Treatments vary in content, duration and age of subjects, while the group of subjects is also highly selective, with most interventions targeting individuals at risk, with risk defined differently in each case. While individual interventions provide information as to which ingredients make an intervention successful, there is also a need for universal programs, and evaluation of such programs for the entire population.

\subsection{Outline and Results}

Each of the following chapters contributes to the understanding of the role personality traits play in the development of human capital. To demonstrate the productive nature and investment potential of personality traits, three questions need to be answered. First of all, are personality traits relevant? Do people with more desirable traits perform better in education, the labor market, or in terms of health or social outcomes? If people with more desirable personality traits are more productive, the second question arises: are personality traits variable? Do personality traits change over the life cycle or as the result of certain experiences? Or were people that now have a more productive set of personality traits just lucky at birth? If genes are not solely responsible for personality development, a third question regarding arises: are personality traits malleable? Can desirable personality traits be stimulated or trained? Is investment in these traits possible, and what are the results of such investments?

Chapter 2 presents the main conclusions from the current literature on the three questions of relevance, variability and malleability of personality traits. An attempt is made to replicate these findings, using representative samples of the Dutch and German population. Some inconsistencies arise and are discussed, highlighting issues that need to be addressed in analyzing the importance and development of noncognitive skills. The following chapters the each focus on one of the three questions, contributing to the literature on the relevance (Chapter 3), variability (Chapter 4), and malleability (Chapter 5) of personality traits. Chapter 2 concludes that while there are strong tendencies in the literature to be able to answer all three questions confirmatively, the results from various studies are not consistent as to which specific traits are most productive, and for which outcomes. A concern with results based on contemporaneous measures of personality and outcomes is the possibility of reverse causation. Regarding variability, there is a general consensus that life events are significantly correlated with personality development, but that these correlations need not be causal. Most of the evidence on the malleability of personality traits stems from intensive, small-scale projects targeted at specific groups of disadvantaged children. 
Chapter 3 uses data from the 1970 British Cohort Study to demonstrate the relevance of personality traits, and conscientiousness in particular, for a wide range of adult socioeconomic outcomes. Using mother-rated personality at age 16, the issue of reverse causality is dealt with. The role of potential mediators between childhood personality and adult outcomes are accounted for, lending support for a causal interpretation of the correlation between personality traits and socio-economic outcomes.

The estimates suggest a significant and sizeable correlation between mother-rated age-16 conscientiousness and adult economic, health, and criminal outcomes, even after controlling for other traits, early behavioral problems, the child's home environment, educational career, early sociability and occupational sorting. Measurement error in personality traits is corrected for by applying IV-techniques, errors-in-variables estimators and structural equation modeling, but does not alter the conclusions drawn. Conscientiousness and, to a lesser extent, agreeableness are associated with better adult outcomes. Extraversion reveals a mixed pattern, being associated with a higher likelihood of smoking, drug use, and arrests, while also being associated with significantly higher life satisfaction. Similar to the evidence on self-control (Moffitt, Arseneault, Belsky, Dickson, Hancox, Harrington, Houts, Poulton, Roberts, Ross, Sears, Thomson \& Caspi, 2011), the findings suggest that there is a gradient of conscientiousness that is worthwhile investigating. Those showing declines in the distribution of conscientiousness between ages 10 and 16 end up with significantly less favorable scores on our socio-economic outcomes. The results did not indicate any systematic gender differences. These results show that particular personality traits have predictive value for a range of outcome measures. The next question is then whether or not these traits vary within in a individual, or whether they are genetically predetermined.

Chapter 4 shows that personality traits are variable by analyzing changes to the environment that are exogenous to the individual. Children's maturation in terms of personality traits is dependent on the environment they grow up in. This is demonstrated that experiencing a family shock in early childhood impacts the development of personality traits. A change in the family environment during childhood, as measured by the experience of losing one of two natural parents, has a detrimental impact on the rate of growth and the final level of desirable personality traits.

Three measures of personality are used: self-esteem, internal locus of control, and behavior problems. Parental loss is significantly associated with lower scores on age-16 internal locus of control and self-esteem, and higher scores for behavior problems. The order of magnitude around one quarter of a standard deviation. When using the Big Five traits used in the Chapter 3, the same pattern and effect sizes arise, with the effects on conscientiousness, extraversion, agreeableness, and emotional stability averaging around a quarter of a standard deviation lower for children who experienced parental loss prior to reaching age 16. These effects are however heterogeneous, with effect sizes depending on gender of the child, as well as the reason for parental loss. In terms of personality development, the effects of divorce are more severe than those associated with experiencing the parental death. Regarding gender, boys are more negatively affected by parental death than girls, and there are also indications that girls suffer more from a separation or divorce of parents than boys do. There is also evidence that the effects are larger the younger the child is at the time of parental loss.

The association between personality development and parental loss is partially driven by selection. Placebo regressions reveal significant correlations between eventual parental loss and personality of the child before the change took place. For the case of divorce, this is not surprising, since the event of divorce might be the end of a longer process during which the 
home environment was unstable or less stimulating. The omitted variable bias is mitigated by the consideration of a range of control variables, uncovering possible mechanisms through which the selection operates. The correlations between family structure and the development of various personality traits reveal the importance of the environment, thus leading to the next step: changing the environment to stimulate personality traits.

Chapter 5 presents a set of estimates suggesting that personality traits are malleable, which is shown by positive treatment effects of a change in the high school curriculum on desirable personality traits. Using administrative and questionnaire data on some 1,200 Dutch high school students, Chapter 5 investigates the effects of the introduction of mandatory community service and a class on study and social skills. While academic achievement in high school is not significantly affected by the treatment, boys who received the treatment seem to fair better in terms of several desirable personality traits, compared to boys who graduated prior to the changes in the curriculum.

As of 2006, students had to complete 40 hours of community service, and a new course was introduced, aimed at developing and improving students' study and social skills. This course involved weekly 1-hour lesson periods, over the course of 3 years, starting at age 15 . While there are slight indications that results on some school exams suffered from the additions to the curriculum, the average effect was found not to be significant. Nevertheless, this point illustrates caution is required when making changes to an existing curriculum. Hours spent in new classes, as well as time spent studying at home for these additional courses, might take away time and concentration for other courses. Given the nature and content of the program, treatment was also hypothesized to improve noncognitive skills in students. Big Five personality traits, and attribution style were measured using student questionnaires. The latter measures the extent to which success and failure are the result of own action or just luck or misfortune. Boys in the treatment group report higher scores on Big Five traits conscientiousness, agreeableness, and emotional stability than boys in the control group. They also score higher on attribution of positive events, indicating the treated have higher self-esteem and motivation. These associations between treatment and personality are much lower for girls, and not significantly different from zero.

This dissertation provides a contribution to the discussion of personality traits as a crucial facet of human capital. Three main questions are used to guide the discussion: are personality traits relevant?, are personality traits variable?, and are personality traits malleable? A variety of angles can be taken to answer any one of these questions. Chapter 2 describes a number of angles taken thus far in the literature on personality traits, revealing that a policy constructed on the basis of answers provided by one angle would seem to be unsuccessful in the light of answers provided by another angle. The remaining chapters provide additional angles to answering these questions, contributing to the existing body of evidence. There is growing evidence that personality traits are related to outcomes all along their gradient, even after controlling for environmental factors (e.g. Chapter 3, and Moffitt et al., 2011). Malcolm Gladwell's conclusion about Christopher Langan also echos the importance of noncognitive skills, but, at the same time, also of a stable home environment. His conclusion is "he'd had to make his way alone, and no one - not rock stars, not professional athletes, not software billionaires, and not even geniuses - ever make it alone." (Gladwell, 2008, p. 132). Within the specific nature of a single policy issue, one angle might be sufficient, if the situation matches that of the study. For general policy, continued investigation of these three questions from different angles, using different methods, and in different situations and contexts, is necessary. 


\title{
The Investment Potential of Noncognitive Skills Overview and Evidence from the Netherlands and Germany
}

\begin{abstract}
This chapter highlights three aspects of personality traits: relevance, variability, and malleability. This is done by discussing results found in the existing literature, and comparing these findings with data on representative samples of Dutch and German adults. First, the relevance of personality traits is reflected in the predictive power of personality traits for a wide range of socio-economic outcomes, as demonstrated by a wide range of empirical studies. Using a Big Five taxonomy of personality, conscientiousness is found to be most strongly associated with various outcomes. Partial correlations obtained from the Dutch and German samples reveal that emotional stability and openness to experience also correlate strongly with various socio-economic outcomes. Second, variability is shown by reporting on results from meta-analysis studies on the development of Big Five personality traits over the life cycle. Cross-sectional and longitudinal estimates on the Dutch and German data lead to similar conclusions. Personality develops throughout the life cycle, but is most volatile in early years. Results from recent empirical studies reveal that intra-individual differences are related to life experiences and changes in the environment, confirming that personality is not merely a reflection of genetic build. Malleability of personality traits is discussed by summarizing the evidence on experimental interventions and education programs.
\end{abstract}




\section{$2.1 \quad$ Introduction}

Over half a century ago, Gary Becker (1964) introduced human capital as a productive factor, alongside physical capital. The following decades lead to further development of human capital theory, with more recent trends emphasizing the multifaceted nature of human capital. Within the framework of human capital theory, people need to know which qualities are valued, if they can change or improve in terms of these qualities, and how to invest in these qualities, and what the potential returns of such investments would be. The role of individuals' noncognitive skills, usually conceptualized in the form of personality traits, are concluded to be a particular importance in shaping human capital. Therefore, this chapter highlights three aspects of personality traits: their relevance, their variability, and their malleability. This is done by discussing results found in the existing literature, and comparing these findings with data on representative samples of Dutch and German adults.

Traditional measures of human capital such as years of schooling and job experience or tenure have shown to be relevant predictors of labor market success, as well as for a range of other socio-economic outcomes. These global measures of human capital do not reveal which components of human capital are driving these correlations. A growing body of evidence suggests there is a crucial distinction between cognitive and noncognitive abilities or skills. Whereas cognitive skills are usually measured using achievement tests, noncognitive skills are measured using a variety of personality measures. ${ }^{1}$ This chapter discusses three main questions surrounding the view of personality traits as investment opportunities: Are they relevant?; Are they variable within individuals?; and Are they malleable? This is done by discussing results found in the existing literature, and comparing these findings with data on representative samples of Dutch and German adults.

Heckman, Stixrud \& Urzua (2006) demonstrate that both cognitive and noncognitive skills affect a wide range of outcomes. ${ }^{2}$ The effect sizes on noncognitive skills are generally of the same order of magnitude as those on cognitive skills, and in some cases, the effects of noncognitive skills are even larger. Using cross-sectional variation, we know that noncognitive skills, or personality traits, are relevant for a wide range of socio-economic outcomes. The next question is then whether or not these traits are variable within individuals. Cunha \& Heckman (2007) refute the idea that skills are merely a reflection of genes, and conclude that both genes and the environment are critical to human development. Thus, while individuals are predisposed to be more or less skilled or able, their skills develop over the life cycle, and the environment plays a crucial role in this development.

Cunha \& Heckman (2007) developed a model that captures the process of skill formation, which has become the leading framework for analyzing skill formation and change. Future skills $\left(\theta_{t+1}\right)$ are modeled as a function of parental characteristics $(h)$, current skills $\left(\theta_{t}\right)$, and current investments $\left(I_{t}\right)$ :

$$
\theta_{t+1}=f_{t}\left(h, \theta_{t}, I_{t}\right)
$$

Despite its simple nature, the framework is able to explain most important findings from the field of skill formation and child development. One of the main ingredients of the model is the self-productivity of skills, reflecting the fact the skills beget skills. Skills acquired early in life, make it easier to acquire more skills later in life. This also explains the key finding following from this technology of skill formation: early investments in skills are more productive than late investments. Investments today, enhance skills tomorrow, which in

\footnotetext{
${ }^{1}$ See Borghans et al. (2008a) for a description of competing taxonomies of personality.

${ }^{2}$ See also Borghans et al. (2008a) for a review of the predictive power of personality (noncognitive skills).
} 
turn enhance skills in all future periods. Even if the direct effects of investments only last one period, investments have longlasting indirect effects on the process of skill formation, due to the self-productivity of skills.

Cunha \& Heckman (2007) consider one's skill set to be composed of both cognitive and noncognitive skills. To be able to estimate the model, measures for both cognitive and noncognitive skills need to be constructed. Almlund, Duckworth, Heckman \& Kautz (2011) discuss different alternatives to measuring both cognitive and noncognitive skills. Although the terminology of cognitive skills is generally well-established, measurement remains difficult. IQ test scores and achievement test scores are often used to measure cognitive skills, but seem to include noncognitive elements as well. Borghans, Meijers \& Ter Weel (2008b) and Segal (2012) show for example that a large part of the obtained test scores can be attributed to motivation and differences in personality traits. The measurement of noncognitive skills is also difficult. Borghans et al. (2008a) structure the discussion by introducing taxonomies and alternative models to capture noncognitive skills. Most theories of personality assume a hierarchical structure of personality, similar to that found for intelligence. Personality is generally not found to be reducible to one factor, and the most commonly used and most widely accepted taxonomy of personality traits is the Big Five. ${ }^{3}$ The Big Five taxonomy of personality allows us to capture the relative importance of different dimensions of an individual's personality (e.g. Goldberg, 1993; McCrae \& John, 1992). The schedule below presents the descriptions of the traits as agreed upon by the American Psychology Association. The final column presents facets of these five personality traits measured in Child surveys.

\begin{tabular}{|c|c|c|}
\hline Big Five factor & $\begin{array}{l}\text { American Psychology } \\
\text { Association Dictionary } \\
\text { description }\end{array}$ & Childhood traits \\
\hline Openness & $\begin{array}{l}\text { "the tendency to be open to new } \\
\text { aesthetic, cultural, or intellectual } \\
\text { experiences" }\end{array}$ & $\begin{array}{l}\text { Sensory sensitivity, pleasure in low } \\
\text { intensity activities, curiosity }\end{array}$ \\
\hline Conscientiousness & $\begin{array}{l}\text { "the tendency to be organized, } \\
\text { responsible, and hardworking" }\end{array}$ & $\begin{array}{l}\text { Attention, distractibility, effortful, } \\
\text { self control, impulse control, } \\
\text { persistence, activity }\end{array}$ \\
\hline Extraversion & $\begin{array}{l}\text { "an orientation of one's interests and } \\
\text { energies toward the outer world of } \\
\text { people and things rather than the } \\
\text { inner world of subjective experience; } \\
\text { characterized by positive affect and } \\
\text { sociability" }\end{array}$ & $\begin{array}{l}\text { Social dominance, social vitality, } \\
\text { sensation seeking, shyness, activity, } \\
\text { positive emotionality, } \\
\text { sociability/affiliation }\end{array}$ \\
\hline Agreeableness & $\begin{array}{l}\text { "the tendency to act in a } \\
\text { cooperative, unselfish manner" }\end{array}$ & Irritability, aggressiveness, wilfulness \\
\hline $\begin{array}{l}\text { Neuroticism / } \\
\text { Emotional Stability }\end{array}$ & $\begin{array}{l}\text { Neuroticism is "a chronic level of } \\
\text { emotional instability and proneness } \\
\text { to psychological distress." Emotional } \\
\text { stability is "predictability and } \\
\text { consistency in emotional reactions, } \\
\text { with absence of rapid mood } \\
\text { changes." }\end{array}$ & $\begin{array}{l}\text { Fearfulness, behavioral inhibition, } \\
\text { shyness, irritability, frustration, } \\
\text { sadness }\end{array}$ \\
\hline
\end{tabular}

\footnotetext{
${ }^{3}$ Almlund et al. (2011) provide a discussion on the history of personality psychology, as well as difficulties concerning the conceptualization of both cognitive and noncognitive skills, concluding that contrasts between the two are not easy to make.
} 
While there is no clear consensus on which measures are to be used to capture cognitive and noncognitive skills, the use of certain measures over others is largely dictated by the availability of data. Using existing data from panel studies, one is limited to use the items that were asked at the time of the interviews. Recent evidence using a variety of measures simultaneously suggests that the different measures of personality could capture various productive capacities of personality, each revealing independent predictive value for a range of socio-economic outcomes (Becker, Deckers, Dohmen, Falk \& Kosse, 2012). For this chapter, we rely on the Big Five taxonomy of personality, since these are present in both the Dutch and German data used in this chapter. One initiative that aims to enhance the collaboration on personality research and increase comparability across personality measures is the website hosting the International Personality Item Pool (http://ipip.ori.org/), items of which have been used to construct Big Five personality traits used in Chapter 5. This website provides access to 2,413 items, which have been categorized by their fit to a range of pre-existing personality taxonomies and constructs.

Knowing that personality develops over the life cycle, the next question is how and to what extent desirable traits are malleable. In other words, using IQ scores or achievement tests measures of cognitive skills $\left(\theta^{c}\right)$, and personality traits as noncognitive skills $\left(\theta^{n c}\right)$, productive investments $(I)$ need to be found. Can people invest in noncognitive skills, and what is the cost of such investments, also in comparison to investments in the development of cognitive skills. In later work, Flavio Cunha and James Heckman (2008) formulate and estimate their technology of skill formation, highlighting the role of parental investment in shaping children's skill set. Parental investment stimulates the development of both cognitive and noncognitive skills, but is more effective in enhancing noncognitive skills. While investments are most effective in early childhood, both for cognitive and noncognitive skills, noncognitive skills are also affected at later ages.

This chapter is structured as followed. The following section describes the main research findings on the relevance of personality traits and compares them to own calculations obtained from data on Dutch and German individuals. Section 2.3 then highlights the main findings on the variability of personality traits over the life cycle, which are generally supported by patterns found in the Dutch and German data. Section 2.4 summarizes the effects of a number of intervention studies, focusing on the effects found in terms of the development of desirable personality traits. Finally, Section 2.5 concludes.

\section{$2.2 \quad$ Relevance}

Almlund et al. (2011) provide a detailed discussion of the empirical evidence on the predictive power of personality traits for life outcomes. In most cases, the predictive power of IQ is larger than that of any particular personality trait, yet there are also some cases in which the effects of personality traits rival that of IQ. Especially traits related to conscientiousness and, to a lesser extent, emotional stability are found to be predictive of a range of outcomes.

Almlund et al. (2011) discuss four outcome domains: education, employment, health, and crime. Conscientiousness is found to be a strong predictor of overall educational attainment and achievement (e.g. Goldberg, Sweeney, Merenda \& Hughes, 1998; Van Eijck \& De Graaf, 2004), and is most strongly correlated with grades at all education levels: primary, secondary, and postsecondary education (Poropat, 2009). Next to conscientiousness, openness is also significantly related to years of schooling and grades. For years of schooling, the 
correlation for openness is stronger than that for conscientiousness (Goldberg et al., 1998; Van Eijck \& De Graaf, 2004). However, using a broad measure such as years of schooling, and estimating a linear (or even monotonic) relationship with personality traits might not be correct. Heckman et al. (2006) demonstrate this when investigating the association between facets related to emotional stability (self-esteem and locus of control) and schooling. They find that the probability of graduating from, and stopping at, high school increases with better adolescent personality traits in the lower quantiles of the personality distribution, but decreases in the upper quantiles of the personality distribution. This may be explained by the fact that most pupils in the upper quantiles continue on to college after high school. When it comes to the chances of graduating from college, the significant correlation between measured personality and graduation is again positive, at all deciles.

When it comes to labor market outcomes, Almlund et al. (2011) conclude that conscientiousness and traits associated with emotional stability play a particularly important role in determining job performance and wages. For example, using 1996 data from the Dutch household panel, Nyhus \& Pons (2005) find that emotional stability and agreeableness are significant predictors of log hourly wages. These effects are generally stronger for women, than they are for men. Mueller \& Plug (2006) use data from the Wisconsin Longitudinal Study (WLS) to evaluate the relation between Big Five personality traits and log hourly wages for a sample of 5,025 men and women. The authors also find that emotional stability and agreeableness correlate significantly with wages, but find that the point estimates are larger for men, than they are for women. Conscientiousness is associated with higher hourly wages for women only. ${ }^{4}$ Additionally, the size of the effects depends on tenure and educational level (Nyhus \& Pons, 2005). Conscientiousness seems to be rewarded particularly at the beginning of an employment relationship, whereas men are rewarded for autonomy (openness) as tenure increases. Heckman et al. (2006) find that self-esteem and locus of control predict adult wages to a similar degree as cognitive skills do, and like Nyhus \& Pons (2005), find that the effects vary across educational levels. Almlund et al. (2011) conclude that personality traits are more important for people with lower levels of education and job complexity, whereas cognitive skills are more important at higher levels.

Educational and job performance are common economic outcome measures, but personality traits are also shown to be significantly related to health indicators and criminal behavior. For a discussion of the literature, see Almlund et al. (2011). In general, traits related to conscientiousness, extraversion, and agreeableness are associated with longevity and healthy behaviors, such as less smoking, more exercise, and better self-rated health. These findings are supported by own calculations using data on Dutch and German individuals (See Figure 2.1), but also by results in Chapter 3, demonstrating that higher conscientiousness is associated with lower body mass index, lower rates of alcohol dependency and lower rates of smoking.

Regarding criminality, Heckman et al. (2006), using data from the Unites States, find that higher noncognitive skills (self-esteem and internal locus of control) are associated with lower probabilities of incarceration and less participation in illegal activities. Almlund et al. (2011) describe evidence that suggests that specifically conscientiousness and agreeableness,

\footnotetext{
${ }^{4} \mathrm{An}$ interesting difference between the findings of these two studies is the point estimates for openness. Nyhus \& Pons (2005) do not find a significant main effect of openness, whereas Mueller \& Plug (2006) find that this trait is most strongly associated with wages. One explanation for this might be the use of different questionnaires to assess the Big Five traits. Nyhus \& Pons (2005) have available the 100-item Five-Factor Personality Inventory, whereas Mueller \& Plug (2006) make use of a 29-item (abbreviated) version of the BFI.
} 
but also, to a lesser extent, extraversion, are related to juvenile delinquency. Similarly, using British data, Chapter 3 reveals that those scoring higher on conscientiousness and agreeableness, or lower on extraversion, are less likely to be arrested or to smoke cannabis on a regular basis.

Especially conscientiousness seems to be strongly related to most outcome domains, and one could ask the question what it is that makes conscientiousness so important. Roberts, Bogg, Walton, Chernyshenko \& Stark (2004) investigate the lower-order factor structure of conscientiousness and reveal eight components, capturing different facets of conscientiousness. One of these facets is self-control or impulse control. Moffitt et al. (2011) find that childhood self-control is predictive of adult income and social status, as well as physical health, substance dependence and criminal conviction. Roberts \& Bogg (2004) find that social responsibility, another facet of conscientiousness, assessed at age 21, predicted midlife outcomes related to family, work, and substance use. Using data from the British Cohort Study, Chapter 3 adds to these findings, demonstrating that, of a range of personality items measured when children are aged 16 , items related to conscientiousness show the strongest association with various socio-economic outcomes.

Becker et al. (2012) use data from the German Socio-Economic Panel (GSOEP) to demonstrate the predictive role of a range of personality measures. They contribute to the discussion of which concepts to use as measures of noncognitive skills. Psychologists seem to agree on the fact that the Big Five taxonomy of personality captures the various dimensions of one's personality. ${ }^{5}$ The measure for noncognitive skills used by Cunha and Heckman $(2007,2008)$ is an average of the scores on measures for self-esteem and internal locus of control, which are said to be related to emotional stability. Finally, economists more often rely on economic preference measures such as risk aversion, trust, and reciprocity to classify different responses.

Becker and co-authors show that these varying sets of noncognitive skills capture different productive attributes of individuals (Becker et al., 2012, Table A.5). Using various outcome measures, they add the Big Five traits as regressors, alongside internal locus of control and a range of economic preference measures. With each trait demonstrating significant point estimates for most of the outcomes, Becker and co-authors conclude that these varying personality measures are complements, rather than substitutes. Each of the Big Five traits are shown to be significant predictors of all five outcomes: subjective health, life satisfaction, gross hourly wage, being unemployed, and years of education.

Of the Big Five traits, openness and emotional stability generally show the highest correlations, demonstrating that these are generally desirable traits. The results for the other three traits are rather mixed. While conscientiousness, agreeableness, and extraversion are significantly positively associated with subjective health and life satisfaction, they are also negatively related to years of schooling. Agreeableness and extraversion are additionally significantly associated with lower gross hourly wages and, to a lesser extent, also to higher probability of being unemployed. Conscientiousness is again significantly positively related to higher hourly wages and lower likelihood of unemployment, although the effect sizes are smaller than for openness and emotional stability.

\footnotetext{
${ }^{5}$ See Borghans et al. (2008a) for a description of competing taxonomies of personality.
} 


\subsubsection{Evidence from the Netherlands and Germany}

Own calculations on the predictive power of Big Five personality traits (Figure 2.1) generally support the findings documented in earlier studies, but also highlight the effects of measurement problems. Using representative samples of the Dutch and German populations, openness and emotional stability are generally found to be significantly related to a wide range of outcomes, whereas the effects of the other traits differ by outcome, but also by sample. The confidence intervals of the estimates are much larger for the Dutch sample, given the much smaller sample size. Controlling for cognitive skills does not alter the pattern of effects, and the pattern of effects is similar for men and women.

Results from own calculations are shown in Figure 2.1, depicting regression coefficients of models in which various outcomes are regressed on the Big Five personality traits, while controlling for gender and age. The left panel uses data from the Dutch National Bank Household Survey (DHS), and the right panel uses data from the German Socio-Economic Panel (GSOEP). The Appendix provides details on the measurement of the Big Five personality traits (Tables 2.A.1 and 2.A.2) and the outcome variables (Table 2.B.1). The scores on personality traits are standardized within the regression sample (e.g. mean of zero and standard deviation of one), which makes the point estimates easier to interpret and comparable across samples. Three outcome domains are considered: income, a set of success indicators, and satisfaction. The top panel of Figure 2.1 shows the impact of the Big Five traits on the logarithm of both gross and net income. The middle panel reports point estimates for four dummy indicators: being employed, having completed tertiary education, being a smoker, and being overweight. The bottom panel reports estimates on self-reported satisfaction with work and life in general, and on self-rated health.

Openness to experience is significantly associated with education and labor market outcomes, and so is emotional stability. A standard deviation higher openness is associated with around $8 \%$ higher net household income for the Dutch sample (DHS, left panel Figure 2.1 and with $4.5 \%$ higher income (both gross and net) for the German sample (GSOEP, right panel Figure 2.1). For emotional stability, for the German sample, a standard deviation higher emotional stability is associated with $8.8 \%$ higher net income, and as much as $10 \%$ higher gross income. While the point estimates is not significant for the Dutch sample, the effect size for gross income is comparable, at 9\%. Emotional stability is further associated with a 4 percentage point higher probability of being employed (in either sample). For tertiary education, openness to experience is the stronger predictor. Those scoring a standard deviation higher on openness are 7 (GSOEP) to 15 (DHS) percentage points more like to have a tertiary degree. A standard deviation higher emotional stability is associated with 3 to 5 percentage points higher likelihood of having completed tertiary education.

Additionally, the German sample reveals a negative relationship with wages for agreeableness. The point estimates for gross wages for the German sample are in line with those reported by Mueller \& Plug (2006) and Nyhus \& Pons (2005). Conscientiousness and extraversion are not significantly related to log wages, whereas a standard deviation higher agreeableness is associated with about six percent lower wages. ${ }^{6}$ The point estimates for openness and emotional stability obtained from the GSOEP are reversed, in comparison to Mueller \& Plug (2006), associated with 5 and 10 percent higher gross wages, respectively. ${ }^{7}$

\footnotetext{
${ }^{6}$ The point estimate obtained by Nyhus \& Pons (2005) is -.064, and that for the GSOEP is -.058. Mueller \& Plug (2006) also finds a point estimate of -.064, but only for men. The estimate for women is lower, at -.031 .

${ }^{7}$ Mueller \& Plug (2006) finds that openness is associated with 10 percent higher wages, and emotional
} 
Figure 2.1: Point estimates of Big Five Traits on Socio-Economic Outcomes

DNB Household Survey (DHS)
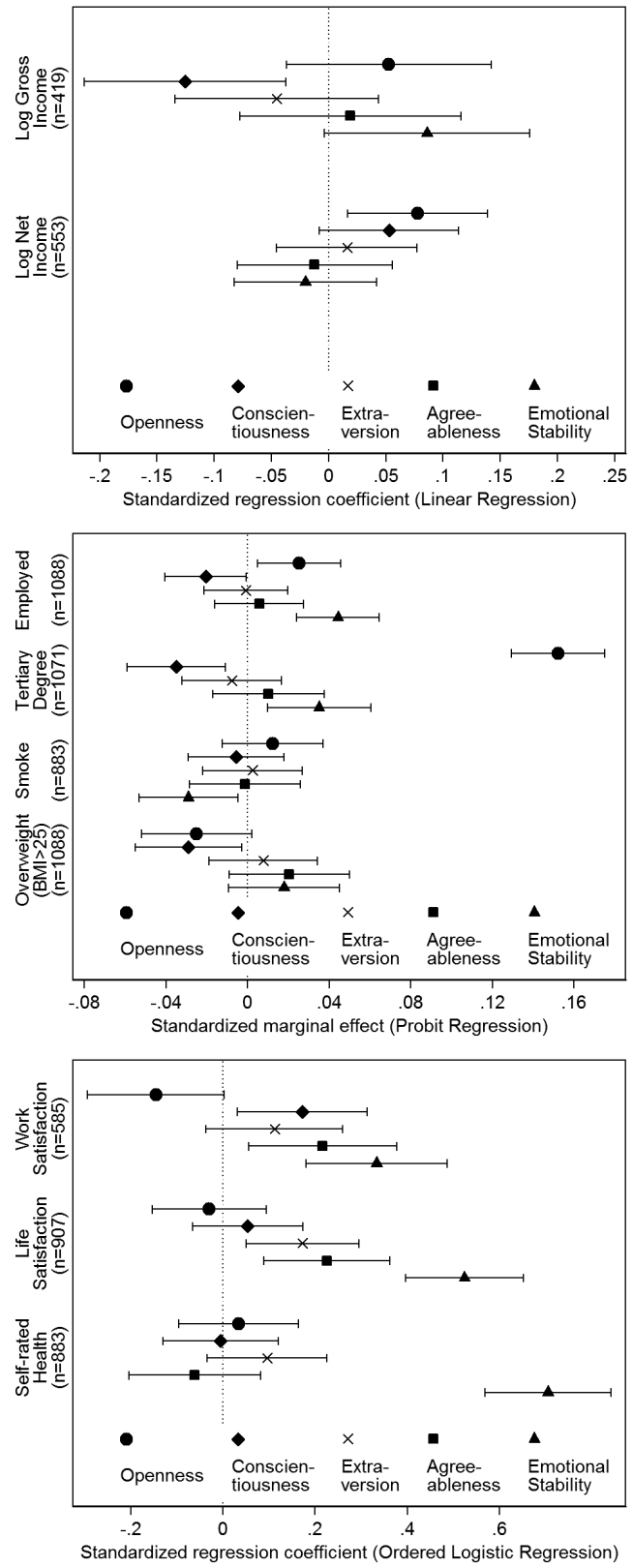

German Socio-Economic Panel (GSOEP)
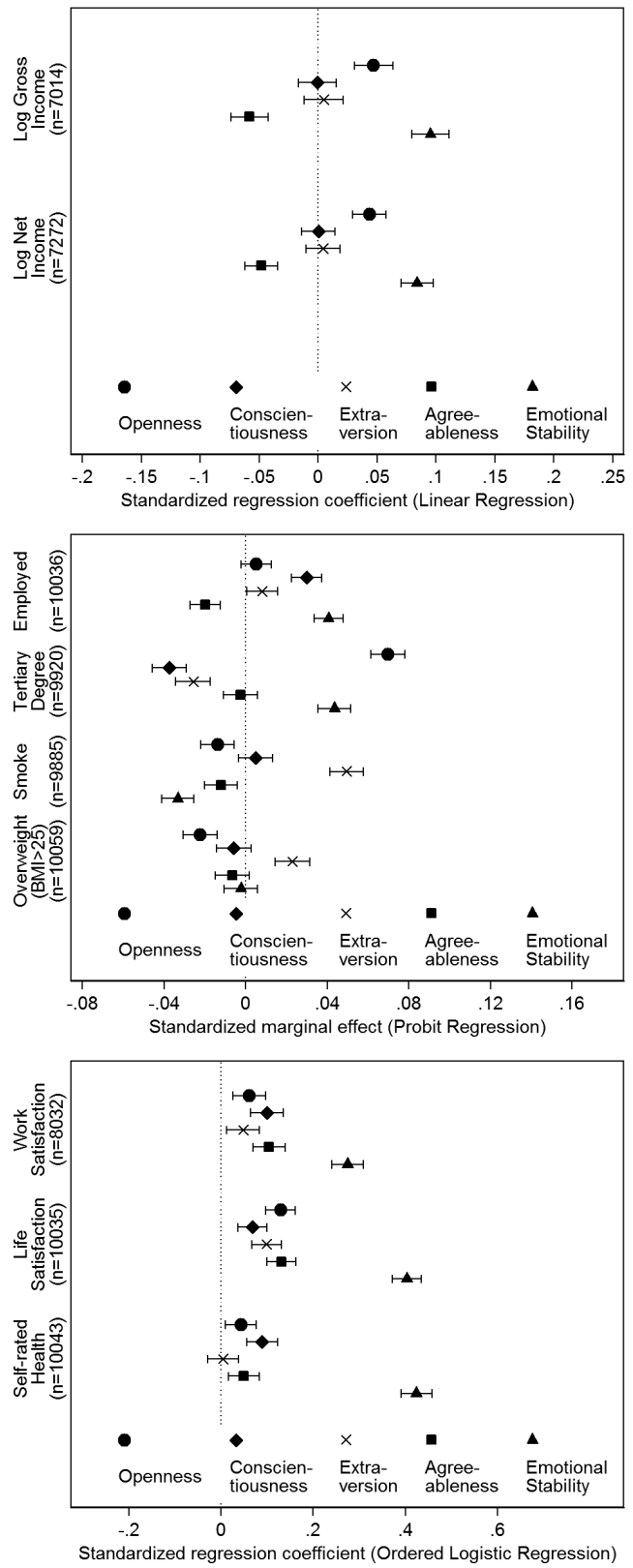

Note: Standardized coefficients and 90\% confidence intervals for the Big Five personality traits, using representative samples of Dutch (left panel) and German (right panel) adults (aged 25 through 64). Specifications additionally control for gender, age, and $\operatorname{age}^{2}$. Personality is measured in 2005, and outcomes and age are measured in 2009. 
Regarding the health indicators of being a smoker or being overweight, the results of the two samples do not compare very well. For the Dutch sample, none of the point estimates are significant at the $5 \%$ level. For the German sample, openness is significantly negatively related to smoking and being overweight, and extraversion significantly positively, yet the effect sizes are rather small. When it comes to satisfaction, however, most traits show a positive correlation with work satisfaction, life satisfaction, and self-rated health. The strongest predictor is emotional stability, showing large and significant effects in both the Dutch and German samples. The effect sizes for the other traits are only small in magnitude, and often only marginally significant.

The strong effect of emotional stability for this wide range of outcomes is in line with the findings by Heckman et al. (2006). Measuring noncognitive skills as an average of traits related to emotional stability (e.g. self-esteem and internal locus of control), they demonstrate that noncognitive skills predict various labor market and educational outcomes.

Almlund et al. (2011) discuss how facets related to emotional stability (self-esteem and locus of control) are significantly related to higher rates of high school graduation for samples from the United States, but that the estimated effect is much smaller once cognitive skills and the home environment are controlled for. Figure 2.2 shows the effects of controlling for cognitive skills. For a subset of respondents, the GSOEP contains information on cognitive skills. ${ }^{8}$ The left panel of Figure 2.2 reports the effects of the base model (controlling for age and gender, alongside the Big Five personality traits) for this smaller sample. The right panel shows the point estimates for each of the Big Five traits from the same model, yet with additional controls for crystallized and fluid intelligence. While cognitive skills are a significant predictor for most outcome measures, there are no significant changes in the point estimates of the Big Five traits. The left and right panel of Figure 2.2 are almost identical.

A second dimension to consider is the effect of gender on the estimated correlations between personality traits and socio-economic outcomes. As documented by Nyhus \& Pons (2005) and Mueller \& Plug (2006), the association between wages and various traits may differ for men and women. The left and right panels of Figure 2.3 shows the results for women and men, respectively. There are only slight differences in the point estimates, none of which seem significant. The overall pattern is the same for both men and women. ${ }^{9}$ Other factors not yet taken into account are the conditions of the home environment one grew up in, or other confounding factors, that are strongly correlated with both personality and the outcome measures. Chapter 3 investigates possible confounding factors, and finds that the correlations between childhood personality traits and adult outcomes are only partially driven by family background or parental characteristics.

\subsubsection{Discussion}

As discussed by Almlund et al. (2011), there are a number of issues when addressing the predictive power of personality traits. In sum, the problems relate to measurement. First, which constructs are used to define personality, and which items are used to assess these

stability with 5 percent higher wages. Nyhus \& Pons (2005) however, do not find a significant baseline effect for openness, but conclude later that men are rewarded for openness as tenure increases.

${ }^{8}$ See Appendix 2.B for a description of the measures for cognitive skills.

${ }^{9}$ Results obtained using British data also confirmed that there are no significant differences between men and women in terms of the correlation between childhood personality traits and adult outcomes. See Chapter 3. 
Figure 2.2: Point estimates of Big Five Traits, Controlling for Cognitive Skills (GSOEP)

Not controlling for cognitive skills
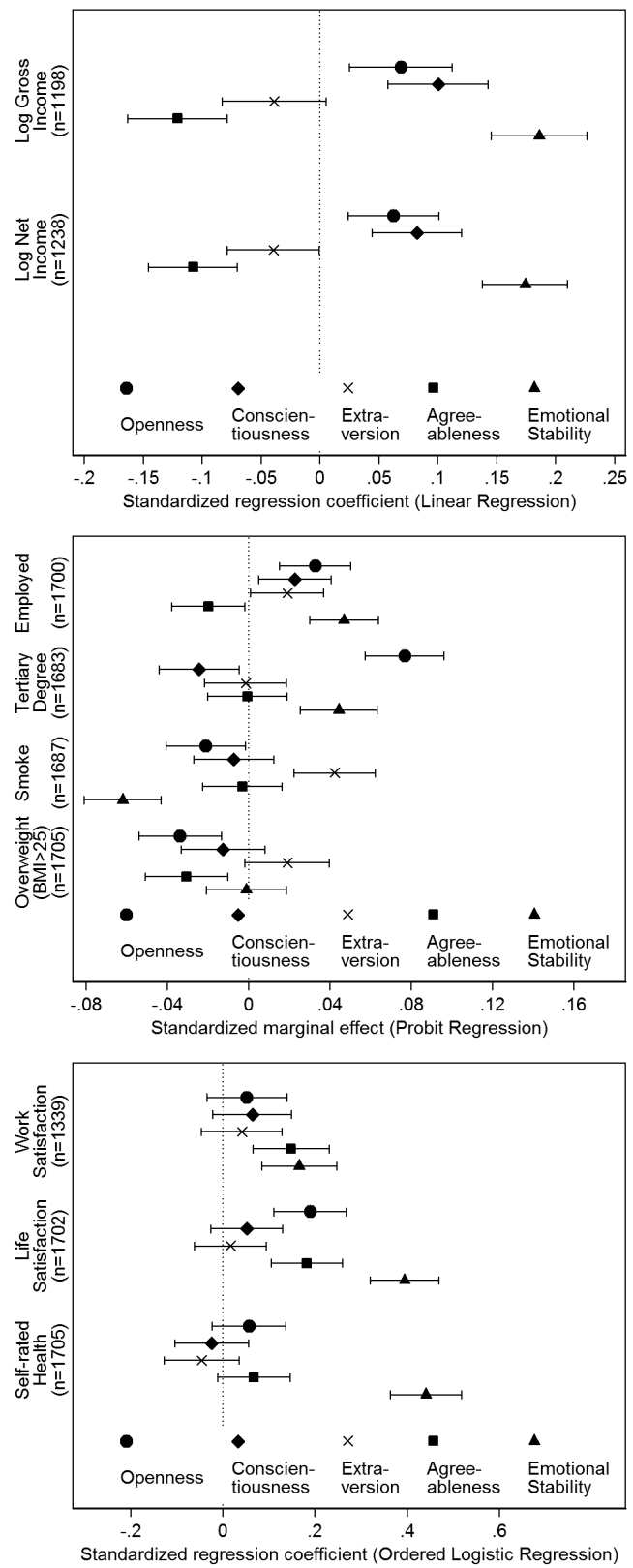

Adjusted for cognitive skills
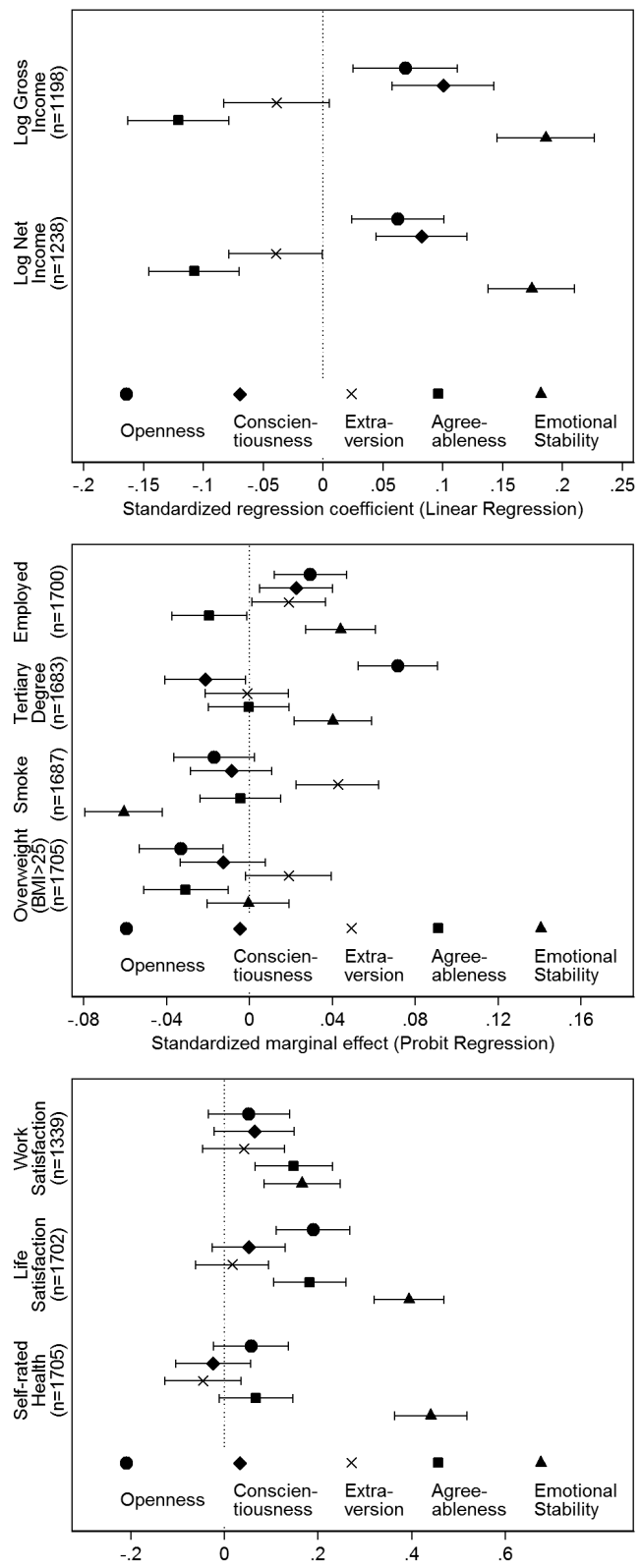

Standardized regression coefficient (Ordered Logistic Regression)

Note: Standardized coefficients and 90\% confidence intervals for the Big Five personality traits, using data from the GSOEP, from adults aged 25 through 64 , with valid scores on the cognitive skills tests taken in 2006. All specifications control for gender, age, and age $^{2}$.The right panel additionally controls for fluid and crystallized intelligence, as measured by the scores on the cognitive skills tests administered in 2006. Personality is measured in 2005, and outcomes and age are measured in 2009 . 
Figure 2.3: Point estimates of Big Five Traits, by Gender (GSOEP)
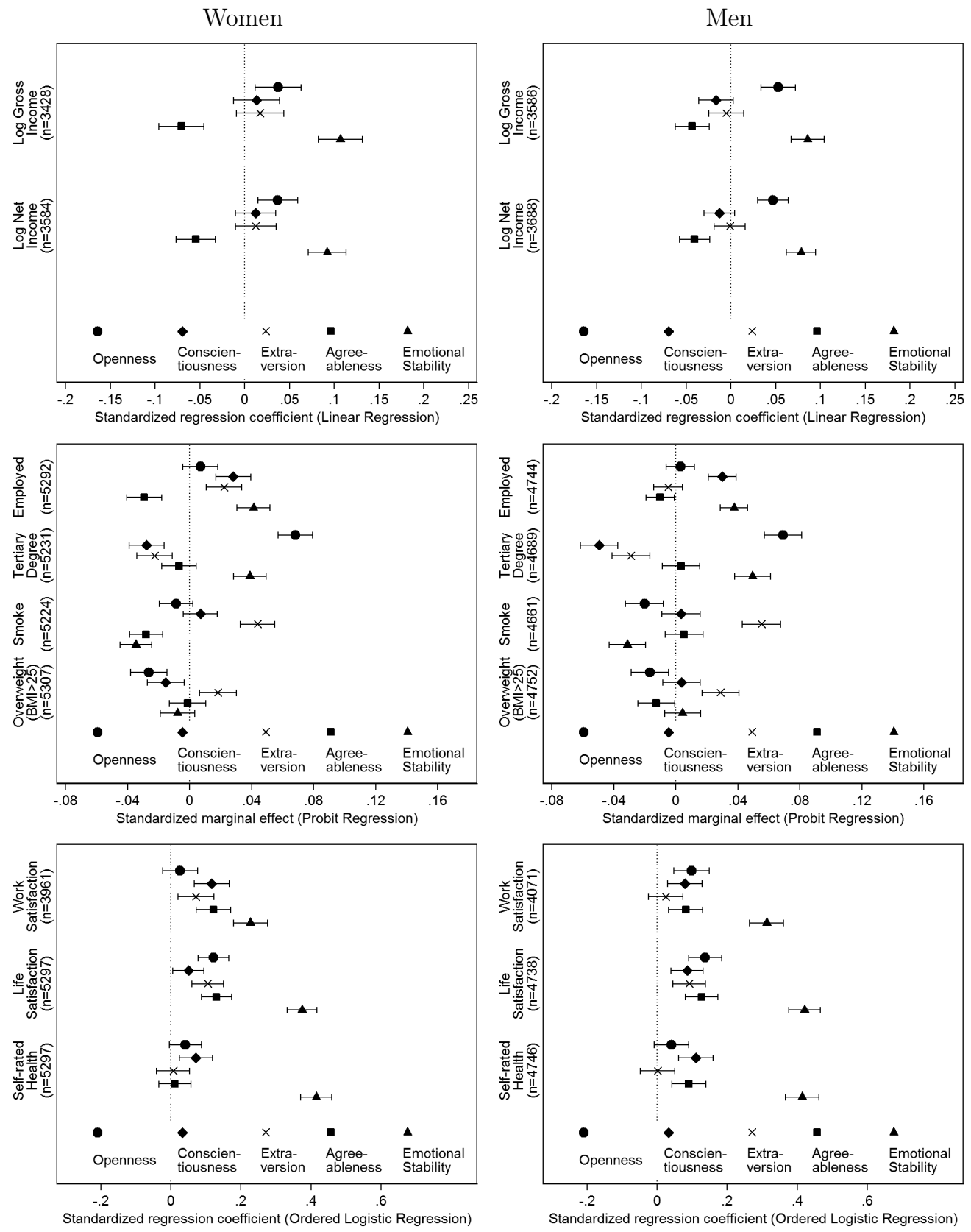

Note: Standardized coefficients and $90 \%$ confidence intervals for the Big Five personality traits, using data from the GSOEP, from adults aged 25 through 64. Left panel reports results for women, and right panel reports results for men. Specifications additionally control for gender, age, and age ${ }^{2}$. Personality is measured in 2005, and outcomes and age are measured in 2009. 
constructs. Second, different samples might produce different results. Selection on demographic characteristics (nation, age, or gender) might affect results. Attrition might also yield samples with different personality distributions than the original representative sample. Third, which outcomes are considered, and how are they measured? Seemingly obvious measures such as wages and educational outcomes can be measured in a number of ways, possibly affecting the relationship with measured personality traits. Fourth, which controls are used in the models? The conclusions about the predictive power of personality traits are conditional upon which other confounding factors have been considered and have been accounted for.

The GSOEP data only contains three items to measure each of the personality traits. The resulting constructs show reasonably high reliability, and the scores are relatively normally distributed for openness, extraversion, agreeableness, and emotional stability. The problem lies with conscientiousness. After averaging the three conscientiousness items, each rated on a seven-point scale, 45 percent of the sample score higher than 6 , and 18 percent score the maximum of 7 on conscientiousness. Should the association between conscientiousness and outcome measures be stronger within the higher deciles of the personality distribution, it is not surprising that there are no significant effects for conscientiousness.

This problem of measurement is, however, not present in the Dutch panel. Using ten items per construct results in a fairly normal distribution of scores for all Big Five traits. However, the Dutch panel is limited in size, with only one-tenth of the sample size available for analysis as is the case for the German sample. This explains the much larger confidence intervals shown for the DHS data (left panel of Figure 2.1). While both the Dutch and German samples reveal that openness to experience and emotional stability are predictive of a range of outcomes, their conclusions regarding the association between conscientiousness and labor market outcomes contradict each other, and are also not in line with general findings discussed above, that conscientiousness is generally positively associated with a range of adult outcomes. Where the DHS seems to indicate that conscientiousness is negatively associated with employment and wages, results from the GSOEP reveal a positive relationship with employment, and no significant correlation with wages. A possible explanation might lie in the nature or content of the items used to measure conscientiousness. The conscientiousness items measured in the Dutch data might capture different facets of conscientiousness (e.g. Roberts et al., 2004) than those measured in the German data, and these different facets might be differently associated with outcomes. ${ }^{10}$

An alternative explanation for the difference in results regarding income or wages is related to how seemingly comparable outcome measures can be measured in different ways. Wages are reported in terms of yearly household income for the DHS data, whereas, for the GSOEP, income from employment in the preceding month is recorded. This might be one reason for the different results. Second, wages are often recoded in terms of hourly wages. Becker et al. (2012) use the same sample of German respondents to estimate the returns to personality traits on wages, but calculate hourly wages using reported hours worked, and find a positive and significant association between conscientiousness and log gross hourly wages.

A related problem is that of the set of control variables used. When comparing the GSOEP results in Figure 2.1 to those in Figure 2.2, when selecting individuals with valid information on cognitive skills, the results are neither quantitatively nor qualitatively the same, despite

\footnotetext{
${ }^{10}$ Nevertheless, as noted above, the findings from the GSOEP regarding the correlation between personality traits and wages are in line with those found by Mueller \& Plug (2006) for a sample of working men in the United States.
} 
the fact that the model and set of controls has not changed. The most extreme example is the association between conscientiousness and income. While the full sample revealed no significant correlation between the two, the reduced sample, with the same set of controls (left panel of Figure 2.2), shows a large and significant positive association between conscientiousness and self-reported monthly income. While selection or attrition might be driving some of the results, others argue that much of the association between personality traits and labor market outcomes stems from their effects on educational attainment and occupational sorting (Almlund et al., 2011; Borghans, Ter Weel \& Weinberg, 2008c). Chapter 3 provides evidence that educational attainment only partially mediates the predictive power of personality, while the wage returns to personality traits are indeed largely driven by occupational sorting. Additionally, combining the results discussed in Almlund et al. (2011), Figure 2.2, and Chapter 3, we can also conclude that, while cognitive skills have strong predictive power for many socio-economic outcomes, it is not an explanation or a major mediator for the correlations between personality traits and these outcomes.

\section{$2.3 \quad$ Variability}

This section addresses the stability and change of personality over the life cycle. Change in personality can be measured in terms of rank-order change or mean-level change. Rankorder change refers to the change one makes in terms of the ordering in the distribution of a trait, and is measured by the correlation between traits at two points in time. A mean-level change is measured by a change in the absolute measure of a trait between two points in time.

McCrae \& Costa (1994) summarize the evidence on the stability of personality from the 70 's through to the early 90's. They conclude that personality stabilizes around age 30, and that this conclusion is independent of whether stability is measured in terms of test-retest correlations (rank-order stability) over substantial time intervals or in terms of mean level patterns. In terms of rank-order stability, stability coefficients at that age are typically in the range of .60 to .80 , which is comparable with short-term test-retest reliabilities, which range from .70 to .90 . This indicates that the largest part of the reliable variance in personality traits is stable.

Brent Roberts and co-authors take a more qualitative approach in estimating the stability of personality, both in terms of rank-order stability (Roberts \& DelVecchio, 2000) and mean level patterns of Big Five personality traits (Roberts, Walton \& Viechtbauer, 2006). In both studies, the authors use meta-analytic techniques to test whether personality traits stabilize at a specific period in the life course. They challenge the conclusions drawn by McCrae \& Costa (1994). Roberts \& DelVecchio (2000) compiled 3,217 test-retest correlations from 152 longitudinal studies to measure the consistency of personality traits. Their meta-analytic estimates show that trait consistency increases throughout the life cycle, from .31 in childhood, to .54 during the college years and .64 by the age of 30 , and finally peaking at .74 between ages 50 and 70. Analyzing the various dimensions of the studies used, they find that the correlations generally decrease with the time interval between first and second measurement of traits, ranging from an average correlation of .55 at 1-year intervals, to .52 at 5-year intervals, .49 at 10-year intervals, and as low as .41 with 20-year intervals. Additionally, test-retest correlations are dependent on the type of personality trait measured. Whereas childhood measures of temperament generally show lower test-retest correlations than adult 
measures of Big Five personality traits, among the Big Five, extraversion and agreeableness are found to have higher rank-order stability than the other three traits.

Using data from 92 samples, Roberts et al. (2006) investigate the life-cycle patterns of mean levels of personality traits. Their results show that people increase in extraversion, conscientiousness, and emotional stability, and that these changes occur mainly in young adulthood. Agreeableness also increases in young adulthood, but shows further increases later in life, after age 45. For openness, they also find increases in young adulthood, but also decreases at old age (after 55). Regarding extraversion, an interesting pattern emerges, since Roberts et al. (2006) analyze the patterns for two facets of extraversion separately: social vitality and social dominance. Social dominance increases until the age of 35, and then stabilizes, whereas social vitality remains rather constant throughout adulthood, and starts to decline after age 55. As was the case when investigating rank-order stability, Roberts and co-authors find that measures of mean-level change depend on the time-interval between measurements, as well as on the cohort of the sample. These effects are particularly noticeable for agreeableness and conscientiousness. Samples with larger time-interval between measurements, as well as samples of younger cohorts, report larger mean-level increases in agreeableness and conscientiousness.

Combining the results from the two meta-analytic studies, Roberts et al. (2006) summarize that populations can demonstrate high rank-order stability, while at the same time also demonstrating significant mean-level changes, demonstrating that different measurements of change or stability provide answers to different questions and highlight different aspects of personality development. Nevertheless, the studies on personality development lead to a conclusion that is in line with the conclusion attached to the technology of skill formation (e.g. Cunha \& Heckman, 2008). With age, people become increasingly consistent, in terms of their rank order in the distribution of personality traits. At the same time, mean level changes in personality traits are largest in childhood and early adulthood. The two ingredients in the technology of skill formation are skills and investments. Noncognitive skills, or personality traits, develop in three ways: through the self-productivity of noncognitive skills, through the short-run direct effects of early investments on these skills, and through the long-run indirect effects (through heightened noncognitive skills) of early investments.

Given that the development and rate of change is not merely a reflection of genetic maturation, but is also influenced by the environment one grows up in, ${ }^{11}$ the next challenge is to map the factors most relevant in shaping personality. Goldberg et al. (1998) use a representative sample of U.S. working adults to investigate the correlations between personality traits and four demographic variables: gender, age, ethnic/racial status, and educational level. In line with findings from Roberts et al. (2006) and from the results of our own calculations described below, the correlation with age is most strong for conscientiousness, with a raw correlation of .32 (and .31 when controlling for the other demographic variables). The correlations for the other traits are much smaller, ranging from .00 for intellect, to .12 for agreeableness. Regarding years of education, the only trait showing a correlation larger than .20 is intellect (openness), with a raw correlation of .34 (and .31 when controlling for the other demographic variables). These correlations are similar to those found by Vassend \& Skrondal (1995), who using a representative sample of the non-institutionalized Norwegian population aged 15 and above. The strongest correlation with age is observed for conscientiousness, at .46 , while openness shows the strongest correlation with education, at $.37 .{ }^{12}$

\footnotetext{
${ }^{11}$ See Roberts et al. (2006) for a discussion of the theories on personality development.

${ }^{12}$ Interestingly, Vassend \& Skrondal (1995) find that the correlation between conscientiousness and edu-
} 
Regarding the demographics of gender and race, Goldberg et al. (1998) finds that women rate themselves as slightly less intellectual (open) than men, and African Americans and Hispanic Americans rate themselves as slightly less conscientious compared to caucasians.

Using data from the Household, Income and Labour Dynamics in Australia (HILDA) survey, Cobb-Clark \& Schurer (2012) also look at the changes in personality traits over the life cycle, while also investigating the role of adverse life events to explain intra-individual differences in the rate of change. Retaining a sample of 6073 respondents ages 25 to 64 with valid information on Big Five personality traits from the years 2005 and 2009, the authors begin by defining personality change by simply subtracting the individual 2005 scores on each of the five personality traits from their 2009 counterparts. With personality traits measured on a scale from 1 to 7 , the median change between 2005 and 2009 is zero for all traits, with half of all individuals reporting changes of no more than half a point in either direction. While the authors conclude that changes in the Big Five traits are generally independent of age, they also report evidence from parallel analysis indicating that personality change is larger among the young (ages 15 to 24 ) and the old (65 and over).

Second, Cobb-Clark \& Schurer (2012) wish to shed light on whether or not shocks in life have meaningful impacts on the development of personality traits, and if such shocks contribute to explaining the intra-individual difference in reported changes in personality traits. They examine three types of shocks: family shocks, income shocks, and health shocks. They create dummy indicators for all three domains, grouping respondents based on the total number of negative changes occurring between 2006 and 2009 within each of three domains. ${ }^{13}$ Of the three domains, negative employment shocks are most closely related to personality changes. Experiencing five or more employment shocks between 2006 and 2009 (more than 3 standard deviations (std)) is associated with a quarter of a standard deviation (std) lower emotional stability, but also a quarter of a standard deviation higher openness to experience for men, whereas women who had this experience score a quarter of a standard deviation higher on conscientiousness. Health shocks seem to only affect men, with men experiencing health shocks reporting decreases in conscientiousness (-.12 standard deviations) and emotional stability (-.18 standard deviations). Shocks in the domain of family, as measured by deaths of those one is close to, have no significant relationship with personality changes.

Specht, Schmukle \& Egloff (2011) investigate the same questions as Cobb-Clark \& Schurer (2012), but come to a different conclusion. They use data from the German Socio-Economic Panel. Items related to Big Five personality traits are available in 2005 and 2009 for a sample of 14,718 individuals age 16 to 82 . To account for the moderate reliability coefficients ${ }^{14}$, the Big Five personality traits are modeled as latent variables. Cobb-Clark \& Schurer (2012) start out by evaluating mean levels and mean-level changes across the life cycle. Rather than plotting averages for different age groups, they fit a latent growth model, allowing for linear, quadratic, and cubic effects on both the level (intercept) of personality, as well as the change (slope) between 2005 and 2009. The effect of age is shown to be largest for openness and conscientiousness. Openness reveals a pattern of decline across the life cycle, with larger declines in young (under 30) and old age (post 60). Cross-sectionally,

cation is significant and negative, with a raw correlation of -.22. All other traits also correlate significantly with age and education, yet the absolute correlations are all below .15 .

${ }^{13}$ The following events are considered as negative shocks: family: death of a spouse, child, relative, or friend, or being a victim of property crime; employment: worsening of finances, retiring, being fired, or becoming unemployed; health: serious illness or injury, physical violence, or new health conditions.

${ }^{14}$ In the German Socio-Economic Panel, there are only three items to capture each of the Big Five personality traits. 
conscientiousness seems to increase until around age 40, whereas agreeableness seems to increase mainly in old age (post 60). Extraversion shows a linear but modest decline over the life cycle, which is in line with the results shown by Roberts et al. (2006), given that the scale in the GSOEP focuses on social vitality, which was found to diminish slowly with age. Regarding the development of the other traits, the results are rather dissimilar, when compared to the patterns described by Roberts et al. (2006).

When it comes to the effects of specific life events on the development of personality, Specht et al. (2011) find both several selection effects and several socialization effects, meaning that personality traits predict the occurrence of major life events, but also change as the result of experiencing them. Some examples of selection effects are the finding that those higher in extraversion are more likely to move in with their partner in the ensuing years, whereas women who are less emotionally stable, are more likely to get married in the following years. Examples of socialization effects can also be, effecting mainly the development of extraversion and openness. Leaving the parental home, moving in with one's partner, and getting married, are all associated with following declines in extraversion and openness. Getting married is additionally associated with declines in agreeableness and conscientiousness of about one tenth of a standard deviation. A divorce is similarly associated with increases in these traits, with effect sizes of .19 and .25 standard deviations, respectively.

An interesting finding, is that occupational changes seem to have only limited effects on personality development. Retiring and entering one's first job are only statistically significantly associated with changes in conscientiousness, where it increases by about two tenths of a standard deviation after entering one's first job, and declines again by almost that same amount after retirement. Entering into unemployment is only associated with statistically significant changes in openness (-.08 standard deviations). These results are not consistent with those discussed by Cobb-Clark \& Schurer (2012). Whereas Cobb-Clark \& Schurer (2012) find negative employment shocks to be associated with increasing openness for men, and increasing conscientiousness for women, the results shown for entering unemployment and retirement by Specht et al. (2011) suggest negative employment shocks are associated with declines in these traits. Specht et al. (2011) suggest that the inconsistencies with other findings might be related to different approaches to looking at single events or clusters of events.

Although personality is found to be most stable in (late) adulthood, substantial changes at the individual level continue to exist, and are significantly associated with the experience of different major life events. Given that personality is more prone to changes in childhood and adolescence, the effects of experiencing life events early in life might also be more detrimental to personality development. Knudsen, Heckman, Cameron \& Shonkoff (2006) describe how children raised in disadvantaged environments are exposed to a number of risk factors that are associated with diminished economic success and decreased quality in life in adulthood. They come to these conclusions describing results obtained from two early childhood intervention programs: the Perry Preschool Program and the Abecedarian Program. The authors conclude that these negative patterns can be prevented or limited by means of interventions, and that such interventions are more successful when applied at younger ages. This conclusion is in line with the argumentation behind the technology of skill formation (Cunha et al., 2006).

The technology of skill formation postulates that skills, both cognitive and noncognitive, develop over the life cycle, but that the rate of growth and the final skill level is dependent on early levels of these skills, as well as investments in these skills over the life cycle. Earlier 
investments are more productive for two reasons. First, early investment lowers the cost of later investment, since children receiving early education or additional stimulus, are less likely to fall behind, are and then also less likely to repeat grades or require additional tutoring or special education services. Second, early investment increases early skills. A crucial ingredient in the technology of skill formation is that skills beget skills. What this means is that skills required early in life make it easier to acquire skills in following years. Coneus, Laucht \& Reuss (2012) use data on 357 children from the Mannheim Study of Children at Risk to examine the impact of parental investments on the development of cognitive, mental, and emotional skills up to the age of 11 .

Coneus et al. (2012) confirm the main ingredients of the skill production function of Cunha \& Heckman (2007). The first is the observation that skills beget skills. Both cognitive and noncognitive skills show self-productivity, in the sense that higher cognitive (noncogntive) skills today are associated with higher cognitive (noncognitve) skills tomorrow. This selfproductivity also increases with age, highlight the importance of acquiring as much of these skills as possible as early as possible. The second crucial ingredient is the effectiveness of parental investment. Using a variety of measures of parental investment, including parental health behavior, playing and talking with the child, and play materials, Coneus et al. (2012) demonstrate that the impact of parental investment on cognitive and noncognitive skills is largest at younger ages, becoming insignificant factors as early as age 8. Interestingly, they also find evidence suggesting that the impact of parental investment is different for different noncognitive skills. The effects of parental investment are stronger for traits related to conscientiousness, while noncognitive skills associated with emotional stability and agreeableness are not significantly effected by parental investment. ${ }^{15}$ Lastly, the authors find that the estimated pattern is different for boys and girls. While the self-productivity of cognitive and noncognitive skills are fairly similar for boys and girls throughout childhood, the correlation between noncognitive skills and later cognitive skills are larger for girls than for boys. Parental investment seems to impact the cognitive development of boys more strongly, whereas for noncognitive skills, the impact of parental investment is larger for girls.

Results from a number of studies on animal behavior can provide us with insights into the mechanisms behind the diminishing returns to parental investment. Knudsen et al. (2006) summarize findings from studies on macaque monkeys, owls, and rats. For the macaque monkeys, the results provided evidence suggesting the existence of sensitive periods for the emotional development of monkeys. Monkeys removed from their mothers at one week of age grew up to demonstrate atypical social behavior, and remediation, in terms of providing a surrogate mother, was proven effective only if introduced within the first month of the infant's life. Recent evidence from Conti, Hansman, Heckman, Novak, Ruggiero \& Suomi (2012) support these findings. Using experimental data on 231 rhesus monkeys, the authors reveal that a lack of secure, nurturing relationship with the mother, has negative long-term effects on physical and metal health. The data on the barn owls reveals the value of learning skills at early ages (Knudsen et al., 2006). Early learning allows for increased functional plasticity of the neuron circuits in the brain, providing an explanation for why adults can easily relearn a language that they have learned as children. The experiments involving rats

\footnotetext{
${ }^{15}$ Coneus et al. (2012) distinguish two sets of noncognitive skills: mental skills and emotional skills. Mental skills are a mix of persistence and activity level, whereas emotional skills sum up traits like adaptability, approach, and prevailing mood. Whereas persistence is related to conscientiousness, adaptability and mood are associated with emotional stability and agreeableness. Extraversion is present in both types of noncognitive skills, with both approach and activity reflecting extraversion. Parental investment significantly affects mental skills, but not emotional skills.
} 
demonstrate that although genetics constrains the range of characteristics one can express, early experience can modify these characteristics to a large extent.

Evidence regarding the effects of lack of emotional stimulation during infancy and possible remediation of these effects comes from findings regarding studies involving the development of Romanian orphans. Due to the ban on abortion and contraception until the late 80's and other stimuli to stimulate population growth, Romanian couple often gave birth to more children than they wanted or could take for. The result was that this 'surplus' of children was left in the care of the state. However, the conditions in these orphanages were generally very poor: few staff members, no toys or educational activities, and little to no interaction or communication with the children (e.g. Rutter, Beckett, Castle, Colvert, Kreppner, Mehta, Stevens \& Sonuga-Barke, 2007). This institutional deprivation had significant long-term effects, effecting the development of both cognitive and noncognitive skills. Rutter et al. (2007) compare 165 children from Romania to 52 non-institutionalized UK children, all of which were adopted by UK families. Despite the lack of a nurturing environment in the first months of life, there was significant catch-up after adoption. However, severe problems in terms of psychological functioning still remained for children placed after the age of six months.

Ghera, Marshall, Fox, Zeanah, Nelson, Smyke \& Guthrie (2009) evaluate the differences between children who remained under institutional care and those who were randomly assigned to foster care. Children were evaluated on emotion tasks at 30 and 42 months of age, and for both age points, the data revealed that children receiving foster care showed higher levels of attention and positive affect. Zeanah, Egger, Smyke, Nelson, Fox, Marshall \& Guthrie (2009) also analyze the effects of removing young children from institutional care and placing them in foster care. For 136 children, randomly assigned to continued institutional care and placement in foster care, information is available from psychiatric interviews of caregivers. At the time of this interview, the children were 54 months of age. Children removed from institutional care were less likely to have psychological disorders. Placement in foster care was thus associated with significantly reduced internalizing disorders, although these affects are only visible for girls. These findings are in line with the result from the rhesus monkey experiments of Conti et al. (2012). Female monkeys reared by a surrogate mother performed at par with those reared by their own mother, whereas those being reared by peers, with a lack of secure attachment relationship, demonstrated worse physical and mental health later in life. ${ }^{16}$

While there seems to be a lack of consensus regarding the age at which personality stabilizes, or if it even does stabilize, there is agreement on the fact that most changes in personality occur early in life. Additionally, changes in personality traits are affected both by genetics and by the environment. Life events or shocks to one's environment have a significant impact on the development of both cognitive and noncognitive skills. Moving from the extreme situation of institutional deprivation found in Romanian orphans to the less extreme shock of divorce of one's parents, the main conclusions remain. Firstly, children from divorced families fair significantly worse on various outcome measures, when compared with children from intact families. Results from meta-analyses reveal effect sizes ranging from one tenth of a standard deviation lower scores on self-concept, to two tenths of a standard deviation lower scores on conduct and psychological adjustment. ${ }^{17}$ However, these associations are shown to

\footnotetext{
${ }^{16}$ A special edition of the Monographs of the Society for Research in Child Development is devoted to the English and Romania Adoptees (ERA) study (Rutter, Sonuga-barke, Beckett, Castle, Kreppner, Kumsta, Schlotz, Stevens \& Bell, 2010).

${ }^{17}$ See Amato \& Keith (1991) and Amato (2001) for meta-analyses of the effects of divorce on childhood
} 
depend on the methodology applied in the study. Simple models without covariates reveal higher correlations between parental divorce and outcomes, whereas results based on larger samples reveal weaker effect sizes.

Besides an overall main effect of environmental factors, the results described above also demonstrate the existence of sensitive periods, and the importance of the first years of a child's life for the development of both cognitive and noncognitive skills. Whereas longer exposure to institutional care for the Romanian orphans is more detrimental for long-term health of the orphans, the effects of experiencing negative shocks in the family composition during childhood are also larger when these shocks occurred early in life (e.g. Ermisch, Francesconi \& Pevalin, 2004; Ermisch \& Francesconi, 2001). Effects of shocks on personality development not only depend on model specification and age at shock, but possibly also on gender. Results from the rhesus monkey experiments (Conti et al., 2012), as well as those from the Romanian orphans (Zeanah et al., 2009), suggest that remediation of the effects of negative environmental shocks is less likely to be successful for males. Along the same lines, many studies conclude that the negative consequences of divorce are more severe for boys, than they are for girls. Yet, several others report no significant interaction between family type and gender of the child (Amato \& Keith, 1991; Amato, 2001). Chapter 4 contributes to this discussion by analyzing the impact of losing one of two natural parents on the development of a child's personality. While parental loss is found to have a negative impact on both changes in, and final level of, desirable personality traits, adding more controls to the model reduces the effect size. The impact of parental loss is also found to be dependent on age at loss, the reason for loss, and, finally, also on the gender of the child.

\subsubsection{Evidence from the Netherlands and Germany}

Figure 2.4 shows the rank-order stability of Big Five personality traits for two samples. The left-panel reports results obtained from using the DHS, whereas the right panel reports results obtained using the GSOEP. Rank-order stability is measured as five-year test-retest correlations for each of the Big Five personality traits. There are clear differences between the samples, but pattern also differs slightly between the five domains of the Big Five taxonomy of personality. However, the general pattern is that stability of the various personality traits increases until about age 30, then remains roughly constant until retirement age (around 65), and declines again thereafter. These results are in line with McCrae \& Costa (1994), who argue that personality traits peak at about age 30, after which they remain stable, and seems to be contradicting the evidence obtained by Roberts and co-authors, that personality does not stabilize until a much later age, both in terms of rank-order stability Roberts \& DelVecchio (2000), and in terms of mean level change Roberts et al. (2006).

Regarding mean levels of personality traits, Figure 2.5 shows cross-sectional age patterns of mean levels. ${ }^{18}$ The cross-sectional results are roughly in line with those obtained by the rank-order stability in Figure 2.4, demonstrating that personality is most volatile before age 30 , showing increases in traits, and again at old age, showing patterns of decline after the age of 70. Over the life cycle, openness and extraversion seem to decline, at a rather constant rate. For the other traits, there are some differences between the patterns obtained from

\footnotetext{
development.

${ }^{18}$ Figure 2.5 shows cross-sectional age patterns of mean levels of each of the Big Five personality traits using data on personality traits from 2005 for both the DHS and the GSOEP. Using personality information from 2009 yields almost identical patterns.
} 
Figure 2.4: Stability of Big Five Traits over the Life Cycle

DNB Household Survey (DHS)
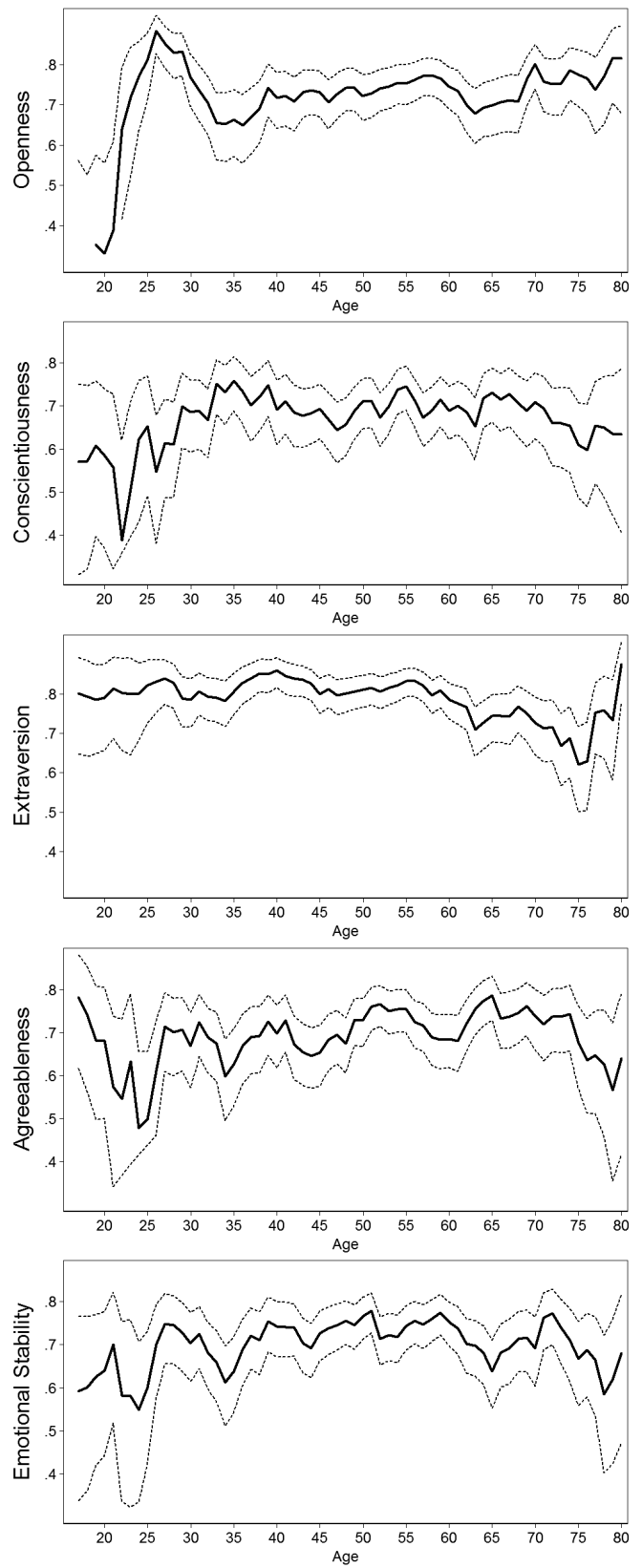

German Socio-Economic Panel (GSOEP)
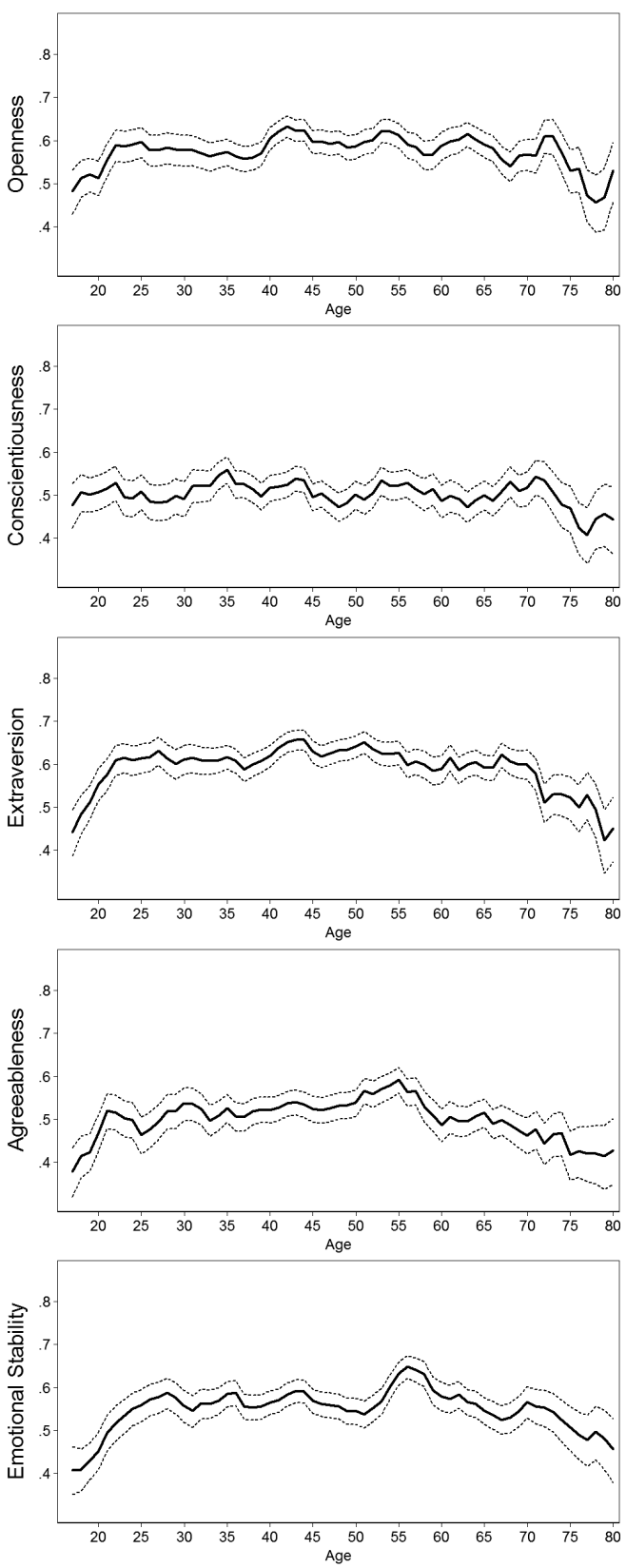

Note: Test-retest correlations of Big Five personality traits between 2005 and 2009, by age in 2005, using representative samples of the Dutch (left panel) and German (right panel) population. To obtain less erratic patterns, 7- and 5-year moving averages were used, for the Dutch and German samples, respectively. For example, using the GSOEP data, the stability of conscientiousness at age 25 is measured by the correlation between 2005 and 2009 conscientiousness for respondents aged between 22 and 27 in 2005. 
the Dutch sample (left panel), and those obtained from the German sample (right panel). Openness, conscientiousness and agreeableness are shown to be increasing until about age 25 or 30 in the Dutch sample, after which they stabilize, or even slowly decline in the case of openness. For the German sample, this initial period of growth is only observable for conscientiousness, and continues longer, until the age of 35 .

Figure 2.6 shows individual changes on the Big Five traits, as measured by the differences between the 2005 and 2009 scores on each of the Big Five traits. These individual differences are then averaged over individuals with the same age, to get a measure of absolute change on self-rated personality traits, over a four year period. If the items measure what they are designed to measure, one would expect similar patterns resulting from cross-sectional differences by age, and from using individual changes over a four year period. To a large extent, this is also the case. The cross-sectional age patterns shown in Figure 2.5 are in line with the individual changes between 2005 and 2009 (Figure 2.6), yet the conclusions one would draw could differ, depending on which of the two one looks at.

An example in which both views yield similar conclusions is the development of extraversion in the German sample (GSOEP). Figure 2.5 shows that, over the life cycle, extraversion starts out flat, and then continuously declines, but at a slow pace. Similarly, Figure 2.6 reveals that below age 20, respondents do not report any changes in extraversion between 2005 and 2009, while from age 25 onwards, the reported change is negative, indicating declines in extraversion with age. An example in which the two figures do not coincide is the development of conscientiousness in the German sample (GSOEP). Whereas the cross-sectional pattern of conscientiousness reveals a concave pattern of increasing conscientiousness scores up to the age of 35, and no significant changes from thereafter. The results from the individual changes between 2005 and 2009 do indeed show increases at young ages, and that these increases occur at a diminishing rate, yet conscientiousness scores stop increasing already before age 25 , and starts declining thereafter.

\subsubsection{Discussion}

Clearly, the conclusions concerning the stability of personality traits differ across samples and methods used. Nevertheless, a number of results are consistent. Across the life cycle, conscientiousness and agreeableness show higher rank-order stability than the other three traits. Rank-order stability across the Big Five is lowest at early age, and increases until around the age of 30 . The results from mean level comparisons are roughly in line with this conclusion, demonstrating that personality is most volatile before age 30 , showing overall increases in traits, and again at old age, showing patterns of decline after the age of 70 . Over the life cycle, openness and extraversion seem to decline, albeit at a slow rate, and conscientiousness seems to increase with age.

These results are in line with McCrae \& Costa (1994), who argue that personality traits peak at about age 30, after which they remain stable. Associated test-retest correlations vary between .60 and .80 , confirmed by the results using the DHS data, with slightly lower correlations resulting from the GSOEP data (.50 to .60). Roberts and co-authors, however, argue that personality does not stabilize until a much later age Roberts \& DelVecchio (2000), demonstrating higher rest-retest correlations for age groups 50-59 and 60-73 than for earlier age groups. However, fewer studies and samples were used to estimate these correlations than those for other age groups, and are thus based on smaller sample sizes, while also overrepresenting traits extraversion and emotional stability, hinting towards possible differences 
Figure 2.5: Levels of Big Five Traits over the Life Cycle

DNB Household Survey (DHS)
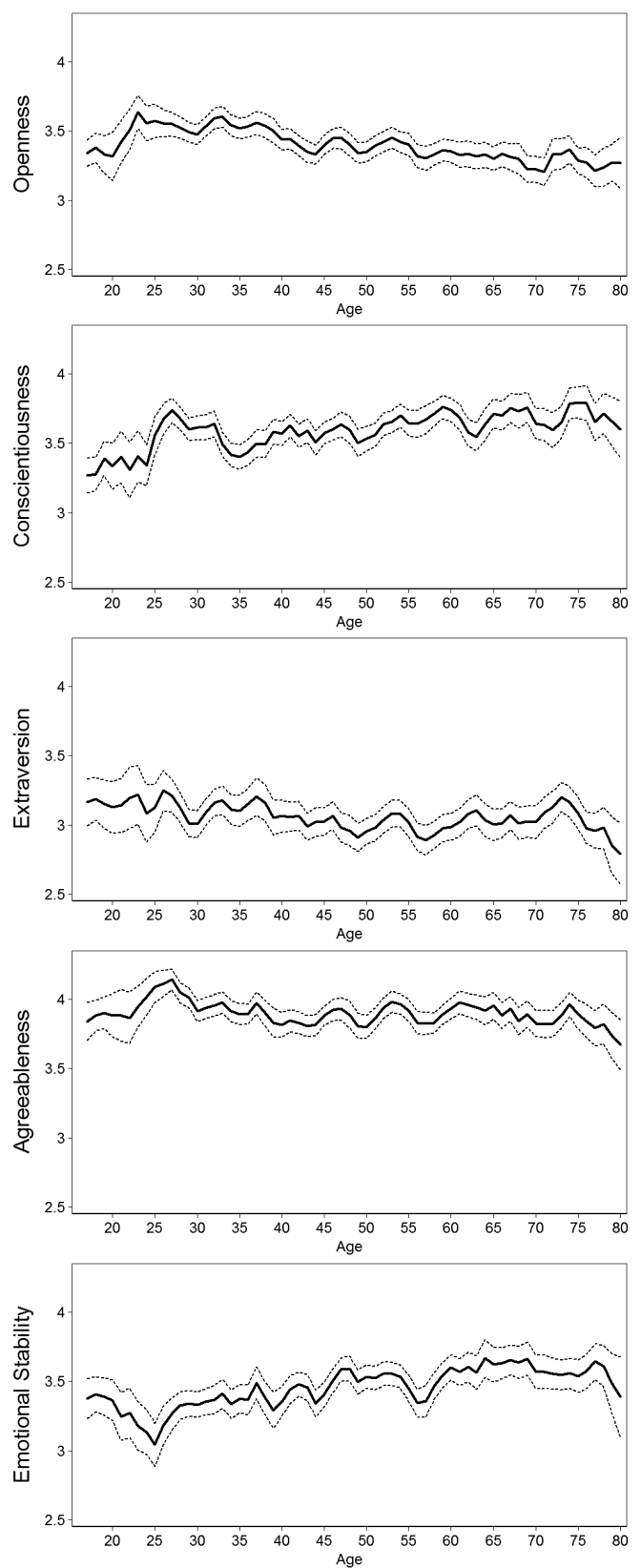

German Socio-Economic Panel (GSOEP)
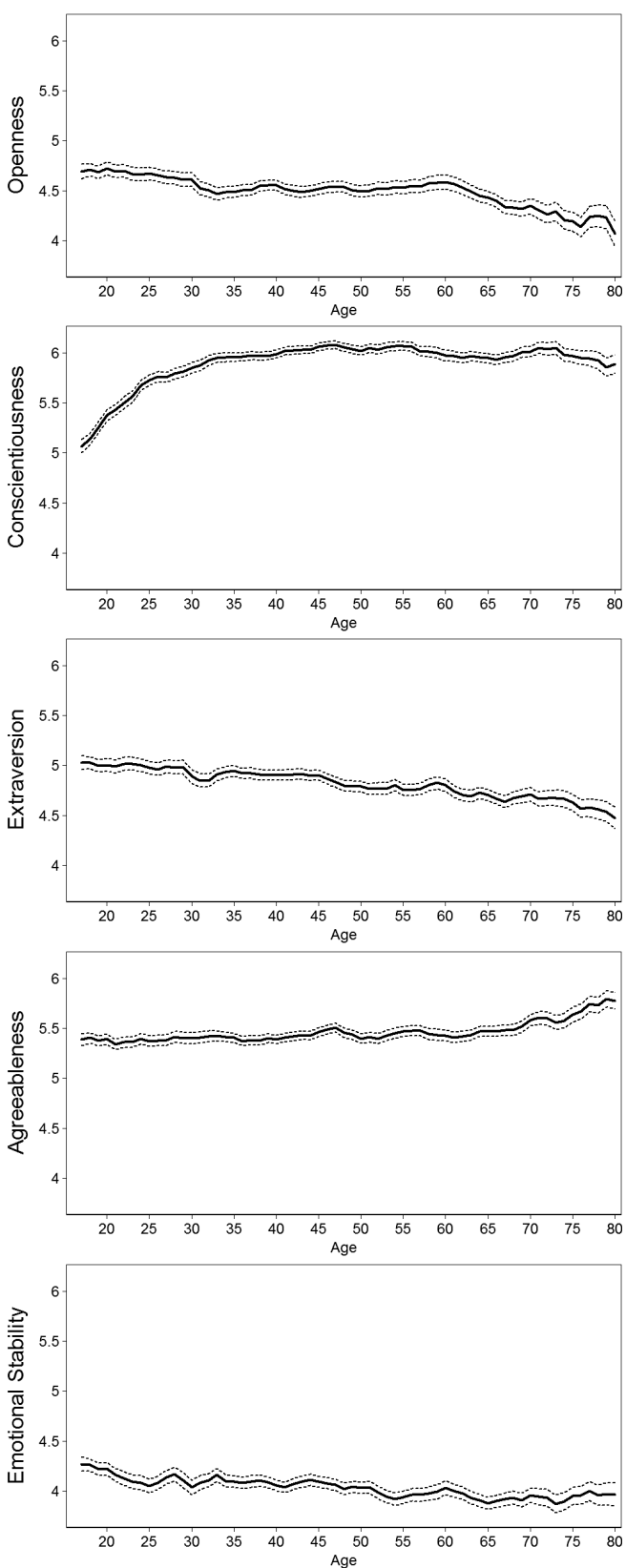

Note: Mean level of Big Five traits in 2005, by age in 2005, using representative samples of the Dutch (left panel) and German (right panel) population. To obtain less erratic patterns, 3-year moving averages have been used. For example, the mean level of age- 25 conscientiousness was obtained using conscientiousness scores of all respondents aged 24, 25, or 26 . 
Figure 2.6: Mean Level Change of Big Five Traits over the Life Cycle

DNB Household Survey (DHS)
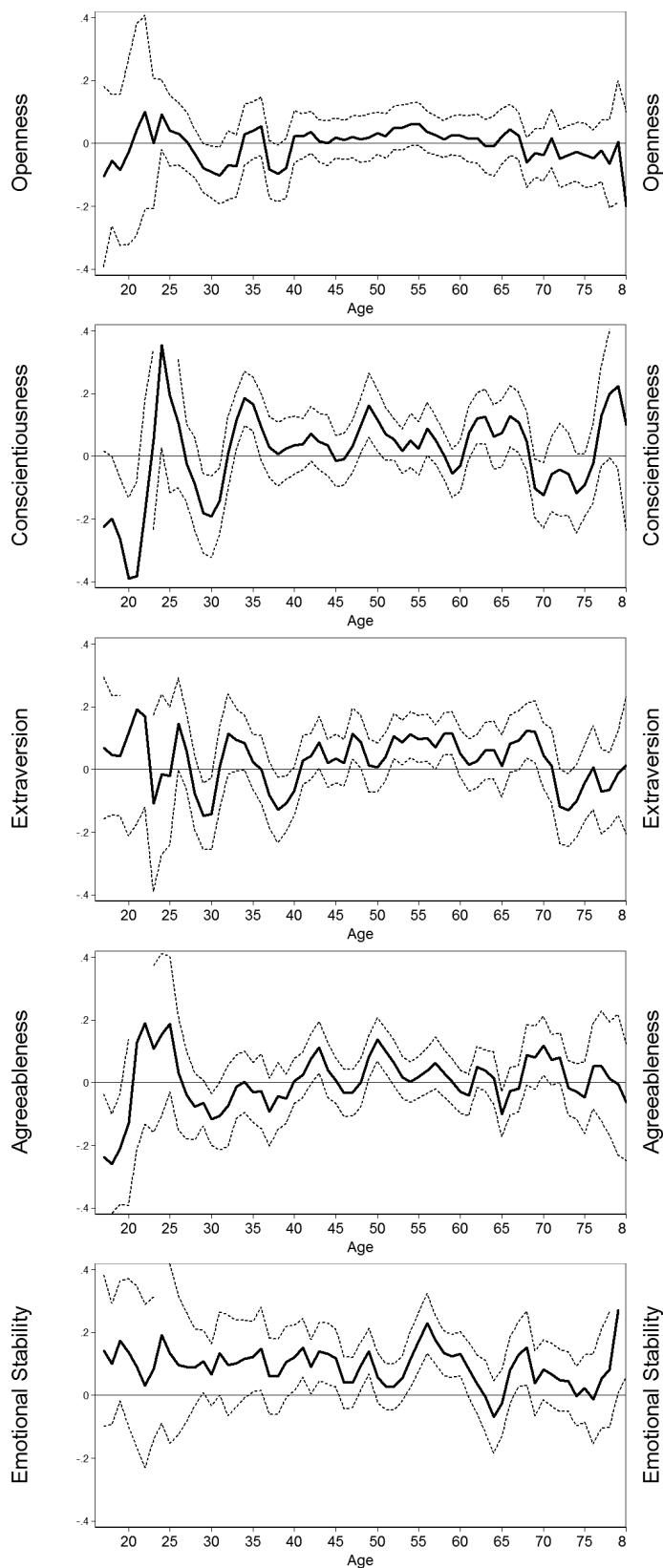

German Socio-Economic Panel (GSOEP)
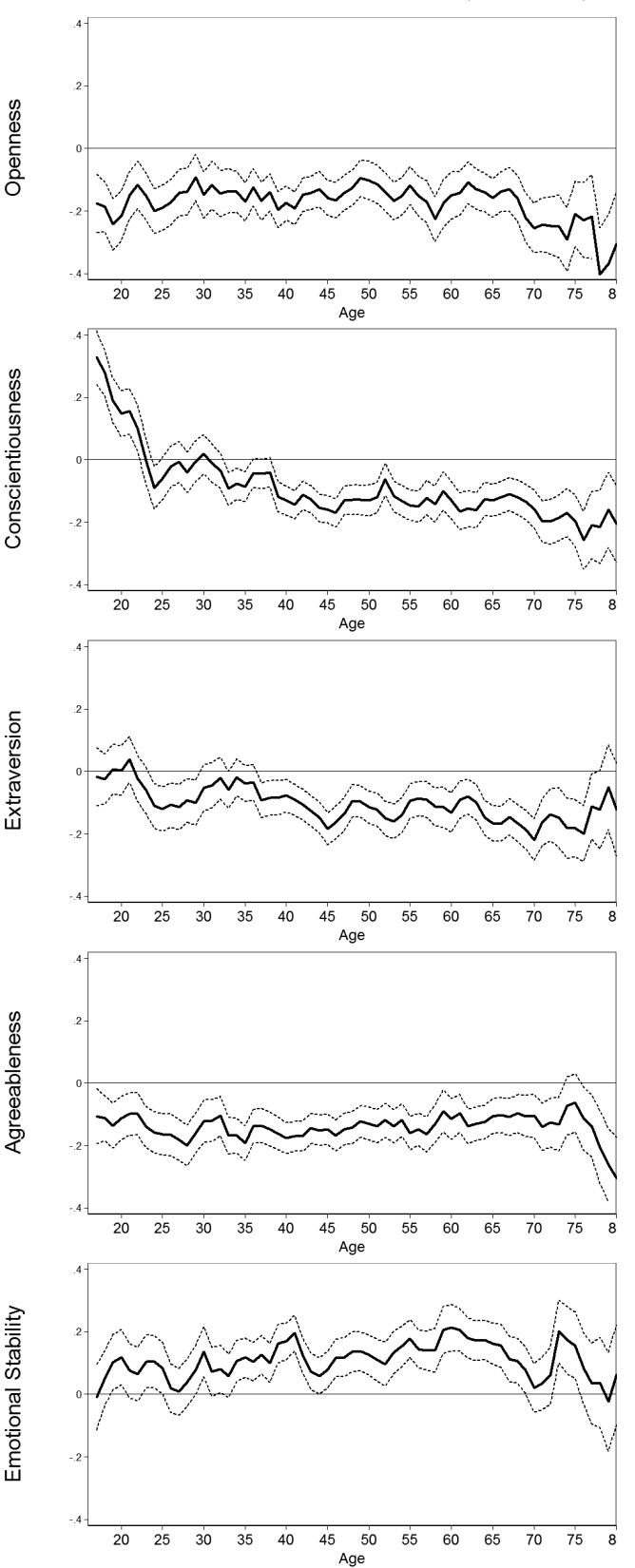

Note: Mean level change in Big Five traits between 2005 and 2009, by age in 2005, using representative samples of the Dutch (left panel) and German (right panel) population. To obtain less erratic patterns, 3 -year moving averages have been used. For example, the mean level change of age-25 conscientiousness was obtained using their 2005 and 2009 conscientiousness scores of all respondents aged 24, 25, or 26 in 2005. 
in measurement of personality traits for those older age groups. When it comes to mean level change, Roberts et al. (2006) also conclude that personality continues to develop, even in older ages. While McCrae's conclusion that personality stabilizes at 30 seems to contradict this, it all depends on how one looks at the data.

Comparing the patterns described above with those found by Roberts et al. (2006), both claims seem to be supported. Stability of traits seems to stabilize in young adulthood, yet changes occur over the entire life cycle, yet the magnitude of those changes differs by trait and may not be large. What is illustrated by the literature on personality change, and the results from the two nationally representative samples shown above, is that different samples, different measurement systems, and different age-grouping influence the extent of stability or change measured.

Two factors that contribute to the deviating patterns are sample size and measurement error. When it comes to the test-retest correlations presented in Figure 2.4, it is obvious that the Dutch sample generally reveals higher rank-order stability of all personality traits than does the German sample. This is not surprising, given that each trait is measured using ten items in the Dutch DHS, resulting in higher reliability of the resulting constructs, compared to the constructs obtained using the German data from the GSOEP, which only provides three items per trait. The Cronbach's alphas associated with the Dutch Big Five constructs all well exceed the common acceptability threshold of 0.7 (ranging from .76 to $.86)$, whereas the reliability of the measures used in the German data is somewhat lower, with Cronbach's alphas around 0.6. ${ }^{19}$. At the same time, the results from the DHS are more volatile, and have larger confidence intervals, which is a result of the much smaller sample size. For most age comparisons, the GSOEP samples are ten times as large as the DHS samples. Given that there are just under 1,200 respondents in the Dutch sample with valid information on personality in 2005 and 2009, it is not surprising that, when this sample is further reduced into narrow age brackets, the pattern of changes in the left panel of Figure 2.6 (DHS) seems to reveal that none of the Big Five traits show significant changes over the life cycle.

Despite the generally observed gender differences in levels of various personality traits ${ }^{20}$, men and women change in similar ways with respect to their mean levels of personality traits (Roberts et al., 2006; Specht et al., 2011). Hence, gender does not significantly alter the development of noncognitive skills. The general experience of adverse life events in adulthood also does not seem to significantly affect personality development ${ }^{21}$, yet more specific life events are both preceded by certain personality changes (selection effects) and followed by specific patterns of personality change (socialization effects). ${ }^{22}$ When it comes to (adverse) life events experienced in childhood, shocks that alter the family composition are significantly associated with less desirable personality development and higher rates of personality, social, and health disorders. The channels through which this process operates are likely to be a combination of lack of parental affection and lack of experienced socialization. In the terminology of the technology of skill formation, early investment, at time $t=0$, is lacking or completely absent, limiting the development of cognitive and noncognitive skills between

\footnotetext{
${ }^{19}$ As reported in the appendix, in Tables 2.A.1 and 2.A.2.

${ }^{20}$ Specht et al. (2011) show that women score about .46 standard deviations lower on emotional stability than men, and .42 and .26 standard deviations higher on agreeableness and extraversion, respectively. The differences in terms of conscientiousness and openness to experience are smaller, but still significant, with, respectively, .08 and .04 higher scores for women.

${ }^{21}$ See, for example, Cobb-Clark \& Schurer (2012).

${ }^{22}$ See Specht et al. (2011).
} 
$t_{0}$ and $t_{1}$. Due to the self-productivity and cross-productivity of skills, in periods to follow, those who experience such a shock will fall even further behind, compared to children who did not experience such a shock.

\subsection{Malleability}

Section 2.2 highlights some of the findings revealing the importance of various personality traits for a range of socio-economic outcomes. The preceding section demonstrates that personality develops over the life cycle, and that this development is negatively affected if individuals are exposed to environmental shocks or adverse life experiences. Given the crucial period of childhood for personality development, and the role of parental stimulation and the educational environment herein, the next step is to answer whether personality traits, or noncognitive skills, can be targeted by public policy. A number of childhood intervention programs provide some interesting, yet inconclusive, answers. ${ }^{23}$

Many early childhood interventions have little or no effect on cognitive skills, yet they still show sizeable returns on a range of other socio-economic outcomes. These effects on later life outcome must operate through other channels than cognitive skills (e.g. Borghans et al., 2008a; Heckman et al., 2008). Early childhood interventions like Perry Preschool, Abecedarian, Head Start, and Nurse/Family Partnership all provide a mix of academic and parental support and have been shown to have long-term effects on educational attainment, employment, earnings, but also on crime. While these programs were not mainly targeted at the improvement of noncognitive skills, researchers have argued that improvements in noncognitive or social skills are likely to be key mediators for the long-term effects of these interventions (Heller et al., 2012). Since many childhood intervention programs are targeted specifically at at-risk populations, rather than being based on random assignment to treatment, and given that few include good measures of noncognitive skills, it is difficult to draw clear conclusions for the design of social policy.

The oldest, and most influential childhood intervention study is the Perry Preschool Program, demonstrating sizeable and economically meaningful treatment effects (Heckman et al., 2010, 2012). Conducted in Ypsilanti, Michigan, in the early 1960's, the program targeted disadvantaged African-American children with low socio-economic background and low IQ. Children were aged 3 at the start of treatment, and follow-ups occurred over the entire life cycle, with yearly measurements between ages 3 and 15, and three additional follow-ups at ages 19, 27, and 40. The total sample comprises 123 children, randomly assigned intro treatment $(n=58)$ and control $(n=65)$ groups. The program was very intensive, lasting 2 years, with 2.5 hours of daily intervention, five days per week. Additionally, teachers made house visits once a week, for the duration of 1.5 hours, to involve the mother in the educational process, and to implement the curriculum at home. The curriculum aimed at fostering children's skills in planning, execution and evaluation of tasks, as well as social skills, such as cooperation and conflict resolution.

While the Perry Preschool Program initially boosted IQ, this effect faded after the end of the two-year program. Nevertheless, the program was to have long-lasting effects when measuring outcomes at later ages. The treated score higher on achievement tests taken at

\footnotetext{
${ }^{23}$ See e.g. Almlund et al. (2011), Brunello \& Schlotter (2011), and Heller, Pollack, Ander \& Ludwig (2012) for more complete discussions of the various intervention programs, with intervention starting at varying ages.
} 
age 14, obtain higher levels of income by age 27, and have lower numbers of arrests, as measured at age 40. Heckman et al. (2012) make use of a battery of items from the Pupil Behavior Inventory (PBI) questionnaire to construct two personality constructs: personal behavior, and socio-emotional state. ${ }^{24}$ Personal behavior is measured using items that are said to be related to the Big Five trait conscientiousness, whereas socio-emotional state relates to the Big Five trait emotional stability. The treatment group scores significantly higher in terms of these noncognitive traits, and this holds both for males and females.

Heckman et al. (2012) go on to decompose the total treatment effects of the Perry Preschool Program on the later life outcomes into components corresponding to changes in cognitive skills, personal behavior, socio-emotional state, and other factors. For men, most of the significant treatment effects are related to crime, and in explaining these lifetime treatment effects, cognition and socio-emotional state are found to play no role. In line with the predictive value of conscientiousness described earlier, and also its association with lower arrest rates (see also Chapter 3), it is not surprise to find that the lifetime effects of the program are mediated by its effects on personal behavior. For women, treatment affected a wider range of outcomes, and decomposing these effects reveals a significant role for cognitive skills, as well as both personal behavior, and socio-emotional state. To conclude, the Perry Preschool Program is the oldest intervention program, with random assignment to treatment, intervention starting at age 3, measures of both cognitive and noncognitive skills, as well as long-term life outcomes. The significant treatment effects for later life outcomes seem to be largely driven by changes in noncognitive skills.

A program issued at the same stage of childhood (ages 3 and 4), is the Tools of the Mind preschool program. Almlund et al. (2011) list various results from random assignment studies that evaluate the effects of this program on a number of outcomes, and conclude that, in short-term follow-ups it improves classroom behavior, as well as executive function of the children. Another randomized experiment, yet at older ages (6 to 9), is the Fast Track program. The Fast Track program is aimed at improving social skills among elementary school children in the United States. Schools from three regions were asked whether or not they would like to participate in the program. After schools decided, the school were randomly assigned to be intervention or control schools. The final sample included 2,937 students with complete information from Grades 1 through 3, as well as information on social health and sociometric outcomes. The program included roughly 40 lessons in each of the Grade years 1 to $3 .^{25}$ Bierman et al. (2010) find sizeable and statistically significant effects of the program in terms of positive developments of the students' social skills. Authority acceptance increased by .24, cognitive concentration by .12, and social competence by .34 standard deviations.

There are also a number of studies evaluating programs for adolescents. Martins (2010) analyzes data from EPIS, a program developed to improve achievement of students aged 13 to 15 in Portugal by increasing motivation, self-esteem, and study skills. The program consists of one-on-one meetings with a trained staff member or meetings in small groups. The intervention was tailored to each participant's individual skill deficit. Overall, the program was successful, cost-effectively decreasing grade retention by 10 percentage points. A similar program from the UK is the XL clubs program. It was designed explicitly to improve pupils' noncognitive skills, such as self-confidence, locus of control, self-esteem, and

\footnotetext{
${ }^{24}$ Both the Stanford-Binet IQ test and the Pupil Behavior Inventory (PBI) questionnaire were obtained at ages 7 to 9 .

${ }^{25}$ Bierman, Coie, Dodge, Greenberg, Lochman, McMahon \& Pinderhughes (2010) provide a more detailed description of the setup and contents of the program.
} 
motivation. Once again, this program targets students deemed at risk of school exclusion or worse educational trajectories. However, in this case, treatment is not random, leading to concerns of selection. The program is rather extensive, covering 500 English secondary schools, which is roughly a fifth of the total number of schools. The program ran for two years, on students aged 14 in 2004, with weekly group meetings that lasted at least three hours. Holmlund \& Silva (2009) analyzed the impact of this program on academic achievement. National test scores at ages 11 and 14 were used as baseline measurements, and scores on the national exams taken at age 16 were used as posttreatment outcome. Despite the use of a wide variety of estimation techniques, the programme was found not to have any significant effect on the academic achievement of pupils. As described by Brunello \& Schlotter (2011), a qualitative evaluation of the program, however, revealed that participants did improve their noncognitive skills in terms of better motivation and behavior towards other students, as well as more self-esteem and confidence.

Similarly, Heller et al. (2012) report on the results from a randomized field experiment they carried out in the Chicago Public Schools. The assigned 2,740 disadvantaged male youth in grades 7-10 to one year of social-cognitive skill development, or to a control group. On average, each participant attended 13 one to two hour sessions. The intervention was found to have significantly improved schooling outcomes by .19 standard deviations the year after the program. Data from student surveys indicate that changes in noncognitive skills are one of the mechanism behind the effects. In their Appendix, Heller et al. (2012) review the evidence from studies on similar short-duration interventions that were designed to promote the development of social-cognitive skills in their participants. The authors conclude that empirical support for the claim on the effectiveness of such interventions stems largely from non-experimental studies that are susceptible to selection bias. Among the set of studies included in several influential meta-analyses, Heller et al. (2012) were only able to identify six randomized experiments designed to improve social-cognitive skills in adolescents (ages 13 to 18). Of these six experiments, only one showed statistically significant impacts on some measure of anti-social behavior. On the other hand, all of these experiments involved small samples of highly selective participants, who were already involved in either the criminal justice system or some form of mental health treatment. Thus, prevention was no longer an option, and statistical power was an issue.

Given that the above intervention programs specifically target youth at risk, one may hypothesize that any average treatment effects of programs applying to the full student population would be smaller in magnitude. The operating assumption here is that effect sizes are larger for those at the bottom of the distribution. When it comes to general education, Heckman et al. (2006) demonstrate the positive effect of years of schooling on noncognitive scales. Compared to having completed 12 years of schooling, completing less than 12 years of schooling is associated with significantly lower scores on internal locus of control and self-esteem. Those with more than 12 years of schooling score significantly higher in terms of self-esteem, but are comparable to those with 12 years of schooling in terms of locus of control. Durlak, Weissberg, Dymnicki, Taylor \& Schellinger (2011) evaluate the contribution of school-based, universal social and emotional learning (SEL) programs to the development of such noncognitive skills in pupils. Chapter 5 adds to this literature by evaluating a school-based program at a Dutch high school, aimed at developing socio-emotional skills in adolescents.

Durlak et al. (2011) apply meta-analytic techniques to summarize the findings from 213 studies, covering a total of 270,034 students aged between 5 and 18. All studies included 
control groups. Just over half of the programs were delivered to elementary school children, some thirty percent involved middle school children, and the remaining studies involved high school students. Three-quarter of the programs lasted less than a year, and the remaining quarter was evenly divided between programs lasting up to 2 or more than 2 years. Five domains of student outcomes were defined: social and emotional skills, attitudes, positive social behavior, conduct problems, emotional distress, and academic performance. Where the measures for social and emotional skills and academic performance reflect performance assessed in test situations, the remaining outcomes mainly rely on student- or teacherreports. The grand mean over all studies and outcomes was .30 standard deviations, with the largest effects found for social and emotional skills, at .57 standard deviations. The effect sizes for the remaining outcomes, including academic performance, were around one quarter of a standard deviation. The authors additionally compare their estimates with those from other meta-analyses, and find that they are comparable in magnitude, with the estimates from other studies falling between two tenths and four tenths of a standard deviation.

Chapter 5 evaluates the impact of a change in the curriculum of a Dutch high school, using a sample of 1,200 former graduates from that particular high school. In 2006, a course on educating students important life and social skills was introduced, alongside a mandatory community service project. Students followed the course and completed their community service in the upper classes of secondary education. The course is followed over three years, averaging at 1 hour a week, and the community service project covered 40 hours, outside standard school hours. While the course is not found to have any significant impact on academic achievement, results from student surveys indicate that students who were subjected to treatment score higher on self-reported measures of noncognitive skills. In comparison to the control group, the treatment group score about a third of standard deviation higher on conscientiousness and agreeableness, while also reporting a quarter of a standard deviation higher scores on internal and stable attribution of positive events.

\subsection{Conclusion}

This chapter has discussed some of the evidence on the role of personality traits as a component of productive human capital. Each of the preceding three sections addressed one of three main questions: ${ }^{26}$

- is personality relevant?

- is personality variable?

- is personality malleable?

Personality traits have strong predictive power for a range of socio-economic outcomes, demonstrating the relevance of personality. These personality traits are shown to develop over the life cycle, with the largest changes occurring in childhood and adolescence. The variability of personality traits over the life cycle is partially the result of biological maturation, but is also shown to be significantly affected by (changes in) the environment one

\footnotetext{
${ }^{26}$ The studies on the relevance, variability, and malleability discussed in this chapter are by no means a comprehensive summary of all the relevant findings, but rather highlight some of the more influential and most often cited studies. For more extensive reviews of the literature on the importance and development of personality, see for example Almlund et al. (2011); Borghans et al. (2008a); Brunello \& Schlotter (2011); Heller et al. (2012).
} 
grows up in. Finally, the previous section demonstrated that personality is also malleable, as demonstrated by positive effects of programs designed to stimulate noncognitive skills in children and pupils.

Although all three questions can be answered affirmatively, a lot is still to be learned. Noncognitive skills are shown to be significantly correlated with many socio-economic outcomes, yet results are not consistent as to which skills or personality traits are the most important, even when comparing results that are based on comparable sets of personality traits. Many results rely on contemporaneously measured personality traits, which raises concerns about reverse causality. When it comes to the influence of life events and shocks on the development of personality, it is clear that there is a statistically significant relationship. At the same time, there are questions as to the economic significance of these impacts. Answers to this question depend on which point estimates are used to estimate the total impact of personality changes associated with specific events. Regarding these specific events, one also needs to address the question as to whether the events are exogenous. Finally, conclusions about the malleability of personality rest largely on the effects associated with early childhood interventions, which are mostly small-scale, very specific, and targeted at disadvantaged or at-risk individuals. The question arising here is whether these conclusions generalize to larger populations and in different settings.

The discussion of the literature and the additional estimates obtained using the Dutch and German samples highlight several issues that need to be considered carefully in any evaluation of program effects or policy suggestions. The relevance of personality traits varies with the measures or constructs used to capture the personality of subjects. While the most prominent typology of personality is the Big Five taxonomy, it seems that not all productive aspects of individuals' personality are captured by this taxonomy. As demonstrated by Becker et al. (2012), the Big Five traits, measures of economic preferences, as well as locus of control, are all complements in predicting life outcomes, rather than substitutes. The results from studies using seemingly comparable Big Five taxonomies of personality are also not always consistent. This may be the result of differences in the items used to model the different traits, but may also result from differences in the samples or estimation techniques across studies.

Various other study characteristics may also affect the point estimates and conclusions. While correlations between personality traits and outcomes might differ along various demographics, such as nationality, age, or gender, the role played by sample selection, confounding factors, and measurement problems is perhaps less obvious, and perhaps therefore more important. The role of sample selection was already demonstrated above, in the estimated effects of Big Five traits on wages, using data from the GSOEP. The literature shows that cognitive skills are correlated with personality, hence showing the need to correct for it, when possible. However, the results from the full German sample (Figure 2.1), and those from the selective sample with relevant information on cognitive skills (Figure 2.2) yield very distinct conclusions regarding the predict power of Big Five personality traits for wages.

Given the possibility of reverse causality using simultaneous measurements of personality and outcomes, Chapter 3 uses childhood measures of personality to predict a wide range of adult outcomes. Measurement issues are addressed, as well as the role of possible mediators or confounding factors which might be driving the raw correlations. To the extent that personality changes precede or even predict the occurrence of major life events or outcomes, controlling for these short-run or medium-run outcomes is necessary in estimating the impact of personality on the final long-term outcomes of interest. In evaluating personality 
changes following the occurrence of major life events, one should also be careful in evaluating the chain of causality between the two. Chapter 4 reveals how a negative shock in the family composition in childhood is associated with less favorable patterns of personality development after the shock. However, careful inspection of the home environment prior to the event, reveals that divorce of one's parents is endogenous, and adjusting for this selection lowers the correlations between personality change and experiencing divorce.

Finally, while the results of numerous randomized experiments reveal significant effects of education programs, these programs are often targeted at disadvantaged youth and the results based on small samples, bringing in to question to what degree the results generalize to other samples and settings. An important finding is the indication that changes in noncognitive skills or personality are likely to be key mediators of the correlation between program participation and later outcomes. This finding will hopefully stimulate policy makers to emphasize the role of noncognitive factors in the design of any new education programs or social policy. Whereas small-scale one-to-one interventions, targeted at those deemed to be at risk, require a program tailored specifically to the situation and the targeted population, global school-based programs can - and need to - have a more basic design. Chapter 5 provides an example of such a universal, school-based program, demonstrating that an increased focus on study and social skills of pupils is associated with higher scores on valuable personality traits. 


\section{Appendix 2.A Big Five Traits}

\section{A.1 DNB Household Survey (DHS)}

The DNB Household Survey (DHS) is a panel survey launched in 1993, consisting of six questionnaires, pertaining to different areas of life. ${ }^{27}$ A set of 50 personality items measured in 2005 and 2009 capture the five domains of the Big Five taxonomy of personality. ${ }^{28}$ There are 10 items per construct, allowing us to construct scales for invididuals' openness, conscientiousness, extraversion, agreeableness, and emotional stability. The items and the associated reliability scores (Cronbach's alphas) are shown in Table 2.A.1. All items are measured on a five-point scale, ranging from 1 "Not at all applicable" to 5 "Highly applicable". After inverting the scaling of the negatively formulated items, the measures for the Big Five personality traits are then constructed by averaging the scores on the 10 items.

\section{A.2 German Socio-Economic Panel (GSOEP)}

The German Socio-Economic Panel is a representative longitudinal study of German households launched, and started in 1984. The data provide information on household members, on a wide range op topics, including employment, earnings, health, satisfaction indicators, and of course also on personality traits. A set of 15 personality items measured in 2005 and 2009 capture the five domains of the Big Five taxonomy of personality. There are 3 items per construct, allowing us to construct scales for invididuals' openness, conscientiousness, extraversion, agreeableness, and emotional stability. The items and the associated reliability scores (Cronbach's alphas) are shown in Table 2.A.2. All items are measured on a sevenpoint scale, ranging from 1 "Does not apply to me at all" to 7 "Applies to me perfectly". After inverting the scaling of the negatively formulated items, the measures for the Big Five personality traits are then constructed by averaging the scores on the 3 items.

\footnotetext{
${ }^{27}$ These questionnaires are 1. Work and Pensions, 2. Housing and Mortgages, 3. Income and Health, 4. Assets and Debts, 5.+6. Economic and Psychological Concepts.

${ }^{28}$ The 10 items pertaining to conscientiousness are not only measured in 2005 and 2009 , but in all years from 2004 onwards. Additionally, there is another set of personality items available for 1996, containing 20 items per Big Five trait.
} 


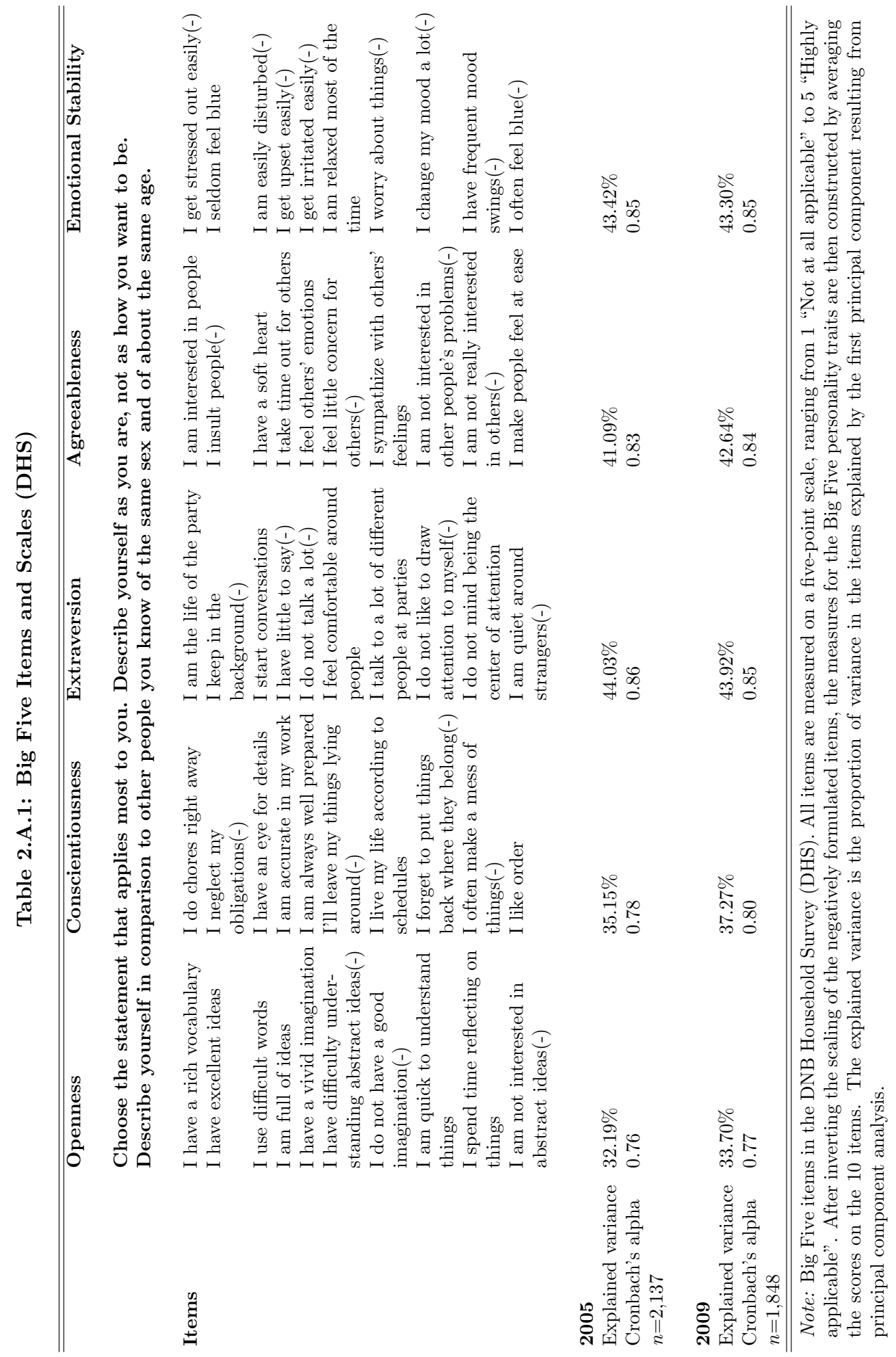




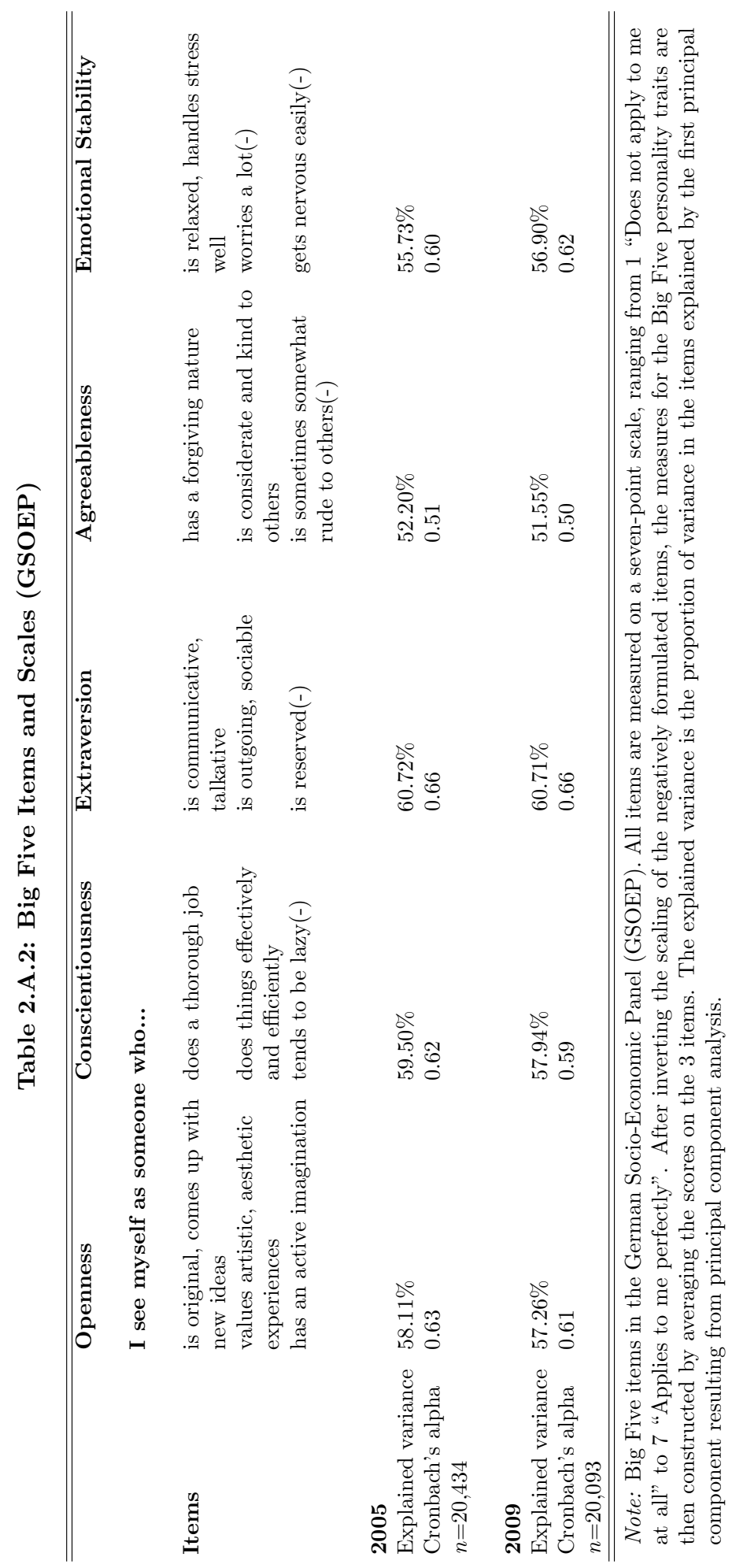




\section{Appendix 2.B Outcome Measures}

Table 2.B.1 provides a definition of the various outcomes measures used to create the results shown in Figures 2.1-2.3. In addition to measures on personality and outcomes, Figure 2.2 requires information on cognitive skills. The Dutch household panel does not provide such information, but the German Socio-Economic Panel does. In 2006, two cognitive test were administered, one providing a measure for fluid intelligence, the other for crystallized intelligence.

Crystallized intelligence is measured by means of a word fluency test, in which respondents are asked to name as many different animals as possible within ninety seconds. The number of unique and correct animals mentioned is then the score on the test. Crystallized intelligence is measured using performance on a symbol correspondence test. Respondents are asked to match as many numbers and symbols as possible, according to a given correspondence list which is shown to them on a screen. This test is also limited to ninety seconds, and again, the number of unique and correct numbers and symbols mentioned is then the score on the test. As with personality traits, the scores were standardized (mean zero, standard deviation one) prior to inclusion in the regression models. 
Table 2.B.1: Outcome Measures for DHS and GSOEP

\begin{tabular}{|c|c|c|}
\hline $\begin{array}{l}\text { Dataset } \\
\text { Outcome }\end{array}$ & $\overline{\text { DHS }}$ & GSOEP \\
\hline $\begin{array}{l}\text { Log Gross } \\
\text { Income }\end{array}$ & $\begin{array}{l}\text { How much was your taxable income for } \\
2008 \text { ? We mean your joint income for } \\
\text { your tax form. }\end{array}$ & $\begin{array}{l}\text { How high was your gross income from } \\
\text { employment last month? }\end{array}$ \\
\hline $\begin{array}{l}\text { Log Net } \\
\text { Income }\end{array}$ & $\begin{array}{l}\text { What is the total net income for your } \\
\text { household in } 2008 ?\end{array}$ & $\begin{array}{l}\text { How high was your net income from } \\
\text { employment last month? }\end{array}$ \\
\hline Employed & $\begin{array}{l}\text { Dummy variable equal to one if the } \\
\text { primary occupation of the respondent is } \\
\text { one of the following: employed on a } \\
\text { contractual basis, works in own business, } \\
\text { or free profession, freelance, } \\
\text { self-employed. }\end{array}$ & $\begin{array}{l}\text { Dummy variable equal to one if } \\
\text { respondent indicates to be full-time or } \\
\text { part-time employed. Question is "Are } \\
\text { you currently engaged in paid } \\
\text { employment? Which of the following } \\
\text { applies best to your status?" Dummy is } \\
\text { zero if answer is one of the following: } \\
\text { marginally/irregularly employed, } \\
\text { approaching retirement with zero } \\
\text { working hours, military service, } \\
\text { communicty service, not employed. }\end{array}$ \\
\hline $\begin{array}{l}\text { Tertiary } \\
\text { Degree }\end{array}$ & $\begin{array}{l}\text { Dummy variable equal to one if highest } \\
\text { level of education completed is vocational } \\
\text { colleges or university education } \\
\text { (equivalanet to a dummy for ISCED } 5 \\
\text { and } 6 \text { ) }\end{array}$ & $\begin{array}{l}\text { Dummy variable equal to one if } \\
\text { generated variable for education level is } \\
\text { vocational colleges or university } \\
\text { education (equivalanet to a dummy for } \\
\text { ISCED } 5 \text { and } 6 \text { ) }\end{array}$ \\
\hline Smoke & $\begin{array}{l}\text { Dummy variable equal to one if answer } \\
\text { to question "Do you smoke cigarettes at } \\
\text { all?" is either "Yes, I smoke every now } \\
\text { and then" or "Yes, I smoke every day" } \\
\text { and is zero if answer to that question is } \\
\text { "No" }\end{array}$ & $\begin{array}{l}\text { Dummy variable equal to one if answered } \\
\text { "Yes" to question "Do you currently } \\
\text { smoke, be it cigarettes, a pipe or cigars?" } \\
\text { and zero if answered "No." Question } \\
\text { from } 2008 \text { survey. }\end{array}$ \\
\hline $\begin{array}{l}\text { Overweight } \\
(\mathrm{BMI}>25)\end{array}$ & $\begin{array}{l}\text { Dummy variable equal to one if Body } \\
\text { Mass Index exceeds } 25 . \text { BMI is } \\
\text { calculated using self-reported length in } \\
\text { centimeters and weight in kilograms. }\end{array}$ & $\begin{array}{l}\text { Dummy variable equal to one if Body } \\
\text { Mass Index exceeds } 25 . \text { BMI is prodived } \\
\text { in the datafile with generated variables } \\
\text { for } 2008 \text { survey. }\end{array}$ \\
\hline $\begin{array}{l}\text { Work } \\
\text { Satisfaction }\end{array}$ & $\begin{array}{l}\text { How satisfied are you all in all with your } \\
\text { current work? } 1 \text { "very dissatisfied" } 2 \\
\text { "dissatisfied" } 3 \text { "satisfied nor dissatisfied" } \\
4 \text { "satisfied" } 5 \text { "very satisfied." }\end{array}$ & $\begin{array}{l}\text { How satisfied are you with your job? } \\
\text { Scored on an 11-point scale from } 0 \\
\text { "completetly dissatisfied" to } 10 \\
\text { "completely satisfied." Resulting score } \\
\text { was divided by two, to make effect sizes } \\
\text { comparable to those for the DHS. }\end{array}$ \\
\hline $\begin{array}{l}\text { Life } \\
\text { Satisfaction }\end{array}$ & $\begin{array}{l}\text { All in all, to what extent do you consider } \\
\text { yourself a happy person? } 1 \text { "very } \\
\text { unhappy" } 2 \text { "unhappy" } 3 \text { "neither happy } \\
\text { nor unhappy" } 4 \text { "happy" } 5 \text { "very happy." }\end{array}$ & $\begin{array}{l}\text { How satisfied are you with your life, all } \\
\text { things considered? Scored on an 11-point } \\
\text { scale from } 0 \text { "completetly dissatisfied" to } \\
10 \text { "completely satisfied." Resulting score } \\
\text { was divided by two, to make effect sizes } \\
\text { comparable to those for the DHS. }\end{array}$ \\
\hline $\begin{array}{l}\text { Self-rated } \\
\text { health }\end{array}$ & $\begin{array}{l}\text { In general, would you say your health is: } \\
1 \text { "poor" } 2 \text { "not so good" } 3 \text { "fair" } 4 \\
\text { "good" } 5 \text { "excellent". }\end{array}$ & $\begin{array}{l}\text { How would you describe your current } \\
\text { health?: } 1 \text { "Bad" } 2 \text { "Poor" } 3 \\
\text { "Satisfactory" } 4 \text { "Good" } 5 \text { "Very good." }\end{array}$ \\
\hline
\end{tabular}

Note: All outcomes are measured in the 2009 surveys of the Dutch National Bank Household Survey (DHS) or the German Socio-Economic Panel (GSOEP). There are two exceptions, namely being a smoker and being overweight for the German sample, which is measured in 2008, since the 2009 survey did not contain those items. 



\title{
The Importance of Early Conscientiousness for Socio-Economic Outcomes ${ }^{1}$
}

\begin{abstract}
This research estimates models of the importance of conscientiousness for socioeconomic outcomes. We use measures of conscientiousness and other personality traits at age 16 to explain adult wages and other outcomes, such as crime, health and savings behavior. We use several waves from the 1970 British Cohort Study. Our estimates suggest a significant and sizeable correlation between early conscientiousness and adult outcomes, even after controlling for other traits, early behavioral problems, the child's home environment, educational career, early sociability and occupational sorting. Measurement error in personality traits is corrected for by applying IV-techniques, errors-in-variables estimators and structural equation modeling. Investigation of the lower-order structure of conscientiousness suggests that facets related to reliability, decisiveness and impulse control are most strongly correlated with outcomes. We also investigate changes in early conscientiousness and find that those who experience declines in the personality distribution between the ages 10 and 16 seem to be worse off in terms of a variety of socio-economic outcomes.
\end{abstract}

\footnotetext{
${ }^{1}$ This chapter is based on joint work with Bas ter Weel: Tyas Prevoo and Bas ter Weel. (2012). The Importance of Early Conscientiousness for Socio-Economic Outcomes. Working paper, Maastricht University.
} 


\subsection{Introduction}

For many socio-economic outcomes personality is as predictive as cognition. Economists have recently been drawing attention to differences in personality as a key consideration to explaining individual outcomes (see e.g. Almlund et al., 2011; Borghans et al., 2008a, for reviews of this literature). Evidence from other academic disciplines, such as the neurosciences, behavioral genetics and psychology, suggests that differences in personality are important in explaining a variety of socio-economic outcomes. ${ }^{2}$ A growing body of evidence from personality psychology suggests that especially personality measures related to conscientiousness predict a range of socio-economic outcomes. ${ }^{3}$ Conscientiousness is broadly defined and referred to as the propensity to follow socially prescribed norms and rules to be goal-directed, able to delay gratification and to control impulses (e.g. John \& Srivastava, 1999; McCrae \& Costa, 1994). Moffitt et al. (2011) present evidence that conscientiousness, which they define as part of the umbrella of self-control, predicts a range of socio-economic outcomes, such as physical health, substance dependence, personal finances and criminal offending outcomes. The pattern they obtain is a gradient in which children with less self-control have worse adult outcomes. They also show that children who move up the self-control rank (from childhood to young adulthood) obtain better outcomes as adults.

In this study we extend the literature in economics by investigating the role of early conscientiousness in explaining a range of socio-economic outcomes. We do so in an empirical fashion that builds on the body of literature on personality traits in psychology. The work is motivated by the observation that conscientiousness predicts a range of outcomes but that estimation of these relationships is not very careful and informative. Most studies report correlations between conscientiousness and outcomes. In addition to presenting such correlations, we apply several strategies to move towards predictions. In particular we deal with measurement error in traits by using instrumental variables techniques (2SLS), errorsin-variables (EIV) regressions and structural equation modeling (SEM). Furthermore, it is not clear which facets of conscientiousness are important for what outcomes. The inputs that psychologists have used to construct measures of conscientiousness seem to come close to what economists have defined as measures of time discounting, risk aversion and social preferences. At this point, empirical knowledge is too limited to judge how conscientiousness relates to the concepts and parameters economists typically model to predict outcomes, but by investigating the lower-order structure of conscientiousness we present a set of estimates constructive to understand differences in socio-economic outcomes and useful to bridge the gap between economists and psychologists.

We empirically explore the link between early personality indicators and a range of socioeconomic outcomes at age 34. The outcomes are adult wages, savings, indicators of health (body mass index (BMI), alcoholism, smoking, drug use), involvement in criminal activities, and a number of indicators for life satisfaction (satisfaction with life so far, the extent to which people get out of life what they want, and the way in which they are able to run their lives). The database of the working population is constructed from several waves of

\footnotetext{
${ }^{2}$ See e.g. Almlund et al. (2011); Borghans et al. (2008a); Cunha et al. (2006); Dohmen, Falk, Huffman \& Sunde (2010); Heckman (2007); Knudsen et al. (2006); Lebel \& Beaulieu (2011); Moffitt et al. (2011); Roberts (2009).

${ }^{3}$ See Jackson, Bogg, Walton, Wood, Harms, Lodi-Smith, Edmonds \& Roberts (2009); Roberts et al. (2004); Roberts, Wood \& Caspi (2008) for meta-analyses with a focus on conscientiousness as a predictor for outcomes. They summarize and review the literature from personality psychology. Almlund et al. (2011) present an overview of evidence from other academic fields on the importance of conscientiousness as well.
} 
the British Cohort Study (BCS). The BCS is a longitudinal survey that consists of 17,196 individuals at the start of the survey, including all children born in Britain in one particular week in April 1970. The data include information about measured personality items at age 16. We use these items to build a personality inventory consistent with the Big Five personality inventory. ${ }^{4}$ In addition, we decompose conscientiousness to investigate the facets important in explaining different outcomes. Finally, changes in conscientiousness are used to shed light on the importance of its development during childhood.

We start by estimating the magnitude and importance of personality traits at age 16 in explaining socio-economic outcomes. We find that personality traits explain about 3 percent of the variance in wages at age 34. In addition, when considered in isolation, a one standard deviation increase in conscientiousness increases hourly wages by 8.6 percent. In our preferred specification, controlling for cognitive ability and other personality traits, this estimate drops to 4.1 percent. For other outcomes conscientiousness seems to be important too. Higher levels of conscientiousness are associated with less unhealthy behavior and crime, and with higher savings and life satisfaction. After establishing a correlation between early conscientiousness and socio-economic outcomes at age 34, a number of different models are estimated. In these models we control for the child's home environment, educational outcomes, other measures of personality (Rutter scores, self-esteem and locus of control) and social behavior in school at age 16 . In addition, we take into account that people with different personality traits sort into different occupations. Our estimates of conscientiousness and other early personality traits remain similar in terms of significance and size. This suggests that the estimated differences in outcomes attributed to personality traits are not the result of differences in the early environment, investments or other behavioral characteristics.

Second, few economists or psychologists working on the relationship between personality and outcomes address the issue of causality (e.g. Almlund et al., 2011). They apply - like we do here - measures of early cognition and personality to predict later outcomes. This yields endogeneity with errors in variables problems. We deal with measurement error in three ways. First, we apply instrumental variables techniques (2SLS) in which we instrument the mother-rated items at age 16 with the items at age 10 . This way we deal with possible correlation between the error term and traits. Second, we use structural equation modeling (SEM), which is based on maximum likelihood. The main advantage of SEM is that it takes into account measurement error at the level of the individual items we use to construct our personality measures. Finally, we apply errors-in-variables (EIV) regressions, which is a latent variable technique dealing with the fact that we possibly measure personality with error. After applying these three techniques to deal with measurement errors in our personality measures, our estimates remain similar both in terms of magnitude and significance.

Next, we explore the lower-order structure of conscientiousness following the decomposition made by personality psychologists (e.g. Jackson et al., 2009; Roberts et al., 2004). The decomposition of conscientiousness in different types or facets is based on the categorization that results from meta-analyses. The meta-analyses attempt to structure individual items across different data sources, countries and age of measurement to dig out facets of the lower-order structure of conscientiousness. We use the facets of conscientiousness that personality psychologists generally agree about. These are impulse control (as used by Mof-

\footnotetext{
${ }^{4}$ The Big Five personality inventory is the most commonly used inventory for measuring personality traits. It includes five measures: openness, conscientiousness, extraversion, agreeableness and neuroticism (or emotional stability). See Borghans et al. (2008a) for an elaborate overview of the history, use across disciplines and potential problems of this way of characterizing personality.
} 
fitt et al., 2011), reliability, decisiveness and orderliness. The estimates for wages suggest that higher levels of early impulse control, reliability, and decisiveness are facets that are correlated with adult wages. Orderliness is also correlated with wages, but the pattern is less strong. In general, the facet of orderliness also has the least relevance for the other socio-economic outcomes considered. Higher levels of decisiveness are correlated with less unhealthy behaviors and crime, and with higher savings, which is consistent with the findings of Borghans et al. (2008c). The same is true for facets related to impulse control and reliability.

Finally, we examine the policy perspective. Much effort has gone into trying to improve cognitive ability and a child's home environment. Our findings suggest that there is also a gradient of conscientiousness that is worthwhile investigating. Controlling for age-10 personality, persons who face declines in the conscientiousness distribution between the ages of 10 and 16 end up with significantly less favorable scores on our socio-economic outcomes. Those experiencing a decline in conscientiousness during childhood are significantly more likely to be alcohol dependent, to smoke, use cannabis or get arrested as adults, while also reporting significantly lower life satisfaction and a less healthy body mass index. A decline in the distribution of conscientiousness by one standard deviation is associated with 5.5 percent lower hourly wages, and 8.6 and 5.7 percentage point higher likelihoods to be a smoker or regular cannabis user. On the one hand, these results suggest that policymakers are most effective in preventing child development from falling behind, while on the other hand, personality at age 10 in itself has predictive value for socio-economic outcomes, pointing to the importance of the overall stimulation of the development of valuable personality traits, and conscientiousness more specifically.

The analysis presented in this chapter contributes to a recent literature in economics that has focused on the distinction between cognitive and noncognitive skills. It has been triggered by the outcomes of intervention programmes, in which the most prominent outcome has been better behavior, not better cognitive skills (e.g. Heckman et al., 2008; Schweinhart, Montie, Xiang, Barnett, Belfield \& Nores, 2005). Cunha \& Heckman (2007, 2008); Cunha, Heckman \& Schennach (2010) estimate models of skill formation with the notion of complementarity between different types of skills. The results most relevant for our work emphasize the role of personality traits that seem to be important for later outcomes. We contribute to this literature by presenting estimates of specific facets of conscientiousness that are important for socio-economic outcomes.

A closely related body of work applies these models more directly to labor-market outcomes to show the relevance of personality traits. Heckman et al. (2006) show the relevance of and changes in personality traits (locus of control and self-esteem) over the life cycle. Mueller \& Plug (2006) estimate the effect of personality on earnings. They find that some personality traits are penalized whereas others have positive returns. Borghans et al. (2008c); Cobb-Clark \& Tan (2011); Krueger \& Schkade (2008) show the importance of occupational sorting when measuring the returns to different traits. This has recently also been picked up in personality psychology by Roberts (2009) who emphasizes the importance of different environments and states in which people perform. Finally, early work by Filer (1983) suggests that personality is important in explaining labor-market outcomes and gender wage differentials. ${ }^{5}$ We also take into account the importance of sorting and add to these approaches a longitudinal approach and a distinction between types of traits.

\footnotetext{
${ }^{5}$ The relationship between noncognitive skills and the gender pay gap is also addressed in Borghans, Ter Weel \& Weinberg (2006) and Grove, Hussey \& Jetter (2011).
} 
Thirdly, economists and psychologists have been trying to link economic preference parameters to personality traits to predict outcomes. ${ }^{6}$ Borghans et al. (2008a) and Almlund et al. (2011) summarize these attempts and suggest models for understanding and building productive linkages. Becker et al. (2012) empirically explore three datasets to link personality traits to economic preference parameters and find complementarity between the two. Borghans et al. (2008b) find that performance motivation, fear of failure, internal locus of control, curiosity, low discount rates, and risk aversion are positively associated with more correct answers on a cognition test. Our results are also consistent with experimental evidence from Sutter, Kocher, Glatzle-Ruetzler \& Trautmann (2013), who find that students with higher levels of impulse control fare better in school and are more likely to obtain good labor-market outcomes. We use a longitudinal approach to find the predictive power of conscientiousness and relate the lower-order structure to evidence on economic preference parameters.

Finally, in personality psychology there is a recent literature on conscientiousness. From meta-analyses Roberts \& Bogg (2004) and Jackson et al. (2009) obtain that conscientiousness is a construct of a number of important facets related to industriousness, orderliness, reliability, decisiveness and impulse control. We obtain estimates suggesting that wages and other outcomes seem to be related to impulse control, reliability and decisiveness as a child. Investigation of these lower-order structures could help bridge the gap between economics and (personality) psychology.

We proceed as follows. Section 3.2 documents the construction of the database from the BCS and presents descriptive statistics. Section 3.3 presents a set of basic estimates showing correlations between early personality traits and adult outcomes. Section 3.4 deals with the effects of measurement error. Section 3.5 explores the anatomy of conscientiousness by considering the lower-order structure of personality traits. Section 3.6 discusses the policy perspective. Section 3.7 concludes.

\subsection{Data}

We analyze socio-economic outcomes of employed persons as measured in the 2004 wave of the British Cohort Study (BCS). The BCS is available from the Centre for Longitudinal Studies (Institute of Education, University of London). The database contains data on births and families of all babies born in Great Britain in one particular week in April, 1970. These children were then followed throughout their lives, and data were collected roughly every 4 to 5 years. The last available wave is from 2008 .

The main strength of the BCS is that it follows a complete cohort for a substantial period of time, which allows for an analysis of adult socio-economic outcomes. The BCS contains

\footnotetext{
${ }^{6}$ Unfortunately our database does not contain measures of preference parameters. Nevertheless, impulse control is related to risk aversion, reliability is related to social preferences, and decisiveness is related to time preference (e.g. Daly, Harmon \& Delaney, 2009). These three facets are the strongest predictors for the set of outcomes considered. More precisely, higher scores on impulse control are correlated with higher wages and savings and lower rates of unhealthy behavior. This seems consistent with the evidence in economics about risk aversion (e.g. Dohmen et al., 2010). Similarly, higher levels of decisiveness are correlated with higher wages, less crime and better health outcomes, which is consistent with the evidence on time discounting (e.g. Frederick, Loewenstein \& O'Donoghue, 2002). Finally, higher levels of reliability are correlated with higher scores on life satisfaction, health outcomes and wages. The facet of reliability is related to social preferences. Reliable persons are more likely to be trustworthy and are more altruistic (e.g. Fehr, 2009).
} 
a wide range of items measuring cognitive and personality development. Data on children and their families were collected when the respondents were aged $0,5,10$, and 16 . The adult waves at ages $26,30,34$, and 38 provide a set of outcome variables. In terms of adult outcomes we use the 2004 wave. There are two reasons. First, at the age of 34, all persons have left education and have been working for a while. This should yield reliable information about labor-market outcomes and other social outcomes. Second, we prefer to use the 2004 wave over the 2008 wave, because of the larger sample.

Of the initial 17,196 babies born in 1970, 9,665 respondents remain in 2004. Of this group, 8,013 are employed, of which 6,106 report gross hourly wages. After further selecting individuals with valid information on childhood ability and personality, we retain a working sample of 2,934 respondents used for the analyses in this research. Table 3.C.1 in the Appendix lists all variables and the way in which they are constructed or defined. Issues of attrition and selection are discussed in Section 3.2.4 and illustrated in Table 3.C.2.

\subsubsection{Personality Measures}

Personality psychologists have developed measurement systems for personality traits, which economists have begun to use. Most prominent is the Big Five personality inventory, which contains five personality traits (OCEAN): openness, conscientiousness, extraversion, agreeableness and neuroticism (emotional stability). The Big Five taxonomy of personality allows us to capture the relative importance of different dimensions of an individual's personality (e.g. Goldberg, 1993; McCrae \& John, 1992).

The BCS offers items on personality and behavior from which we are able to construct measures capturing a child's conscientiousness, extraversion, agreeableness and emotional stability. It is not possible to capture openness with the available items. ${ }^{7}$ We compensate for the lack of a measure of openness by including cognitive test scores.

Mothers are asked to rate the behavior of their child on two sets of 19 items, both at ages 10 and 16. After removing 5 items on motor skills and 11 items on child behavior, we group the remaining 22 items into four clusters, representing conscientiousness, extraversion, agreeableness, and emotional stability. The clustering is consistent with the clustering obtained by personality psychologists (e.g. Goldberg, 1993), and confirmed by both cluster analysis and principal component analysis on the set of 22 items. $^{8}$ The first four components of the principal component analysis return eigenvalues larger than one, and after orthogonal rotation, the items load highly on their respective factors (and not on the other factors). The results of these analyses are described in the Appendix (Section 3.A).

Each trait is measured by extracting the first principal component from the set of items belonging to that trait. To increase the number of observations, we impute missing values for individuals who miss 1 or 2 of the 22 items used for constructing our personality measures. We apply multiple imputations through chained equations using the remaining 21 items as

\footnotetext{
${ }^{7}$ Personality traits are distinguished from intelligence. Most measures of personality are only weakly correlated with measures of cognitive ability (e.g. McCrae \& Costa, 1994; Webb, 1915). There are, however, a small number of exceptions. Most notably, cognitive ability is moderately associated with Openness. The reported correlations are of the order of .3 or lower (see e.g. Borghans et al., 2008a). We compensate for the lack of a measure of openness by including cognitive test scores.

${ }^{8}$ Similar items have been used to diagnose mental health conditions (e.g. Currie \& Stabile, 2006). However, the items in the BCS are consistent with those identified by the American Psychology Association Dictionary as capturing Big Five personality traits.
} 
predictors for the item of interest. Table 3.1 shows the grouping of the 22 mother-rated personality items into the four personality domains, along with the reliability of the resulting constructs, both for the set of items without and with imputed missing observations. Conscientiousness, agreeableness, and emotional stability show strong reliability, with Cronbach's alphas of .8 (indicating .36 error variance in the scores of their items). Extraversion has a Cronbach's alpha of .6. The principal component for conscientiousness captures 65 percent of the variance in its items. For extraversion, this number is 37 percent, and the constructs for agreeableness and emotional stability explain 45 and 56 percent of the variance in their items, respectively. These results indicate that there is relatively more measurement error in extraversion, an issue we return to in Section 3.4.

\subsubsection{Outcome Measures}

We measure adult outcomes at age 34 . The gross hourly wage is one outcome measure. It is defined as gross pay per week divided by usual hours worked per week. Respondents report their gross pay alongside the period of pay, which may be one week, two weeks, four weeks, a calendar month, or a year. Observations in the lowest and highest percentile are deleted, which means excluding those reporting earnings below 32.5 pounds or above 3,073 pounds per week. ${ }^{9}$ Further, we exclude those reporting to work more than 80 or fewer than 5 hours per week, as well as those reporting to work full-time, but reporting fewer than 30 weekly working hours.

Next to wages, a number of other socio-economic outcomes are considered. A dummy for savings behavior indicates whether or not respondents save any amount of their monthly income (Save). We observe health by looking at the Body Mass Index (BMI), the CAGE measure for alcoholism (Alcoholic), and whether or not the respondent is a smoker (Smoke). A value of zero on our smoking dummy includes individuals who have never smoked before, but also ex-smokers. A value of one includes occasional smokers, as well as respondents smoking more than 20 cigarettes a day. The CAGE index is an assessment for alcohol dependence and alcohol abuse using self-reported answers to four yes-or-no questions. We construct a dummy for alcoholism using a cut-off point of 2 ( 0 if the score is below $2 ; 1$ otherwise) on the four items of the CAGE questionnaire. ${ }^{10}$

Criminal behavior is constructed by applying two dummy variables, indicating whether or not the individual uses cannabis on a regular basis (Cannabis) and whether or not the respondent has been arrested between ages 16 and 34 (Arrested). For cannabis use, a value of zero indicates the respondent either has never tried cannabis, or has used cannabis in the past, but never uses it nowadays. Values of one include respondents who use cannabis regularly, be it only on special occasions or on most days. The dummy for arrests equals zero if the respondent indicated never to have been arrested before and one if (s)he had been arrested at least once.

Finally, we measure life satisfaction with three different variables. On a scale from 0 to 10 , respondents are asked to indicate how satisfied or dissatisfied they are with the way life has turned out so far (Satisfaction). In addition to this life satisfaction scale, we use two dummy

\footnotetext{
${ }^{9}$ We do not include hours worked overtime in our calculations. Removal of outliers, by deleting observations with gross hourly wages below 2 or above 50 pounds, yields similar results; using net wages and using age 30 or age 38 wages does so too. These results are available upon request.

${ }^{10}$ The CAGE questionnaire has been validated as a screening tool in general population samples, using the same cut-off point of 2 (e.g. Buchsbaum, Buchanan, Centor, Schnoll \& Lawton, 1991; King, 1986).
} 


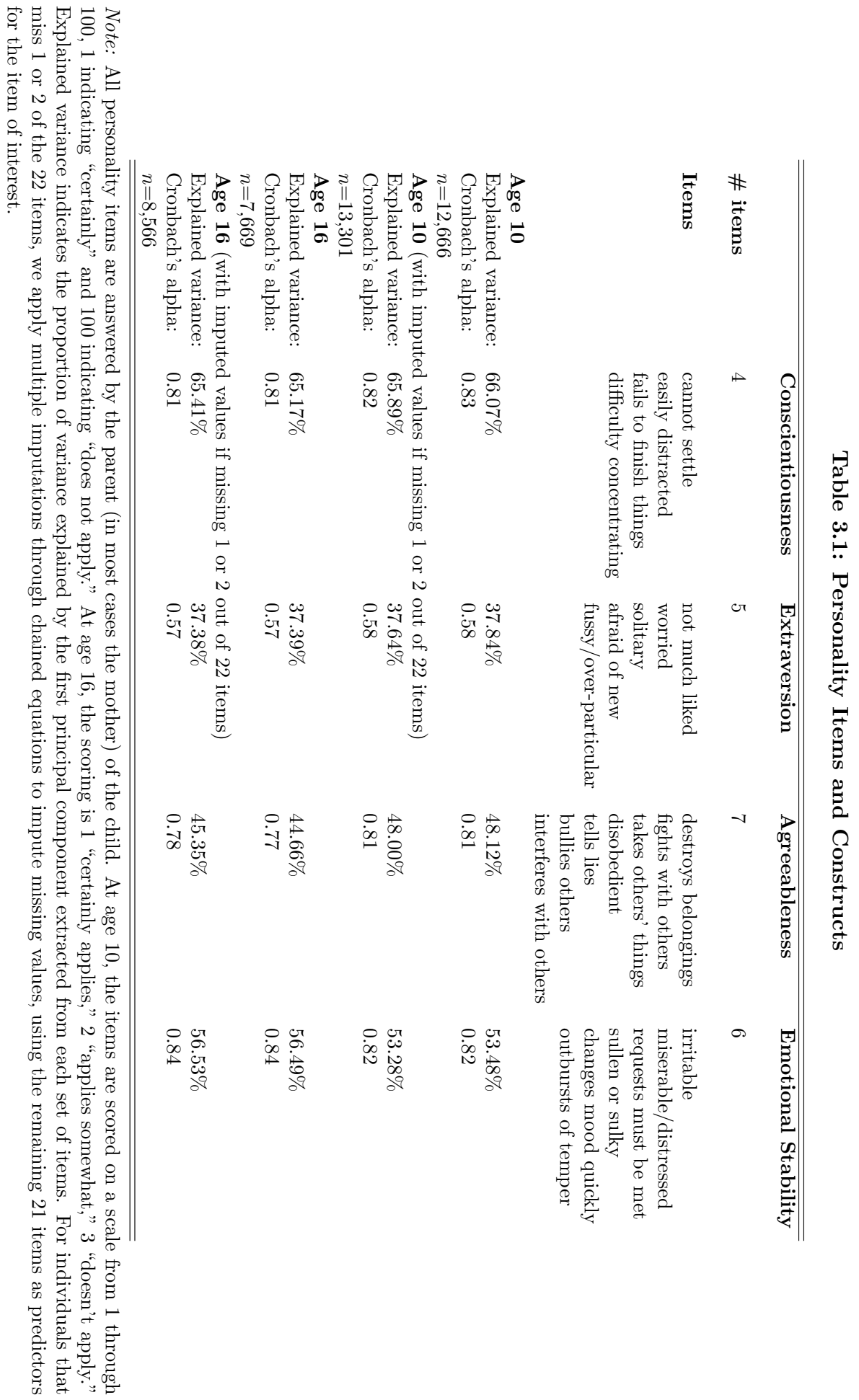


indicators that indicate whether respondents feel they get what they want out of life (Life Get), and whether they feel they can usually run their life more or less as they want to (Life Run). In both cases, a value of one indicates a positive view to life, whereas a value of zero indicates, respectively, that respondents feel they never really seem to get out of life what they want and that they usually find life's problems just too much to handle.

\subsubsection{Other Measures}

Besides the personality measures and outcome measures discussed above, we also extract information about cognitive ability and various other measures which we use as controls in our models. We consider a child's cognitive ability. We construct a measure using test scores at age 10 because cognitive ability seems to be set at that age in the sense that it is rank-order stable (e.g. Lebel \& Beaulieu, 2011). Cognitive ability is measured by extracting the first principal component from a set of eight standardized test scores, all measured at the age of 10. The test scores include the four British Ability Scales (word definitions, recall of digits, similarities, matrices), as well as the Shortened Edinburgh Reading Test, the CHES Pictorial Language Comprehension and Friendly Maths tests, and a spelling test. Cronbach's alpha on the set of test scores is .89 and the explained variance of the resulting principal component is 58 percent.

School performance, the home environment a child grew up in, social skills as a child, and final education and occupation are also measured. These other measures are used alongside the Big Five personality measures to estimate the effects of personality on outcomes, and are introduced and discussed in Section 3.3. Table 3.C.1 provides the definitions and construction of the various variables. Table 3.C.2 presents descriptive statistics for these variables, both for the restricted working sample of 2,934 employed respondents with wage information and the unrestricted sample containing all respondents.

\subsubsection{Selection}

When we restrict our sample to employed respondents with valid wage information, the sample shows significant differences in terms of personality and socio-economic outcomes compared to the full population of respondents with valid information on these measures (the unrestricted sample). As Table 3.C.2 reveals, the working sample scores about a tenth of a standard deviation higher on all personality traits. The unrestricted sample shows a higher share of smokers, cannabis users, and arrests, and is on average less satisfied with life than when we restrict the sample to the working sample.

The same holds for the different sets of control variables. Parents of the average respondent in the working sample are more highly educated and have higher social class. Subjects themselves are also more highly educated and have higher social class, while also displaying less behavioral problems and higher self-esteem and internal locus of control as a child. Selection on being employed and reporting wages significantly affects the sample statistics, and might also influence the estimated relationship between personality and outcomes. While all analyses in this study are restricted to the working sample for consistency in the estimation population, the results are robust to relaxing this selection for the other socio-economic outcomes. 
Table 3.2: Correlations of Personality with Socio-Economic Outcomes

\begin{tabular}{lcccc}
\hline \hline & C & E & A & ES \\
\hline Personality & & & & \\
(C) Conscientiousness (16) &. & .26 & .48 & .49 \\
(E) Extraversion (16) & .26 &. & .24 & .43 \\
(A) Agreeableness (16) & .48 & .24 &. & .55 \\
(ES) Emotional Stability (16) & .49 & .43 & .55 &. \\
Outcomes & & & & \\
Wage & .15 & .05 & .11 & .12 \\
Save & .12 &. & .09 & .09 \\
BMI & -.09 &. & -.08 & -.04 \\
Alcoholic & -.05 &. &. &. \\
Smoke & -.17 &. & -.17 & -.11 \\
Cannabis & -.08 &. & -.09 & -.04 \\
Arrested & -.13 & .04 & -.15 & -.07 \\
Satisfaction & .12 & .10 & .10 & .10 \\
Life Get & .16 & .12 & .11 & .11 \\
Life Run & .11 & .09 & .10 & .08 \\
\hline \hline
\end{tabular}

Note: Correlation coefficients. Only those significant at the 5 percent level or higher are reported. The sample applied is our working sample of 2,934 individuals with valid information on adult wages, age-10 cognitive ability, and age-16 personality.

\subsubsection{Descriptive Statistics}

Table 3.2 shows the correlations between personality traits as well as their correlations with our outcome measures. This yields a first indication of the relationship between childhood personality and adult outcomes. Traits correlate significantly with outcomes, and in the expected direction. One exception is extraversion, which is only significantly correlated with wages and measures of satisfaction. Conscientiousness consistently shows the strongest correlations. A more detailed picture of the correlation between conscientiousness and outcomes is presented in Figure 3.1. It shows mean outcomes by deciles of conscientiousness. The upper deciles are put together because we cannot discriminate in terms of conscientiousness. There is a clear gradient in conscientiousness for most outcomes, where those lower in the distribution of conscientiousness obtain less favorable outcomes than those higher in the distribution. The bottom ten percent report average gross hourly wages below 11 pounds, whereas the top forty percent earn over 14 pounds per hour. In terms of smoking behavior, the bottom ten percent is twice as likely to smoke compared to the top forty percent (40 vs. 20 percent). As can be seen from Figure 3.1, similar patterns are obtained for other outcomes.

Since we want to explore the relationship between childhood personality and a range of adult socio-economic outcomes, we need to account for possible confounding relationships. Cognitive ability, the home environment, sociability and education are all domains that relate to adult wages and other socio-economic outcomes as well as to childhood personality. They may therefore also influence estimates of the relationship between personality traits and socio-economic outcomes. Table 3.C.3 in the Appendix compares respondents who score below average on wages and the four personality traits with those who score above average on each of these measures. Below and above average scorers are compared in terms of averages on variables relating to the above mentioned domains. The obtained patterns suggest that there are sizeable associations between these domains and both wages and personality. 
Figure 3.1: Socio-Economic Outcomes by Deciles of Conscientiousness
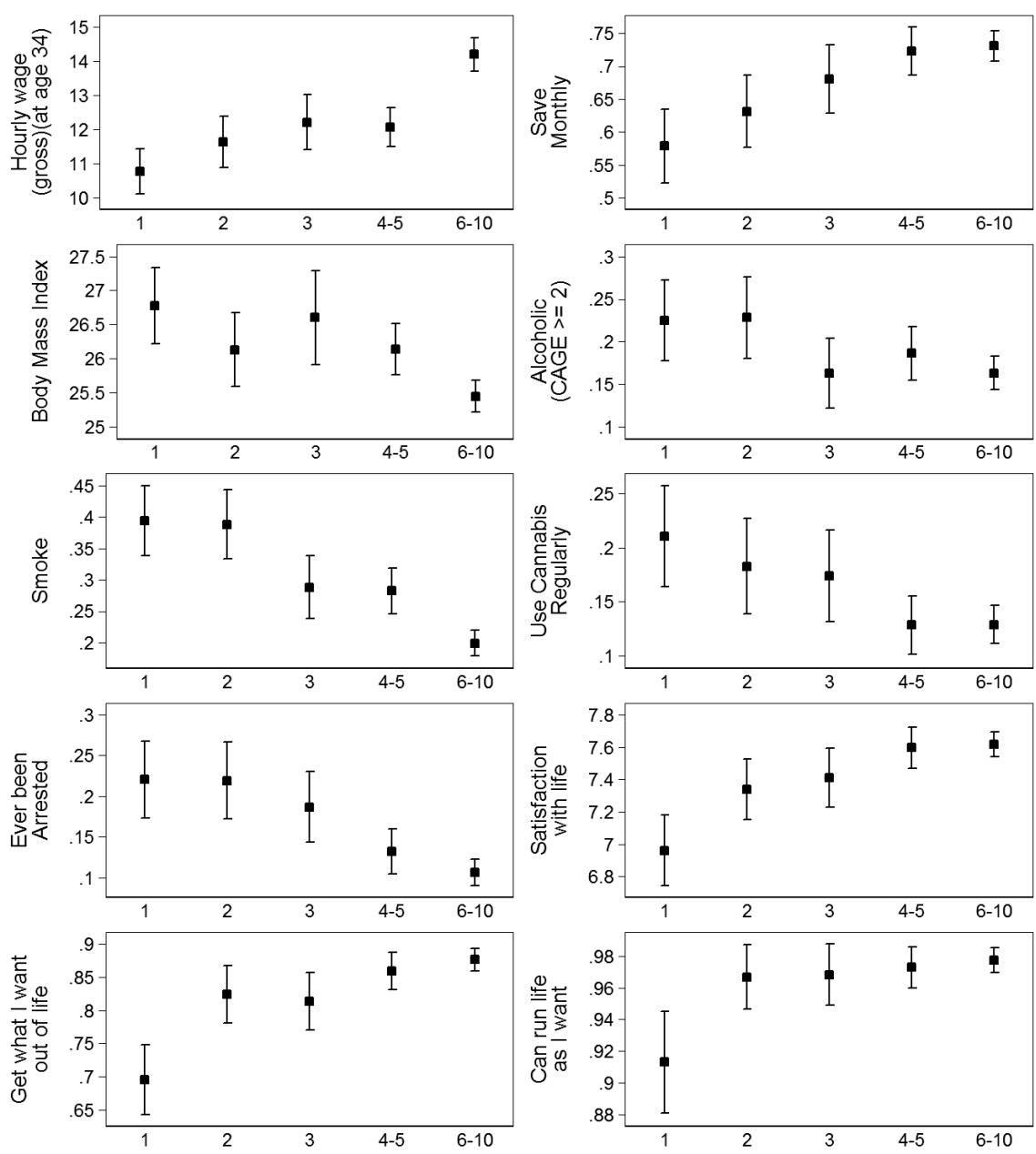

Means and 95\% Upper and Lower Limits (vertical axis) by deciles of age 16 Conscientiousness (horizontal axis)

Note: Averages and 95 percent confidence intervals of socio-economic outcomes by deciles of age-16 conscientiousness; The upper deciles 4 and 5, and 6 through 10, are grouped together since we cannot discriminate between them due to the limited range of the scale on conscientiousness. The sample applied is our working sample of 2,934 individuals with valid information on adult wages, age-10 cognitive ability, and age-16 personality. 
Those ending up earning above average hourly wages by age 34 scored significantly higher on all personality measures, both at age 10 and age 16 . Consistent with the notion that cognitive ability and education have significant effects on labor-market outcomes, they also scored significantly higher on ability tests and went on to complete more years of schooling. Additionally, above average earners had significantly better home environments when growing up and scored significantly higher on most measures of sociability.

At the same time, these measures are also significantly associated with childhood personality. Those with above average conscientiousness or agreeableness had better home environments when growing up. To a lesser extent, the same holds for extraversion and emotional stability. Above average personality traits are also associated with significantly higher sociability measures; this applies to all four traits, specifically to agreeableness.

When it comes to the association between personality traits and cognitive ability and educational achievements, the differences between the below- and above-average groups are significant for conscientiousness and agreeableness, and most pronounced for conscientiousness. Those with above average conscientiousness score .4 of a standard deviation higher on our cognitive ability measure. Above average conscientiousness is also associated with completing about 1.2 years more schooling.

Since both outcomes and personality traits are associated with childhood circumstances, sociability and final educational achievement, it seems important to control for these domains when estimating the relationship between personality traits and outcomes. Given the sizeable and significant association between personality traits and ability measures, as observed in Table 3.C.3, it is also important to account for cognitive ability in our models.

\subsection{Personality Traits and Outcomes}

Our first task is to show that there is a sizeable correlation between personality traits at age 16 and adult outcomes. This section presents estimates with different sets of controls.

\subsubsection{Basic Estimates}

Table 3.3 presents estimates of models in which outcomes are explained by measured personality traits at age 16. Control variables for cognitive ability at age 10, region of birth and dummies for gender and fulltime employment are added to these models. Investigation of the four rows in Table 3.3 reveals that there is a statistically significant correlation between all adult outcomes and the measure of conscientiousness. Agreeableness is also correlated with most outcomes, yet to a lesser extent when compared to the correlations for conscientiousness. The correlations for extraversion are mixed in nature, with higher childhood extraversion being associated with higher adult satisfaction with life, but also with less savings, higher rates of tobacco and cannabis use, and higher rates of arrest. The measure of emotional stability is only significantly correlated with savings and crime. The size of the coefficients varies. In general, the size of the coefficient on conscientiousness is the largest.

Since our personality measures are standardized to have mean zero and a standard deviation of one within each regression sample, the coefficients can be interpreted as a ceteris paribus change in the outcome measure for a one standard deviation increase in the measured personality traits. Using this way of interpreting the estimates, individuals who have a one 


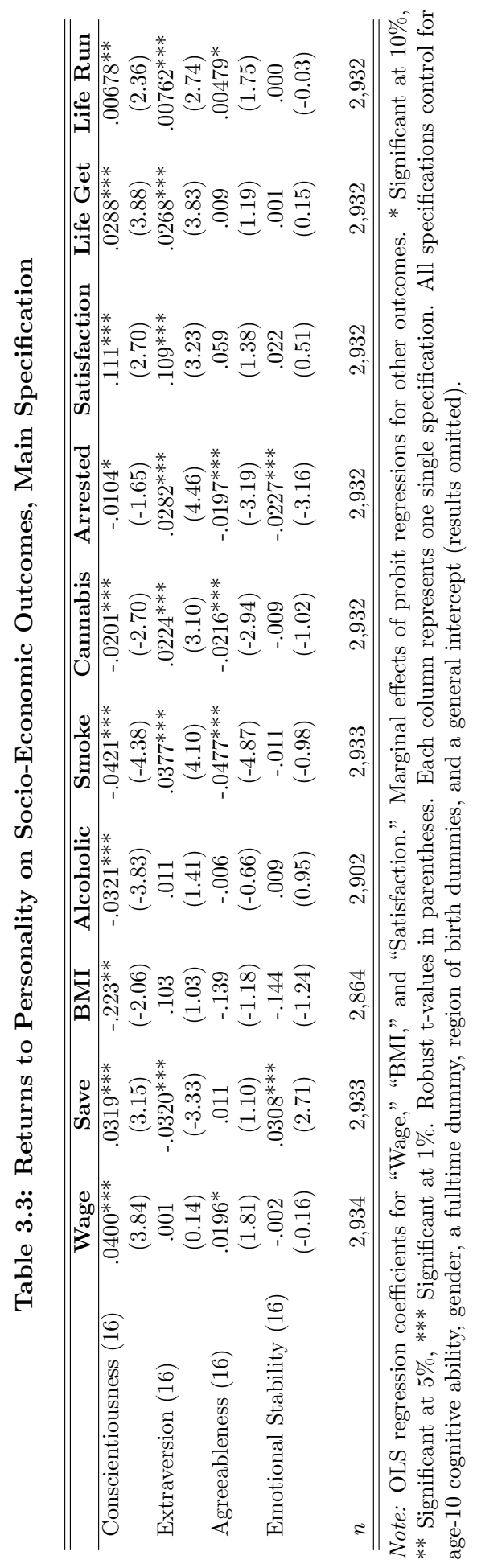


standard deviation above average conscientiousness at the age of 16, earn on average 4.1 percent higher gross hourly wages $\left(e^{.0400}-1\right)$ by the age of 34 . Their BMI at that age is .22 points lower, and (on a scale from 0 to 10 ) they rate their life satisfaction .11 points higher. On average, they are also 3.2 percentage points more likely to save, 3.2 percentage points less likely to be alcoholic, 4.2 percentage points less likely to smoke, and 2 percentage points less likely to use cannabis on a regular basis. A one standard deviation increase in conscientiousness is further associated with a 1 percentage point lower likelihood of ever having been arrested, and with improved feelings of getting out of life what one wants and feeling one can run one's life as desired (2.9 and .7 percentage points higher, respectively).

The same analysis has been performed for men and women separately. Using data from the Wisconsin Longitudinal Study, Mueller \& Plug (2006) find that the coefficients on the different traits differ across gender. This merits further analysis because they find that especially female outcomes are sensitive to differences in conscientiousness. However, we do not find statistically significant differences between the sexes when we repeat the analysis presented in Table 3.3 for men and women separately. ${ }^{11}$ The effect sizes for males are somewhat higher and for females they are somewhat lower. The estimated effects on wages (comparable to Table 3.3, column (1)) are .0544 for men and .0244 for women. The estimated effects remain statistically significant. The estimation results split by gender are available upon request.

\subsubsection{Extensions}

The fact that particularly conscientiousness at age 16 is correlated with later-life outcomes needs further analysis. We extend the analysis into four directions. First, we investigate the role of parents and the home environment. A sound home environment and parental inputs are key factors for child development (e.g. Herrnstein \& Murray, 1994; Shonkoff \& Phillips, 2000). Second, we examine the role of education. Abilities and traits are to a large extent created and education may help to build these (e.g. Cunha et al., 2010). Third, we add measures of sociability, self-esteem and locus of control. These covariates help shape a more balanced personality and are positively correlated with labor-market success (e.g. Borghans et al., 2008c; Heckman et al., 2006; Persico, Postlewaite \& Silverman, 2004). Finally, we conduct analyses in which we control for the average level of personality traits within one's occupation. The reason for doing so is that absolute levels of personality traits could be misleading and that relative measures determine success (e.g. Borghans et al., 2008c; Gronau, 1974). Table 3.4 and Table 3.5 present the results. Whereas Table 3.4 only reports the coefficient on conscientiousness, Table 3.C.4 in the Appendix displays the estimates for the other three measures of personality in the same way as documented in Table 3.4.

\section{Home Environment}

If it is the home environment that is the key factor influencing adult wages, personality traits should have no effect on outcomes if we control for parental investments. We add a number of controls for the child's home environment to the basic model: dummies for the absence

\footnotetext{
${ }^{11}$ The only exception is regular use of cannabis. The effects of conscientiousness on cannabis use are only significant for men. When adding interaction terms of personality traits with the male dummy, the differences in coefficients for men and women are only significant for cannabis use.
} 


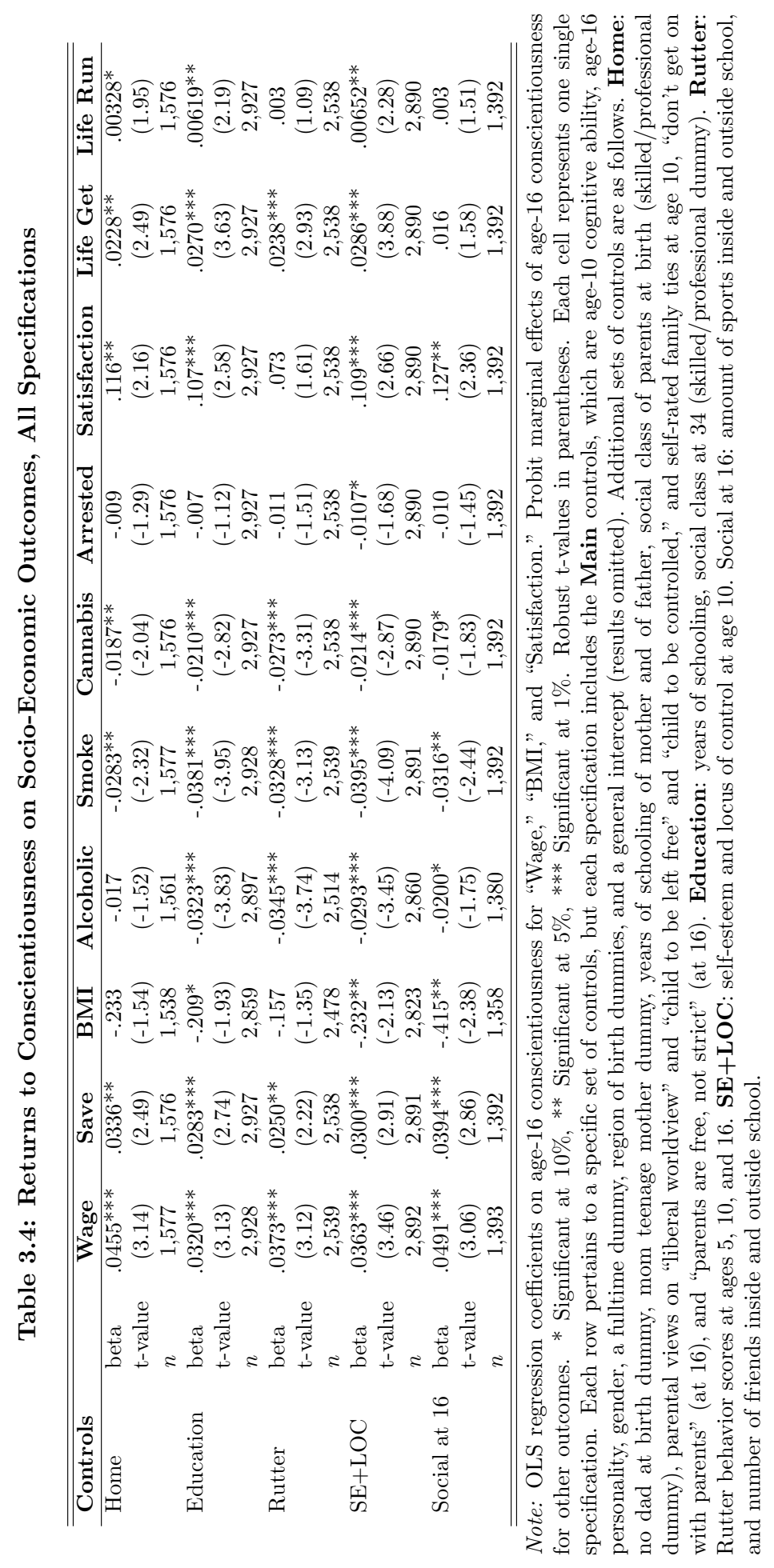


of the father at birth and for having a teenage mother; years of education of the parents; social class of the parents measured by whether or not parents had a skilled or professional occupation when the child was born; parenting styles and parent-child relationships; parents holding of a liberal worldview; parental beliefs in giving a child some freedom and teaching the child discipline at age 5; the child's view on family ties at age 10, and on parental skills at age $16 .^{12}$

The variables are documented and defined in Table 3.C.1 and descriptive statistics are shown in Tables 3.C.2 and 3.C.3 in the Appendix. The descriptive information presented in Table 3.C.3 suggests that above average earners grew up in more beneficial home environments. Their parents completed more years of schooling and had a higher social class. At age 5, their parents had a more liberal world view and believed less in strict authoritarian child rearing. At age 10, they experienced stronger family ties than below average earners did at that age. The first row of Table 3.4 shows that controlling for the home environment does not substantially affect the correlation between the measure of early conscientiousness and adult outcomes. The coefficients are comparable to the ones in Table 3.3, and remain significant, except for the coefficients on BMI, alcohol dependence and crime (being arrested). While similar in magnitude, these coefficients are no longer statistically significant.

\section{Education}

The positive relationship between educational achievement and wages is well-known, and is also apparent from Table 3.C.3. If personality is predictive of outcomes because it affects final educational achievement, controlling for education would result in insignificant, or significantly lower, estimated effects for conscientiousness. To control for educational attainment, we use completed years of schooling. We also control for social class by adding a dummy that equals one if the respondent's job is of a skilled or professional nature. The second row of Table 3.4 shows that the results of these analyses do not alter the picture, with the exception of crime. In general, measured conscientiousness is correlated with measures of education and social class, but the estimated correlations between conscientiousness and outcomes are not significantly affected.

The estimated effects of education and social class on wages are relatively large. In a causal interpretation of the estimates, an additional year of schooling is estimated to yield 1.3 percent higher gross hourly wages. Being employed in a skilled or professional occupation is associated with about 30 percent higher hourly wages, compared to lower level jobs. Adjusting for social class at earlier ages (30 and 26) yields similar results.

\section{Early Sociability, Self-esteem and Locus of Control}

Another channel through which conscientiousness could affect outcomes is sociability. Being more sociable and having a better social standing is likely to influence success in school or

\footnotetext{
${ }^{12}$ Adding more covariates to the regression models reduces the number of observations. However, the pattern of results remains similar. Parental social class, child rearing style, and good parent-child relationships do seem to matter most in terms of explaining outcomes. Additional measures associated with the home environment are number of younger and older siblings (at ages 5, 10, and 16), being read to as a 5-year old, being in a single parent family and living with both natural parents (at ages 0,5, 10, and 16), and having experienced separation, divorce, and/or death of parent(s) between birth and age 16. When adding these to our models, they do not significantly affect outcomes, nor do they have an impact on the estimated effects of personality.
} 
the labor market. Since personality measures could be correlated with early sociability, we incorporate a number of sociability measures into our models.

The Rutter score is a measure of behavioral problems, and is achieved by summing up the scores on 16 mother-rated items. Self-esteem relates to someone's sense of self-worth and confidence. It is constructed by summing up the scores on 12 self-rated items. Locus of control measures whether respondents see the world as deterministic or that an individual can alter outcomes through hard work and effort. The measure for locus of control results from adding up the scores of 15 self-rated items. The Rutter, self-esteem, and locus of control scores are standardized to have mean zero and standard deviation one within each regression sample. Sociability at age 16 includes a self-rated amount of sports and numberof-friends indicator, both within and outside school. The Appendix provides details about the individual items and the construction of the measures applied here. Tables 3.B.1 and 3.B.2 provide descriptive statistics for these measures. ${ }^{13}$

The last three sets of estimates in Table 3.4 present the results of these regression models. Controlling for self-esteem and locus of control does not seem to alter the estimates of measured conscientiousness for wages and other socio-economic outcomes. Including Rutter scores at ages 5, 10 and 16 or sociability at age 16 seems to affect the outcomes on the life satisfaction indicators only. ${ }^{14}$

Table 3.C.4 reports the coefficients on the other three measured personality traits. While the effects of conscientiousness remain intact after controlling for the home environment, many of the effects for the three other personality measures reduce and often become insignificant. In general, the same holds when we add controls for childhood behavior problems (Rutter) or sociability at age 16 (Sociability). Controlling for educational achievements or for self-esteem and locus of control at age 10, however, does not alter the associations with outcomes for the other personality traits. Thus, the correlation between personality and adult outcomes is distinct from correlations between these outcomes and education and social class, as well from the associations between measures of early behavioral problems and outcomes.

\section{Sorting}

Different workers flock to different jobs in the sense that personality is likely to influence a person's occupational choice and match efficiency (e.g. Krueger \& Schkade, 2008). We construct measures of occupations from the Standard Occupational Classification of 2000 (SOC2000) to determine the possible effects of selection into different occupations on our estimates.

\footnotetext{
${ }^{13}$ We use measures of self-esteem and locus of control as measured at the age of 10 , but we also derived these measures at age 16. However, we are only able to construct these measures for a limited number of individuals at age 16 . The sample is reduced to about 1,100 . The estimates remain comparable to the ones we present here.

${ }^{14}$ Other age-10 sociability measures considered in our analyses are teacher rated popularity with peers and number of friends, as well as teach rated boldness (as opposed to shyness) and cooperativeness. These are positively associated with wages, but leave our personality estimates unchanged. Other age-16 sociability measures considered are having any hobbies and number of hours spent on them (at 16), having a very close friend and ever having had a boy/girlfriend (at 16), ever having been removed from class, suspended from school, and been in contact with the law (at 16). None of these influence wages if we add them to our main specification, and they also do not affect our personality estimates. The same holds for controlling for age-16 social outcomes: ever tried cannabis, ever tried cocaine, alcohol consumption, criminal activity and temptation, and being arrested.
} 
Table 3.5: Returns to Personality on Wages, Controlling for Occupational Sorting

\begin{tabular}{|c|c|c|}
\hline & $(1)$ & $(2)$ \\
\hline Conscientiousness (16) & $\begin{array}{c}.016 \\
(1.63)\end{array}$ & \\
\hline Extraversion (16) & $\begin{array}{c}.008 \\
(0.87)\end{array}$ & \\
\hline Agreeableness (16) & $\begin{array}{c}.008 \\
(0.79)\end{array}$ & \\
\hline Emotional Stability (16) & $\begin{array}{l}-.002 \\
(-0.13)\end{array}$ & \\
\hline Avg Occ. Conscientiousness (16) & $\begin{array}{c}.573 * * * \\
(5.93)\end{array}$ & \\
\hline Avg Occ. Extraversion (16) & $\begin{array}{c}.147 \\
(1.57)\end{array}$ & \\
\hline Avg Occ. Agreeableness (16) & $\begin{array}{c}-.357^{* * *} \\
(-3.21)\end{array}$ & \\
\hline Avg Occ. Emotional Stability (16) & $\begin{array}{c}.267^{* * *} \\
(3.02)\end{array}$ & \\
\hline Above Avg Occ. C (16) & & $\begin{array}{c}.0430^{* *} \\
(2.19)\end{array}$ \\
\hline Above Avg Occ. E (16) & & $\begin{array}{c}.026 \\
(1.41)\end{array}$ \\
\hline Above Avg Occ. A (16) & & $\begin{array}{c}-.008 \\
(-0.37)\end{array}$ \\
\hline Above Avg Occ. ES (16) & & $\begin{array}{l}-.008 \\
(-0.40)\end{array}$ \\
\hline$n$ & 2,913 & 2,913 \\
\hline R-squared & 0.338 & 0.321 \\
\hline
\end{tabular}

Note: OLS regression coefficients with log hourly wage at age 34 as the dependent variable. ${ }^{*}$ Significant at $10 \%,{ }^{* *}$ Significant at $5 \%,{ }^{* * *}$ Significant at $1 \%$. Robust t-values in parentheses. All specifications control for age-10 cognitive ability, gender, a fulltime dummy, tenure in current job, social class dummies, region of birth dummies, and a general intercept (results omitted). Respondents are grouped in occupations using the first two digits of the SOC2000. Column (1) uses averages of age-16 personality traits by occupation alongside individual scores on the same traits. Column (2) uses four dummy variables, one for each trait, indicating whether an individual scores above or below his/her occupation average on that trait.

Table 3.C.5 shows the different categories and demonstrates that people in different occupations differ significantly in terms of personality traits. For example, Science and Technology Professionals score significantly higher than average conscientiousness, agreeableness, and emotional stability at age 16. On the other hand, people becoming Mobile Machine Drivers at age 34 score over half of a standard deviation below average on conscientiousness and agreeableness. These statistics suggest that there is value in analyzing the effects of occupational differences in personality traits.

Table 3.5 shows the results of two models in which we control for average personality traits within occupations. Since the personality of people in different occupations differs, the correlation between conscientiousness and wages drops.

We explore two sets of equations. The first set adds the average personality traits within one's occupation ("Avg Occ. ... (16)"). The second set of estimates does not include the personality trait itself, but a set of dummy variables indicating whether or not the individual 
scores above the occupational average on each personality trait. For example, to arrive at the dummy "Above Avg Occ. C (16)", we first subtract the average level of conscientiousness in the occupation an individual is employed in from his own conscientiousness at age 16. The dummy indicator is set to one in case the resulting difference is positive, and it is set to zero otherwise. In addition to our main controls, we further control for number of years on the job and add social class dummies to the model. ${ }^{15}$

In column (1) we observe that average occupational personality traits seem to be significant predictors of wages. The effect of individual conscientiousness is much lower, once average conscientiousness within one's occupation is controlled for. The estimate drops from .040 in Table 3.3 to .016, and is no longer significantly different from zero, at conventional significance levels. This suggests that much of the estimated wage premium for early conscientiousness could result from occupational sorting.

The final specification, presented in column (2), compares those with below average personality traits to those with above average personality traits. Individuals with traits above the occupational average, in terms of conscientiousness, earn on average 4.4 percent higher gross hourly wages than those below the average, suggesting that even within one's occupation, with a more homogeneous distribution of personality traits, it pays to be more conscientious. This is, however, not the case for the other traits.

\subsection{Measurement Error}

Measurement error in personality traits could bias our estimated effects of personality traits on outcomes. We deal with possible effects of measurement error in three ways. We reestimate the models documented in Table 3.3 by using 2SLS, errors-in-variables (EIV) regressions and structural equation modeling (SEM). The results are presented in Table 3.6; the first-stage estimates of the 2SLS models are displayed in the Appendix (Table 3.C.6).

The OLS regressions presented in Table 3.3 could be biased because of correlation between the independent variables and the error term. The most common way to deal with this problem is to apply an instrumental variables technique. We use the age-10 personality constructs as instruments for those measured at age 16 (see Table 3.1 for reliability coefficients). We assume that measurement error in the mother-rated items at both points in time is uncorrelated, which seems plausible given the six-year window between the two surveys. The first-stage results shown in Table 3.C.6 look fine and the F-tests well exceed the threshold of 10. The predicted traits obtained from the first stage are standardized to have mean zero and standard deviation one, such that the resulting coefficients can be compared with those from the main specifications reported in Table 3.3. The second-stage estimates are shown in the top panel of Table 3.6. The coefficients for conscientiousness are generally slightly smaller, and estimated with less precision, which is demonstrated by the lower t-statistics. This is especially true for the measures of life satisfaction, for which the effects of conscientiousness are no longer significantly different from zero. The same pattern of changes exists for the other personality traits. The main exception is the estimated correlation between conscientiousness and wages, which has become stronger, with a point estimate of $.049 .{ }^{16}$

\footnotetext{
${ }^{15}$ We also conducted the analysis using age-10 information on personality traits. The results are qualitatively similar to the ones presented here.

${ }^{16}$ As an alternative to using the same mother-rated items at age 10, we consider age- 10 personality constructs obtained from teacher-rated items. The first-stage results are strong, and the second-stage
} 


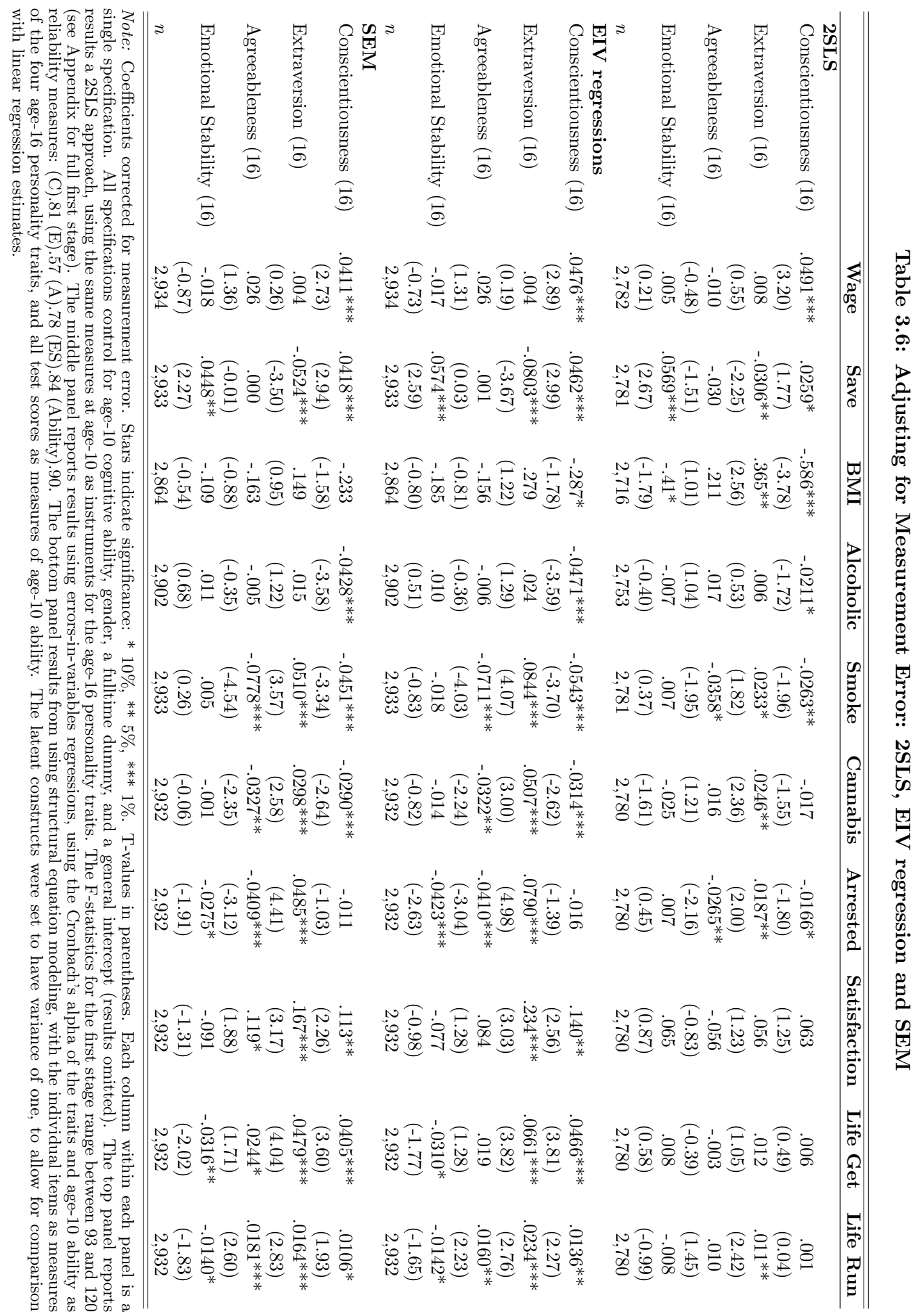


A second concern with our measures of personality is that the reliability of the four traits differs. A constructed trait less prone to measurement error is more likely to yield significant estimates, which would lead to flaws in our interpretation. To deal with this possibility we use EIV regressions in which Cronbach's alphas (see Table 3.1) are applied as reliability measures for the traits. The Cronbach's alpha associated with cognitive ability at age 10 is .90 , and is also applied. The second panel of Table 3.6 presents the estimates. Generally, the coefficients turn out to be similar to the ones presented in Table 3.3 in terms of statistical significance. The point estimates are generally slightly larger. For conscientiousness we again obtain a higher order of magnitude, with a coefficient of .048 .

Finally, SEM is a maximum likelihood technique to deal with measurement error. It takes into account measurement error at the level of the 22 items we use to construct our four measures of personality traits. More specifically, the errors in the items are part of the estimation procedure and incorporated in the measurement model. The bottom panel in Table 3.6 shows the estimation results of correcting for measurement error at the item-level. Once again, the pattern of significance is similar to the results from Table 3.3, with slightly higher estimates, which are measured less precisely. The estimated effect on hourly wages of a standard deviation increase in conscientiousness (.041) is similar to that obtained in Table $3.3(.040)$.

All in all, the predictions in Table 3.3 do not change substantially when we correct for possible measurement error in the measured traits. The associations found in Table 3.3 remain significant, even with slightly larger point estimates. In the next sections we therefore continue by using OLS estimators.

\subsection{Decomposing Conscientiousness}

The estimation results point towards an important role for conscientiousness in explaining outcomes relative to the other personality traits. We continue our analysis with a more detailed decomposition and investigation of the importance of early conscientiousness in explaining outcomes at age 34 .

\subsubsection{Lower-Order Structure}

Our measure of conscientiousness is constructed from a number of items from which we have constructed the Big Five inventory to relate to the most common way of analyzing personality traits in the literature. Personality psychologists have examined the lower-order structure of measured conscientiousness and other personality traits. Roberts et al. (2004) and Jackson et al. (2009) use a psycholexical method to investigate in a large number of

estimates again show the same pattern of strong and significant effects for conscientiousness. The precision of the estimates reduces somewhat, with slightly smaller t-statistics. These results are available upon request. Teachers describe the respondents at age 10 by rating them on 53 items, many of which are similar to the items rated by the mothers. After removing items related to motor skills and behavioral problems, a subset of 27 items is used to construct age-10 teacher-rated constructs for conscientiousness (11 items), extraversion (6 items), agreeableness (5 items), and emotional stability (5 items). Cronbach's alphas are $.93, .84, .88$, and .86 , respectively; with the first principal components explaining $58,56,69$, and 65 percent of the variance of the items, respectively. 
databases whether or not measures of conscientiousness consist of multiple components. ${ }^{17}$ Roberts et al. (2004) performed a principal component analysis on 83 items drawn from over 2,000 surveys. It turns out that measured conscientiousness consists of a number of facets. Roberts et al. (2004) find nine facets, Jackson et al. (2009) five. The five most important facets of conscientiousness that appear from these meta-analyses are impulse control, orderliness, decisiveness, reliability, and industriousness.

Jackson et al. (2009) find that no existing personality measure includes all facets of conscientiousness identified from the psycholexical search. Roberts et al. (2004) show that there are good levels of discriminant validity with the remaining traits in the Big Five. This allows us to add facets of conscientiousness along with the other three traits (extraversion, agreeableness and emotional stability).

\begin{tabular}{lll}
\hline \hline $\begin{array}{l}\text { Facet of } \\
\text { conscientiousness }\end{array}$ & Description & BCS item \\
\hline $\begin{array}{l}\text { Impulse control } \\
\text { Orderliness }\end{array}$ & $\begin{array}{ll}\text { "The propensity to inhibit proportional responses" } \\
\text { "The propensity to be organized and neat" }\end{array}$ & $\begin{array}{l}\text { Easily distracted } \\
\text { Difficulty } \\
\text { concentrating } \\
\text { Decisiveness }\end{array}$ \\
$\begin{array}{l}\text { Reliability } \\
\text { Industriousness }\end{array}$ & "The propensity to make deliberate decisions" & Cannot settle \\
\hline \hline
\end{tabular}

Source: Roberts et al. (2004) and Jackson et al. (2009).

Investigation of the list of 83 items explored by Roberts et al. (2004) suggests that our items of conscientiousness (see Table 3.1) can be put into four facets of conscientiousness. The item "cannot settle" falls into the category of decisiveness; "easily distracted" in impulse control; "fails to finish things" in reliability; and "difficulty concentrating" in orderliness. Our database also contains a measure of locus of control, which is related to impulse control.

Table 3.7 displays correlation coefficients among the four facets of conscientiousness, as well as their correlations with the measured personality traits and outcome variables. Only those coefficients that are significant at the 5 percent level are shown. Note that positive correlation coefficients indicate that better behavior is positively associated with the variable at hand. Of these four facets, "fails to finish things" and "easily distracted" show the highest correlations with the conscientiousness construct, as well as with our outcome measures. This is consistent with the observation by Jackson et al. (2009) and Roberts et al. (2004), who also find the strongest outcomes on these two facets of measured conscientiousness in their search for a lower-order structure of personality traits. Locus of control is also statistically significantly correlated with conscientiousness and with the four facets. The correlation coefficients between locus of control and the facets of conscientiousness are much lower compared to the correlations of the four facets with one another, which is consistent with the findings in Table 3.4. Its correlation with measured emotional stability, pointed at in some other studies, is low, relative to its correlation with conscientiousness (e.g. Almlund et al., 2011).

\footnotetext{
${ }^{17}$ Roberts et al. (2004) and Jackson et al. (2009) present an overview of the relevant literature from which the lower-order structure of conscientiousness is derived.
} 
Table 3.7: Correlations of Conscientiousness Items with Personality and SocioEconomic Outcomes

\begin{tabular}{lccccc}
\hline \hline & $(\mathrm{C} 1)$ & $(\mathrm{C} 2)$ & $(\mathrm{C} 3)$ & $(\mathrm{C} 4)$ & $(\mathrm{loc})$ \\
\hline Conscientiousness items & & & & & \\
(C1) fails to finish things (reliability) &. & .57 & .57 & .52 & .21 \\
(C2) easily distracted (impulse control) & .57 &. & .49 & .47 & .28 \\
(C3) difficulty concentrating (orderliness) & .57 & .49 &. & .47 & .19 \\
(C4) cannot settle (decisiveness) & .52 & .47 & .47 &. & .19 \\
(loc) Locus of control (16) (impulse control) & .21 & .28 & .19 & .19 &. \\
& & & & & \\
Personality constructs & & & & & \\
(C) Conscientiousness (16) & .84 & .80 & .79 & .76 & .28 \\
(E) Extraversion (16) & .17 & .20 & .22 & .23 & .09 \\
(A) Agreeableness (16) & .39 & .42 & .32 & .40 & .22 \\
(ES) Emotional Stability (16) & .40 & .40 & .37 & .38 & .23 \\
& & & & & \\
Outcomes & & & & & .32 \\
Wage & .14 & .14 & .10 & .11 & .15 \\
Save & .11 & .11 & .08 & .10 & -.10 \\
BMI & -.07 & -.08 & -.05 & -.10 &. \\
Alcoholic & -.06 & -.04 & -.04 &. & -.19 \\
Smoke & -.16 & -.16 & -.08 & -.13 &. \\
Cannabis & -.09 & -.08 & -.05 & -.04 & .12 \\
Arrested & -.10 & -.13 & -.08 & -.11 & .19 \\
Satisfaction & .11 & .09 & .09 & .10 & .19 \\
Life Get & .15 & .12 & .11 & .11 & .16 \\
Life Run & .09 & .08 & .10 & .08 & .10 \\
\hline \hline
\end{tabular}

Note: Correlation coefficients. Only those significant at the 5 percent level or higher are reported. Although formulated negatively, each item is scaled such that higher scores are more desirable. Locus of control is standardized (mean 0, st.dev. 1) and higher scores indicate higher internal locus of control. The sample applied is our working sample of 2,934 individuals with valid information on adult wages, age-10 cognitive ability, and age-16 personality. 


\subsubsection{Returns to Different Items}

The next step is to add the individual facets of measured conscientiousness to the regression models to see what aspects of conscientiousness explain the various outcomes at age 34 . Table 3.8 reports the estimates for wages with different sets of controls. Table 3.9 reports the estimates for the other outcomes for the main specification.

Each column in Table 3.8 is the result of estimating a specification as shown in Table 3.4. Each cell refers to a separate analysis in which we have included the individual facets instead of measured conscientiousness. For example, when estimating the wage effect of conscientiousness item "fails to finish things", we regress adult wages on that item, age-16 personality measures extraversion, agreeableness, and emotional stability, and on other controls, depending on the specification used; but we do not include the construct of conscientiousness itself. We have estimated models for the four individual facets of conscientiousness and for locus of control.

Investigation of the rows in Table 3.8 suggests that the facets "fails to finish things" and "easily distracted" and the trait "locus of control" return significant and sizeable effects on wages. This is true to a lesser extent for the facet "cannot settle", which is insignificant when we control for the home environment or early sociability. The facet "difficulty concentrating," which is related to orderliness, does not seem to be a significant determinant of wages at age 34 .

Table 3.9 reports the estimates of the facets of conscientiousness on the other socio-economic outcomes. The estimates support the results from Table 3.3. Those who have a higher level of measured conscientiousness at age 16, are significantly more likely to save, more satisfied with their lives, and less likely to be alcohol dependent, to smoke and to use cannabis. The facet "cannot settle" is most strongly associated with savings, BMI, smoking and crime. This suggests that more decisive persons are less likely to make mistakes or behave in an unhealthy way. The item "fails to finish things," related to reliability, is significantly associated with more healthy behavior and higher life satisfaction. The facets "easily distracted" and "locus of control," related to impulse control, show similar effects.

In terms of what facets of conscientiousness are important for adult wages, we see that reliability, decisiveness and impulse control when young seem to be relevant. Scoring a standard deviation higher on locus of control at age 16, is associated with 10 percent higher hourly wages at age 34 . The facet of reliability comes close to what personality psychologists have also identified as social responsibility. Roberts \& Bogg (2004) show for example that this facet of conscientiousness is a good predictor for adult outcomes related to family, work and substance use. Impulse control is related to the rate of risk aversion used in economics. People who are better able to imagine the consequences of their behavior experience better outcomes (e.g. Borghans et al., 2008a, for a discussion). Becker et al. (2012) obtain similar outcomes for Germany. They show that risk aversion and conscientiousness are correlated, without investigating individual facets. Decisiveness is related to the rate of time preference and self-control. In general, persons with a lower discount rate make less mistakes (unhealthy behaviors, crime) save more and earn higher wages. This is also borne out by the correlations we obtain in Table 3.9. Moffitt et al. (2011) confirm this result, by showing that children with poor self-control were more likely to make mistakes as adolescents, resulting in poorer health outcomes, a higher probability to become unplanned teenage parents and a higher probability to commit crime. 
Table 3.8: Returns to Conscientiousness Items on Wages, All Specifications

\begin{tabular}{|c|c|c|c|c|c|c|}
\hline Controls & Main & Home & Education & Rutter & $\mathrm{SE}+\mathrm{LOC}$ & Social at 16 \\
\hline (C1) fails to finish things & $.0624^{* * *}$ & $.0940^{* * *}$ & $.0529^{* * *}$ & $.0647 * * *$ & $.0576^{* * *}$ & $.0929 * * *$ \\
\hline (reliability) & $(4.12)$ & $(3.94)$ & $(3.52)$ & $(3.77)$ & $(3.77)$ & $(3.56)$ \\
\hline R-squared & 0.215 & 0.231 & 0.248 & 0.214 & 0.224 & 0.236 \\
\hline (C2) easily distracted & $.0470 * * *$ & $.0654^{* * *}$ & $.0348^{* *}$ & $.0493^{* * *}$ & $.0415^{* * *}$ & $.0669^{* * *}$ \\
\hline (impulse control) & $(3.25)$ & $(3.10)$ & $(2.45)$ & $(3.06)$ & $(2.83)$ & $(2.95)$ \\
\hline R-squared & 0.214 & 0.227 & 0.246 & 0.212 & 0.222 & 0.233 \\
\hline (C3) difficulty concentrating & .019 & .011 & .016 & .004 & .016 & .028 \\
\hline (orderliness) & $(1.12)$ & $(0.43)$ & $(0.92)$ & $(0.21)$ & $(0.89)$ & $(1.02)$ \\
\hline R-squared & 0.211 & 0.222 & 0.244 & 0.209 & 0.22 & 0.228 \\
\hline (C4) cannot settle & $.0547 * * *$ & .040 & $.0426^{* *}$ & $.0488^{*}$ & $.0521^{* *}$ & .038 \\
\hline (decisiveness) & $(2.65)$ & $(1.37)$ & $(2.11)$ & $(1.80)$ & $(2.49)$ & $(1.19)$ \\
\hline R-squared & 0.212 & 0.223 & 0.245 & 0.21 & 0.221 & 0.228 \\
\hline$n$ & 2,934 & 1,577 & 2,928 & 2,539 & 2,892 & 1,393 \\
\hline (loc) Locus of control (16) & $.0967^{* * *}$ & $.0849^{* * *}$ & $.0774^{* * *}$ & $.0970^{* * *}$ & $.0864^{* * *}$ & $.0918^{* * *}$ \\
\hline (impulse control) & $(7.75)$ & $(6.10)$ & $(6.32)$ & $(7.30)$ & $(6.83)$ & $(6.35)$ \\
\hline$n$ & 1,634 & 1,336 & 1,631 & 1,423 & 1,610 & 1,219 \\
\hline R-squared & 0.244 & 0.248 & 0.28 & 0.243 & 0.25 & 0.253 \\
\hline
\end{tabular}

Note: OLS regression coefficients with log hourly wage at age 34 as the dependent variable. ${ }^{*}$ Significant at $10 \%,{ }^{* *}$ Significant at $5 \%,{ }^{* *}$ Significant at $1 \%$. Robust t-values in parentheses. Each cell represents one single specification. Each row reports results of using that item, rather than the construct of conscientiousness, in the set of personality traits. Although formulated negatively, each item is scaled such that higher scores are more desirable: 1 "totally applies," 2 "applies somewhat," 3 "does not apply." Locus of control is standardized (mean 0, st.dev. 1) within each regression sample and higher scores indicate higher internal locus of control. Each column pertains to a specific set of controls, but each specification includes the Main controls, which are age-10 cognitive ability, age-16 extraversion, agreeableness, and emotional stability, gender, a fulltime dummy, region of birth dummies, and a general intercept (results omitted). Additional sets of controls are as follows. Home: no dad at birth dummy, mom teenage mother dummy, years of schooling of mother and of father, social class of parents at birth (skilled/professional dummy), parental views on "liberal worldview" and "child to be left free" and "child to be controlled," and self-rated family ties at age 10, "don't get on with parents" (at 16), and "parents are free, not strict" (at 16). Education: years of schooling, social class at 34 (skilled/professional dummy). Rutter: Rutter behavior scores at ages 5, 10, and 16. SE+LOC: self-esteem and locus of control at age 10. Social at 16: amount of sports inside and outside school, and number of friends inside and outside school. 


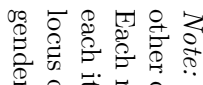

क्षे

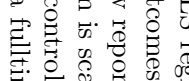

: ?

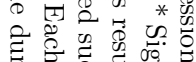

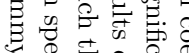

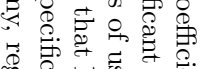

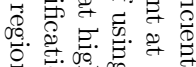

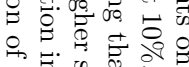

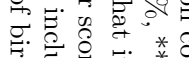

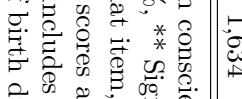

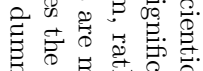

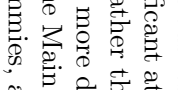

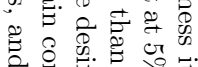

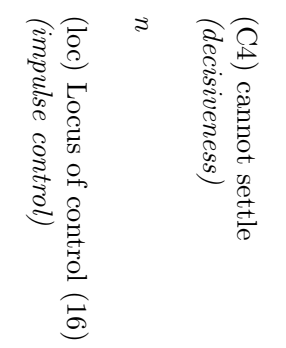

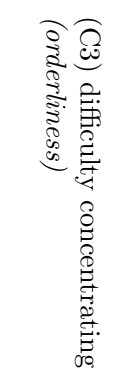

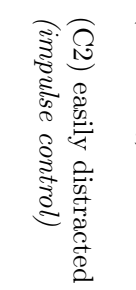

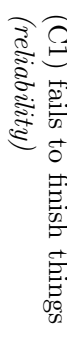

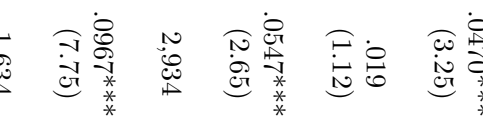

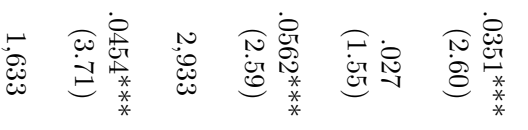

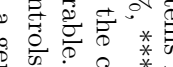

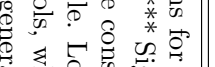

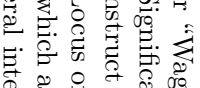

要

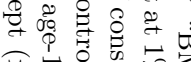

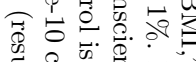

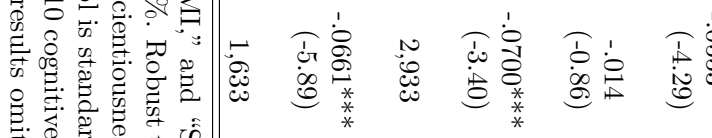

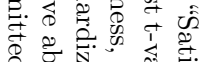

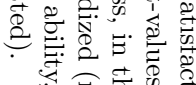

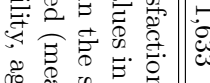

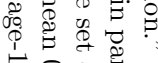

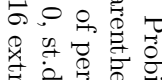

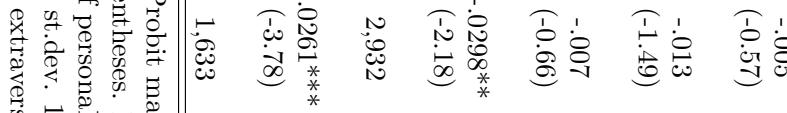

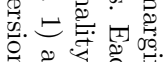

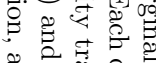

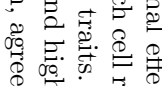

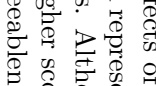

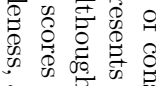

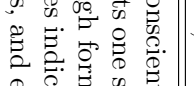

通范哭.

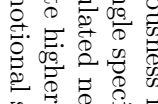

की

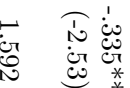

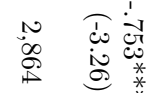

İ.

I:

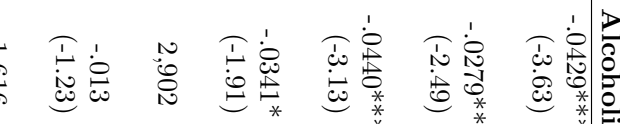

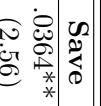

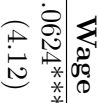

क्ष

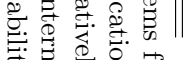

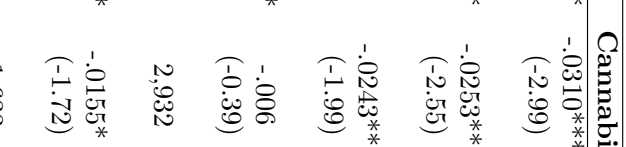
空 ب.

อ

2
0
0
0
0.0
0
0
0
0
0
0
0
0
0

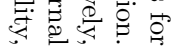




\subsection{Policy Perspective}

From the point of view of policy our findings are relevant. Many educational programs have been designed to promote educational equity. There is economic value in equalizing educational opportunities and achievement for all because underdeveloped human potential burdens economic efficiency. Most programs have been focussing on increasing cognitive ability of poor and disadvantaged children. Heckman et al. (2008) show for example that, while the positive effects on cognitive ability are only short-lived, the Perry preschool program in the United States has produced reductions in teen pregnancy, school dropout, delinquency and work absenteeism. Above, we have presented similar effects of early personality traits on wages, savings, unhealthy behaviors and crime.

From a policy point of view it is interesting to search for a possible gradient of conscientiousness and its malleability. If a gradient of conscientiousness in outcomes exists, the policymakers' interest should be to investigate whether they can intervene and move people up the gradient. As described in Section 3.2, Figure 3.A.1 plots the averages of the age 34 socio-economic outcomes by the deciles of the age-16 conscientiousness distribution. Less conscientiousness at the age of 16 is associated with lower wages, less savings and lower satisfaction with life by age 34 . At the same time, respondents who were more conscientious as children, have a lower body mass index, are less likely to be dependent on alcohol, to smoke or use cannabis regularly, and are less likely to have ever been arrested. These cross-sectional patterns reveal the existence of a gradient of conscientiousness worth investigating.

Although measured on a different scale, the items we use to construct age-16 conscientiousness, extraversion, agreeableness, and emotional stability are also available at the age of 10 , which allows us to rank respondents on each personality trait at two points in time. Our data do not include an experimental intervention, but we can explore individual changes in the distribution of these traits between ages 10 and 16 to predict socio-economic outcomes. We present two sets of estimates that demonstrate that especially changes in conscientiousness matter for socio-economic outcomes, and that large declines in the distribution of conscientiousness are particularly harmful.

Table 3.10 shows regression results from adding the change in personality traits between 10 and 16 as covariates alongside the levels of these same traits at age 10. Prior to calculating changes in personality, the factor scores on both age 10 and age 16 personality traits are standardized to have mean zero and standard deviation one, within the regression sample. This way, we avoid changes in averages and variance in personality due to attrition or selection bias. Besides these personality measures, we include the same controls as used in our main specification (see Table 3.3).

The pattern of the coefficients on the age-10 personality traits is consistent with that found in Table 3.3, for the age-16 personality traits. Conditional on the level of the personality traits at age 10, especially changes in conscientiousness between the ages of 10 and 16 are significant and sizeable explanations for socio-economic outcomes. The change in conscientiousness is predictive of all outcomes, except body mass index and being arrested; that latter being the only outcome significantly affected by changes in emotional stability. The change in extraversion from 10 to 16 is predictive of the same behaviors, and in the same way as age-16 extraversion in Table 3.3. The change in the distribution of extraversion between 10 and 16 is positively associated with the three life satisfaction measures, while also being associated with less saving, more tobacco and cannabis use, and higher rates of arrest. 


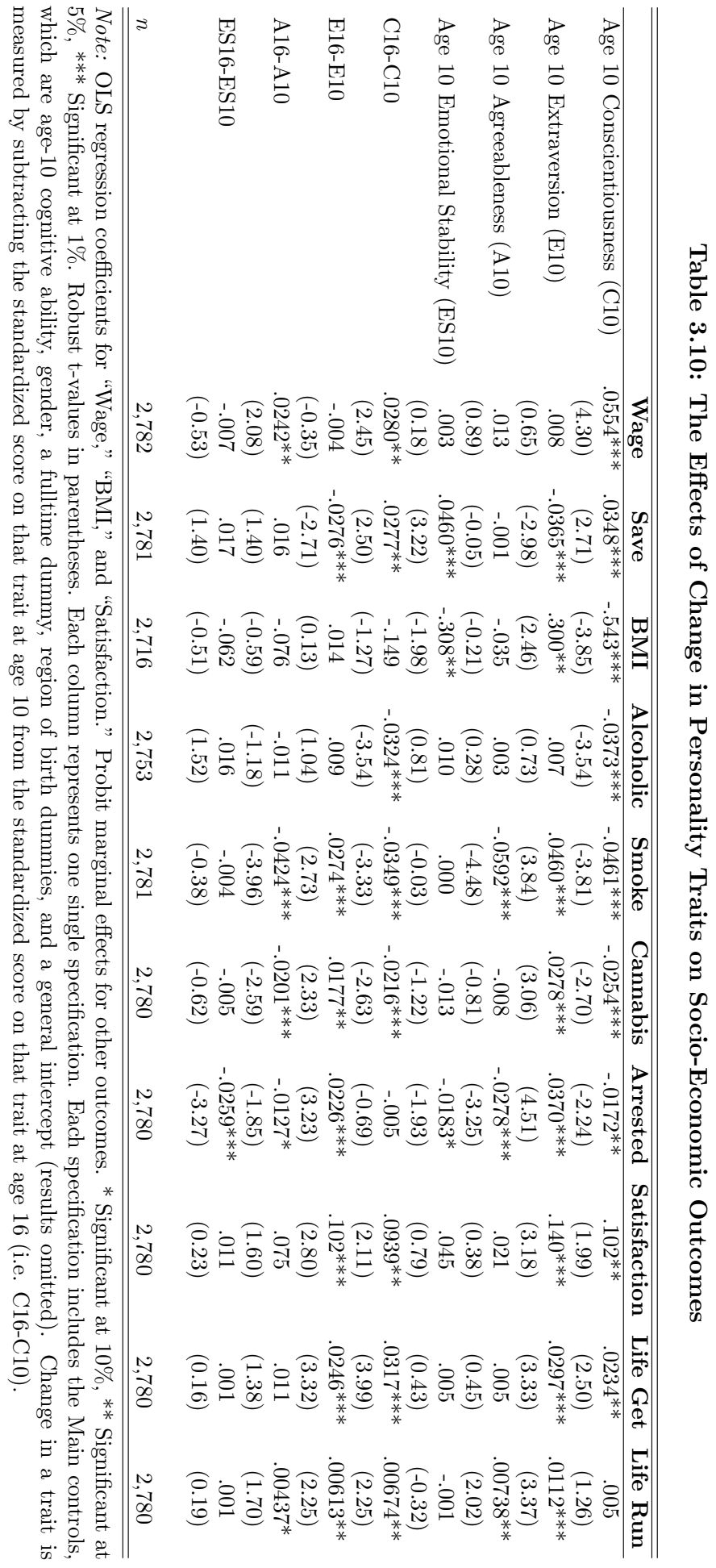


The estimated effect of a change in conscientiousness on wages .028. This indicates, that a respondent who improved in conscientiousness, from being average at age 10 to scoring one standard deviation above average six years later, earns on average 2.8 percent higher gross hourly wages at age 34 than an individual scoring the same at age 10 and age 16 on conscientiousness $(C(16)-C(10)=0)$. This hypothetical individual then also has a 3.2 percentage point lower likelihood of being alcohol dependent, a 3.5 percentage point lower likelihood to be a smoker, and a 2.2 percentage point lower likelihood to be a regular cannabis user. The results in Table 3.10 show that it is not only the stock of personality traits at one point in time, but also the development in terms of these traits over time that matter for later life outcomes.

Changes in personality can be both negative and positive, the results in Table 3.10 do not allow us to distinguish the effects of rising or falling in the distribution. The results may also understate the importance of changes. Given that personality measures show high levels of correlation, even at young ages (e.g. Roberts \& DelVecchio, 2000), most individuals report only small changes. Even in the absence of real changes, measurement error will lead to small observed changes. If it is the case that only substantial changes matter for outcomes, the estimates in Table 3.10 understate the importance of distributional changes. We therefore explore the effect of large increases and decreases in personality traits between the ages of 10 and 16.

Rather than looking at absolute changes in the distribution, we distinguish between risers and fallers in terms of personality. We consider the top and bottom quartile in terms of changes in personality traits (i.e., $C 16-C 10$ ) as risers and fallers, respectively, with those in the middle representing respondents relatively stable on the trait at hand. Defining stable individuals as those reporting absolute changes smaller than half a standard deviation and defining two dummy variables to indicate either large decreases $(\Delta C<-.5)$ or large increases $(\Delta C>.5)$, fits this approach well, while facilitating comparison and interpretation of coefficients. For conscientiousness, 56 percent of respondents reports absolute changes smaller than half a standard deviation. For agreeableness and emotional stability this share is 48 percent, and it is 41 percent for extraversion. For each trait, risers and fallers are (by construction) equally distributed among the remaining respondents.

Table 3.11 presents the estimates of this approach. The estimates suggest that the importance of changes in personality for adult wages is more likely to be associated with a decrease in personality during childhood. Only 7 out of 50 rise dummies are significant at the 10 percent level, which is at chance level. On the other hand, the same holds for 16 out of 50 fall dummies. For conscientiousness, a large decline in the distribution is significantly associated with all ten socio-economic outcomes, whereas a rise is not significantly associated with any of these outcomes. Compared to someone stable in terms of all four traits, an individual that experienced a large decline in conscientiousness between ages 10 and 16 earns 5.5 percent lower gross hourly wages. The likelihood of being an alcoholic, a smoker, or a cannabis user is also higher (5.7, 8.3 and 5.5 percentage points higher, respectively), and the individual is also 3.4 percentage points more likely to have ever been arrested. Given that 18 percent of our working sample are alcohol dependent, 26 percent are smokers, 15 percent use cannabis regularly, and 14 percent have been arrested, these effects are quite substantial.

These results suggest that policymakers could be most effective in preventing children from falling behind. However, personality at age 10 also has predictive value for these same outcomes, which points to the importance of the overall stimulation of developing personality traits and conscientiousness more specifically. 


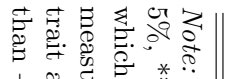

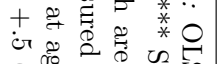
ํ.

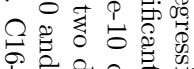

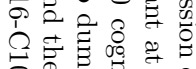
จे ن

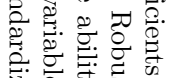

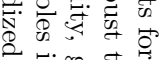

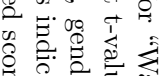
की 8 范 声总实它 प

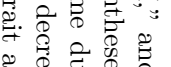
थृ \% क

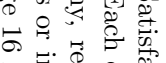
क. ㅋ.

过

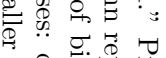
율 政

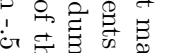

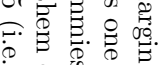
की

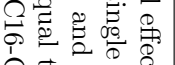
$\Omega$ के क्षे की

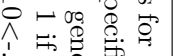

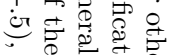
늘

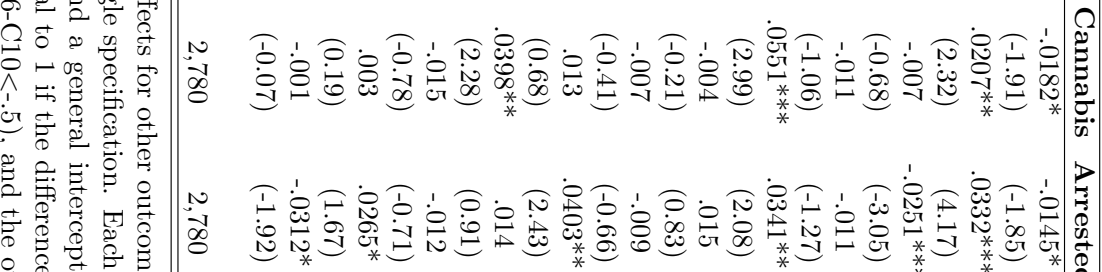
○ จ

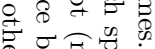

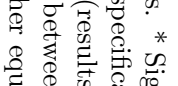
๑

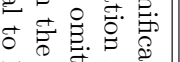
ज. की क्षे है

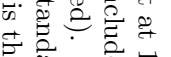

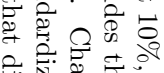

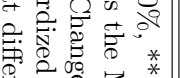

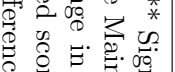

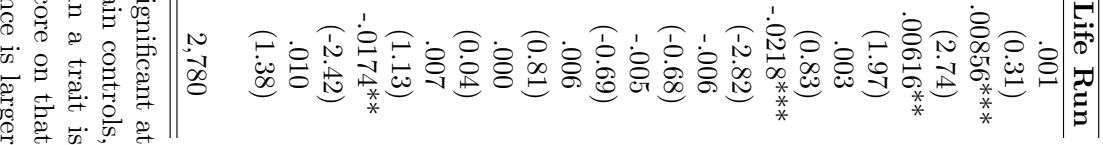

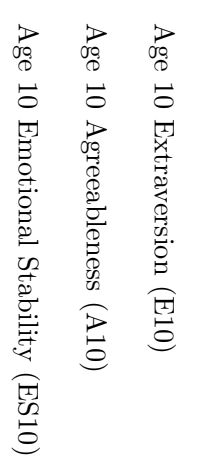

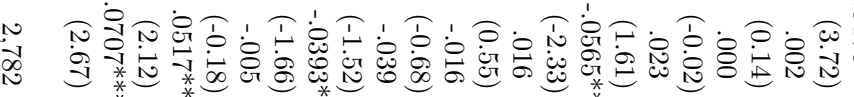

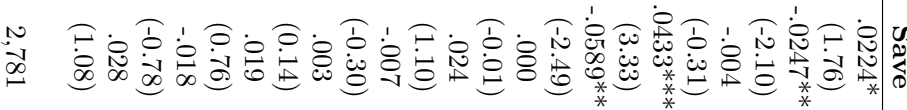
N I:

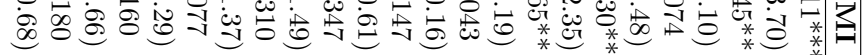

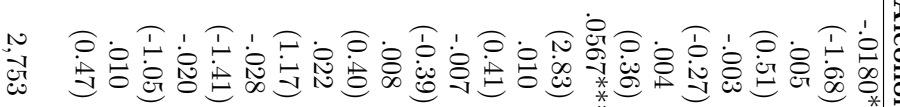

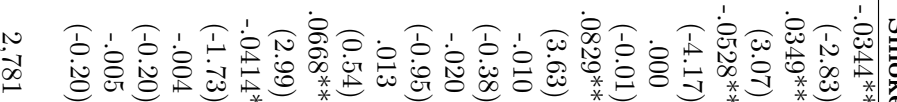

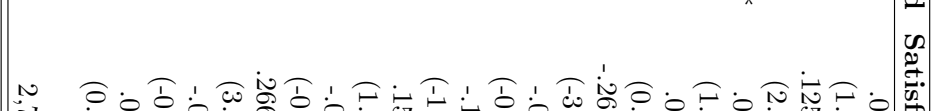

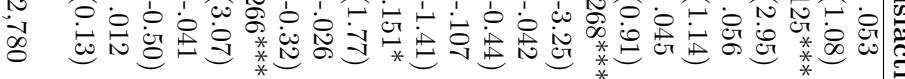
N o. I!

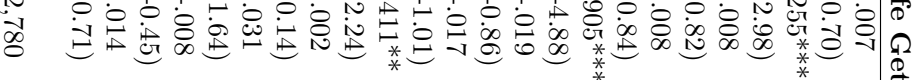




\subsection{Conclusion}

This research has presented an analysis of correlations between early measures of personality traits and adult outcomes using data from several waves of the 1970 British Cohort Study. Our main findings suggest that early conscientiousness is strongly correlated with adult wages and other socio-economic outcomes. Controlling for a number of measures related to the childhood home environment, early sociability and educational achievement does not alter this result. In addition, measurement error does not seem to plague our estimated effects, since three different types of analyses to deal with measurement error do not substantially change the estimation results. A substantial share of the conscientiousness wage premium is likely to stem from sorting into higher paying occupations, while within a single occupation, it still pays to have above average conscientiousness. Investigating a variety of measures and structures of personality suggests that impulse control, decisiveness and reliability are among the most important facets of conscientiousness in explaining outcomes. These facets can be related to economic parameters such as risk aversion, social preferences and time preference.

Our findings are consistent with previous research that suggests that differences in personality traits are important in explaining differences in outcomes. We know that cognitive ability and low social class origins are hard to improve through intervention programmes (e.g. Heckman et al., 2008). In addition, looking at our gradient of conscientiousness, it turns out that conscientiousness is heterogeneous and a strong determinant of socio-economic outcomes. From a policy point of view it seems beneficial to investigate possibilities to improve conscientiousness (e.g. Moffitt et al., 2011), or at least to prevent children from falling behind in their development throughout childhood.

Further research by economists and psychologists is necessary. Borghans et al. (2008a) present a research agenda for economists and Roberts (2009) presents suggestions for improvement for psychologists. This chapter has taken up a small part of this agenda, but a deeper understanding of the interactions between early traits and adult outcomes seems relevant. Also, the interplay with the home environment, school and different states of a child and his later outcomes is not well-understood. Finally, dealing with measurement error in traits remains an important direction for improvement and further research. Both theoretical and empirical effort is required to make progress and to be able to design effective policies. 


\section{Appendix}

This appendix presents supporting materials. All data come from the 1970 British Cohort Study. The 1970 British Cohort Study began by collecting data on births and families of all children born in Great Britain in a particular week in April of 1970. These children/respondents were then followed and re-interviewed roughly every 4 or 5 years over the course of their life. Of the initial 17,196 babies born in 1970, 9,665 respondents remain in 2004. After selecting employed individuals with valid information on wages, childhood ability and personality, we retain a working sample of 2,937 respondents used for the analyses in this research. In Section 3.A we show the details of the cluster analysis and principal component analysis used to construct the personality measures related to the Big Five inventory. Section 3.B provides details on the items used to construct our sociability measures: the Rutter behavior scores, self-esteem, and locus of control.

Section 3.C provides supporting tables. Table 3.C.1 describes the core variables used in this study. The table consists of six sets of variables. First, the outcome variables at age 34 are presented. The next set consists of our personality measures (covered in more detail in the next section), and is followed by sets of variables relating to the home environment, educational achievement, early sociability, and occupational sorting. The variables in Table 3.C.2 and Table 3.C.3 are set up in the same order. Table 3.C.2 presents a number of descriptive statistics for these sets of variables, both for the working sample used in all analyses in this study, as well as for the unrestricted sample. Table 3.C.3 provides averages for all variables for those scoring above and below average on our age-16 personality measures. Table 3.C.4 provides the coefficients for the traits extraversion, agreeableness, and emotional stability that belong to the analyses reported on in Table 3.4. Table 3.C.5 displays the grouping of respondents in occupations and associated average personality traits, which is used for the analysis reported on in Table 3.5. To conclude, Table 3.C.6 provides the first-stage results of the 2SLS results reported in Table 3.6. 


\section{Appendix 3.A Personality Measures}

A Big Five-type taxonomy of personality would allow us to capture the relative importance of different dimensions of an individual's personality. The BCS70 offers a number of alternatives, although these sets of items do not offer items to capture openness. Hence, we are able to construct measures capturing a child's conscientiousness, extraversion, agreeableness, and emotional stability (neuroticism).

At age 10, the teachers of the respondents are asked to complete a set of 53 items on the child's developmental behaviors, of which we retain 27 items to construct a teacher rated Big 4 taxonomy of personality. At age 16, respondents themselves fill in a set of 27 items under the heading "Knowing Myself," 18 of which can be used to construct measures for each of the Big 5, although the strength of the construct for openness is rather weak. Since these two sets of items are not the same, and rated by different people, we prefer a third set of items that the BCS70 offers: a set of 38 parent-rated items, available at age 10 as well as age 16. A cluster analysis of a subsample of 22 of these items (excluding items related to fine and gross motor skills) shows the expected grouping of items into four clusters, representing conscientiousness, extraversion, agreeableness, and emotional stability (See Figure 3.A.1).

An additional benefit of using the set of mother-rated items is that this set contains more valid observations, both at ages 10 and 16. To further increase the number of observations, we impute missing values for individuals that miss 1 or 2 of the 22 items used for constructing our personality measures. We apply multiple imputation through chained equations using the remaining 21 items as predictors for the item of interest. By doing so, we increase the number of observations with valid age-10 personality measures by over 5 percent (from 6,493 to 6,845 ), and by as much as 12 percent for age-16 personality (from 3,751 to 4,205 ).

For each of the 22 items $i$, we estimate the following model to predict missing values:

$$
\text { Item }_{i}=\alpha_{i}+\sum_{j \neq i} \beta_{j} \text { Item }_{j}+\epsilon_{i}
$$

This process starts with the item with least amount of missing observations. Missing observations are then imputed, and the process continues to the item with next fewest missing observations. At age 10, the items are scored on a scale from 1 through 100, 1 indicating "certainly" and 100 indicating "does not apply". We thus apply the above model using linear regression. Imputed values below 1 are set to 1 , and those above 100 are set to 100 . For the age-16 items we use multinomial logit regression to impute missing values, since the items are scored 1 "certainly applies," 2 "applies somewhat," 3 "doesn't apply."

Figure 3.A.1 shows a dendrogram of the clustering of the 22 items measured at age 16 (including imputed values). The grouping of items is as expected and is also confirmed by the table below. After extracting four factors from the same set of 22 items using principal component analysis, and applying orthogonal rotation to the loadings, the table below shows the factor loadings and the unexplained variance of the 22 items used to construct our four personality measures (conscientiousness, extraversion, agreeableness, and emotional stability). Only loadings larger than .2 are reported. The resulting four factors explain 52.3 percent of the variance among the items. 
Figure 3.A.1: Clustering of Age-16 Personality Items into Four Big Five Traits

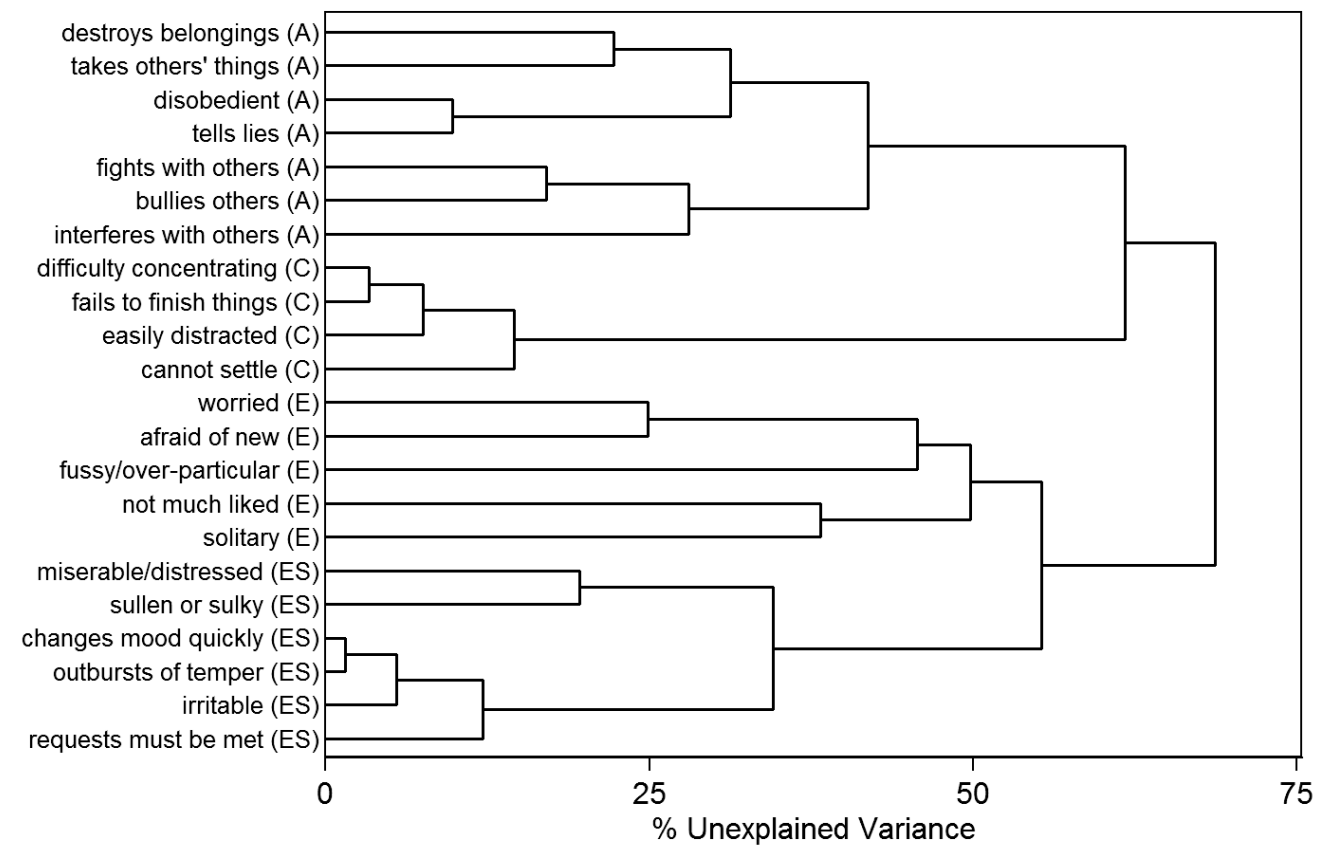

\begin{tabular}{|c|c|c|c|c|c|}
\hline & $\mathrm{C}$ & $\bar{E}$ & $\mathbf{A}$ & ES & Unexplained \\
\hline fails to finish things (C) & .513 & & & & .274 \\
\hline easily distracted (C) & .468 & & & & .357 \\
\hline difficulty concentrating (C) & .496 & & & & .362 \\
\hline cannot settle $(\mathrm{C})$ & .410 & & & & .433 \\
\hline fussy/over-particular (E) & & .292 & & & .702 \\
\hline solitary $(\mathrm{E})$ & & .417 & & & .644 \\
\hline afraid of new $(\mathrm{E})$ & & .522 & & & .479 \\
\hline worried $(\mathrm{E})$ & & .548 & & & .415 \\
\hline not much liked (E) & & .248 & .327 & & .635 \\
\hline bullies others (A) & & & .394 & & .510 \\
\hline fights with others (A) & & & .378 & & .516 \\
\hline tells lies (A) & & & .337 & & .486 \\
\hline disobedient $(\mathrm{A})$ & & & .200 & .212 & .484 \\
\hline takes others' things (A) & & & .435 & & .475 \\
\hline destroys belongings (A) & & & .435 & & .517 \\
\hline interferes with others (A) & & & & & .611 \\
\hline outbursts of temper (ES) & & & & 419 & .341 \\
\hline changes mood quickly (ES) & & & & .430 & .319 \\
\hline irritable (ES) & & & & .412 & .395 \\
\hline requests must be met (ES) & & & & .368 & .444 \\
\hline sullen or sulky (ES) & & & & .355 & .514 \\
\hline miserable/distressed (ES) & & 244 & & .221 & .575 \\
\hline
\end{tabular}




\section{Appendix 3.B Rutter, Self-esteem, and Locus of con- trol}

In Section 3.3.2 we apply a number of other personality measures to control for early sociability. These measures include Rutter scores at various ages, indicative of behavioral problems, and measures for self-esteem and locus of control, measuring respondents' sense of self-worth and believe in the importance of trying hard.

At ages 5, 10, and 16, the respondents' parents, usually the mother, are asked to indicate to what extent a certain description applies to the respondent. At ages 5 and 16, the items are scaled 0 "does not apply" 1 "applies somewhat" 2 "certainly applies." The age-10 items are scaled 1 through 100, where 1 indicates "does not apply" and 100 indicates "certainly applies." Higher scores indicate more severe behavioral problems.

Table 3.B.1 shows the inter-item correlations or covariances for the 19 items, and the Cronbach's alpha statistic for the scale formed from them. The three Rutter scores, at ages 5, 10 , and 16, are constructed by summing the scores on the 19 mother-rated items, and then standardizing the resulting score to have mean zero and standard deviation one.

Self-esteem assesses respondents' self-esteem with reference to teachers, peers and parents and consists of 12 items, while locus of control measures children's perceived achievement control with a list of 15 items. Items are scaled 0 "yes" 1 "don't know" 2 "no," except the first self-esteem item "Parent like to hear about ideas" and the locus of control item "Believe in planning ahead," which are reversely coded. Higher scores thus indicate higher self-esteem and higher internal locus of control. Table 3.B.2 shows the inter-item correlations or covariances for these sets of items, and the Cronbach's alpha statistic for the scale formed from them, both for ages 10 and 16. The self-esteem and locus of control scores are constructed by summing the scores on the set of $12 / 15$ items, and then standardizing the resulting score to have mean zero and standard deviation one.

Similar to the imputation applied for personality items, for each item $i$ within each set of Rutter/self-esteem/locus of control items, we estimate the following model to predict missing values:

$$
\text { Item }_{i}=\alpha_{i}+\sum_{j \neq i} \beta_{j} \text { Item }_{j}+\epsilon_{i}
$$

This process starts with the item with least amount of missing observations. Missing observations are then imputed, and the process continues to the item with next fewest missing observations. For the age-10 Rutter score we apply the above model using linear regression, since the items are scaled from 1 through 100. Imputed values below 1 are set to 1 , and those above 100 are set to 100 . For the age- 5 and age-16 Rutter scores, and the age-10 and age-16 self-esteem and locus of control scores, we use multinomial logit regression to impute missing values. 
Table 3.B.1: Inter-item Correlations and Covariances of Rutter Items

\begin{tabular}{|c|c|c|c|c|c|c|c|c|c|c|c|c|}
\hline & \multicolumn{4}{|c|}{ Age $5(n=12,965)$} & \multicolumn{4}{|c|}{ Age $10(n=13,337)$} & \multicolumn{4}{|c|}{ Age $16(n=8,609)$} \\
\hline & 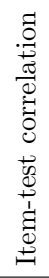 & 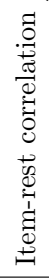 & 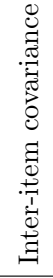 & $\frac{\widetilde{\pi}}{\frac{\pi}{4}}$ & 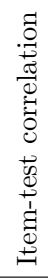 & 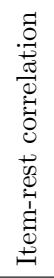 & 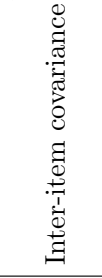 & $\frac{\pi}{\frac{\pi}{2}}$ & 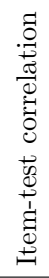 & 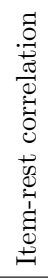 & 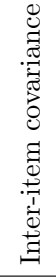 & $\frac{\frac{\pi}{2}}{\frac{\pi}{4}}$ \\
\hline Rutter & & & .04 & .73 & & & 106.61 & .80 & & & .04 & .79 \\
\hline restless & .54 & .41 & .04 & .71 & .51 & .39 & 102.64 & .79 & .49 & .39 & .04 & .78 \\
\hline squirmy/fidgety & .54 & .42 & .04 & .71 & .56 & .46 & 101.40 & .78 & .51 & .43 & .04 & .78 \\
\hline destroys belongings & .49 & .39 & .04 & .71 & .51 & .46 & 109.11 & .79 & .46 & .41 & .04 & .78 \\
\hline fights with others & .49 & .39 & .04 & .71 & .53 & .45 & 106.26 & .78 & .53 & .46 & .04 & .78 \\
\hline not much liked by others & .31 & .25 & .05 & .72 & .45 & .38 & 109.51 & .79 & .42 & .36 & .04 & .78 \\
\hline worried & .38 & .26 & .04 & .72 & .49 & .38 & 103.85 & .79 & .52 & .41 & .04 & .78 \\
\hline solitary, does things on own & .36 & .22 & .04 & .73 & .40 & .28 & 108.06 & .79 & .46 & .33 & .04 & .79 \\
\hline irritable & .57 & .45 & .04 & .70 & .59 & .49 & 99.57 & .78 & .62 & .52 & .04 & .77 \\
\hline miserable, tearful, distressed & .46 & .37 & .04 & .71 & .55 & .48 & 106.11 & .78 & .56 & .49 & .04 & .78 \\
\hline takes things belonging to others & .41 & .32 & .04 & .72 & .49 & .43 & 109.76 & .79 & .50 & .44 & .04 & .78 \\
\hline has twitches/mannerisms & .20 & .15 & .05 & .73 & .37 & .30 & 112.55 & .79 & .28 & .23 & .04 & .79 \\
\hline sucks thumb or fingers & .19 & .02 & .05 & .75 & .26 & .14 & 113.98 & .80 & .25 & .16 & .04 & .79 \\
\hline bites nails or fingers & .30 & .15 & .05 & .73 & .37 & .23 & 108.68 & .80 & .40 & .25 & .04 & .80 \\
\hline disobedient & .58 & .49 & .04 & .70 & .60 & .52 & 101.15 & .78 & .63 & .55 & .04 & .77 \\
\hline cannot settle & .54 & .44 & .04 & .71 & .56 & .47 & 102.44 & .78 & .59 & .51 & .04 & .77 \\
\hline afraid of new things/situations & .33 & .20 & .04 & .73 & .42 & .31 & 107.56 & .79 & .46 & .35 & .04 & .78 \\
\hline fussy or over-particular & .36 & .22 & .04 & .73 & .40 & .28 & 108.43 & .79 & .42 & .29 & .04 & .79 \\
\hline tells lies & .48 & .39 & .04 & .71 & .56 & .49 & 105.29 & .78 & .57 & .50 & .04 & .78 \\
\hline bullies others & .45 & .37 & .04 & .72 & .52 & .47 & 109.20 & .79 & .48 & .42 & .04 & .78 \\
\hline
\end{tabular}

Note: Sample includes all respondents with valid information on the individual items, as well as imputed values for respondents with 1 or 2 missing values in the set of 19 rutter items. Values are imputed using multiple imputation through chained equations using the remaining items as regressors. Age 5 and 16 items are scaled 0 "does not apply" 1 "applies somewhat" 2 "certainly applies." Age 10 items are scaled 1 through 100, where 1 indicates "does not apply" and 100 indicates "certainly applies." Higher scores thus indicate more severe behavioral problems. 
Table 3.B.2: Inter-item Correlations and Covariances of Self-esteem and Locus of Control Items

\begin{tabular}{|c|c|c|c|c|c|c|c|c|}
\hline & \multicolumn{4}{|c|}{$\begin{array}{l}\text { Age } 10(n=12,624 \\
\text { for self-esteem and } \\
12,560 \text { for locus of } \\
\text { control })\end{array}$} & \multicolumn{4}{|c|}{$\begin{array}{l}\text { Age } 16 \quad(n=4,439 \\
\text { for self-esteem and } \\
5,479 \text { for locus } \\
\text { control })\end{array}$} \\
\hline & 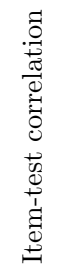 & 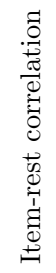 & 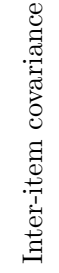 & $\frac{\text { 疋}}{\frac{2}{2}}$ & 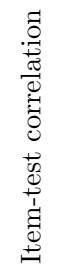 & 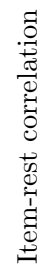 & 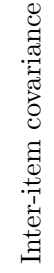 & $\frac{\frac{\pi}{\pi}}{\frac{Z}{4}}$ \\
\hline Self-esteem & & & .10 & .69 & & & .09 & .70 \\
\hline 1. Parents like to hear about ideas & .26 & .12 & .11 & .69 & .38 & .23 & .09 & .70 \\
\hline 2. Feel lonely at school & .47 & .35 & .10 & .67 & .52 & .42 & .09 & .68 \\
\hline 3. Others fall out with you & .59 & .42 & .09 & .65 & .49 & .37 & .09 & .68 \\
\hline 4. Others say nasty things about you & .55 & .40 & .09 & .65 & .57 & .43 & .08 & .67 \\
\hline 5. Feel shy in front of teachers & .45 & .27 & .10 & .68 & .59 & .42 & .08 & .67 \\
\hline 6. Feel sad because nobody to play/talk with & .55 & .40 & .09 & .65 & .48 & .32 & .09 & .69 \\
\hline 7. Like to change lots of things about self & .49 & .31 & .10 & .67 & .48 & .30 & .09 & .69 \\
\hline 8. Feel foolish talking to peers & .47 & .31 & .10 & .67 & .52 & .32 & .08 & .69 \\
\hline 9. Feel foolish talking to teacher & .44 & .31 & .10 & .67 & .58 & .44 & .08 & .67 \\
\hline 10. Often have to find new friends & .56 & .39 & .09 & .66 & .53 & .33 & .09 & .69 \\
\hline 11. Feel foolish talking to parents & .28 & .20 & .11 & .68 & .33 & .23 & .10 & .70 \\
\hline 12. Others think you tell lies & .52 & .39 & .10 & .66 & .43 & .29 & .09 & .69 \\
\hline Locus of control & & & .06 & .63 & & & .08 & .71 \\
\hline 1. Not worth trying hard & .48 & .35 & .06 & .60 & .53 & .42 & .08 & .68 \\
\hline 2. Wishing makes good things happen & .29 & .12 & .07 & .63 & .30 & .15 & .09 & .71 \\
\hline 3. People good to you no matter what & .18 & .02 & .07 & .65 & .29 & .14 & .09 & .71 \\
\hline 4. Useless to try in school, others cleverer & .50 & .39 & .06 & .59 & .52 & .43 & .08 & .68 \\
\hline 5. High mark just a matter of luck & .57 & .42 & .05 & .58 & 61 & .50 & .07 & .67 \\
\hline 6. Tests just a lot of guess work & .47 & .34 & .06 & .60 & .58 & .48 & .07 & .67 \\
\hline 7. Blamed for things not your fault & .43 & .25 & .06 & .61 & .45 & .28 & .08 & .70 \\
\hline 8. Believe in planning ahead & .19 & .01 & .07 & .65 & .36 & .20 & .08 & .71 \\
\hline 9. Bad things someone else's fault & .38 & .22 & .06 & .62 & .39 & .25 & .08 & .70 \\
\hline 10. Someone angry, impossible to make friend again & .40 & .23 & .06 & .62 & .32 & .19 & .09 & .71 \\
\hline 11. Nice things only good luck & .55 & .40 & .06 & .59 & .50 & .38 & .08 & .68 \\
\hline 12. Arguments other person's fault & .26 & .11 & .07 & .63 & .29 & .15 & .09 & .71 \\
\hline 13. Surprised when teacher says done well & .47 & .32 & .06 & .60 & .51 & .36 & .08 & .69 \\
\hline 14. Low marks even when study hard & .54 & .41 & .06 & .59 & .59 & .47 & .07 & .67 \\
\hline 15. Studying for tests is waste of time & .32 & .22 & .07 & .62 & .48 & .37 & .08 & .69 \\
\hline
\end{tabular}

Note: Sample includes all individuals with valid information on the individual items, as well as imputed values for individuals with 1 or 2 missing values in the set of self-esteem or locus of control items. Values are imputed using multiple imputation through chained equations using the remaining items as regressors. Items are scaled 0 "yes" 1 "don't know" 2 "no," except the first self-esteem item "Parents like to hear about ideas" and locus of control item "Believe in planning ahead," which are reversely coded. Higher scores thus indicate higher self-esteem and higher internal locus of control. 



\title{
Appendix 3.C Supporting Tables
}

\author{
Table 3.C.1: Description of Variables
}

\begin{tabular}{|c|c|}
\hline Variable & Description \\
\hline \multicolumn{2}{|l|}{ Socio-economic Outcomes } \\
\hline Gross hourly wage (34) & $\begin{array}{l}\text { Gross pay per week divided by usual hours worked per week. Gross pay } \\
\text { per week constructed using reported gross pay and reporting period } \\
\text { (one week, two weeks, four weeks, one calendar month, one year). } \\
\text { Respondent excluded if reported weekly hours is below } 5 \text { or exceeds } 80 \text {, } \\
\text { and if pay per week is below } 32.5 \text { pounds }(1 \%) \text { or above } 3073 \text { pounds } \\
(1 \%) \text {. }\end{array}$ \\
\hline Log gross hourly wage (34) & Log of Gross hourly wage (34) \\
\hline Save & $\begin{array}{l}\text { "Do you save any amount of your income?" Dummy variable. } 0 \text { "No" } 1 \\
\text { "Yes." }\end{array}$ \\
\hline BMI (Body Mass Index) & Standard Body Mass Index (Weight in kilos/(Length in meters $\left.{ }^{2}\right)$ ). \\
\hline Alcoholic (CAGE $\geq 2$ ) & $\begin{array}{l}\text { Dummy variable equal to one if respondent answered yes to two, three } \\
\text { or all four questions from the CAGE (Cutting down, Annoyance by } \\
\text { criticism, Guilty feeling and Eye-openers) questionnaire. Equal to zero } \\
\text { is answered zero or one of the questions with yes. It indicates potential } \\
\text { alcohol dependence or abuse. }\end{array}$ \\
\hline Smoke & $\begin{array}{l}\text { Dummy variable equal to one if respondent smokes (from occasionally } \\
\text { to more than } 20 \text { cigarettes daily). Equal to zero if respondent has never } \\
\text { smoked or is an ex-smoker. }\end{array}$ \\
\hline (Use) Cannabis & $\begin{array}{l}\text { Dummy variable equal to one if respondent uses cannabis (from } \\
\text { occasionally to on most days). Equal to zero if respondent never tried } \\
\text { cannabis or never uses cannabis nowadays. }\end{array}$ \\
\hline (Ever) Arrested & $\begin{array}{l}\text { "Have you been arrested by a police officer and taken to a police } \\
\text { station? (Type in number of times)" Dummy variable. } 0 \text { "0" } 1 \text { "1-9." }\end{array}$ \\
\hline Satisfaction (with life (0-10)) & $\begin{array}{l}\text { "How satisfied or dissatisfied are you with the way life has turned out } \\
\text { so far?" Scaled } 0 \text { through 10. } 0 \text { "Completely dissatisfied" to } 10 \\
\text { "Completely satisfied." }\end{array}$ \\
\hline $\begin{array}{l}\text { Life Get (I get what I want } \\
\text { out of life) }\end{array}$ & $\begin{array}{l}\text { Dummy variable. "Which of these two statements is more true for } \\
\text { you?" } 0 \text { "I never really seem to get what I want out of life." } 1 \text { "I } \\
\text { usually get what I want out of life." }\end{array}$ \\
\hline $\begin{array}{l}\text { Life Run (I can run life as I } \\
\text { want) }\end{array}$ & $\begin{array}{l}\text { Dummy variable. "Which of these two statements is more true for } \\
\text { you?" } 0 \text { "I usually find life's problems just too much for me." } 1 \\
\text { "Usually I can run my life more or less as I want to." }\end{array}$ \\
\hline \multicolumn{2}{|l|}{ Personality } \\
\hline Conscientiousness (10) & $\begin{array}{l}\text { Standardized Principal Component of } 4 \text { age- } 10 \text { items related to } \\
\text { Conscientiousness. See Table } 3.1 \text { and Appendix 3.A for details. }\end{array}$ \\
\hline Extraversion (10) & $\begin{array}{l}\text { Standardized Principal Component of } 5 \text { age- } 10 \text { items related to } \\
\text { Extraversion. See Table } 3.1 \text { and Appendix } 3 . \text { A for details. }\end{array}$ \\
\hline Agreeableness (10) & $\begin{array}{l}\text { Standardized Principal Component of } 7 \text { age-10 items related to } \\
\text { Agreeableness. See Table } 3.1 \text { and Appendix 3.A for details. }\end{array}$ \\
\hline Emotional Stability (10) & $\begin{array}{l}\text { Standardized Principal Component of } 6 \text { age- } 10 \text { items related to } \\
\text { Emotional Stability. See Table } 3.1 \text { and Appendix 3.A for details. }\end{array}$ \\
\hline Conscientiousness (16) & $\begin{array}{l}\text { Standardized Principal Component of } 4 \text { age- } 16 \text { items related to } \\
\text { Conscientiousness. See Table } 3.1 \text { and Appendix } 3 . \text { A for details. }\end{array}$ \\
\hline Extraversion (16) & $\begin{array}{l}\text { Standardized Principal Component of } 5 \text { age- } 16 \text { items related to } \\
\text { Extraversion. See Table } 3.1 \text { and Appendix } 3 . \text { A for details. }\end{array}$ \\
\hline Agreeableness (16) & $\begin{array}{l}\text { Standardized Principal Component of } 7 \text { age- } 16 \text { items related to } \\
\text { Agreeableness. See Table } 3.1 \text { and Appendix 3.A for details. }\end{array}$ \\
\hline Emotional Stability (16) & $\begin{array}{l}\text { Standardized Principal Component of } 6 \text { age- } 16 \text { items related to } \\
\text { Emotional Stability. See Table } 3.1 \text { and Appendix 3.A for details. }\end{array}$ \\
\hline
\end{tabular}


Table 3.C.1: (continued)

\begin{tabular}{|c|c|}
\hline Variable & Description \\
\hline \multicolumn{2}{|l|}{ Home Environment } \\
\hline No dad at birth & $\begin{array}{l}\text { Dummy variable equal to one if father absent in household at birth of } \\
\text { respondent, zero if father present. }\end{array}$ \\
\hline Mom teenage mother & $\begin{array}{l}\text { Dummy variable equal to one if mother's age at first birth was below } \\
20, \text { and zero if age at first birth was } 20 \text { or higher. }\end{array}$ \\
\hline Yrs of schooling mom & Age mother left full-time education minus six \\
\hline Yrs of schooling dad & Age father left full-time education minus six \\
\hline Parent skilled/prof. (0) & $\begin{array}{l}\text { Social class at birth: fathers occupation (or mothers if missing). } \\
\text { Dummy variable. } 0 \text { if student, unskilled, or partly skilled. } 1 \text { if skilled } \\
\text { (non-)manual, managerial/technical, or professional. }\end{array}$ \\
\hline Liberal worldview (5) & $\begin{array}{l}\text { Principal component of } 5 \text { mother-rated items at age } 5 . \text { Higher score } \\
\text { indicates more liberal views. }\end{array}$ \\
\hline Child to be left free (5) & $\begin{array}{l}\text { Principal component of } 13 \text { mother-rated items at age } 5 . \text { Higher score } \\
\text { indicates disagreement with authoritarian child-rearing. }\end{array}$ \\
\hline Child to be controlled (5) & $\begin{array}{l}\text { Principal component of } 7 \text { mother-rated items at age } 5 \text {. Higher score } \\
\text { indicates disagreement with the opinion that children should be } \\
\text { allowed to be themselves. }\end{array}$ \\
\hline Strong family ties (10) & $\begin{array}{l}\text { Average score on } 7 \text { family activities (go for walks, outings, holidays, go } \\
\text { shopping, go to restaurants, have meals, have talks together), each } \\
\text { scaled } 1 \text { "rarely/never" } 2 \text { "sometimes" } 3 \text { "often" (Cronbach's alpha } \\
0.66 \text { ) }\end{array}$ \\
\hline $\begin{array}{l}\text { Don't get on with parents } \\
\text { (16) }\end{array}$ & $\begin{array}{l}\text { Average score on } 11 \text { self-rated items about how parents treat } \\
\text { respondent (overprotective, treat me like a child, don't understand me, } \\
\text { are strict/bossy), each scaled } 0 \text { "no" } 1 \text { "yes" (Cronbach's alpha 0.73) }\end{array}$ \\
\hline $\begin{array}{l}\text { Parents are free, not strict } \\
(16)\end{array}$ & $\begin{array}{l}\text { "Some parents are very strict, and others give lots of freedom. What } \\
\text { about yours?" Scaled } 1 \text { "very strict" through } 7 \text { "very free." }\end{array}$ \\
\hline \multicolumn{2}{|l|}{ Educational Achievement } \\
\hline Cognitive Ability & $\begin{array}{l}\text { We construct a measure using test scores at age } 10 \text { because cognitive } \\
\text { ability seems to be set at that age (e.g., Lebel and Beaulieu, 2011). } \\
\text { Cognitive ability is measured by extracting the first principal } \\
\text { component from a set of } 8 \text { standardized test scores, all measured at the } \\
\text { age of } 10 \text {. The resulting score is standardized to have zero mean and a } \\
\text { standard deviation of one. The test scores include the four British } \\
\text { Ability Scales (word definitions, recall of digits, similarities, matrices), } \\
\text { as well as the Shortened Edinburgh Reading Test, the CHES Pictorial } \\
\text { Language Comprehension and Friendly Maths tests, and a spelling test. } \\
\text { Cronbach's alpha on the set of test scores is } 0.89 \text { and the explained } \\
\text { variance of the resulting principal component is } 58 \text { percent. }\end{array}$ \\
\hline Years of schooling (34) & Age left full-time education minus six \\
\hline Skilled/prof. (34) & $\begin{array}{l}\text { Social class at age } 34 \text {, from occupation. Dummy variable. } 0 \text { if } \\
\text { unskilled, or partly skilled. } 1 \text { if skilled (non-)manual, } \\
\text { managerial/technical, or professional. }\end{array}$ \\
\hline \multicolumn{2}{|l|}{ Sociability } \\
\hline Rutter score (5) & $\begin{array}{l}\text { Standardized sum of scores on } 19 \text { mother-rated age- } 5 \text { items on behavior } \\
\text { problems (mean } 0 \text {, st.dev. 1). Missing values are imputed for } \\
\text { respondents with } 1 \text { or } 2 \text { missings out of } 19 \text { items. See Appendix 3.B for } \\
\text { details on items. }\end{array}$ \\
\hline Rutter score (10) & $\begin{array}{l}\text { Standardized sum of scores on } 19 \text { mother-rated age- } 10 \text { items on } \\
\text { behavior problems (mean } 0 \text {, st.dev. 1). Missing values are imputed for } \\
\text { respondents with } 1 \text { or } 2 \text { missings out of } 19 \text { items. See Appendix 3.B for } \\
\text { details on items. }\end{array}$ \\
\hline
\end{tabular}


Table 3.C.1: (continued)

\begin{tabular}{l|l}
\hline \hline Variable & Description \\
\hline Rutter score (16) & $\begin{array}{l}\text { Standardized sum of scores on 19 mother-rated age-16 items on } \\
\text { behavior problems (mean 0, st.dev. 1). Missing values are imputed for } \\
\text { respondents with } 1 \text { or } 2 \text { missings out of } 19 \text { items. See Appendix 3.B for } \\
\text { details on items. }\end{array}$ \\
\hline Self-esteem (10) & $\begin{array}{l}\text { Standardized sum of scores on 12 self-rated age 10 self-esteem items } \\
\text { (mean 0, st.dev. 1). Missing values are imputed for respondents with 1 } \\
\text { or } 2 \text { missings out of } 12 \text { items. See Appendix 3.B for details on items. }\end{array}$ \\
\hline Locus of control (10) & $\begin{array}{l}\text { Standardized sum of scores on 15 self-rated age 10 locus of control } \\
\text { items (mean 0, st.dev. 1). Missing values are imputed for respondents } \\
\text { with } 1 \text { or } 2 \text { missings out of } 15 \text { items. See Appendix 3.B for details on } \\
\text { items. }\end{array}$ \\
\hline Sports in school & $\begin{array}{l}\text { "During the past year, which of the following sports did you play when } \\
\text { they were in season?" Count of sports indicated to have played in } \\
\text { school in the past year }\end{array}$ \\
\hline Sports outside school & $\begin{array}{l}\text { "During the past year, which of the following sports did you play when } \\
\text { they were in season?" Count of sports indicated to have played out of } \\
\text { school in the past year }\end{array}$ \\
\hline No. friends in school & $\begin{array}{l}\text { "How many other close friends have you got at your school or outside?" } \\
\text { Ranging from 0 "0" to } 9 \text { "9 or more." }\end{array}$ \\
\hline No. friends outside school & $\begin{array}{l}\text { "How many other close friends have you got at your school or outside?" } \\
\text { Ranging from 0 "0" to } 9 \text { "9 or more." }\end{array}$ \\
\hline
\end{tabular}

\begin{tabular}{l|l}
\hline \multicolumn{2}{l}{ Occupational Sorting } \\
\hline $\begin{array}{l}\text { Avg Occ. Conscientiousness } \\
(16)\end{array}$ & $\begin{array}{l}\text { Average score on age } 16 \text { conscientiousness, by age 34 occupation. See } \\
\text { Table 3.C.5 for list of occupations and averages. }\end{array}$ \\
\hline Avg Occ. Extraversion (16) & $\begin{array}{l}\text { Average score on age } 16 \text { extraversion, by age 34 occupation. See Table } \\
\text { 3.C.5 for list of occupations and averages. }\end{array}$ \\
\hline Avg Occ. Agreeableness (16) & $\begin{array}{l}\text { Average score on age } 16 \text { agreeableness, by age 34 occupation. See Table } \\
\text { 3.C.5 for list of occupations and averages. }\end{array}$ \\
\hline $\begin{array}{l}\text { Avg Occ. Emotional Stability } \\
(16)\end{array}$ & $\begin{array}{l}\text { Average score on age } 16 \text { emotional stability, by age 34 occupation. See } \\
\text { Table 3.C.5 for list of occupations and averages. }\end{array}$ \\
\hline $\begin{array}{l}\text { Above Avg Occ. } \\
\text { Conscientiousness (16) }\end{array}$ & $\begin{array}{l}\text { Dummy equal to } 1 \text { if respondents age-16 conscientiousness is larger } \\
\text { than the average age-16 conscientiousness of men in the same age 34 } \\
\text { occupation. }\end{array}$ \\
\hline $\begin{array}{l}\text { Above Avg Occ. Extraversion } \\
\text { (16) }\end{array}$ & $\begin{array}{l}\text { Dummy equal to } 1 \text { if respondents age-16 extraversion is larger than the } \\
\text { average age-16 extraversion of men in the same age 34 occupation. }\end{array}$ \\
\hline Above Avg Occ. & $\begin{array}{l}\text { Dummy equal to } 1 \text { if respondents age-16 agreeableness is larger than } \\
\text { the average age-16 agreeableness of men in the same age 34 occupation. }\end{array}$ \\
\hline $\begin{array}{l}\text { Agreeableness (16) Avg Occ. Emotional } \\
\text { Stability (16) }\end{array}$ & $\begin{array}{l}\text { Dummy equal to } 1 \text { if respondents age-16 emotional stability is larger } \\
\text { than the average age-16 emotional stability of men in the same age 34 } \\
\text { occupation. }\end{array}$ \\
\hline \hline
\end{tabular}


Table 3.C.2: Descriptive Statistics (Working Sample and Unrestricted Sample)

\begin{tabular}{|c|c|c|c|c|c|c|c|c|c|}
\hline & \multicolumn{6}{|c|}{ Working Sample } & \multicolumn{3}{|c|}{ Unrestricted Sample } \\
\hline & $\min$ & $\max$ & count & mean & sd & median & count & mean & sd \\
\hline \multicolumn{10}{|l|}{$\begin{array}{l}\text { Socio-economic } \\
\text { outcomes }\end{array}$} \\
\hline Log gross hourly wage (34) & -0.59 & 4.72 & 2,934 & 2.41 & 0.54 & 2.41 & 6,106 & 2.40 & 0.54 \\
\hline Gross hourly wage (34) & 0.55 & 112.18 & 2,934 & 12.95 & 8.23 & 11.17 & 6,106 & 12.83 & 8.14 \\
\hline Save & 0.00 & 1.00 & 2,933 & 0.70 & 0.46 & 1.00 & 9,630 & $0.62^{*}$ & 0.49 \\
\hline BMI (Body Mass Index) & 9.58 & 66.56 & 2,864 & 25.92 & 4.76 & 25.17 & 9,355 & 25.89 & 4.93 \\
\hline Smoke & 0.00 & 1.00 & 2,933 & 0.26 & 0.44 & 0.00 & 9,634 & $0.31^{*}$ & 0.46 \\
\hline Alcoholic (CAGE $\geq 2)$ & 0.00 & 1.00 & 2,902 & 0.18 & 0.39 & 0.00 & 9,386 & 0.18 & 0.39 \\
\hline (Use) Cannabis & 0.00 & 1.00 & 2,932 & 0.15 & 0.35 & 0.00 & 9,598 & $0.16^{*}$ & 0.37 \\
\hline (Ever) Arrested & 0.00 & 1.00 & 2,932 & 0.14 & 0.35 & 0.00 & 10,182 & $0.21^{*}$ & 0.41 \\
\hline Satisfaction (with life $(0-10)$ ) & 0.00 & 10.00 & 2,932 & 7.50 & 1.61 & 8.00 & 9,594 & $7.4^{*}$ & 1.80 \\
\hline $\begin{array}{l}\text { Life Get (I get what I want } \\
\text { out of life) }\end{array}$ & 0.00 & 1.00 & 2,932 & 0.84 & 0.36 & 1.00 & 9,577 & $0.82^{*}$ & 0.38 \\
\hline $\begin{array}{l}\text { Life Run (I can run life as I } \\
\text { want) }\end{array}$ & 0.00 & 1.00 & 2,932 & 0.97 & 0.18 & 1.00 & 9,587 & $0.95^{*}$ & 0.22 \\
\hline \multicolumn{10}{|l|}{ Personality } \\
\hline Conscientiousness (10) & -3.08 & 1.21 & 2,796 & 0.12 & 0.92 & 0.42 & 13,392 & $0^{*}$ & 1.00 \\
\hline Extraversion (10) & -4.25 & 1.60 & 2,786 & 0.04 & 0.98 & 0.25 & 13,353 & $0^{*}$ & 1.00 \\
\hline Agreeableness (10) & -5.23 & 1.32 & 2,787 & 0.14 & 0.83 & 0.23 & 13,337 & $0^{*}$ & 1.00 \\
\hline Emotional Stability (10) & -3.70 & 1.33 & 2,790 & 0.13 & 0.90 & 0.36 & 13,352 & $0^{*}$ & 1.00 \\
\hline Conscientiousness (16) & -4.54 & 0.73 & 2,934 & 0.12 & 0.89 & 0.34 & 8,634 & $0^{*}$ & 1.00 \\
\hline Extraversion (16) & -5.31 & 0.99 & 2,934 & 0.06 & 0.94 & 0.32 & 8,613 & $0^{*}$ & 1.00 \\
\hline Agreeableness (16) & -6.63 & 0.54 & 2,934 & 0.13 & 0.78 & 0.54 & 8,600 & $0^{*}$ & 1.00 \\
\hline Emotional Stability (16) & -4.38 & 0.87 & 2,934 & 0.10 & 0.90 & 0.33 & 8,607 & $0^{*}$ & 1.00 \\
\hline \multicolumn{10}{|l|}{ Home Environment } \\
\hline No dad at birth & 0.00 & 1.00 & 2,932 & 0.02 & 0.15 & 0.00 & 17,099 & $0.05^{*}$ & 0.21 \\
\hline Mom teenmother & 0.00 & 1.00 & 2,919 & 0.15 & 0.36 & 0.00 & 17,078 & $0.2^{*}$ & 0.40 \\
\hline Yrs of schooling mom & 0.00 & 21.00 & 2,917 & 9.84 & 1.76 & 9.00 & 17,049 & $9.66^{*}$ & 1.83 \\
\hline Yrs of schooling dad & 0.00 & 32.00 & 2,845 & 10.08 & 2.36 & 9.00 & 16,213 & $9.92^{*}$ & 2.35 \\
\hline Parent skilled/prof. (0) & 0.00 & 1.00 & 2,934 & 0.82 & 0.39 & 1.00 & 17,175 & $0.76^{*}$ & 0.43 \\
\hline Liberal worldview (5) & -2.30 & 2.41 & 2,662 & 0.11 & 1.01 & 0.10 & 12,978 & $0^{*}$ & 1.00 \\
\hline Child to be left free $(5)$ & -2.60 & 2.83 & 2,664 & 0.12 & 0.94 & 0.10 & 12,990 & $0^{*}$ & 1.00 \\
\hline Child to be controlled (5) & -2.15 & 3.41 & 2,664 & 1.03 & 0.97 & 1.05 & 12,988 & 1.00 & 1.00 \\
\hline Strong family ties (10) & 1.00 & 3.00 & 2,816 & 2.51 & 0.30 & 2.57 & 13,627 & $2.47^{*}$ & 0.32 \\
\hline $\begin{array}{l}\text { Don't get on with } \\
\text { parents(16) }\end{array}$ & -0.45 & 0.55 & 1,866 & -0.23 & 0.21 & -0.27 & 6,349 & $-0.21^{*}$ & 0.21 \\
\hline $\begin{array}{l}\text { Parents are free, not } \\
\text { strict(16) }\end{array}$ & 1.00 & 7.00 & 1,856 & 4.53 & 1.18 & 5.00 & 6,268 & 4.56 & 1.26 \\
\hline \multicolumn{10}{|l|}{ Education } \\
\hline Cognitive ability & -2.97 & 2.86 & 2,934 & 0.28 & 0.91 & 0.33 & 11,116 & $0^{*}$ & 1.00 \\
\hline Years of schooling (34) & 8.00 & 28.00 & 2,933 & 12.86 & 3.81 & 11.00 & 9,632 & $12.67^{*}$ & 3.91 \\
\hline Skilled/prof. (34) & 0.00 & 1.00 & 2,933 & 0.59 & 0.49 & 1.00 & 9,632 & $0.54^{*}$ & 0.50 \\
\hline \multicolumn{10}{|l|}{ Sociability } \\
\hline Rutter score (5) & -1.69 & 4.80 & 2,662 & -0.10 & 0.94 & -0.18 & 12,965 & $0^{*}$ & 1.00 \\
\hline Rutter score (10) & -2.02 & 3.81 & 2,784 & -0.13 & 0.92 & -0.19 & 13,337 & $0^{*}$ & 1.00 \\
\hline Rutter score (16) & -1.08 & 7.95 & 2,930 & -0.12 & 0.86 & -0.37 & 8,609 & $0^{*}$ & 1.00 \\
\hline Self-esteem (10) & 2.00 & 24.00 & 2,909 & 16.78 & 4.45 & 17.00 & 12,624 & $16.39^{*}$ & 4.54 \\
\hline Locus of control (10) & 2.00 & 30.00 & 2,899 & 18.53 & 4.64 & 19.00 & 12,560 & $17.85^{*}$ & 4.75 \\
\hline Sports in school & 0.00 & 57.00 & 1,496 & 9.34 & 8.20 & 8.00 & 5,265 & 9.20 & 8.30 \\
\hline Sports outside school & 0.00 & 60.00 & 1,496 & 8.88 & 7.76 & 7.00 & 5,265 & 8.91 & 8.11 \\
\hline
\end{tabular}


Table 3.C.2: (continued)

\begin{tabular}{l|cccccc|ccc}
\hline \hline & \multicolumn{7}{|c|}{ Working Sample } & \multicolumn{3}{c}{ Unrestricted Sample } \\
& min & max & count & mean & sd & median & count & mean & sd \\
\hline No. friends in school & 0.00 & 9.00 & 1,827 & 5.68 & 2.85 & 5.00 & 6,093 & 5.61 & 2.90 \\
No. friends outside school & 0.00 & 9.00 & 1,792 & 4.83 & 3.21 & 4.00 & 5,967 & 4.90 & 3.19 \\
& & & & & & & & & \\
Occupational Sorting & & & & & & & & & \\
Avg Occ.Conscient.(16) & -0.30 & 0.53 & 2,929 & 0.09 & 0.21 & 0.12 & 7,989 & $0.07^{*}$ & 0.21 \\
Avg Occ.Extrav.(16) & -0.27 & 0.38 & 2,929 & 0.05 & 0.10 & 0.05 & 7,989 & 0.05 & 0.11 \\
Avg Occ.Agreeabl.(16) & -0.35 & 0.43 & 2,929 & 0.10 & 0.14 & 0.13 & 7,989 & $0.09^{*}$ & 0.15 \\
Avg Occ.Emot.Stab.(16) & -0.15 & 0.40 & 2,929 & 0.09 & 0.12 & 0.12 & 7,989 & 0.09 & 0.12 \\
Above Avg Occ. C (16) & 0.00 & 1.00 & 2,929 & 0.69 & 0.46 & 1.00 & 5,011 & 0.67 & 0.47 \\
Above Avg Occ. E (16) & 0.00 & 1.00 & 2,929 & 0.57 & 0.50 & 1.00 & 4,993 & 0.57 & 0.50 \\
Above Avg Occ. A (16) & 0.00 & 1.00 & 2,929 & 0.72 & 0.45 & 1.00 & 4,991 & 0.70 & 0.46 \\
Above Avg Occ. ES (16) & 0.00 & 1.00 & 2,929 & 0.62 & 0.49 & 1.00 & 4,994 & 0.61 & 0.49 \\
\hline \hline
\end{tabular}

Note: Unrestricted sample gives count, mean, and standard deviation of each variable of interest. So the complete set of individuals for which that single variable is measured. The same information is stated for the working sample (as well as minimum and maximum). The working sample only contains the 2,934 individuals with valid data on age 34 gross hourly wages, age-10 cognitive ability, age-16 personality (conscientiousness, extraversion, agreeableness, and emotional stability), and region of birth. ${ }^{*}$ Indicates unrestricted mean is significantly different from working mean at the 10 percent level (2-sided t-test). 
Table 3.C.3: Means for Individuals Below and Above Average Wages and Personality

\begin{tabular}{|c|c|c|c|c|c|c|c|c|c|c|}
\hline & $\begin{array}{l}\text { Gross } \\
\text { hourly } \\
\leq \text { avg. }\end{array}$ & $\begin{array}{l}\text { wage } \\
>\text { avg. }\end{array}$ & $\begin{array}{l}\text { Consc } \\
\text { tiousr } \\
\leq \text { avg. }\end{array}$ & $\begin{array}{l}\text { ien- } \\
\text { ess } \\
>\text { avg. }\end{array}$ & $\begin{array}{l}\text { Extra } \\
\text { versio } \\
\leq \text { avg. }\end{array}$ & n & $\begin{array}{l}\text { Agree } \\
\text { ablen } \\
\leq \text { avg. }\end{array}$ & $\begin{array}{l}\text { ess } \\
>\text { avg. }\end{array}$ & $\begin{array}{l}\text { Emot } \\
\text { Stabi } \\
\leq \text { avg. }\end{array}$ & $\begin{array}{l}\text { ional } \\
\text { ity } \\
>\text { avg. }\end{array}$ \\
\hline $\begin{array}{l}\text { Socio-economic } \\
\text { outcomes }\end{array}$ & & & & & & & & & & \\
\hline Log gross hourly wage (34) & 2.09 & $2.93^{*}$ & 2.32 & $2.46^{*}$ & 2.38 & $2.44^{*}$ & 2.32 & $2.46^{*}$ & 2.35 & $2.45^{*}$ \\
\hline Gross hourly wage (34) & 8.55 & $19.93^{*}$ & 11.56 & $13.61^{*}$ & 12.56 & $13.28^{*}$ & 11.69 & $13.56^{*}$ & 12.22 & $13.39^{*}$ \\
\hline Save & 0.64 & $0.80^{*}$ & 0.63 & $0.73^{*}$ & 0.70 & 0.70 & 0.64 & $0.73^{*}$ & 0.65 & $0.73^{*}$ \\
\hline BMI (Body Mass Index) & 26.07 & $25.69^{*}$ & 26.50 & $25.64^{*}$ & 25.97 & 25.88 & 26.51 & $25.64^{*}$ & 26.21 & $25.75^{*}$ \\
\hline Smoke & 0.31 & $0.19^{*}$ & 0.36 & $0.22^{*}$ & 0.26 & 0.27 & 0.38 & $0.21^{*}$ & 0.31 & $0.24^{*}$ \\
\hline Alcoholic (CAGE $\geq 2$ ) & 0.16 & $0.22 *$ & 0.20 & $0.17^{*}$ & 0.17 & & 0.19 & 0.18 & 0.18 & 0.18 \\
\hline (Use) Cannabis & 0.14 & 0.16 & 0.19 & $0.13^{*}$ & 0.14 & 0.15 & 0.19 & $0.13^{*}$ & 0.16 & 0.14 \\
\hline (Ever) Arrested & 0.16 & $0.13^{*}$ & 0.21 & $0.11^{*}$ & 0.13 & 0.15 & 0.22 & $0.11^{*}$ & 0.17 & $0.13^{*}$ \\
\hline Satisfaction (with life (0-10)) & 7.34 & $7.74^{*}$ & 7.23 & $7.62^{*}$ & 7.32 & $7.65^{*}$ & 7.28 & $7.60^{*}$ & 7.38 & $7.57^{*}$ \\
\hline $\begin{array}{l}\text { Life Get (I get what I want } \\
\text { out of life) }\end{array}$ & 0.79 & $0.92^{*}$ & 0.78 & $0.87^{*}$ & 0.80 & $0.88^{*}$ & 0.78 & $0.87^{*}$ & 0.81 & $0.86^{*}$ \\
\hline $\begin{array}{l}\text { Life Run (I can run life as I } \\
\text { want) }\end{array}$ & 0.96 & $0.98^{*}$ & 0.95 & $0.98^{*}$ & 0.95 & $0.98^{*}$ & 0.95 & $0.98^{*}$ & 0.95 & $0.98^{*}$ \\
\hline & & & & & & & & & & \\
\hline usness (10) & 0.01 & $0.30^{*}$ & -0.36 & $0.35^{*}$ & 0.02 & $0.21^{*}$ & -0.17 & $0.27^{*}$ & -0.05 & $0.23^{*}$ \\
\hline Extraversion (10) & 0.00 & $0.11^{*}$ & -0.07 & $0.10^{*}$ & -0.29 & $0.32^{*}$ & -0.03 & 0.0 & -0.14 & $0.15^{*}$ \\
\hline Agreeableness (10) & 0.08 & & -0.12 & $0.27^{*}$ & 0.07 & & -0.18 & & -0.08 & $0.28^{*}$ \\
\hline Emotional Stability (10) & 0.05 & $0.25^{*}$ & -0.13 & $0.25^{*}$ & -0.08 & $0.30^{*}$ & -0.18 & $0.27^{*}$ & -0.25 & $0.35^{*}$ \\
\hline Conscientiousness (16) & 0.02 & $0.28^{*}$ & -0.92 & $0.61^{*}$ & -0.08 & $0.29^{*}$ & -0.43 & & -0.31 & $0.38^{*}$ \\
\hline Extraversi & 0.02 & $0.12^{*}$ & -0.23 & 0.2 & -0.76 & $0.76^{*}$ & -0.22 & 0.2 & -0.36 & $0.32^{*}$ \\
\hline Agreeableness (16) & 0.07 & $0.24^{*}$ & -0.29 & $0.33^{*}$ & -0.02 & $0.26^{*}$ & -0.64 & 0.5 & -0.26 & $0.37^{*}$ \\
\hline Emotional Stability (16) & 0.04 & $0.21^{*}$ & -0.39 & $0.34^{*}$ & -0.23 & $0.38^{*}$ & -0.53 & $0.41^{*}$ & -0.82 & $0.66^{*}$ \\
\hline & & & & & & & & & & \\
\hline No d & 0.03 & $0.01^{*}$ & 0.03 & 0.02 & 0.03 & 0.02 & 0.03 & 0.02 & 0.03 & 0.02 \\
\hline lage mother & 0.18 & $0.10^{*}$ & 0.19 & $0.13^{*}$ & 0.17 & $0.13^{*}$ & 0.20 & $0.12^{*}$ & 0.19 & $0.13^{*}$ \\
\hline Yrs of sc & 9.57 & $10.27^{*}$ & 9.72 & $9.90^{*}$ & 9.80 & & 9.65 & $9.93^{*}$ & 9.8 & 9.86 \\
\hline Yrs of sc & 9.76 & $10.59^{*}$ & 9.96 & $10.14^{*}$ & 10.05 & 10.11 & 9.75 & $10.24^{*}$ & 9.95 & $10.16^{*}$ \\
\hline /prof. (0) & 0.78 & $0.89^{*}$ & 0.81 & 0.82 & 0.80 & 0.83 & 0.77 & $0.84^{*}$ & 0.79 & $0.84^{*}$ \\
\hline orldview (5) & -0.01 & $0.30^{*}$ & 0.02 & $0.15^{*}$ & 0.02 & $0.19^{*}$ & -0.02 & $0.17^{*}$ & 0.04 & $0.16^{*}$ \\
\hline e left free $(5)$ & 0.03 & $0.27^{*}$ & 0.06 & $0.15^{*}$ & 0.08 & $0.16^{*}$ & 0.04 & $0.16^{*}$ & 0.12 & 0.13 \\
\hline Child to be $\mathrm{cc}$ & 0.99 & $1.08^{*}$ & 0.98 & & 0.97 & $1.07^{*}$ & 0.97 & $1.05^{*}$ & 0.94 & $1.08^{*}$ \\
\hline Strong family ties (10) & 2.49 & & 2.46 & $2.53^{*}$ & 2.49 & & 2.45 & & 2.46 & $2.54^{*}$ \\
\hline $\begin{array}{l}\text { Don't get on with } \\
\text { parents }(16)\end{array}$ & -0.22 & -0.24 & -0.19 & $-0.24^{*}$ & -0.22 & $-0.24^{*}$ & -0.18 & $-0.25^{*}$ & -0.18 & $-0.25^{*}$ \\
\hline $\begin{array}{l}\text { Parents are free, not } \\
\text { strict }(16)\end{array}$ & 4.59 & $4.46^{*}$ & 4.56 & 4.53 & 4.47 & $4.59^{*}$ & 4.60 & 4.51 & 4.52 & 4.54 \\
\hline & & & & & & & & & & \\
\hline Cognitive ability & 0.04 & $0.66^{*}$ & 0.01 & $0.40^{*}$ & 0.20 & $0.34^{*}$ & 0.03 & $0.40^{*}$ & 0.15 & $0.36^{*}$ \\
\hline Years of schooling (34) & 12.16 & $13.96^{*}$ & 12.05 & $13.24^{*}$ & 12.73 & 12.97 & 12.18 & $13.19^{*}$ & 12.54 & $13.05^{*}$ \\
\hline Skilled/prof. (34) & 0.50 & $0.74^{*}$ & 0.47 & $0.65^{*}$ & 0.59 & 0.59 & 0.48 & $0.64^{*}$ & 0.53 & $0.63^{*}$ \\
\hline & & & & & & & & & & \\
\hline Rutter score (5) & -0.03 & $-0.20^{*}$ & 0.21 & $-0.24^{*}$ & 0.12 & $-0.28^{*}$ & 0.27 & $-0.27^{*}$ & 0.20 & $-0.28^{*}$ \\
\hline Rutter score (10) & -0.04 & $-0.27^{*}$ & 0.20 & $-0.29^{*}$ & 0.11 & $-0.33^{*}$ & 0.19 & $-0.28^{*}$ & 0.18 & $-0.32^{*}$ \\
\hline Rutter score (16) & -0.04 & $-0.26^{*}$ & 0.43 & $-0.39^{*}$ & 0.41 & $-0.58^{*}$ & 0.59 & $-0.47^{*}$ & 0.50 & $-0.50^{*}$ \\
\hline Self-esteem (10) & 16.23 & $17.67^{*}$ & 15.91 & $17.19^{*}$ & 16.31 & $17.18^{*}$ & 16.03 & $17.15^{*}$ & 16.24 & $17.11^{*}$ \\
\hline Locus of control (10) & 17.61 & $20.00 *$ & 17.35 & $19.09^{*}$ & 18.06 & $18.93^{*}$ & 17.60 & $18.98^{*}$ & 17.95 & $18.89^{*}$ \\
\hline Sports in school & 9.33 & 9.36 & 9.58 & 9.25 & 9.32 & 9.37 & 10.30 & $8.96^{*}$ & 9.60 & 9.20 \\
\hline
\end{tabular}

(continued on next page) 
Table 3.C.3: (continued)

\begin{tabular}{|c|c|c|c|c|c|c|c|c|c|c|}
\hline & \multicolumn{2}{|c|}{$\begin{array}{l}\text { Gross } \\
\text { hourly wage } \\
<\text { avg. >avg. }\end{array}$} & \multicolumn{2}{|c|}{$\begin{array}{l}\text { Conscien- } \\
\text { tiousness }\end{array}$} & \multicolumn{2}{|c|}{$\begin{array}{l}\text { Extra- } \\
\text { version }\end{array}$} & \multicolumn{2}{|c|}{$\begin{array}{l}\text { Agree- } \\
\text { ableness }\end{array}$} & \multicolumn{2}{|c|}{$\begin{array}{l}\text { Emotional } \\
\text { Stability }\end{array}$} \\
\hline Sports outside school & 8.63 & 9.23 & 9.39 & 8.67 & 8.79 & 8.95 & 9.65 & $8.57^{*}$ & 9.01 & 8.80 \\
\hline No. friends in school & 5.57 & $5.84^{*}$ & 5.72 & 5.67 & 5.57 & 5.78 & 5.82 & 5.62 & 5.45 & $5.81^{*}$ \\
\hline No. friends outside school & 4.93 & 4.69 & 5.27 & $4.65^{*}$ & 4.72 & 4.92 & 5.39 & $4.60^{*}$ & 4.98 & 4.75 \\
\hline & & & & & & & & & & \\
\hline Avg Occ.Consc & 0.02 & $0.20 *$ & 0.03 & $0.12^{*}$ & 0.09 & 0.09 & 0.04 & $0.12^{*}$ & 0.07 & $0.10^{*}$ \\
\hline Avg Occ.Extra & 0.03 & $0.09^{*}$ & 0.05 & 0.05 & 0.04 & $0.06^{*}$ & 0.04 & $0.05^{*}$ & 0.04 & $0.05^{*}$ \\
\hline Avg Occ.Agreeabl.(16) & 0.06 & $0.17^{*}$ & 0.06 & $0.12^{*}$ & 0.10 & 0.10 & 0.06 & $0.12^{*}$ & 0.09 & $0.11^{*}$ \\
\hline Avg Occ.Emot.Stab.(16) & 0.05 & $0.16^{*}$ & 0.07 & $0.10^{*}$ & 0.09 & $0.09^{*}$ & 0.06 & $0.10^{*}$ & 0.07 & $0.10^{*}$ \\
\hline Above Avg Occ. C (16) & 0.66 & $0.73^{*}$ & 0.08 & $0.97^{*}$ & 0.59 & $0.76^{*}$ & 0.45 & $0.80^{*}$ & 0.50 & $0.80^{*}$ \\
\hline Above Avg Occ. E (16) & 0.55 & 0.59 & 0.44 & $0.63^{*}$ & 0.06 & $1.00^{*}$ & 0.45 & $0.62^{*}$ & 0.38 & $0.68^{*}$ \\
\hline Above Avg Occ. A (16) & 0.70 & $0.74^{*}$ & 0.50 & $0.82^{*}$ & 0.64 & $0.79^{*}$ & 0.18 & $0.98^{*}$ & 0.49 & $0.86^{*}$ \\
\hline Above Avg Occ. ES (16) & 0.60 & 0.64 & 0.40 & $0.72^{*}$ & 0.46 & $0.75^{*}$ & 0.32 & $0.76^{*}$ & 0.03 & $0.98^{*}$ \\
\hline Max. Observations & 1,800 & 1,134 & 944 & 1,990 & 1,346 & 1,588 & 958 & 1,976 & 1,111 & 1,823 \\
\hline
\end{tabular}

Note: Average levels of variables (rows) by below or above average wages or personality (columns) for the working sample of 2,934 working men with valid data on age 34 gross hourly wages, age-10 cognitive ability, and age-16 personality (conscientiousness, extraversion, agreeableness, and emotional stability). * indicates that the above average mean is significantly different from the below average mean, at the 5 percent level. Number of observations shows maximum sample size of below and above average groups. 


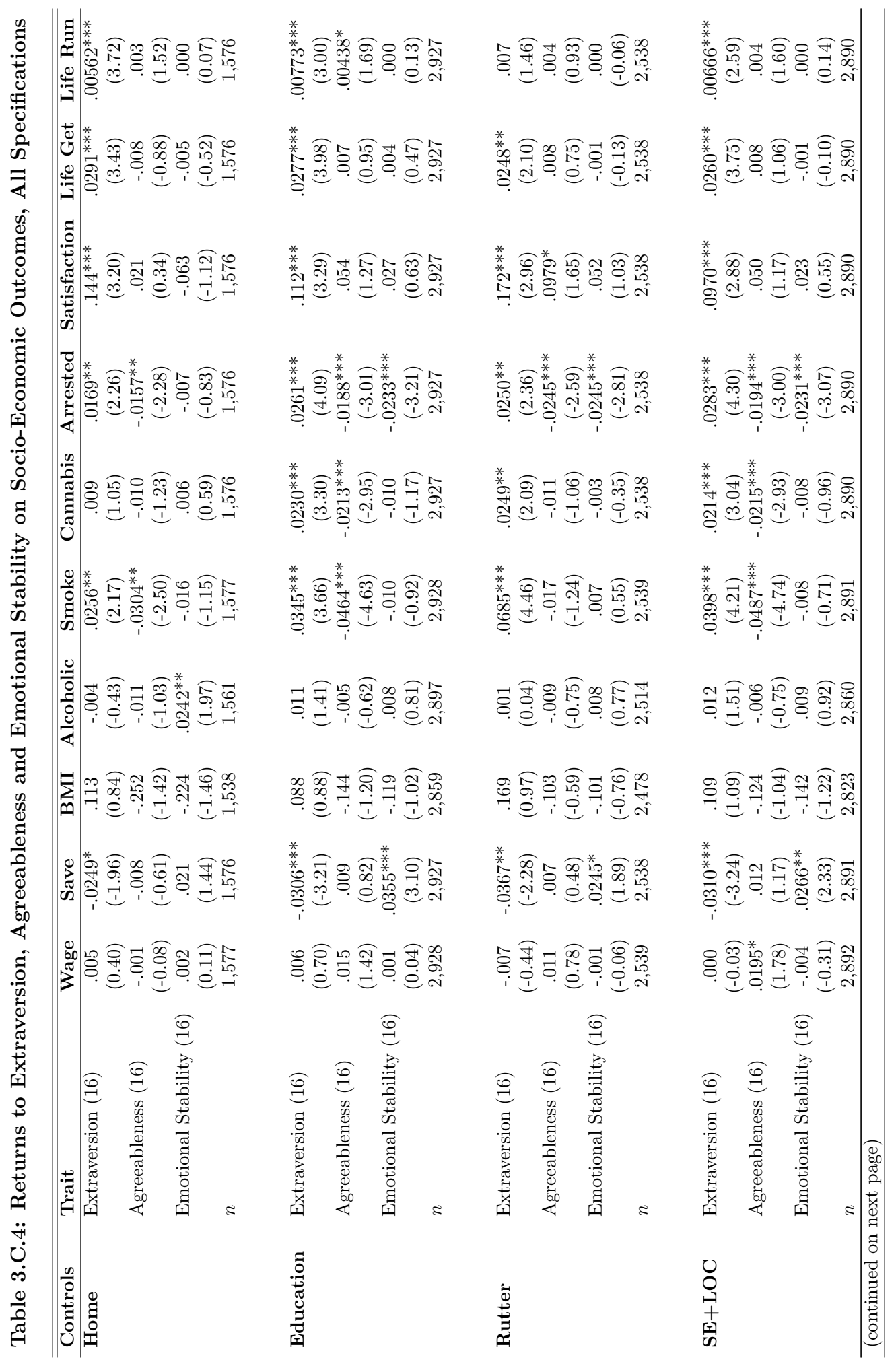




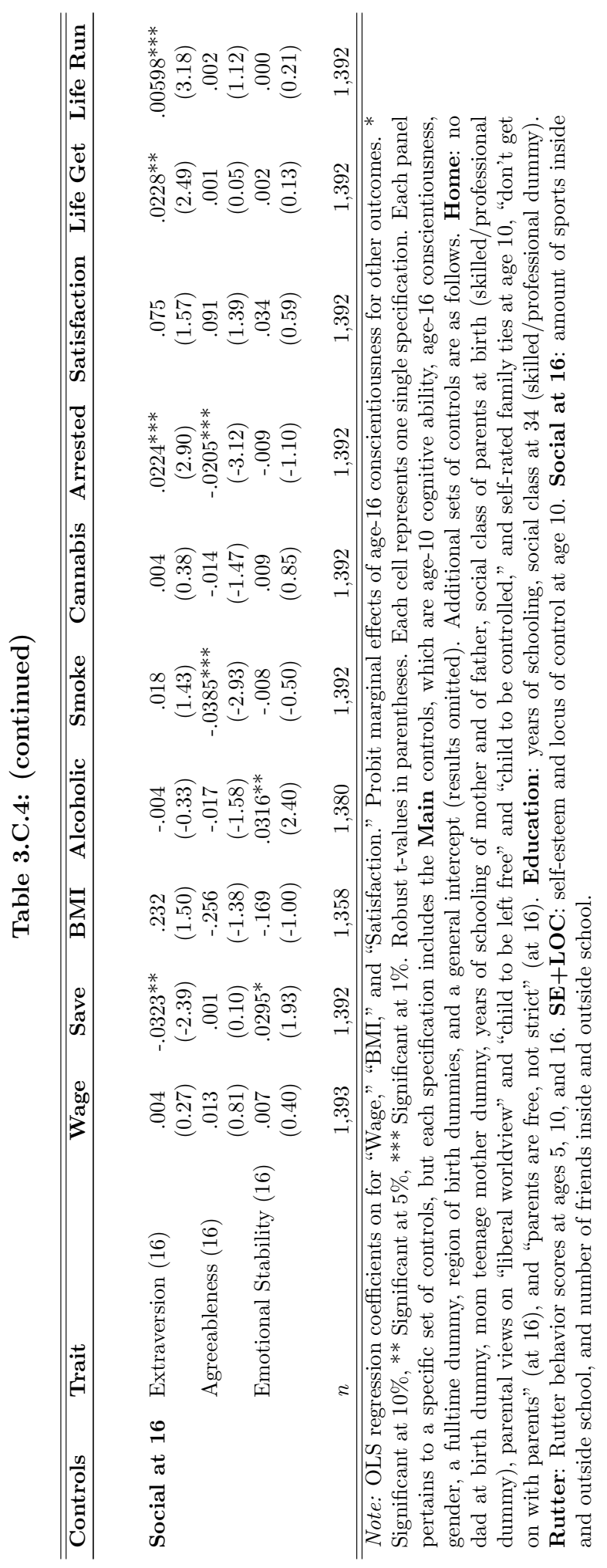


Table 3.C.5: Mean Personality Traits by 2-digit SOC2000

\begin{tabular}{|c|c|c|c|c|c|c|c|}
\hline Description & SOC2000 & $n$ & $\%$ men & $\mathbf{C}$ & $\mathbf{E}$ & $\mathbf{A}$ & ES \\
\hline Corporate Managers & 11 & 457 & $\begin{array}{c}.62 \\
(.02)\end{array}$ & $\begin{array}{l}.11^{* * *} \\
(.04)\end{array}$ & $\begin{array}{l}.07 \\
(.05)\end{array}$ & $\begin{array}{l}.05 \\
(.04)\end{array}$ & $\begin{array}{c}.04 \\
(.05)\end{array}$ \\
\hline $\begin{array}{l}\text { Managers and Proprietors } \\
\text { in Agriculture and Services }\end{array}$ & 12 & 67 & $\begin{array}{l}.63 \\
(.06)\end{array}$ & $\begin{array}{l}-.02 \\
(.10)\end{array}$ & $\begin{array}{l}.00 \\
(.11)\end{array}$ & $\begin{array}{l}.06 \\
(.10)\end{array}$ & $\begin{array}{l}.11 \\
(.08)\end{array}$ \\
\hline $\begin{array}{l}\text { Science and Technology } \\
\text { Professionals }\end{array}$ & 21 & 143 & $\begin{array}{l}.82 \\
(.03)\end{array}$ & $\begin{array}{c}.26^{* * *} \\
(.06)\end{array}$ & $\begin{array}{l}.08 \\
(.07)\end{array}$ & $\begin{array}{l}.20^{* * * *} \\
(.06)\end{array}$ & $\begin{array}{l}.21^{* * *} \\
(.06)\end{array}$ \\
\hline Health Professionals & 22 & 27 & $\begin{array}{l}.59 \\
(.10)\end{array}$ & $\begin{array}{l}.41^{* * *} \\
(.13)\end{array}$ & $\begin{array}{l}-.01 \\
(.17)\end{array}$ & $\begin{array}{c}.36^{* * *} \\
(.06)\end{array}$ & $\begin{array}{l}.40^{* * *} \\
(.13)\end{array}$ \\
\hline $\begin{array}{l}\text { Teaching and Research } \\
\text { Professionals }\end{array}$ & 23 & 147 & $\begin{array}{l}.31 \\
(.04)\end{array}$ & $\begin{array}{l}.22^{* * *} \\
(.07)\end{array}$ & $\begin{array}{l}-.07 \\
(.08)\end{array}$ & $\begin{array}{c}.25^{* * *} \\
(.07)\end{array}$ & $\begin{array}{l}.09 \\
(.08)\end{array}$ \\
\hline $\begin{array}{l}\text { Business and Public } \\
\text { Service Professionals }\end{array}$ & 24 & 141 & $\begin{array}{l}.46 \\
(.04)\end{array}$ & $\begin{array}{c}.46^{* * *} \\
(.05)\end{array}$ & $\begin{array}{l}-.04 \\
(.09)\end{array}$ & $\begin{array}{c}.27^{* * *} \\
(.05)\end{array}$ & $\begin{array}{l}.17^{* *} \\
.08)\end{array}$ \\
\hline $\begin{array}{l}\text { Science and Technology } \\
\text { Associate Professionals }\end{array}$ & 31 & 94 & $\begin{array}{l}.79 \\
(.04)\end{array}$ & $\begin{array}{c}.07 \\
(.08)\end{array}$ & $\begin{array}{l}-.19^{*} \\
(.11)\end{array}$ & $\begin{array}{l}.15^{* *} \\
(.07)\end{array}$ & $\begin{array}{l}.12 \\
(.09)\end{array}$ \\
\hline $\begin{array}{l}\text { Health and Social Welfare } \\
\text { Associate Professionals }\end{array}$ & 32 & 139 & $\begin{array}{l}.16 \\
(.03)\end{array}$ & $\begin{array}{l}.11 \\
(.08)\end{array}$ & $\begin{array}{l}.12 \\
(.08)\end{array}$ & $\begin{array}{l}.07 \\
(.09)\end{array}$ & $\begin{array}{l}-.03 \\
(.08)\end{array}$ \\
\hline $\begin{array}{l}\text { Protective Service } \\
\text { Occupations }\end{array}$ & 33 & 71 & $\begin{array}{l}.76 \\
(.05)\end{array}$ & $\begin{array}{l}-.11 \\
(.12)\end{array}$ & $.29^{* * *}$ & $\begin{array}{l}-.14 \\
(.12)\end{array}$ & $\begin{array}{l}.03 \\
(.12)\end{array}$ \\
\hline $\begin{array}{l}\text { Culture, Media and } \\
\text { Sports Occupations }\end{array}$ & 34 & 45 & $\begin{array}{l}.38 \\
(.07)\end{array}$ & $\begin{array}{l}.12 * \\
(.11)\end{array}$ & $\begin{array}{l}. .07 \\
-.07 \\
(.15)\end{array}$ & $\begin{array}{l}.11 \\
.13)\end{array}$ & $\begin{array}{l}.27^{* * *} \\
(.10)\end{array}$ \\
\hline $\begin{array}{l}\text { Business and Public Service } \\
\text { Associate Professionals }\end{array}$ & 35 & 208 & $\begin{array}{l}.45 \\
(.03)\end{array}$ & $\begin{array}{c}.16^{* * *} \\
(.06)\end{array}$ & $\begin{array}{l}.01 \\
(.07)\end{array}$ & $\begin{array}{l}.10^{*} \\
(.05)\end{array}$ & $\begin{array}{l}.05 \\
(.07)\end{array}$ \\
\hline Administrative Occupations & 41 & 325 & $\begin{array}{l}.23 \\
(.02)\end{array}$ & $\begin{array}{l}-.02 \\
(.06)\end{array}$ & $\begin{array}{l}-.09 \\
(.05)\end{array}$ & $\begin{array}{l}-.01 \\
(.06)\end{array}$ & $\begin{array}{l}-.07 \\
(.06)\end{array}$ \\
\hline $\begin{array}{l}\text { Secretarial and Related } \\
\text { Occupations }\end{array}$ & 42 & 79 & $\begin{array}{l}.06 \\
(.03)\end{array}$ & $\begin{array}{l}-.01 \\
(.10)\end{array}$ & $\begin{array}{l}-.06 \\
(.10)\end{array}$ & $\begin{array}{l}-.02 \\
(.11)\end{array}$ & $\begin{array}{l}-.23^{*} \\
(.13)\end{array}$ \\
\hline Skilled Agricultural Trades & 51 & 17 & $\begin{array}{l}.94 \\
(.06)\end{array}$ & $\begin{array}{l}-.49 \\
(.31)\end{array}$ & $\begin{array}{l}.28 \\
(.17)\end{array}$ & $\begin{array}{l}.01 \\
(.20)\end{array}$ & $\begin{array}{c}.37^{* * *} \\
(.13)\end{array}$ \\
\hline $\begin{array}{l}\text { Skilled Metal and } \\
\text { Electrical Trades }\end{array}$ & 52 & 138 & $\begin{array}{l}.98 \\
(.01)\end{array}$ & $\begin{array}{l}-.11 \\
(.09)\end{array}$ & $\begin{array}{l}-.03 \\
(.09)\end{array}$ & $\begin{array}{l}-.15 \\
(.10)\end{array}$ & $\begin{array}{l}.00 \\
(.08)\end{array}$ \\
\hline $\begin{array}{l}\text { Skilled Construction and } \\
\text { Building Trades }\end{array}$ & 53 & 66 & $\begin{array}{l}1.00 \\
(.00)\end{array}$ & $\begin{array}{l}-.20 \\
(.12)\end{array}$ & $\begin{array}{l}.14 \\
(.12)\end{array}$ & $\begin{array}{l}-.15 \\
(.17)\end{array}$ & $\begin{array}{l}.12 \\
(.10)\end{array}$ \\
\hline $\begin{array}{l}\text { Textiles, Printing and } \\
\text { Other Skilled Trades }\end{array}$ & 54 & 49 & $\begin{array}{l}.65 \\
(.07)\end{array}$ & $\begin{array}{c}-.61^{* * *} \\
(.20)\end{array}$ & $\begin{array}{l}-.22 \\
(.17)\end{array}$ & $\begin{array}{l}-.20 \\
(.16)\end{array}$ & $\begin{array}{l}-.17 \\
(.16)\end{array}$ \\
\hline $\begin{array}{l}\text { Caring Personal } \\
\text { Service Occupations }\end{array}$ & 61 & 138 & $\begin{array}{l}.06 \\
(.02)\end{array}$ & $\begin{array}{l}-.07 \\
(.10)\end{array}$ & $\begin{array}{l}-.02 \\
(.09)\end{array}$ & $\begin{array}{l}.04 \\
(.07)\end{array}$ & $\begin{array}{l}-.07 \\
(.09)\end{array}$ \\
\hline $\begin{array}{l}\text { Leisure and Other Personal } \\
\text { Service Occupations }\end{array}$ & 62 & 35 & $\begin{array}{l}.23 \\
(.07)\end{array}$ & $\begin{array}{l}.20^{*} \\
(.11)\end{array}$ & $\begin{array}{l}.07 \\
(.14)\end{array}$ & $\begin{array}{l}.30^{* * *} \\
(.05)\end{array}$ & $\begin{array}{l}-.04 \\
(.15)\end{array}$ \\
\hline Sales Occupations & 71 & 106 & $\begin{array}{l}.22 \\
(.04)\end{array}$ & $\begin{array}{l}-.23^{*} \\
(.12)\end{array}$ & $\begin{array}{l}-.13 \\
(.11)\end{array}$ & $\begin{array}{l}-.17 \\
(.13)\end{array}$ & $\begin{array}{l}-.21^{*} \\
(.12)\end{array}$ \\
\hline Customer Service Occupations & 72 & 36 & $\begin{array}{l}.08 \\
(.05)\end{array}$ & $\begin{array}{l}.02 \\
(.18)\end{array}$ & $\begin{array}{l}.03 \\
(.15)\end{array}$ & $\begin{array}{l}-.09 \\
(.15)\end{array}$ & $\begin{array}{c}-.34^{* *} \\
(.17)\end{array}$ \\
\hline $\begin{array}{l}\text { Process, Plant and } \\
\text { Machine Operatives }\end{array}$ & 81 & 117 & $\begin{array}{l}.76 \\
(.04)\end{array}$ & $\begin{array}{c}-.38^{* * *} \\
(.11)\end{array}$ & $\begin{array}{l}-.09 \\
(.10)\end{array}$ & $\begin{array}{l}-.18^{*} \\
(.11)\end{array}$ & $\begin{array}{l}-.03 \\
(.11)\end{array}$ \\
\hline $\begin{array}{l}\text { Transport and Mobile Machine } \\
\text { Drivers and Operatives }\end{array}$ & 82 & 80 & $\begin{array}{l}.89 \\
(.04)\end{array}$ & $\begin{array}{c}-.52^{* * *} \\
(.13)\end{array}$ & $\begin{array}{l}.12 \\
(.09)\end{array}$ & $\begin{array}{c}-.64^{* * *} \\
(.17)\end{array}$ & $\begin{array}{c}-.27^{* *} \\
(.12)\end{array}$ \\
\hline $\begin{array}{l}\text { Elementary Trades, Plant and } \\
\text { Storage Related Occupations }\end{array}$ & 91 & 73 & $\begin{array}{l}.85 \\
(.04)\end{array}$ & $\begin{array}{l}-.22^{*} \\
(.13)\end{array}$ & $\begin{array}{l}.11 \\
(.13)\end{array}$ & $\begin{array}{l}-.25 \\
(.15)\end{array}$ & $\begin{array}{l}.14 \\
(.10)\end{array}$ \\
\hline $\begin{array}{l}\text { Elementary Administration and } \\
\text { Service Occupations }\end{array}$ & 92 & 131 & $\begin{array}{l}.44 \\
(.04)\end{array}$ & $\begin{array}{c}-.39^{* * *} \\
(.11)\end{array}$ & $\begin{array}{l}-.01 \\
(.09)\end{array}$ & $\begin{array}{c}-.32^{* * *} \\
(.11)\end{array}$ & $\begin{array}{c}-.33^{* * *} \\
(.11)\end{array}$ \\
\hline$n$ & & 2,929 & 2,929 & 2,929 & 2,929 & 2,929 & 2,929 \\
\hline
\end{tabular}

Note: Entries are mean age-16 personality traits by 2-digit 2000 Standard Occupational Classification (SOC2000). Stars indicate the mean is significantly different from the average of zero: ${ }^{*}$ Significant at $10 \%,{ }^{* *}$ Significant at 5\%, ${ }^{* * *}$ Significant at 1\%. Standard errors in parentheses. The sample applied is our working sample of 2,934 individuals with valid information on adult wages, age-10 cognitive ability, and age- 16 personality. 
Table 3.C.6: First-stage results for 2SLS results in Section 3.4, Table 3.6

\begin{tabular}{lcccc}
\hline \hline & $\mathbf{C}(\mathbf{1 6})$ & $\mathbf{E}(\mathbf{1 6})$ & $\mathbf{A}(\mathbf{1 6})$ & $\mathbf{E S}(\mathbf{1 6})$ \\
\hline Conscientiousness (C)(10) & $.336^{* * *}$ & -.013 & .033 & .003 \\
& $(16.27)$ & $(-0.61)$ & $(1.55)$ & $(0.16)$ \\
Extraversion (E)(10) & $-.0444^{* *}$ & $.324^{* * *}$ & $-.104^{* * *}$ & -.003 \\
& $(-2.29)$ & $(16.18)$ & $(-5.23)$ & $(-0.13)$ \\
Agreeableness (A)(10) & $.0544^{* *}$ & $-.0467^{* *}$ & $.277^{* * *}$ & $.0480^{* *}$ \\
& $(2.50)$ & $(-2.07)$ & $(12.35)$ & $(2.17)$ \\
Emotional Stability (ES)(10) & $.0699^{* * *}$ & $.103^{* * *}$ & $.122^{* * *}$ & $.353^{* * *}$ \\
& $(3.09)$ & $(4.41)$ & $(5.24)$ & $(15.42)$ \\
Age 10 ability & & & & \\
Male dummy & $.112^{* * *}$ & .021 & $.0840^{* * *}$ & $.0538^{* * *}$ \\
& $(6.24)$ & $(1.13)$ & $(4.54)$ & $(2.95)$ \\
Fulltime dummy & -.005 & .054 & -.005 & $.200^{* * *}$ \\
Constant & $(-0.13)$ & $(1.33)$ & $(-0.12)$ & $(5.02)$ \\
& .022 & -.019 & -.021 & $.0942^{*}$ \\
& $(0.45)$ & $(-0.37)$ & $(-0.42)$ & $(1.91)$ \\
$n$ & -.015 & -.013 & .019 & $-.176^{* * *}$ \\
F-test & $(-0.39)$ & $(-0.32)$ & $(0.49)$ & $(-4.56)$ \\
R-squared & & & & \\
\hline \hline
\end{tabular}

Note: First-stage regression results for 2SLS estimates reported for age-34 wage in Table 6. * Significant at $10 \%, * *$ Significant at $5 \%$, *** Significant at $1 \%$. T-values in parentheses. All specifications control for age-10 cognitive ability, gender, a fulltime dummy, region of birth dummies (results omitted), and a general intercept (Constant).

\section{First-stage results for 2SLS reported in Section 4}

As reported in Section 3.4, the OLS regressions presented in Table 3.3 could be biased because of correlation between the independent variables and the error term. Below, in Table 3.C.6, we show the first-stage results of the 2SLS results reported in Table 3.6. Both when the respondent was 10 years of age and 16 years of age, their mothers reported on the same set of personality items used to construct our personality traits. We use the resulting age-10 personality constructs as instruments for those measured at age 16 (See Table 3.1 for reliability coefficients). We assume that measurement error in the mother-rated items at both points in time is uncorrelated, which seems plausible given the six-year window between the two surveys.

The first-stage results are strong, and the F-tests for each of the constructs well exceed the threshold of 10, ranging from 94 for age-16 agreeableness to 119 for age-16 emotional stability $(\mathrm{N}(16))$. The second-stage estimates for all socio-economic outcomes are shown in the top panel of Table 3.6 in Section 4. While the first-stage results here pertain to the regression sample for age-34 wages, the first-stage results for the other socio-economic outcomes are almost identical, and are therefore not reported. 



\title{
Change of Personality Traits During Childhood Loss of a Parent
}

\begin{abstract}
Using data from the 1970 British Cohort Study, this study reveals significant correlations between loss of a parent prior to age 16 and personality development in childhood, even after controlling for a range of family characteristics. These effects of losing a parent mask heterogeneous effects. A child may lose a parent due to death, or because of divorce or separation of parents. Experiencing divorce of one's natural parents seems to have the largest effect on a child's personality, in terms of self-esteem, locus of control, and behavioral problems. The correlations are smaller when the child was older at the time of family breakdown. While the association between overall parental loss and personality does not vary with gender, boys are more negatively affected by parental death than girls, and there are also indications that girls suffer more from a separation or divorce of parents than boys do. The association between personality development and parental loss is, at least partially, driven by selection. Placebo regressions reveal significant correlations between eventual parental loss and personality of the child before the change took place. The omitted variable bias is mitigated by the consideration of a range of control variables, uncovering possible mechanisms through which the selection operates. These include lower parental investment, both pecuniary and non-pecuniary.
\end{abstract}




\subsection{Introduction}

A growing body of literature in economics and psychology reveals personality traits as important predictors of a variety of socio-economic outcomes. ${ }^{1}$ Given the importance of personality traits, the next step is to map the development of these traits and the factors that influence them. Results from personality psychology demonstrate that various personality traits develop in differing ways over the life cycle, with the strongest changes occurring in young adulthood (Roberts \& Mroczek, 2008; Roberts et al., 2008). Individual differences in these patterns are related to specific life experiences.

This chapter adds to the literature on the variability of personality traits in childhood. First of all, descriptive statistics provide insights into the changes that children go through in terms of mean-level development of personality traits. Second, the experience of a shock in the family composition during childhood might have an impact on this development, and such shocks help explain intra-individual differences in personality development. Lastly, while life experiences are generally found to be correlated with personality changes, the exogeneity of these experiences is generally left untested. This chapter demonstrates that the correlations between family dissolution and personality are not causal, and that family composition is endogenous.

The following sections reveal that children mature in terms of personality during childhood, but that the extent of this development is significantly affected by family structure. Using data from the 1970 British Cohort Study, various personality traits are measured at ages 10 and 16. Between these ages, children demonstrate positive personality developments, as shown by increasing scores on self-esteem and internal locus of control scales, as well as decreasing scores on the Rutter index for behavioral problems. These favorable changes are significantly smaller for children who lost a parent during childhood. Loss of a parent is defined as having experienced a switch from living with both natural parents to living with only one natural parent before the age of $16 .^{2}$ Children who do not live with both natural parents throughout childhood not only rank lower in terms of desirable personality traits at the age of 16 , but also improve less between the ages of 10 and 16 .

While simple regressions demonstrate that parental loss is associated with as much as a quarter of a standard deviation less desirable personality traits, the correlations drop when controls for the quality of the home environment are added to the regression model. Schooling and social class of parents are significantly related to the personality traits of their children, yet do not affect the association between parental loss and personality development much. Variables that are related to closeness of the parent-child relationship mediate the relationship between parental loss and personality development. In order to adjust for these confounding factors, and the possible endogeneity of family composition, a full set of controls - including birth conditions, social class, and family characteristics - is used for all further analyses.

\footnotetext{
${ }^{1}$ See for example Chapter 3, Heckman et al. (2006), or Borghans et al. (2008a).

${ }^{2}$ Losing one of two natural parents in the household need not imply the lost parent is completely absent. The change can be the result of death of one parent, in which case the lost parent is indeed lost. In the case of separation or divorce of parents, the role of the lost parent in the child's life may not have changed much at all. In all cases, the lost parents may have been replaced with a stepparent of other mother/father figure. These influences are not taken into consideration in this study.
} 
Looking into the heterogeneity of the found correlations, the reason for parental loss, age at loss, and gender of the child all matter for the size of the estimated effect. While children seem to recover from experiencing death of a parent, children from families that ended in divorce show significantly lower self-esteem and internal locus of control, while also scoring higher on behavioral problems. Further, the effects of parental loss are less severe if the child was older at the time of the change. In terms of the overall effect of parental loss on personality, there seem to be no differences between boys and girls. However, boys seem to suffer more from the death of a parent, relative to girls, while the effect of experiencing divorce of parents is more severe for girls. Loss of a parent is endogenous and families that eventually break down are different from families that remain intact, even before the change. This is demonstrated by reductions in the estimated effect size, once controls for the quality of the home environment are added. Key components are mother's age at birth of the child, parental education, family income, and parental care.

The analyses presented in this study firstly contribute to the literature on the development of personality traits. The stability or instability of personality can be measured in various ways. In terms of mean levels of personality, personality is highly correlated with age. Using meta-analytic techniques, Roberts et al. (2006) show the pattern of mean-level changes in terms of the Big Five personality traits. The largest changes occur early in life. Measuring personality development in terms of rank-order stability, by reporting correlations between personality scores across two points in time, reflects the degree to which the relative ordering of individuals is maintained. These changes in rank order are also largest early in life (Roberts \& DelVecchio, 2000). Theories on personality trait development (see Roberts et al., 2006, for a discussion) attribute personality changes to a combination of environmental and genetic factors, as well as life experiences.

Empirical studies investigating the association between life experiences and personality change are inconclusive. For working-age adults, Cobb-Clark \& Schurer (2012) show that mean-level changes are small, and that intra-individual changes are generally unrelated to adverse employment-, health- and family-related events. Specht et al. (2011), however, conclude that such events do explain a significant part of the variation in personality traits. They also show that when events are clustered, as is the case with Cobb-Clark \& Schurer (2012), effects of the environment are either overlooked, or overgeneralized. Given that personality is more stable in adulthood, changes are likely to be small, and not economically meaningful (Cobb-Clark \& Schurer, 2012). This study therefore focuses on a single adverse event, namely the loss of a parent, occurring in a period in which personality is still very much in development: childhood. With that focus, this study adds to two additional strands of literature: one that emphasizes the importance of the environment and development in early childhood, and a directly related literature on the effects of family breakdown on children.

Knudsen et al. (2006) conclude that being raised in disadvantaged environments is associated with diminished cognitive and social skills. Similarly, Almlund et al. (2011) argue that personality traits are responsive to a wide variety of influences, among which educational and parental investments. The technology of skill formation (Cunha et al., 2006) models the role the quality of the home environment plays in shaping cognitive and noncognitive skills in children. Investments in one period stimulate skills in that same period, but through the selfproductivity of skills, also in the periods thereafter. This model highlights the importance of the early childhood environment, and explains the associations between disadvantaged early environments and later life outcomes. 
The literature on the effects of divorce and parental death shows a strong association between loss of a parent and a range of outcomes (for a review of the early literature, see Amato \& Keith, 1991; Amato, 2001). The experience of losing a parent in the household implies an adverse shock in terms of parental investment, be it through the loss of income, or a reduction in quality time spent with parents. The empirical results are mixed as to whether the effects of parental loss are the result of selection, i.e. a loss in parental investment, or whether the effects are causal. Addressing the endogeneity by adding various controls generally reduces the strength of the correlations between parental loss and child outcomes. Some find that the adverse effects remain (e.g. Ermisch et al., 2004; Ermisch \& Francesconi, 2001; Francesconi, Jenkins \& Siedler, 2010), while others find the correlations are no longer significant, especially when applying sibling-difference models (e.g. Björklund, Ginther \& Sundström, 2007; Björklund \& Sundström, 2006; Ginther \& Pollak, 2004).

I proceed as follows. Section 4.2 describes which data are used and how the relationship between personality and parental loss is estimated. Section 4.3 presents a basic set of estimates, demonstrating that experiencing loss of a parent during childhood is significantly correlated with both personality level and personality change. Section 4.4 reveals that this relationship varies across reasons for parental loss, age at loss of parent, and gender of the child. Section 4.5 discusses the problem of endogeneity of family dissolution and the effects of sample selection. Finally, Section 4.6 concludes.

\subsection{Data and Approach}

The data comes from the 1970 British Cohort Study (BCS70), and is available from the Centre for Longitudinal Studies (Institute of Education, University of London). The BCS70 began with a birth questionnaire, covering all children born between the 5th and 11th of April 1970 in England, Wales, Scotland, and Northern Ireland. These 17,200 babies were followed throughout life, with waves roughly 5 years apart. This chapter uses data from the first four waves of the BCS70 - 1970, 1975, 1980 and 1986 - to investigate to what extent loss of a natural parent is related to the development of personality traits in childhood. Next to personality measures and family composition, I extract a set of covariates to capture early childhood circumstances related to family structure and personality traits.

\subsubsection{Personality measures}

Three measures are used to capture personality traits: self-esteem, internal locus of control, and the Rutter scale, all measured at ages 10 and 16 (during the 1980 and 1986 waves). ${ }^{3}$ Self-esteem measures an individual's sense of self-worth, internal locus of control measures one's perceived achievement control, and the Rutter scale gives an indication of behavior difficulties in the child. These traits in themselves are significantly related to educational, health, and labor market outcomes. ${ }^{4}$

\footnotetext{
${ }^{3}$ The analyses presented in the following sections have also been repeated with the Big Five personality traits conscientiousness, extraversion, agreeableness, and emotional stability, as used in Chapter 3 . The pattern of results and conclusions are the same as follow from the analyses using self-esteem, locus of control, and Rutter scores. The results are presented and shortly discussed in Appendix 4.B. Details on the construction of the Big Five personality traits can be found in Appendix 3.A.

${ }^{4}$ See for example Chapters 2 and 3; Conti, Heckman \& Urzua (2010); Feinstein (2000); Flouri \& Buchanan (2004); Murasko (2007); Von Stumm, Gale, Batty \& Deary (2009).
} 
Table 4.1: Distribution of Raw Personality Scores

\begin{tabular}{l|rrrrr}
\hline \hline & obs. & mean & st.dev. & min. & max. \\
\hline Raw personality scores & & & & & \\
Self-Esteem Age 16 (SE16) & 4,439 & 17.81 & 4.24 & 0 & 24 \\
Locus of Control Age 16 (LoC16) & 5,479 & 21.78 & 5.05 & 2 & 30 \\
Rutter Score Age 16 (Rutter16) & 8,609 & 4.54 & 4.21 & 0 & 38 \\
& & & & & \\
Self-Esteem Age 10 (SE10) & 12,624 & 16.39 & 4.54 & 0 & 24 \\
Locus of Control Age 10 (LoC10) & 12,560 & 17.85 & 4.75 & 0 & 30 \\
Rutter Score Age 5 (Rutter5) & 12,965 & 7.83 & 4.62 & 0 & 31 \\
& & & & & \\
(SE16)-(SE10) & 3,592 & 1.08 & 5.36 & -20 & 19 \\
(LoC16)-(LoC10) & 4,424 & 3.29 & 5.34 & -18 & 25 \\
(Rutter16)-(Rutter5) & 7,231 & -3.17 & 4.93 & -28 & 36 \\
\hline \hline
\end{tabular}

Note: Descriptive statistics for raw personality scores for full sample.

Self-esteem and locus of control are measured by asking the children whether or not they agree with various statements. The scores on fifteen items from the CARALOC questionnaire, developed by Gammage (1975), are summed up to give a score for locus of control. Self-esteem is measured with the questionnaire devised by Lawrence (1981). The sum of the scores on the twelve items is used to measure self-esteem. For self-esteem, a higher score indicates higher self-esteem, while a higher score on the locus of control scale indicates a more internal locus of control. A third set of 19 items, completed by the parents of the child, contains indicators of behavior difficulties (Rutter, Tizard \& Whitmore, 1970). The Rutter score is calculated by summing up the scores on the 19 items, with a high score being indicative of behavior adjustment problems. Cronbach's alphas are 0.70 and 0.71 for self-esteem and locus of control, respectively, and 0.80 for the Rutter scale. Details about the sets of items used and the resulting constructs are provided in Appendix 3.B.

Table 4.1 provides information on the raw scores of all personality traits, and reveals that between the ages of 10 and 16, children increase in self-esteem and internal locus of control. At the same time, these children demonstrate less behavioral problems at age 16 than they do at age 5 , as shown by the lower average Rutter scores. ${ }^{5}$ This pattern of mean-level changes is consistent with the generally found positive development of personality during childhood and young adulthood. For example, Lewis, Ross \& Mirowsky (1999) show that internal locus of control increases with age, and Robins \& Trzesniewski (2005) demonstrate the same for self-esteem. Roberts, Robins, Trzesniewski \& Caspi (2003) summarize findings regarding the development of Big Five personality traits, and show that in childhood and adolescence, individuals become more conscientious and agreeable. In terms of emotional stability, individuals either do not change, or become more stable.

\subsubsection{Loss of parent}

The 1986 wave of the BCS70 contains information on who the child lived with at all four waves, covering the family composition at birth, at 5 , at 10 , and at 16 years of age. The parent being interviewed is asked to record how many natural parents the teenager was

\footnotetext{
${ }^{5}$ The Rutter items are available at ages 5,10 and 16, yet those at age 10 are reported on a different scale, thus making a comparison between the age 10 and age 16 raw scores impossible. Once scores are standardized, as is done for the regression analyses, the Rutter scores at age 10 can be compared to those at age 16 .
} 
living with at these times, as well as indicate the reason for any changes between birth and age 5 , between ages 5 and 10 , and between ages 10 and 16 . This information is available for 8,978 individuals, representing many different family compositions and many different patterns of change. Since I am interested in the effects of losing a single biological parent, I discard individuals who experienced more than one change (going from living with both to living with a single biological parent and back again; or vice versa) and those who at some stage lived with neither natural parent. This leaves a sample of 8,641 individuals who either always lived with two natural parents or lost one natural parent at some point between birth and age 16. Of this group, 78 percent $(n=6,771)$ lived with both natural parents from birth through age 16 . The remaining 22 percent experienced a breakdown of the two parent family structure before the age of 16 .

Table 4.2 compares these two groups of children, both in terms of personality traits, as well as on a set of birth and family characteristics. Children who experience family breakdown between birth and age 16 score significantly lower in terms of self-esteem and internal locus of control, whether measured at age 10 or at age 16. They also score significantly higher on the Rutter index for behavioral problems. In terms of personality development between ages 10 and 16, they also show less improvement during childhood, in comparison to children from intact families. This is demonstrated by significantly lower increases in self-esteem and locus of control between ages 10 and 16, as well as significantly lower reductions in behavior problems between ages 5 and 10 ((Rutter16)-(Rutter5)).

\subsubsection{Family characteristics}

Children from families that eventually break down, score significantly different on a range of background characteristics. For example, Chen, Chen \& Liu (2009) find that deceased parents are most likely to be less educated and to have had their first child at a younger age. Similarly, Gould \& Simhon (2011) show that the education of both parents is lower in families that experience death of either the mother or father of the child. These background characteristics, which are indicators of the quality of the home environment, are also predictive of a range of outcomes. Both Ermisch \& Francesconi (2001) and Ginther \& Pollak (2004) find that controlling for family income significantly reduces the association between family disruption and educational outcomes. Given their significant correlations with family structure as well as outcomes, it is important to include these background characteristics as covariates in the analyses.

The set of covariates considered covers birth conditions, social class indicators, and early family characteristics, and was selected in such a manner as to maximize the sample with complete information, while covering the most important characteristics that could be driving the simple correlation between personality and parental loss. The controls used are consistent with regressors used in the literature on the effects of family dissolution. ${ }^{6}$ Birth conditions are captured by mother's age at birth, and dummy indicators for having a low birthweight $(<2,500 \mathrm{~g})$, having been breastfed, and whether or not the mother smoked during pregnancy. Years of schooling of both mother and father, and whether the parents hold a skilled or professional job, are used as indicators for social class. There are a number of family characteristics, measured at ages 5 and 10 . The age- 5 measures include the number of older and the number of younger siblings, and a dummy indicating whether or not the

\footnotetext{
${ }^{6}$ See for example Björklund et al. (2007); Björklund \& Sundström (2006); Ermisch \& Francesconi (2001); Gould \& Simhon (2011).
} 
parents read to the child every day. Family income and strength of family ties are measured in the 1980 wave, when the children are 10 years of age. ${ }^{7}$ Table 4.2 reports the averages among children who did and who did not experience parental loss by the age of 16 .

Children who lose one of their natural parents before reaching the age of 16 score less favorable on all domains, compared to children from intact families. They are less likely to have been breastfed as babies, and more likely to have had a low weight at birth. The proportion of smoking among mothers is also higher for this group, and, on average, their parents have fewer years of education and are less likely to have read to their children on a daily basis. Family income, and the strength of family ties are also significantly lower among children experiencing parental loss, compared to children from families that remained intact. Given that these variables are correlated with family structure, and might also be associated with a child's personality development, they need to be taken into consideration when estimating the effects of parental loss on a child's personality development.

\subsubsection{Estimation}

For age-16 personality traits self-esteem, locus of control, and Rutter score, as well as changes in those personality traits between ages 10 and 16, the following relationship is estimated:

$$
Y_{i}=\alpha+\beta(\text { Lost Parent })_{i}+\gamma \mathbf{X}_{\mathbf{i}}+\epsilon_{i}
$$

for each individual $i$, and for each outcome $Y$. The coefficient on the parental loss dummy LostParent then measures how children, who lost a natural parent by the age of 16, differ in personality level and development from children who lived with both natural parents throughout childhood. In the baseline specification, the vector $\mathbf{X}$ is empty. I then add an increasing number of covariates, to control for quality of the home environment a child is born into.

Four sets of additional variables are considered, which are cumulatively added to the model as measures of parental investment and quality of the home environment. These controls cover birth conditions, social class indicators, and family characteristics at ages 5 and 10 . The controls for birth conditions include mother's age at birth, low birthweight, breastfeeding and mother's smoking during pregnancy. In the next specification, I add social class indicators alongside birth conditions. These include years of schooling of both mother and father, and whether the parents hold a skilled or professional job. Thirdly, family characteristics (at 5) are added: the number of older and the number of younger siblings, and a dummy indicating whether or not the five-year old was read to every day. Finally, family income and strength of family ties at age 10 complete the list of control variables (family (at 10)).

\footnotetext{
${ }^{7}$ Family income is a categorical variable measuring gross weekly family income in 50 pound brackets, ranging from 0 "under 35 pound" and 1 "35-49 pound," covering the lowest bracket, to 6 " 250 pound or more." Strength of family ties is measured by averaging how often the family engages in a variety of activities as a family. The activities are go for walks, go for outings, go on holidays, go shopping, go to restaurants, have meals, and have talks. Each item is scaled 1 "rarely/never," 2 "sometimes," 3 "often." Cronbach's alpha on the set of seven items is 0.66 .
} 
Table 4.2: Descriptives by Loss of Parent

\begin{tabular}{|c|c|c|c|c|c|c|}
\hline & \multicolumn{6}{|c|}{ Lost parent? } \\
\hline & \multicolumn{3}{|c|}{ No } & \multicolumn{3}{|c|}{ Yes } \\
\hline & mean & $s d$ & obs. & mean & $s d$ & obs. \\
\hline \multicolumn{7}{|l|}{ Raw personality scores } \\
\hline Self-Esteem Age 16 (SE16) & 17.92 & $(4.12)$ & 2,596 & $17.35^{--}$ & $(4.64)$ & 596 \\
\hline Locus of Control Age 16 (LoC16) & 22.15 & $(4.92)$ & 3,365 & $20.87^{--}$ & $(5.38)$ & 737 \\
\hline Rutter Score Age 16 (Rutter16) & 4.24 & $(3.97)$ & 6,091 & $5.35^{++}$ & $(4.66)$ & 1,603 \\
\hline Self-Esteem Age 10 (SE10) & 16.65 & $(4.52)$ & 5,633 & $16.02^{--}$ & $(4.50)$ & 1,489 \\
\hline Locus of Control Age 10 (LoC10) & 18.24 & $(4.76)$ & 5,603 & $17.42^{--}$ & $(4.61)$ & 1,477 \\
\hline Rutter Score Age 10 (Rutter10) & 425.45 & $(206.61)$ & 6,055 & $466.31^{++}$ & (225.90) & 1,585 \\
\hline Rutter Score Age 5 (Rutter5) & 7.59 & $(4.43)$ & 5,827 & $8.38^{++}$ & $(4.81)$ & 1,473 \\
\hline (SE16)-(SE10) & 0.98 & $(5.36)$ & 2,186 & 1.25 & $(5.44)$ & 485 \\
\hline$(\mathrm{LoC} 16)-(\mathrm{LoC} 10)$ & 3.48 & $(5.26)$ & 2,811 & $2.66^{--}$ & $(5.41)$ & 588 \\
\hline (Rutter16)-(Rutter5) & -3.29 & $(4.72)$ & 5,274 & $-2.93^{++}$ & $(5.32)$ & 1,276 \\
\hline Lost parent & 0.00 & & 6,771 & 1.00 & & 1,870 \\
\hline \multicolumn{7}{|l|}{ reason for loss: } \\
\hline Death & & & 6,771 & 0.18 & $(0.38)$ & 1,421 \\
\hline Divorce & & & 6,771 & 0.64 & $(0.48)$ & 1,421 \\
\hline Separation & & & 6,771 & 0.18 & $(0.39)$ & 1,421 \\
\hline \multicolumn{7}{|l|}{ age at loss: } \\
\hline At birth & & & 6,771 & 0.10 & $(0.30)$ & 1,870 \\
\hline Between 0 and 5 & & & 6,771 & 0.29 & $(0.45)$ & 1,870 \\
\hline Between 5 and 10 & & & 6,771 & 0.27 & $(0.44)$ & 1,870 \\
\hline Between 10 and 16 & & & 6,771 & 0.35 & $(0.48)$ & 1,870 \\
\hline \multicolumn{7}{|l|}{ Birth conditions } \\
\hline Male & 0.49 & $(0.50)$ & 6,771 & 0.49 & $(0.50)$ & 1,870 \\
\hline Mother's age at birth & 26.32 & $(5.21)$ & 6,310 & $24.85^{--}$ & $(5.62)$ & 1,726 \\
\hline Low birth weight & 0.06 & $(0.24)$ & 6,340 & $0.07^{+}$ & $(0.26)$ & 1,732 \\
\hline Breastfed dummy & 0.39 & $(0.49)$ & 5,864 & $0.36^{--}$ & $(0.48)$ & 1,480 \\
\hline Mother smoked during pregnancy & 0.37 & $(0.48)$ & 6,321 & $0.49^{++}$ & $(0.50)$ & 1,719 \\
\hline \multicolumn{7}{|l|}{ Social class } \\
\hline Years of schooling mother & 9.74 & $(1.78)$ & 6,306 & $9.60^{--}$ & $(1.61)$ & 1,724 \\
\hline Years of schooling father & 10.02 & $(2.37)$ & 6,196 & $9.73^{--}$ & $(1.99)$ & 1,606 \\
\hline Parents skilled/professional & 0.8 & $(0.40)$ & 6,338 & $0.72^{--}$ & $(0.45)$ & 1,731 \\
\hline \multicolumn{7}{|l|}{ Family characteristics (at 5) } \\
\hline \# of older siblings & 0.99 & $(1.07)$ & 5,879 & $1.05^{+}$ & (1.22) & 1,491 \\
\hline \# of younger siblings & 0.53 & $(0.64)$ & 5,879 & 0.52 & $(0.65)$ & 1,491 \\
\hline Read to every day & 0.43 & $(0.49)$ & 5,645 & $0.35^{--}$ & $(0.48)$ & 1,426 \\
\hline \multicolumn{7}{|l|}{ Family characteristics (at 10) } \\
\hline Gross weekly family income & 3.16 & $(1.16)$ & 5,657 & $2.51^{--}$ & $(1.31)$ & 1,525 \\
\hline Strength of family ties & 2.5 & $(0.30)$ & 6,152 & $2.42^{--}$ & $(0.33)$ & 1,619 \\
\hline
\end{tabular}

Note: Descriptive statistics for main raw personality scores for sample of 8,641 respondents with valid information on parental loss. Pluses and minuses indicate that the average of respondents who experienced parental loss differs from the average of respondents who lived with both natural parents throughout childhood. ${ }^{++}\left({ }^{+}\right)$indicates that the average of the sample with complete information is significantly larger at the $5 \%(10 \%)$ level, while ${ }^{--}\left({ }^{-}\right)$indicates that that average is significantly smaller at the $5 \%$ (10\%) level. 
Table 4.3: Differences in Personality from Loss of Parent

\begin{tabular}{lccc|ccc}
\hline \hline & SE & LoC & Rutter & $\Delta$ SE & $\Delta$ LoC & $\Delta$ Rutter \\
Lost parent & $-.136^{* * *}$ & $-.255^{* * *}$ & $.268^{* * *}$ & .050 & $-.157^{* * *}$ & $.0972^{* * *}$ \\
& $(-3.00)$ & $(-6.29)$ & $(9.61)$ & $(0.82)$ & $(-3.16)$ & $(2.96)$ \\
Constant & .025 & $.0458^{* * *}$ & $-.0559^{* * *}$ & -.009 & .027 & -.020 \\
& $(1.30)$ & $(2.67)$ & $(-4.39)$ & $(-0.35)$ & $(1.31)$ & $(-1.33)$ \\
& & & & & & \\
$n$ & 3,192 & 4,102 & 7,694 & 2,671 & 3,399 & 6,867 \\
\hline \hline
\end{tabular}

Note: OLS regression coefficients with t-statistics in parentheses. Baseline model, with no further controls.

\subsection{Results}

Personality levels at age 16, as well as personality development between ages 10 and 16, are considered as outcome measures. Since self-esteem, locus of control, and the Rutter score are all measured on a different scale, the scores on the personality scales are all standardized to have a mean of zero and standard deviation of one to make the regression results comparable. ${ }^{8,9}$ The point-estimates on parental loss can thus be interpreted in terms of standard deviation effects on age-16 personality. For personality development, the change in each of the three traits was calculated by subtracting the standardized age-10 score from the standardized age-16 score. Thus, the respondents within each regression sample score on average zero on both personality at age 16, as well as on personality change between ages 10 and $16 .^{10}$

\subsubsection{Baseline results}

Table 4.3 shows the results of equation (4.1) with an empty vector $\mathbf{X}$ : the baseline model. Personality and personality change are regressed on a dummy indicating whether or not the respondent experienced losing a natural parent between birth and age 16. The constant in this table thus represents the average standardized personality (change) for children who lived with both natural parents throughout their childhood. These children score slightly above the overall average in terms of age-16 internal locus of control, as well as in increase in internal locus of control between ages 10 and 16. At the same time, they score below average in terms of age-16 Rutter scores, while also experiencing larger decreases in behavior problems between 10 and 16 .

Looking at the first three columns of Table 4.3, losing a natural parent during childhood is associated with an eighth and a quarter of a standard deviation lower age-16 self-esteem and locus of control, respectively, but also a quarter of a standard deviation higher age-16 Rutter scores. These simple correlations might be reflecting differences in environments, and not only negative emotional effects of losing a parent. The last three columns of Table 4.3 show the correlation with personality development between 10 and 16 . Should the effects on age-16 levels only be reflections of environments, then, under the assumptions that environments are similar at ages 10 and 16 and that environments affect personality

\footnotetext{
${ }^{8}$ The standardization occurs within the regression samples.

${ }^{9}$ Results are qualitatively the same when raw personality scores, rather than standardized scores, are used. Results are available on request.

${ }^{10}$ See Table 4.4 .
} 
levels, but not development, there should be no significant correlation between parental loss and personality change. While the associations are smaller for personality changes than for levels, they are still quite substantial and highly significant.

Children who went from living with two natural parents to living with one natural parent did not change differently in terms of self-esteem from those who lived with both parents throughout childhood. These children did, however, decline 0.16 standard deviations in terms of locus of control relative to those from intact families, while also increasing a tenth of a standard deviation in behavior problems ( $\Delta$ Rutter), thus providing an indication that the experience of losing a parent has effects on personality, beyond the environmental differences between families that remain intact and those that do not.

Environments foster skills, but they may also improve the development of them. The technology of skill formation (Cunha et al., 2006) postulates that skills attained earlier in life make the acquisition of skills later in life easier, and that these early skills are determined by early investments, or environments. In this case, the quality of the home environment a child grows up in determines early personality (noncognitive skills), which in itself enhances the production of personality later in life. Even if the quality of the home is similar at ages 10 and 16, as just assumed, it may still be the case that differences in initial conditions may result in differences in personality development, through the self-productivity of noncognitive skills. The observed correlations may also be biased if they reflect the effects of unobserved variables. The next step is then to control for these omitted variables.

\subsubsection{Selectivity}

The results from the above simple regressions might be capturing part of a bigger picture. The association between family breakdown and outcomes might be the result of selection, rather than causation (see e.g. Björklund et al., 2007; Björklund \& Sundström, 2006; Francesconi et al., 2010; Ginther \& Pollak, 2004). One way to investigate whether the association between noncognitive skills and loss of a parent during childhood truly is an exogenous shock, or whether it is just capturing the effects of parental investment, is to control for other omitted variables that are correlated with both family structure and a child's personality development. Figure 4.1 reveals what happens to the point estimates of loss of a parent during childhood, once an increasing set of covariates is added to the model. As described above, four sets of additional variables are cumulatively added to the model as measures of parental investment and quality of the home environment. These controls cover birth conditions, social class indicators, and early family characteristics. The first line, marked with an $\mathbf{x}$, repeats the results shown in Table 4.3, for the baseline model without additional controls (none). The point estimate is marked with an $\mathbf{x}$, while the bars to the left and right show the 90 percent confidence interval of the coefficient. Similarly, the remaining lines show results from cumulatively adding controls for birth conditions, social class at birth, and family environment at ages 5 and 10 .

As is to be expected, adding controls that are correlated with marital instability reduces the point estimates of the effects of losing a parent on age-16 personality. Ginther \& Pollak (2004), using US data, find that adding other variables as controls often reduces associations between family structure and educational outcomes, often to the point of insignificance. Ermisch \& Francesconi (2001), using British data, however, retain significant effects, even after controlling for the economic environment the child grows up in. Figure 4.1 reflects this inconsistency in findings. With the most complete set of control variables - the bottom line 
Figure 4.1: Point estimates of Loss of Parent on Personality
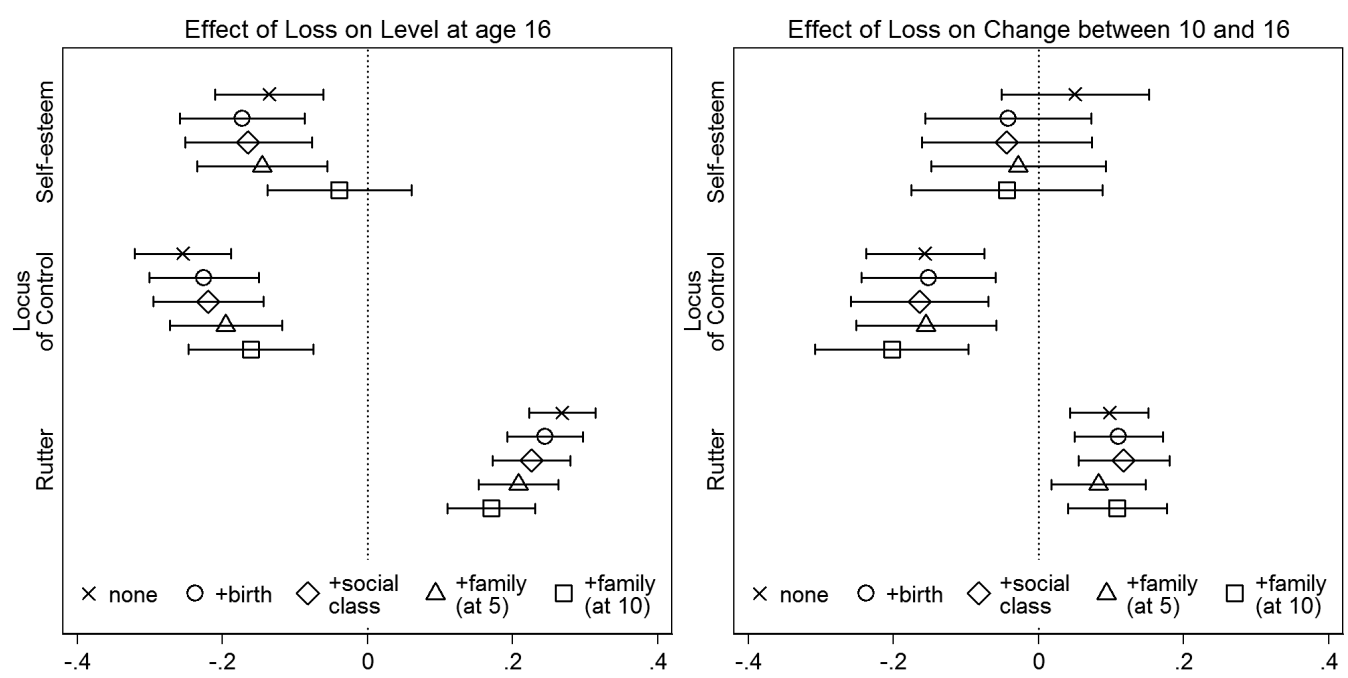

Note: OLS regression coefficients and $90 \%$ confidence intervals for loss of parent (horizontal axis), separately for each personality trait (vertical axis), and for different sets of controls.

for each trait, denoted with a square - , the effect of parental loss on age-16 self-esteem is indeed no longer significantly different from zero, indicating that the correlation between family dissolution and self-esteem is the result of omitted variables. However, for locus of control and the Rutter score for behavior problems, the estimates remain significant and sizeable at -.16 and .17 standard deviations, respectively. These effect sizes are comparable to the mean effect sizes found by Amato (2001). In an update on an earlier meta-analysis (Amato \& Keith, 1991), he finds that children experiencing divorce score just over a fifth of a standard deviation lower in terms of conduct and psychological adjustment, and 0.15 standard deviations lower in terms of social relations.

The full specifications of the results from Figure 4.1 are presented in the Appendix, in Tables 4.A.1 and 4.A.2. Those tables also report the coefficients on the control variables, giving insights into the possible mechanisms driving the correlation between parental loss and a child's personality development. For age-16 personality (Table 4.A.1), each control variable enters significantly in the regression of one or more of the three traits. For example, low birthweight is predictive of low self-esteem and behavior problems, yet not of lower lower locus of control. Mother's smoking during pregnancy, on the other hand, correlates significantly with locus of control and the Rutter score, yet not with self-esteem. The controls that seem to be predictive of personality traits across the board are parental education, and parental care, as proxied by reading to the five-year-old child on a daily basis, as well as the strength of family ties at age 10. Additionally, the number of siblings, and especially the number of younger siblings, has a detrimental effect on personality traits. Finally, there is also an important role for family income, which was also observed by Ginther \& Pollak (2004), who found that after controlling for family income, the effect of living in a singleparent family was often no longer significant.

The sets of covariates are added to mitigate the omitted variable bias in the point estimates for parental loss, and cover various aspects of the home environment before the age of 10 . To the extent that the effects of family characteristics prior to age 10 are already reflected 
in age-10 personality, the association between parental loss and personality change between ages 10 and 16 will be unaffected by the addition of the sets of controls. This is both reflected in the coefficients on the controls, which are largely insignificant, as well as on the dummy for parental loss (Table 4.A.2). Regarding the changes in self-esteem, locus of control, and behavior problems, the ever expanding set of controls does not significantly change the point estimates of parental loss. Regarding self-esteem, the effect was not significantly different from zero to begin with. Combined with the insignificant effect on age-16 self-esteem with the full set of controls, the correlation between parental loss and self-esteem seems to be merely a reflection of omitted variables. However, the point estimates for age-16 locus of control and Rutter scores remain significant, even in the case of the most extensive set of controls, as is also the case for changes in these traits between ages 10 and 16. This result could be interpreted as evidence of a causal relationship between parental loss and locus of control and behavior problems, but may also be driven by other factors not yet taken into account.

Selection thus plays a major role in explaining the observed simple correlation between parental loss and personality development. The reduction in point-estimates indicates that family dissolution is indeed selective, rather than exogenous, yet the estimated effects of parental loss often remain sizeable and significant, providing support for the argument that the negative effects associated with the loss of one of two parents in the household are not merely reflecting a-priori differences between intact and break-down families. However, to be able to make claims about causality, one has to rely on rather strong assumptions of exogeneity, even after controlling for a range of confounding factors. The assumption of exogeneity of parental loss is further investigated in Section 4.5. To limit the effect of selection, the most complete specification will be used for all further analyses, thus controlling for birth conditions, social class at birth, and family characteristics at ages 5 and 10 .

\subsection{Heterogeneous Effects}

Using the most complete specification, I investigate the heterogeneity of effects, by looking into the reasons for parental loss and the age at which the child went from a two-naturalparent home to a one-natural-parent home, while also allowing the effects of parental loss to differ by gender of the child.

\subsubsection{Reasons for Loss}

For most of the children who went from a two-parent to a one-parent household, the reason for the loss of that parent is also known. The move from a two- to one-parent household could be the result of a separation of parents, divorce of parents, or the death of one of the two natural parents. The reason for parental loss was divorce in two-thirds of cases where the reason was known. The remaining third of cases are equally divided between separation of parents and death of one of the parents. ${ }^{11}$ To estimate the results by reason of loss, the Lost Parent dummy in equation (4.1) is replaced by three dummies: one for separation, one

\footnotetext{
${ }^{11}$ Depending on the regression sample, the reason for loss of parent is unknown for 3 to 5 per cent of the complete sample. When only considering those who experienced parental loss (some 22 percent), the reason for parental loss is only known for about 4 out of 5 respondents.
} 
for divorce, and one for death. This results in estimating the following model:

$$
Y_{i}=\alpha+\beta_{1}(\text { Separation })_{i}+\beta_{2}(\text { Divorce })_{i}+\beta_{3}(\text { Death })_{i}+\gamma \mathbf{X}_{\mathbf{i}}+\epsilon_{i}
$$

for each individual $i$, and for each outcome $Y$, while controlling for the full set of controls (X), including birth conditions, social class at birth, and family characteristics at ages 5 and 10. The comparison group - with zero's on all three dummies - again represents children who lived with both natural parents throughout childhood.

Figure 4.2 shows the point estimates and confidence intervals for the reason for loss dummies. Of the three reasons, divorce is the strongest predictor of personality at age 16 . Children experiencing divorce of their natural parents score 0.15 standard deviations lower on age-16 locus of control and 0.17 standard deviations higher on the Rutter score for behavioral problems, compared to children from homes that remained intact. The effects of experiencing death of a parent or separation of parents are both economically and statistically insignificant. These findings are consistent with those from Corak (2001), whose difference-in-difference estimates reveal that the associations between parental loss and income, earnings, and own marital stability are greater in the case of divorce, than in the case of death of a parent.

Figure 4.2: Point estimates of Reasons for Loss of Parent on Personality
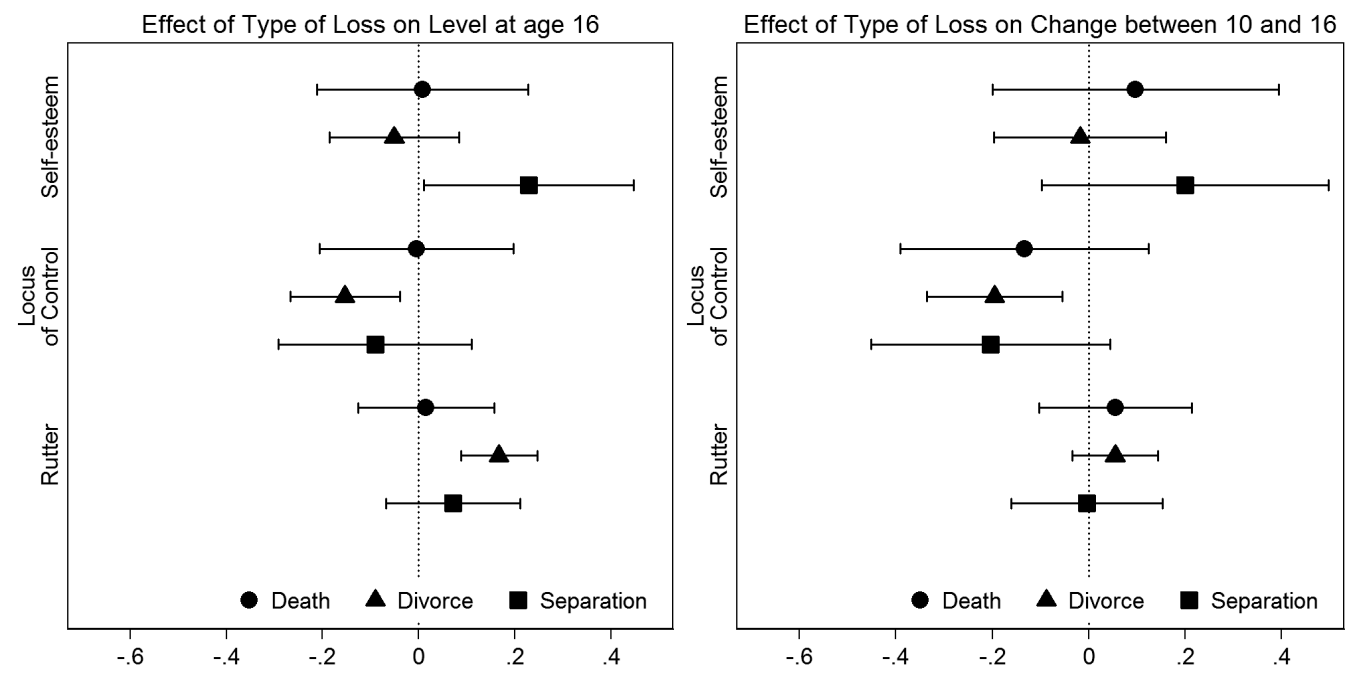

Note: OLS regression coefficients and $90 \%$ confidence intervals for reasons of loss of parent (horizontal axis), separately for each personality trait (vertical axis). Each specification includes three dummies for reason of loss of parent (death, divorce, or separation), as well as a full set of controls, including birth conditions, social class at birth, and family characteristics at age 5 and at age 10 .

In terms of personality changes, the effects of the different reasons for parental loss are mostly insignificant. The only significant result is that children experiencing divorce of their parents, decline 0.2 standard deviations in terms of internal locus of control, compared to children from intact families. The point estimates of experiencing death of a parent or separation of parents are generally comparable in magnitude, yet not significantly different from zero. The lack of effects in terms of personality change might be because the effects of parental loss have already manifested themselves by the age of 10. It might also be the case that crucial variables are missing from the analysis, such as unobserved pre-existing 
health conditions of the parents, family stress or marital instability, which may have affected childhood personality prior to the actual change (e.g. Chen et al., 2009). Both arguments point to selection being the driving force behind the observed correlation between parental loss and personality development.

The selectivity of family structure is also apparent from the results in Table 4.A.3, reporting the point estimates of the three reasons for parental loss for all sets of controls. As already demonstrated in Figure 4.1, adding more covariates to the model, capturing a wider range of family characteristics, reduces the estimated correlation between the various reasons for loss of a parent and personality traits, as measured at age 16. Again, in terms of personality changes, adding more covariates does not alter the associated correlations between parental loss and personality development between the ages of 10 and 16, mainly because the impact of family characteristics is already captured in age-10 personality.

\subsubsection{Age at Loss}

For all children experiencing loss of a parent, it is known between which two waves the change occurred. This information divides the children experiencing a loss of a parent into four groups: a child can be born into a single-parent family, or lose one of two parents between birth and age 5 , between ages 5 and 10 , or between ages 10 and 16 . Of the 1,870 children experiencing parental loss, 10 percent are born into a single parent household. Some 29 percent lose a parent between birth and age 5 , and an additional 27 percent between the ages of 5 and 10. The remaining third of these children lost a parent between the ages of 10 and 16. Creating dummies for each of the four groups, the Lost Parent dummy in equation (4.1) is then replaced by four dummies, leading to the following model:

$$
Y_{i}=\alpha+\beta_{1}(\text { At birth })_{i}+\beta_{2}(0 \text { to } 5)_{i}+\beta_{3}(5 \text { to } 10)_{i}+\beta_{3}(10 \text { to } 16)_{i}+\gamma \mathbf{X}_{\mathbf{i}}+\epsilon_{i}
$$

for each individual $i$, and for each outcome $Y$, while controlling for the full set of controls (X), including birth conditions, social class at birth, and family characteristics at ages 5 and 10. The comparison group - with zero's on all four dummies - again represents children who lived with both natural parents throughout childhood. The results are shown in Figure 4.3 .

The pattern of effects for the different ages at which parental loss occurs differs between the three personality measures. For age-16 self-esteem, being born into a single-parent home, as well as losing one of two natural parents from the household between ages 10 and 16 are associated with significantly lower age-16 self-esteem, while a loss occurring between birth and age 5 , or between ages 5 and 10 , does not lead to significantly different self-esteem scores, in comparison to children from families that remained intact. For locus of control, however, experiencing a loss between 5 and 10 is detrimental, in addition to being born into a one-natural parent home. A change between 5 and 10 is again insignificant when it comes to predicting age-16 Rutter scores. The inconsistent patterns across personality measures highlights the importance of the measure used to define family dissolution or break-down. Family structure measured at any particular age or point in time is only a weak proxy for childhood circumstances, and does not capture any changes during childhood (see e.g. Ginther \& Pollak, 2004). ${ }^{12}$

\footnotetext{
${ }^{12}$ Which controls are added to the specification also plays a role. Figure 4.3 depicts the estimates for the specification with the most complete set of covariates, whereas Table 4.A.4 reports the point estimates
} 
Figure 4.3: Point estimates of Age at Loss of Parent on Personality
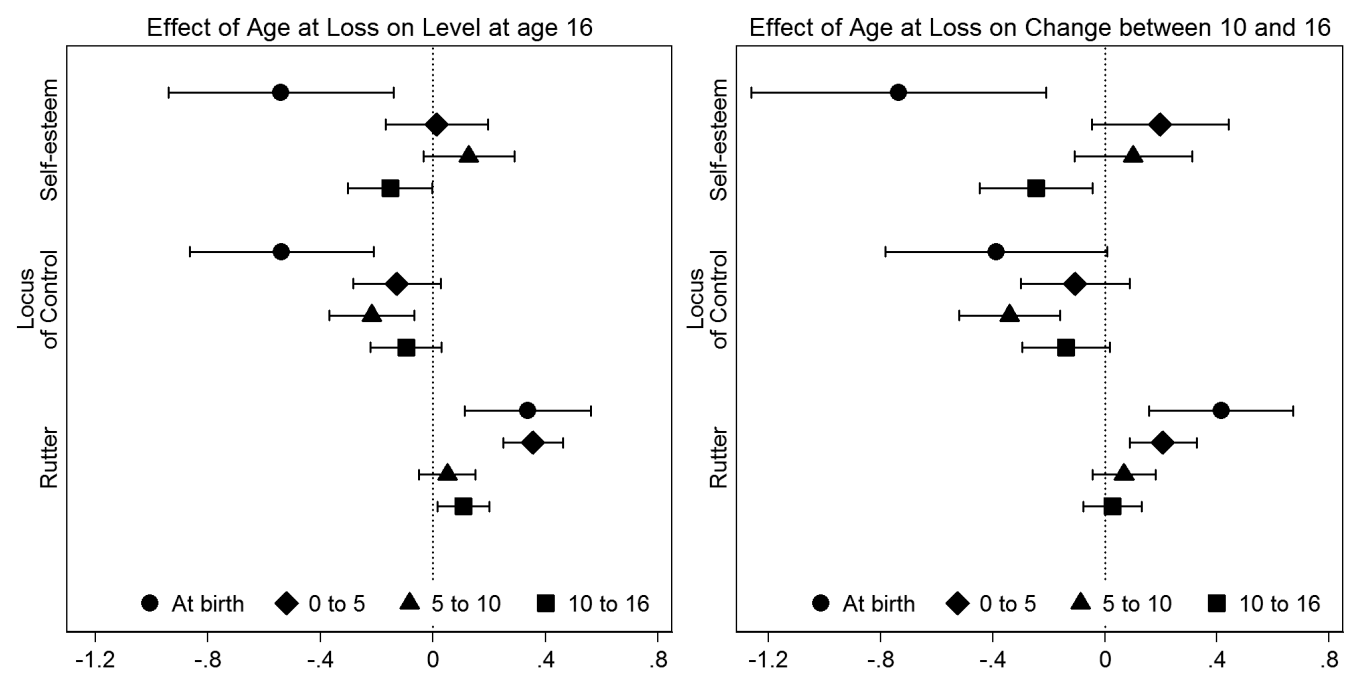

Note: OLS regression coefficients and $90 \%$ confidence intervals for age at loss of parent (horizontal axis), separately for each personality trait (vertical axis). Each specification includes all four age at loss dummies, as well as a full set of controls, including birth conditions, social class at birth, and family characteristics at age 5 and at age 10 .

Generally, the effects of parental loss are less severe if the child was older at the time of the change. More specifically, a loss at birth is significantly associated with all three personality measures, as well as with development in these traits between 10 and 16. Those born into single parent families show the largest difference with respect to children from families that remained intact. These individuals score over half a standard deviation lower on age-16 self-esteem and locus of control, and about a third of a standard deviation higher on the Rutter scale for behavioral problems. Additionally, they decline by about 0.7 standard deviations in the distribution of self-esteem between 10 and 16, while increasing with 0.4 standard deviations in the distribution of Rutter scores, compared to children from twoparent households. These results are consistent with findings from Ermisch and co-authors (2004; 2001), who find that the experience of life in a single-parent family significantly affects young adults' education, inactivity, and smoking behavior, and that the effects are most disadvantageous in the case of early disruption. These findings are also in line with the technology of skill formation, in which early parental investment not only determines early skills, but also later skills and personality, through the self-productivity of these skills (Cunha \& Heckman, 2007). Knudsen et al. (2006) discuss results from economics, developmental psychology, and neurobiology; all highlighting the importance of early experiences.

for all five sets of controls. The pattern of age effects differs not only across personality measures, but also across specifications, each of which includes different control variables. The controls all capture family characteristics, yet are measured at different points in time, and their individual effects might also depend on the age of the child. 


\subsubsection{Gender Differences}

There is a growing literature on the differences in the way boys and girls are affected differently by their environment. Gould, Lavy \& Paserman (2011) show that being exposed to a more modern and higher quality environment leads to better education and higher employment, and that these effects are stronger for girls. Estimating the effect of parental education on child education, Gould \& Simhon (2011) find that the education of parents affects daughters much more than sons. When it comes to childhood intervention programs, there are some mixed results. The Abecedarian program boosted IQ, but primarily for girls (Cunha et al., 2006). Results at age 27 from participants in the Perry Preschool Program are also generally more favorable for girls, yet this pattern reverses when outcomes at age 40 are considered. This section contributes to this discussion by looking at gender differences in the effects of parental loss.

\section{Figure 4.4: Point estimates of Loss of Parent on Personality, by Gender}
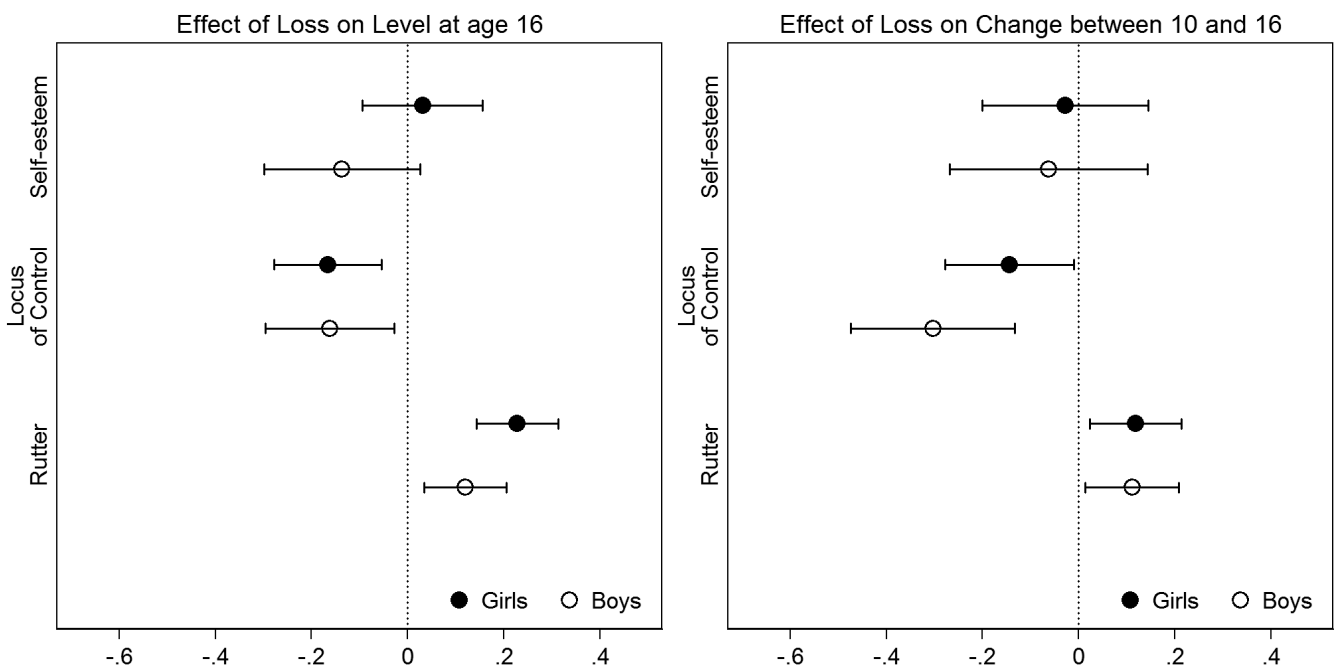

Note: OLS regression coefficients and $90 \%$ confidence intervals for loss of parent (horizontal axis), separately for each personality trait (vertical axis). Separate regressions for girls and boys, each including a dummy indicating the child lost a parent between birth and age 16, as well as a full set of controls, including birth conditions, social class at birth, and family characteristics at age 5 and at age 10 . Full specifications available on request.

Figure 4.4 shows the results of model (4.1) separately for boys and girls. The regressions contain the full set of controls $(\mathbf{X})$, including birth conditions, social class at birth, and family characteristics at ages 5 and 10. While there seem to be slight differences between boys and girls in the point estimates for personality level and personality change, the estimates are not consistently larger for either boys or girls. Boys seems to suffer more from parental loss in terms of age-16 self-esteem, yet the point estimates for both boys and girls are statistically not significantly different from zero. When it comes to age-16 Rutter scores, girls do suffer more from parental loss than boys do. When it comes to personality development between 10 and 16, parental loss impacts the development of locus of control of boys more than it does for girls. 
When looking at the reason for parental loss (model (4.2)), a more detailed picture emerges (see Figure 4.5). Boys are more negatively affected by parental death than girls, and there are also indications that girls suffer more from a separation or divorce of her parents, which is in line with the results obtained by Corak (2001).

Figures 4.4 and 4.5 report results from separate regressions for boys and girls. Regressions on the full sample with an additional interaction term between the parental loss dummy and a gender dummy confirm that the association between parental loss and age-16 Rutter scores is significantly larger for girls than for boys. Their are no significant gender differences in the estimates of parental loss on age-16 self-esteem or locus of control, or any of the personality development measures. Estimating model (4.2) with interaction terms between reasons and gender confirms that boys are significantly more affected by parental death than girls. This is true for the effect of parental death on age-16 self-esteem and Rutter scores, and for change in Rutter scores between 10 and 16. When it comes to parental divorce and separation, the only significant gender interaction effect is that for age-16 Rutter scores. ${ }^{13}$

Figure 4.5: Point estimates of Reasons for Loss of Parent on Personality, by Gender
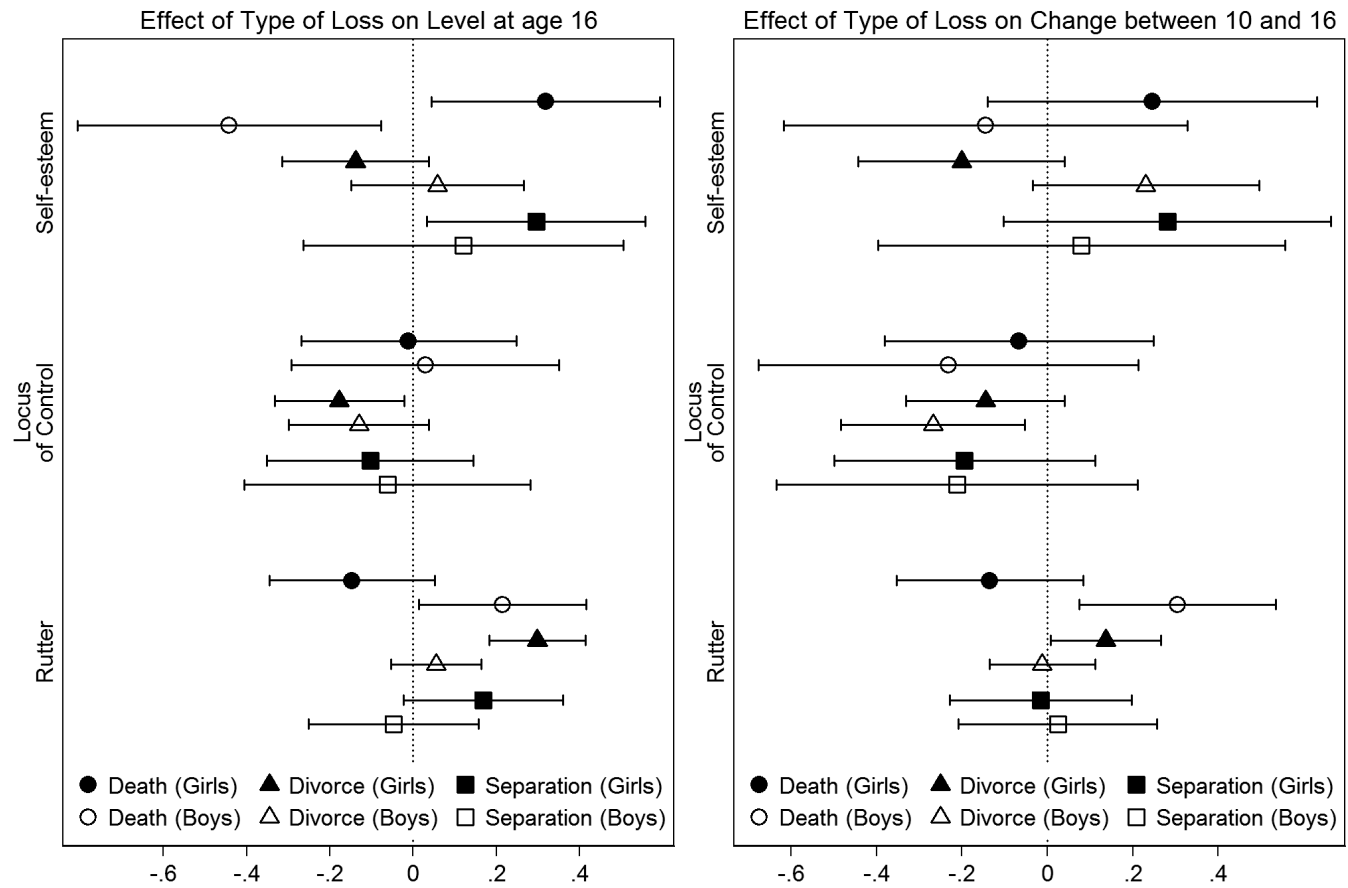

Note: OLS regression coefficients and $90 \%$ confidence intervals for reasons of loss of parent (horizontal axis), separately for each personality trait (vertical axis). Separate regressions for girls and boys, each including three dummies for reason of loss of parent (death, divorce, or separation), as well as a full set of controls, including birth conditions, social class at birth, and family characteristics at age 5 and at age 10 . Full specifications available on request.

\footnotetext{
${ }^{13}$ The pattern of effects for age at loss of parent (model (4.3)) are similar for boys and girls, and a model with interaction terms between the age dummies and gender confirm that there are no significant differences. These results are available on request.
} 


\subsection{Endogeneity and Sample Selection}

The results provided thus far indicate that experiencing parental loss is significantly related to personality development in children. This is in line with previous results on the effects of various forms of family breakdown on child and adult outcomes (for reviews, see Amato \& Keith, 1991; Amato, 2001). However, more recent literature has cast doubt on the causality of the demonstrated correlations. Adding controls reduces the size of the association between family structure and outcomes, even to the point of insignificance (see e.g. Francesconi et al., 2010; Ginther \& Pollak, 2004). Results from sibling-difference models also provide evidence against a causal interpretation, finding that the correlations between family structure and child outcomes are not significant (see e.g. Björklund et al., 2007; Björklund \& Sundström, 2006). While the results demonstrated in Figure 4.1 reveal a reduction of the effect size when additional controls are added to the model, a significant relationship between parental loss and personality development remains. If parental loss is simply capturing the effect of omitted variables, or if the effect is driven by selection in the regression sample, there is no support for a causal interpretation of the uncovered correlations. This section first investigates the endogeneity of family structure with the use of placebo regressions. Second, the role of sample selection is discussed.

\subsubsection{Placebo Effects of Losing a Parent}

If parental loss truly is an exogenous shock, any association between parental loss and personality should only arise after the change in family structure. Under the assumption of a causal relation between family breakdown and personality, parental loss after age 10 should not be significantly related to personality measured at age 10. Since personality traits are measured at age 10, as well as at age 16, the causality of parental loss can thus be tested.

Applying model (4.1) to a restricted sample of children who lived with both natural parents until at least the age of 10 results in estimates on the effect of losing a parent between the ages of 10 and 16. Using personality at age $16(Y(16))$ as dependent variable, the results are the same as those for the (10 to 16) dummy in model (4.3) (see Figure 4.3). However, a significant effect of losing a parent between 10 and 16 on personality at age $10(Y(10))$ would indicate that parental loss is endogenous, and the estimated effects provided earlier are the result of selection. The following relationships are estimated:

$$
\begin{aligned}
& Y(16)_{i}=\alpha+\beta(\operatorname{Lost} \operatorname{Parent}(10 \text { to } 16))_{i}+\gamma \mathbf{X}_{\mathbf{i}}+\epsilon_{i} \\
& Y(10)_{i}=\alpha+\beta(\operatorname{Lost} \operatorname{Parent}(10 \text { to } 16))_{i}+\gamma \mathbf{X}_{\mathbf{i}}+\epsilon_{i}
\end{aligned}
$$

for each individual $i$, and for each personality trait $Y$, and various sets of controls $(\mathbf{X})$, ranging from an empty set $\mathbf{X}$, to a complete set, including birth conditions, social class at birth, and family characteristics at ages 5 and 10 . Figure 4.6 reports the results of the above specifications for self-esteem, locus of control, and Rutter behavior problems.

Children who lose a parent between 10 and 16 - when compared to children from intact families -, score significantly lower in terms of self-esteem and locus of control, and significantly higher on the Rutter scale for behavior problems, when measured at age 16 (left plot in Figure 4.6). Expanding the set of control variables reduces the correlation between parental loss and age-16 personality, thus mitigating the omitted variable bias. For locus of 
Figure 4.6: Placebo Effects: Loss of Parent between 10 and 16 on Personality at 16/10
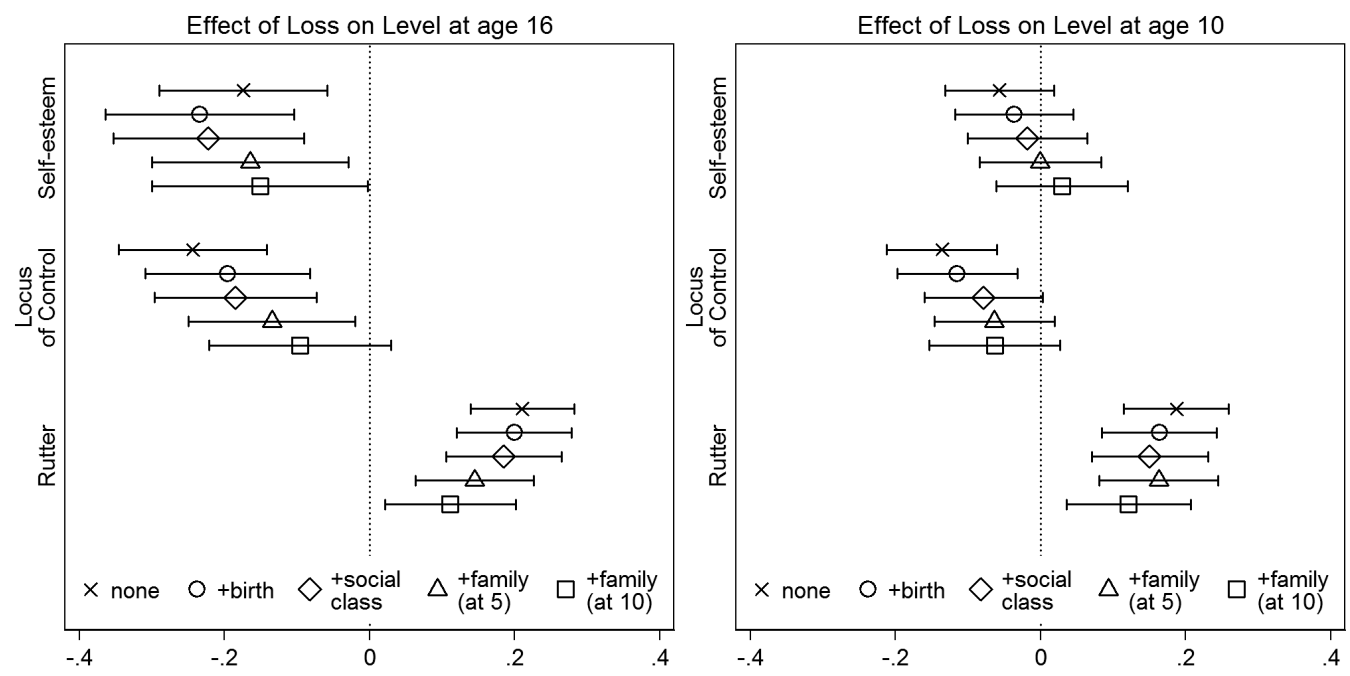

Note: OLS regression coefficients and 90\% confidence intervals for loss of parent between ages 10 and 16 (horizontal axis), separately for each personality trait (vertical axis). Full set of controls, including birth conditions, social class at birth, and family characteristics at age 5 and at age 10 . The sample here only includes children who lived with both natural parents throughout childhood (reference group) and those who lost one natural parent between ages 10 and 16 .

control, the effect is no longer statistically significant when the full set of controls is used. To test whether parental loss is still endogenous, personality traits at age 10 are regressed on parental loss after age 10. The plot on the right in Figure 4.6 reveals that these correlations are much smaller than those with age-16 personality. Using the full set of controls, the point estimate for self-esteem is zero, and that for age-10 locus of control is half of what it is for age-16 locus of control, and not significantly different from zero. These results provide support for the claim that parental loss is exogenous, and that the associations with self-esteem and locus of controls may be causal. However, for Rutter scores, the point estimates on parental loss are equal in magnitude, whether Rutter scores are measured at age 10 or at age 16, which indicates family breakdown is still endogenous. When the dummy for parental loss between 10 and 16 is split up by reason of parental loss, equivalent to model (4.2), a more detailed pattern emerges.

Figure 4.7 shows the results of model (4.2), applied to the restricted sample of children who lived with both natural parents until at least the age of 10. Experiencing parental death between the ages of 10 and 16 is not significantly related to age- 16 personality. The association with age-10 personality is also mostly insignificant, and even turns positive in case of self-esteem and locus of control. These results support the notion that death of a parent is an exogenous event, but nevertheless is not strongly associated with personality development. Divorce and separation, however, seem to be endogenous, despite using the full set of controls. For divorce, the point estimates on age-16 personality traits average at .23 standard deviations. For Rutter score, the association with age-10 and age-16 scores are similar in magnitude and significance (at .17 standard deviations), while the point estimates for age-10 self-esteem and locus of control reduce significantly and are no longer significantly different from zero. 
Figure 4.7: Placebo Effects: Reason for Loss of Parent between 10 and 16 on Personality at $16 / 10$
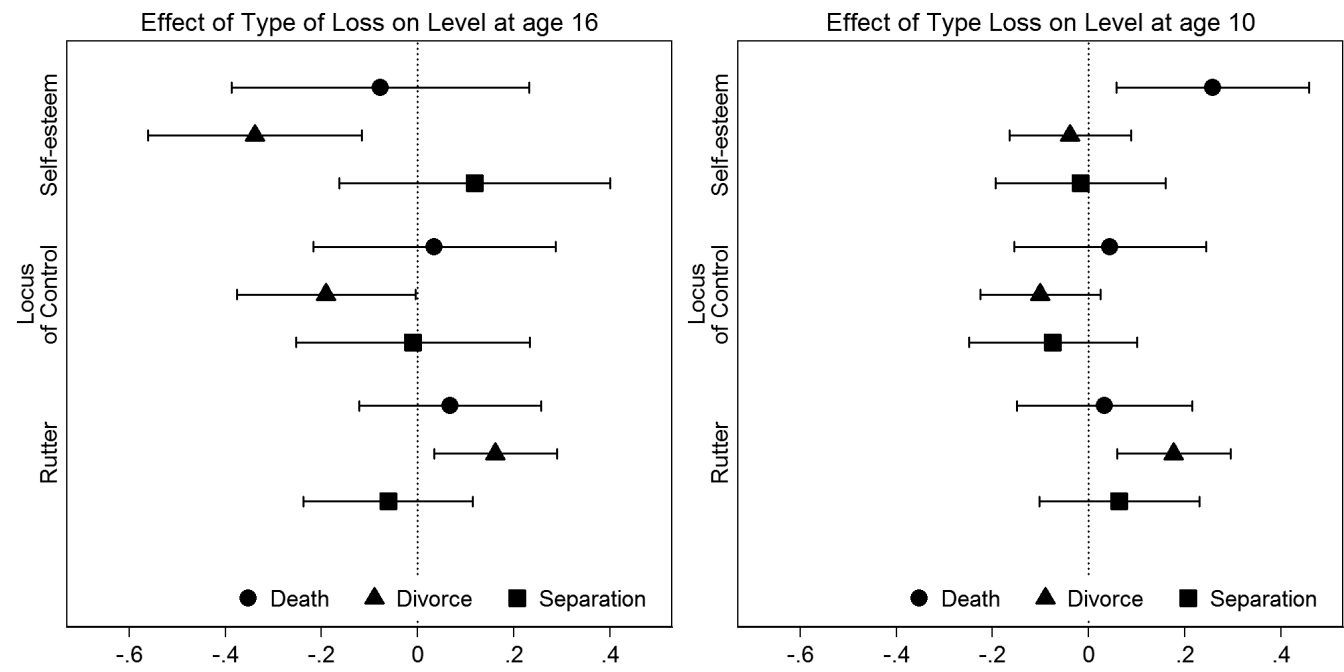

Note: OLS regression coefficients and $90 \%$ confidence intervals for reason for loss of parent between ages 10 and 16 (horizontal axis), separately for each personality trait (vertical axis). Full set of controls, including birth conditions, social class at birth, and family characteristics at age 5 and at age 10 . The sample here only includes children who lived with both natural parents throughout childhood (reference group) and those who lost one natural parent between ages 10 and 16 .

These results demonstrate that the significant point estimates on parent loss, and parental divorce more specifically, cannot be interpreted as causal effects. ${ }^{14}$ While the correlation is significant, the placebo regressions show that part of the association between personality and parental loss already manifests itself before the change in family structure actually occurred. This points to the existence of factors not yet taken into account, that correlate strongly with family dissolution, as well as with childhood personality development.

\subsubsection{Sample Selection}

In the analyses presented above, there are a number of selection rounds, or rounds of sample restrictions. To the extent that this selection is not random, the estimates provided above may be biased. Table 4.4 provides averages for all variables for the complete sample, as well as averages for the sample that remains after each selection round. At the same time,

\footnotetext{
${ }^{14}$ These results demonstrate that the conclusions about effect sizes and causality of family beakdown depend on the controls used, as well as the outcome measure. For self-esteem, the placebo effects show the required results, with point estimates dropping to zero, providing support for making causal claims. In the case of locus of control, a similar pattern emerges, with the conclusion being that endogeneity has been partially accounted for. However, the placebo analysis for Rutter scores reveals correlations of similar magnitude as the main analysis, leading one to conclude that endogeneity is still a big problem and that the set of controls used is not mitigating the omitted variable bias. Given that sample sizes are smallest for self-esteem, and largest for Rutter scores, one could argue that these conclusions hinge on the precision of the estimates. Also, Locus of control and self-esteem are based on a smaller number of child-rated items, resulting in Cronbach's alphas of 0.7. Rutter scores are constructed with the use of a larger set of motherrated items, with a Cronbach's alpha of 0.8 . The conclusions may thus also depend on measurement error or differences in whether the outcomes are self-reported or reported by others.
} 
each column indicates whether the average within the selected sample is significantly different from the average of individuals with incomplete information in that selection round. This gives an idea of the extent of selection and possibly also the direction of bias due to non-response or attrition. The first round of selection involves selecting respondents with valid information on parental loss, as obtained from the 1986 parental questionnaire (Loss). Second, controlling for birth conditions, social class, and family characteristics at ages 5 and 10 reduces the sample available for analyses even further (Controls). Finally, information is needed on age-16 personality traits $(P 16)$, and for the analyses on personality development, also on age-10 personality traits (P10).

First of all, information on family structure during childhood is required. This information is only available for 46 percent of the total target sample $(8,641$ of 18,724$)$. Within this sample (Loss), the share of children experiencing family breakdown is 22 percent. Benson (2010) points out that it is often cited that one in four children children in the UK live with one natural parent at any one time. A less well known statistic is the proportion of children who will live with one natural parent before they are 16 years old. Benson (2010) uses data from cohorts born in the 1980s to demonstrate that among these cohorts, this statistic is as high as 40 percent, and estimates that by 2009, one half of all children will experience family breakdown by the age of 16 . Andersson (2002) provides a very similar statistic for 15 other European countries and the USA. ${ }^{15}$ The average among those countries is 27 percent.

Compared to these statistics, the share of 22 percent obtained from parental reports from the 1986 wave of the British Cohort Study seems quite low. The cohorts reported on by Benson (2010) are younger than the BCS70 cohort, and the UK was not among the countries reported on by Andersson (2002), which makes a direct comparison rather problematic. A statistic that can be more easily verified is the percentage of births outside marriage. Historical statistics for England and Wales show that this percentage was 8.3 percent for 1970 (Office for National Statistics, 2010). This share in the BCS is comparable at 7.4 percent, when using information reported by all mothers present in the 1970 wave. Among respondents with valid information from the 1986 wave on family structure, this share is only 4.4 percent, indicating that unmarried mothers are underrepresented in the regression samples. This then confirms the suspicion that the observed share of children experiencing parental loss ( 22 percent) is lower than one would expect from a representative sample. That selection on parental loss information is non-random, is also confirmed by the second column in Table 4.4, with those with valid information on parental loss having more desirable birth conditions, social class and family characteristics.

This undersampling of instable families becomes more severe after the second round of selection. Of the respondents with data on parental loss, only 65 percent have complete data on the full set of controls $(5,614$ of 8,641). Only 19 percent of these respondents experience loss of a parent before age 16, compared to 27 percent for the 35 percent of respondents with incomplete information on the control variables. Further restricting the sample to those with valid information on self-esteem, locus of control, and Rutter scores, reduces the share of children experiencing family breakdown to 16 percent when age-16 personality information is required (sample $P 16$ ), and to 15 percent when, additionally, information on age-10 personality is required (sample P10). ${ }^{16}$

\footnotetext{
${ }^{15}$ Using synthetic cohorts, Andersson (2002) report the cumulative percent of children living in a family that was ever out of union (not living with both natural parents) at various ages of children, including age 15. The countries with the highest percentages are USA with 50 percent, and Sweden, France, Austria and Germany, all with shares between 30 and 34 percent.

${ }^{16}$ The regression analyses use the maximum number of observations available. This means that after
} 
Table 4.4: Means for Selective Samples

\begin{tabular}{|c|c|c|c|c|c|}
\hline $\begin{array}{l}\text { Selection } \\
\text { Baseline sample } \\
\text { max. obs. } \\
\text { Sample name }\end{array}$ & $\begin{array}{l}\text { No selection } \\
\text { Full sample } \\
18,724 \\
\text { Full sample } \\
\end{array}$ & $\begin{array}{l}(1) \\
\text { Full } \\
8,641 \\
\text { Loss }\end{array}$ & $\begin{array}{c}(1,2) \\
(1) \\
5,614 \\
\text { Controls }\end{array}$ & $\begin{array}{c}(1,2,3) \\
(1+2) \\
2,044 \\
P 16\end{array}$ & $\begin{array}{c}(1,2,3,4) \\
(1+2+3) \\
1,672 \\
P 10 \\
\end{array}$ \\
\hline Standardized personality scores & & & & & \\
\hline Self-Esteem Age 16 (SE16) & 0.00 & 0.00 & 0.01 & 0.00 & $0.02^{+}$ \\
\hline Locus of Control Age 16 (LoC16) & 0.00 & $0.03^{++}$ & $0.06^{++}$ & 0.06 & $0.10^{++}$ \\
\hline Rutter Score Age 16 (Rutter16) & 0.00 & $-0.02^{--}$ & $-0.05^{--}$ & $-0.12^{--}$ & $-0.14^{--}$ \\
\hline Self-Esteem Age 10 (SE10) & 0.00 & $0.03^{++}$ & 0.03 & $0.10^{++}$ & 0.11 \\
\hline Locus of Control Age 10 (LoC10) & 0.00 & $0.05^{++}$ & 0.06 & $0.24^{++}$ & 0.24 \\
\hline Rutter Score Age 10 (Rutter10) & 0.00 & $-0.04^{--}$ & $-0.05^{-}$ & $-0.16^{--}$ & $-0.18^{--}$ \\
\hline$(\mathrm{SE} 16)-(\mathrm{SE} 10)$ & 0.00 & -0.01 & 0.00 & -0.01 & -0.01 \\
\hline (LoC16)-(LoC10) & 0.00 & 0.01 & $0.03^{+}$ & $-0.01^{--}$ & -0.01 \\
\hline (Rutter16)-(Rutter5) & 0.00 & -0.01 & $-0.03^{--}$ & 0.00 & 0.01 \\
\hline Lost parent & 0.22 & 0.22 & $0.19^{--}$ & $0.16^{--}$ & 0.15 \\
\hline Birth conditions & & & & & \\
\hline Male & 0.52 & $0.49^{--}$ & 0.49 & $0.43^{--}$ & $0.42^{-}$ \\
\hline Mother's age at birth & 25.97 & 26.00 & 25.97 & $26.33^{++}$ & 26.36 \\
\hline Low birth weight & 0.08 & $0.06^{--}$ & 0.06 & 0.06 & 0.06 \\
\hline Breastfed dummy & 0.37 & $0.39^{++}$ & 0.39 & $0.42^{++}$ & 0.42 \\
\hline $\begin{array}{l}\text { Mother smoked during pregnancy } \\
\text { Social class }\end{array}$ & 0.41 & $0.40^{--}$ & 0.39 & $0.34^{--}$ & 0.35 \\
\hline Years of schooling mother & 9.66 & $9.71^{++}$ & 9.73 & $10.00^{++}$ & 10.01 \\
\hline Years of schooling father & 9.92 & $9.96^{+}$ & 9.97 & $10.31^{++}$ & 10.34 \\
\hline Parents skilled/professional & 0.76 & $0.78^{++}$ & $0.79^{++}$ & $0.83^{++}$ & 0.83 \\
\hline Family characteristics (at 5) & & & & & \\
\hline \# of older siblings & 1.06 & $1.00^{--}$ & $0.97^{--}$ & $0.86^{--}$ & 0.87 \\
\hline \# of younger siblings & 0.52 & 0.53 & 0.53 & 0.51 & 0.51 \\
\hline $\begin{array}{l}\text { Read to every day } \\
\text { Family characteristics (at 10) }\end{array}$ & 0.39 & $0.41^{++}$ & $0.42^{+}$ & $0.48^{++}$ & 0.48 \\
\hline Gross weekly family income & 3.01 & 3.02 & $3.06^{++}$ & $3.20^{++}$ & $3.18^{-}$ \\
\hline Strength of family ties & 2.47 & $2.48^{++}$ & $2.50^{++}$ & $2.52^{++}$ & 2.52 \\
\hline
\end{tabular}

Note: Means for main variables for full sample, as well as for various selective samples (last four columns). Selection refers to selecting respondents with valid/complete information on (1) parental loss dummy, (2) all controls under birth conditions, social class, and family characteristics at ages 5 and 10, (3) age-16 self-esteem, locus of control, and Rutter score, and (4) age-10 self-esteem, locus of control, and Rutter score. Pluses and minuses in the last four columns indicate that the average of respondents in the selective sample is significantly different from the average of respondents within the baseline sample, but with incomplete information on the selection variables. ${ }^{++}\left({ }^{+}\right)$indicates that the average of the sample with complete information is significantly larger at the 5\% (10\%) level, while $-\left(^{-}\right)$indicate that that average is significantly smaller at the $5 \%(10 \%)$ level. 
Attrition and sample selection are not only related to the share of respondents experiencing parental loss, but also to personality traits, birth conditions, and early childhood family characteristics. Respondents still in the sample after selection on parental loss information (sample Loss) rank significantly higher in the distribution of self-esteem and locus of control, and lower in the distribution of Rutter scores. ${ }^{17}$ The differences with the full sample are further exacerbated once selection on the set of control variables is applied (sample Controls). The same pattern is observed for childhood characteristics, with the average home environment becoming more favorable after each selection round. While this does not hold for all control variables, average parental education and social class, and parental care ${ }^{18}$ increase with each selection round.

Given that sample selection is non-random, the effects of parental loss estimated in this study might be biased. The share of children in the regression sample experiencing the event of interest is significantly lower than that same share in the total population. If the children within the sample do not differ systematically on unobservables that (co-)determine personality, point estimates obtained from the regression sample will be estimated with less precision, but not necessarily with bias. There are, however, indications that those leaving the sample are from "worse" families. If the effects of parental loss are more severe at the bottom of the family quality distribution, then the estimates in this study provide a lower bound for the true effect of parental loss. Given that most of the selectivity of the sample lies with the crucial variable on parental loss, it is not possible to correct for selection on this variable. A related issue, selection on control variables, is something that can be investigated.

Adding an increasing set of controls to the model revealed a pattern of reductions in the estimated effect sizes of parental loss, providing partial support to the argument that the association between family dissolution and personality is caused by selection, rather than causation. However, adding more controls also reduces the sample available for analysis, and the observed pattern might simply be the result of selecting "better" families, for which the effect might be smaller to begin with (even without controls). If the model is re-estimated for the five sets of controls for the restricted sample of respondents with valid information on the most complete set of controls (i.e. sample Controls in Table 4.4), this can be tested. Figure 4.8 reports these results and reveals the same pattern as shown in Figure 4.1. Thus, the reduction in effect size resulting from additional controls is not the result of differences in the composition of the samples.

The discussion on endogeneity and sample selection in this section shows that family breakdown is endogenous, and that the association between parental loss and personality development in childhood is partially attributable to selection. When controls for other variables are added, the size of the estimated placebo effect of parental loss reduces, and is no longer significantly different from zero in the case of self-esteem and locus of control. However, for Rutter scores, the placebo effect remains significant, even with the most complete set of

selection on information on parental loss, and the full set of controls, respondents additionally only require information on one of the three personality traits. Thus, the samples resulting from the third $(P 16)$ and fourth $(P 10)$ selection rounds are more restrictive than those producing the results presented in the figures.

${ }^{17}$ The raw personality scores have been standardized to have a mean of zero and a standard deviation of one within all individuals with valid information on that specific personality trait. For the regression analyses, standardization was applied within each regression sample, as to make coefficients comparable across specifications and samples, as well as to make them interpretable in terms of standard deviation effects. For Table 4.4, for the purpose of inspection of attrition or selection bias, the same standardized scores have been used for each sample, such that differences in averages between the samples can be compared.

${ }^{18}$ As proxied by reading to the five-year old on a daily basis, as well as the strength of family ties at 10 . 
Figure 4.8: Point estimates of Loss of Parent on Personality, Restricted Sample
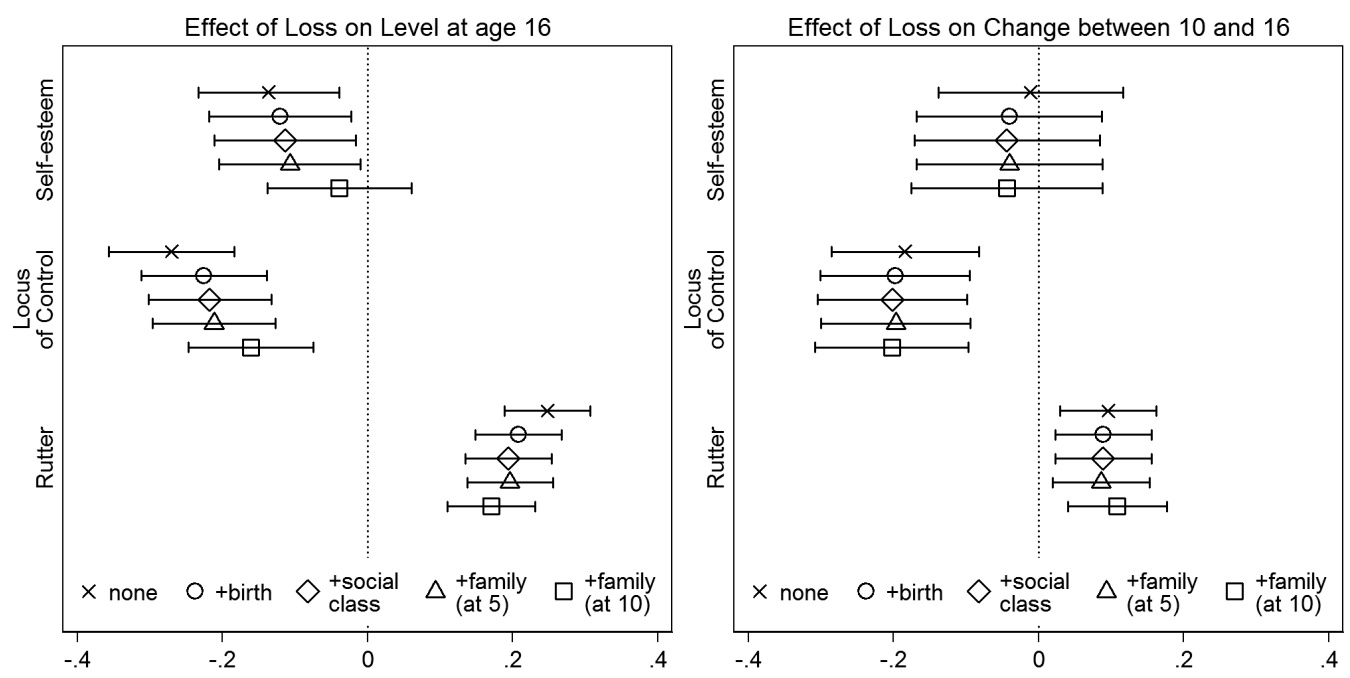

Note: OLS regression coefficients and $90 \%$ confidence intervals for loss of parent (horizontal axis), separately for each personality trait (vertical axis), and for different sets of controls. Only respondents with complete information on the full set of controls - including birth conditions, social class at birth, and family characteristics at age 5 and at age 10 - were considered in the analyses.

controls, indicating that endogeneity is still a concern. Pathways through which the association between parental loss and personality operates may include factors not observed in the data, or changes in the family environment that precede and/or are the result of family dissolution.

\subsection{Conclusion}

The aim of this study was to contribute to the discussion on the development of personality traits in childhood. Two general points were addressed. Firstly, using a variety of personality traits measured at ages 10 and 16, the descriptive statistics indicate that, on average, children show a significant positive development, showing increases in self-esteem and internal locus of control, and declines in behavioral problems. Second, the analyses presented in this study reveal that this positive development is negatively affected by a shock to the family environment. Finally, the correlations between such a shock and personality development are not causal, since family structure is endogenous.

Parental loss is defined as having experienced a switch from living with both natural parents to living with only one natural parent before the age of 16 . In terms of self-esteem, internal locus of control, and behavioral problems, children experiencing parental loss score significantly worse and show less favorable development than children who lived in intact families throughout childhood. ${ }^{19}$ These associations hide more detailed patterns. The effects of parental loss on personality development are generally stronger when the reason was divorce, compared to the case of death of one of the parents. In line with results from Corak

\footnotetext{
${ }^{19}$ These patterns are also found for Big Five personality traits conscientiousness, extraversion, agreeableness, and emotional stability. See Appendix 4.B.
} 
(2001), conditioning on gender, the pattern arises that boys suffer more from the death of a parent than girls do, while there are also indications that divorce of parents affects girls more strongly than boys. The age at which the change occurs also matters, with the effects of losing a parent generally being less severe when the child was older at the time of family breakdown.

In this study, families are split in two groups: those with two-natural parents, and those with only one natural parent. Among families with only one natural parent, there is still quite some variation in family composition. A child may live with it's natural mother or it's natural father, either with or without a step-father or -mother, or other second parental figure. If an additional parental figure is purely of positive value, through additional parental investment, the correlations reported here are underestimates of the impact of losing a parent. However, the role of an extra (non-natural) parental figure need not necessarily be positive. While the sample sizes in the BCS data are too small to estimate these specific sub-events, Ginther \& Pollak (2004) find that the crucial distinction is between children who grow up in traditional nuclear families (i.e. living with both natural parents) and children who grow up in other family structures (i.e. single parent families or blended families). Family fixed-effects models by Chen et al. (2009), however, reveal that maternal death has a much larger impact on education of the child than the death of a father.

Since family structure is endogenous, simple correlations of parental loss with personality development are shown to be biased. With the addition of family characteristics that are correlated with both family structure and children's outcomes, the point estimates of experiencing family breakdown are significantly reduced. Given that much of the associations remain significant after controlling for a range of family characteristics, one might argue in favor of a causal interpretation of the remaining correlations. However, placebo analyses reveal that the problem of endogeneity is not fully addressed with the set of control variables taken into consideration. Part of the association between personality and parental loss already manifests itself before the change in family structure actually occurred. This points to the existence of factors not yet taken into account, that correlate strongly with family dissolution, as well as with childhood personality development.

Given that the negative association between family dissolution and both personality level and personality change is partially the result of selection, future research is needed to uncover the reasons behind the fact that children from intact families make a more positive development, and why children from homes that eventually break down drop in the distribution. Some of the factors controlled for in this study help contribute to this discussion, such as the mediating role of parental education and parental social class, as well as number of siblings, and parental care ${ }^{20}$. These findings are in line with results found by Gould \& Simhon (2011), who argue in favor of a causal role of parental education in shaping children's schooling, which is dependent on the time spent with each parent. Additionally, Corak (2001) finds that family income accounts for part of the association between parental loss and children's personality development.

Lastly, this study adds to the literature casting doubt on a causal interpretation of the correlation between family breakdown and child outcomes. This implies we should be wary to put policy measures in place that stimulate marital stability, if the expectation is that it will lead to better academic and noncognitive outcomes for children. Nevertheless, this study also shows that noncognitive skills, or personality traits, are still in development in childhood,

\footnotetext{
${ }^{20}$ As captured by variables indicating strength of family ties at age 10, and whether or not parents read to the child on a daily basis when the child was 5 years old.
} 
and that the direction and strength of development depends on factors exogenous to the child, and may therefore be susceptible to external influences. While all children mature with age - improving in terms of self-esteem, locus of control, and behavioral problems -, parental investment, in terms of education and income, but also in terms of time and care, plays a mediating or stimulating role. 


\section{Appendix 4.A Regression Tables}

This appendix provides the regression results belonging to Figures 4.1, 4.2, and 4.3. Tables 4.A.1 and 4.A.2 provide the results belonging to the left and right panel of Figure 4.1, respectively. Figure 4.2 shows the point estimates of experiencing death, divorce and separation of parents, but only for the specification with the most extensive set of controls. Table 4.A.3 reports these estimates for five sets of controls. The results from model (5) are those belonging to Figure 4.2. Similarly, Figure 4.3 shows the effects of experiencing parental loss at various ages for the model with the most extensive set of control variables. Table 4.A.4 reports the associated point estimates and t-statistics under model (5), as well as the results using the smaller sets of controls. 


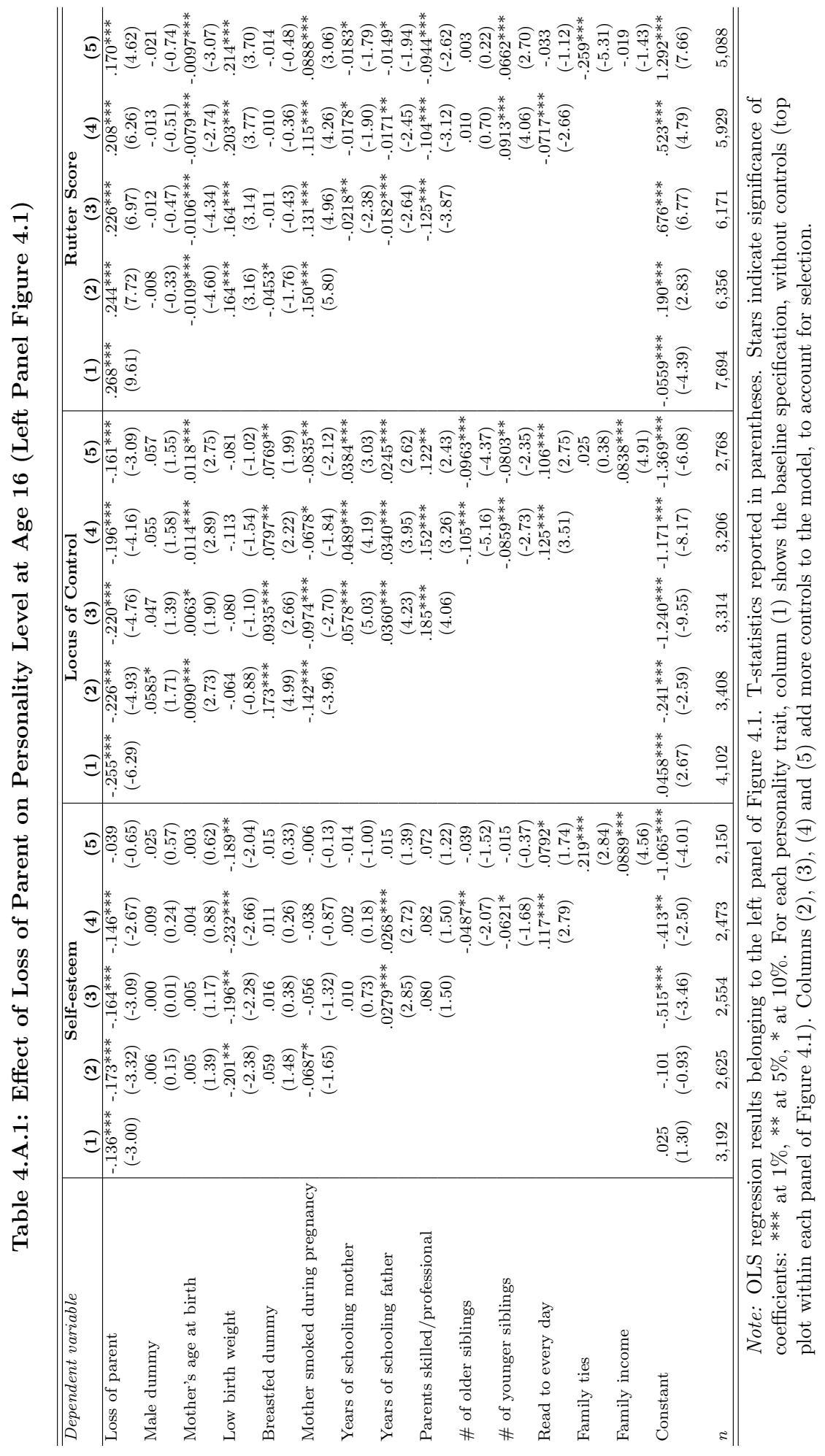




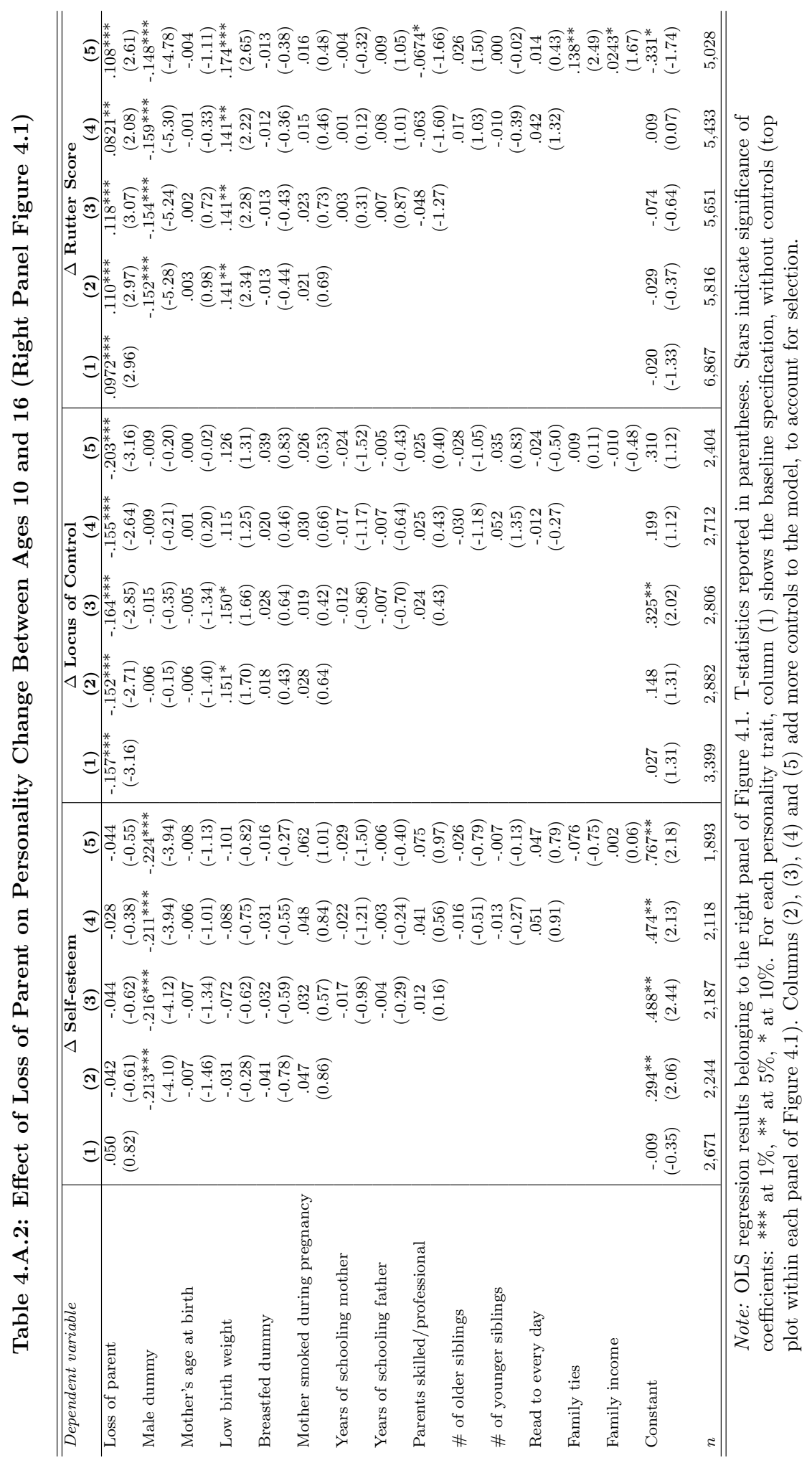




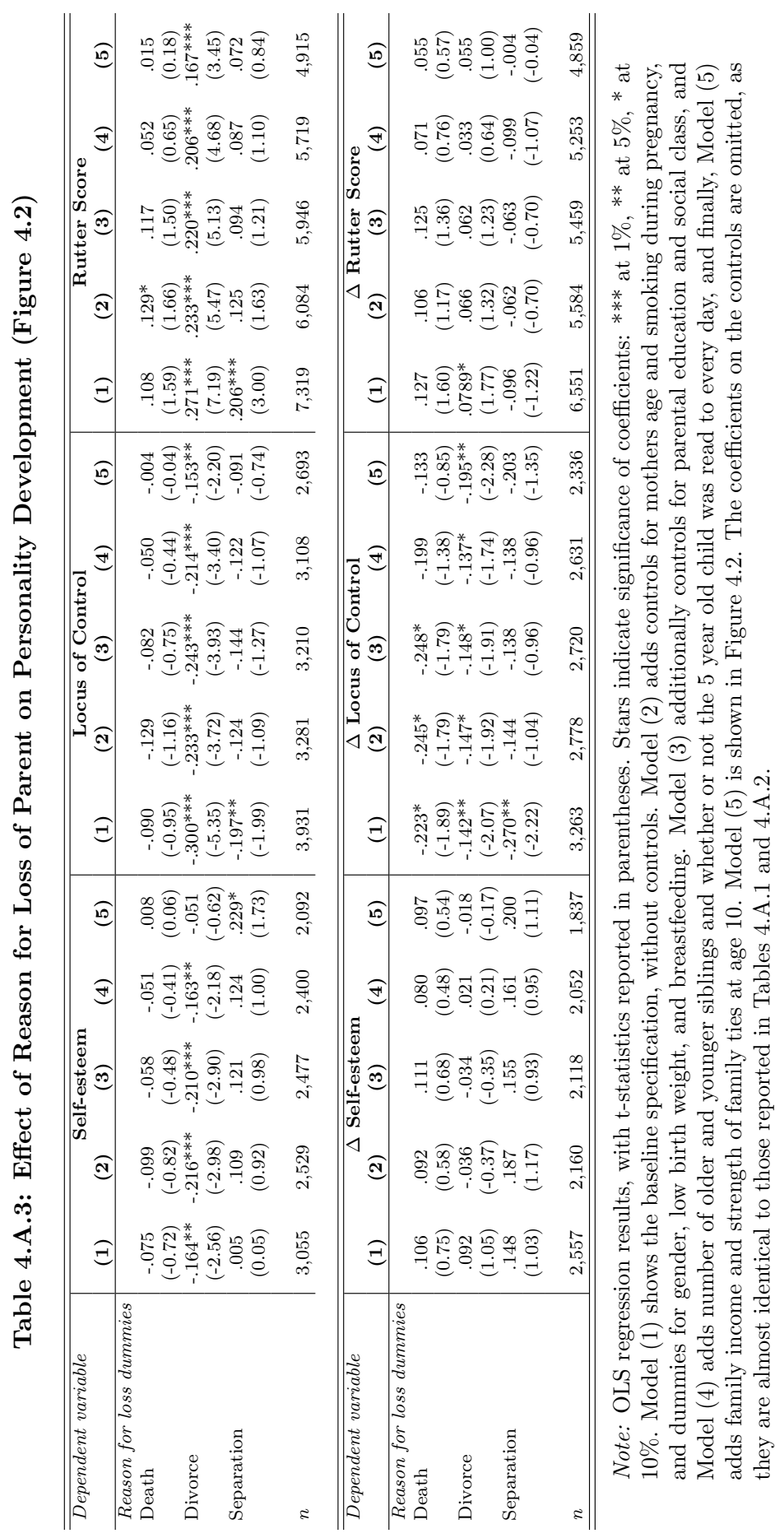




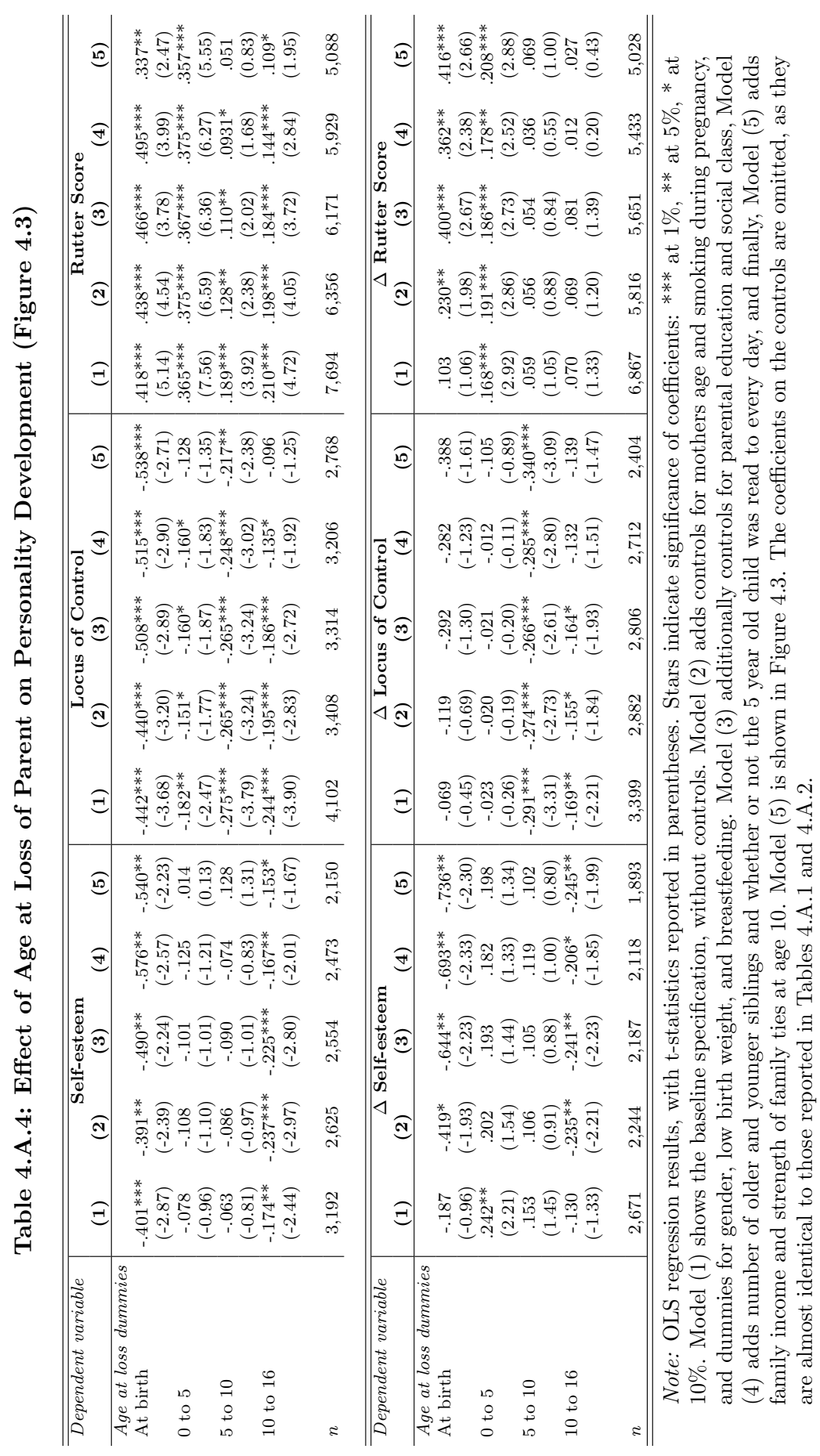





\section{Appendix 4.B Results for Big Five Personality Traits}

Using the measures constructed in Chapter 3, this section reports the main results for a second set of personality traits, covering the Big Five personality traits conscientiousness, extraversion, agreeableness, and emotional stability. The Big Five personality traits - with the exception of openness to experience - are constructed using a set of items rated by the parents of the child. The same set of items is available in 1980 and 1986, allowing the analysis above to be repeated on this second set of personality traits. Details on the construction of the Big Five personality traits and the items associated with each trait are presented in Appendix 3.A. This section provides a brief description of the results. The pattern of effects and conclusions are in line with those presented above, when discussing self-esteem, locus of control, and behavioral problems. Loss of a parent is significantly associated with all four traits. The size of the correlation reduces once more and more family background characteristics are added to the model, yet the effects remain significant, even with the most complete set of controls. A child may lose a parent due to death, or because of divorce or separation of parents. Experiencing divorce of one's natural parents seems to have the largest effect on a child's personality. Regarding age at parental loss, the correlations are smaller when the child was older at the time of family breakdown. Regarding gender effects, boys suffer more than girls when experiencing the death of a parent, whereas girls are more strongly affected by the divorce of parents than boys are.

\section{B.1 Baseline results and Selectivity}

For each of the four personality traits conscientiousness, extraversion, agreeableness, and emotional stability, the following relationships are estimated:

$$
\begin{aligned}
P 16_{i} & =\alpha+\beta(\text { Lost Parent })_{i}+\gamma \mathbf{X}_{\mathbf{i}}+\epsilon_{i} \\
\left(P 16_{i}-P 10_{i}\right) & =\alpha+\beta(\text { Lost Parent })_{i}+\gamma \mathbf{X}_{\mathbf{i}}+\epsilon_{i}
\end{aligned}
$$

for each individual $i$, and for each outcome $P$. The coefficient on the parental loss dummy LostParent then measures how children, who lost a natural parent by the age of 16, differ in personality level and development from children who lived with both natural parents throughout childhood. Since it is likely the case that homes that will eventually break down differ from those that remain intact, even before the breakdown, it is important to control for family characteristics that might be driving the correlation between loss of parent and personality development. In the baseline specification, the vector $\mathbf{X}$ is empty. Four sets of additional variables are considered, which are cumulatively added to the model as measures of parental investment and quality of the home environment. These controls cover birth conditions, social class indicators, and family characteristics at ages 5 and 10 .

Figure 4.B.1 shows the results. Experiencing parental loss during childhood is significantly associated with all four personality traits. Children experiencing family breakdown score significantly lower in terms of age-16 conscientiousness, extraversion, agreeableness, and emotional stability (left panel of Figure 4.B.1). At the same time, relative to children from intact families, they also decline in the distribution of these traits between ages 10 and 16. This is demonstrated by the significantly negative point estimates of parental loss on the changes in these traits (right panel of Figure 4.B.1). As expected, adding controls to account for the selectivity of experiencing loss of a parent reduces the size of the point estimates substantially. With the most complete set of controls - the bottom line for each 
trait, denoted with a square -, the effect sizes (in standard deviations) for the age-16 traits are as following: -.17 for conscientiousness, -.07 for extraversion, -.23 for agreeableness, and -.22 for emotional stability.

The following can be said about the contribution of the control variables. ${ }^{21}$ First of all, there are significant gender differences in the traits, with boys scoring significantly lower on age-16 conscientiousness and agreeableness (-.16 and -.11 standard deviations, respectively), and significantly higher on extraversion and emotional stability (.11 and .19 standard deviations, respectively) In terms of the family characteristics, similar patterns emerge as reported in the analyses for self-esteem, locus of control, and Rutter scores. Mother's smoking during pregnancy, and being born with a low birth weight are significant predictors of age-16 personality traits, reflecting in part parental care prior to birth. The effect of parental education is also significant, as are the proxies for parental care: reading to the five-year old on a daily basis, and strength of family ties, as measured at age 10. Interestingly, in contrast to the results for self-esteem and locus of control, the point estimate for family income at age 10 is very close to zero, and statistically insignificant.

\section{Figure 4.B.1: Point estimates of Loss of Parent on Big Five Traits}
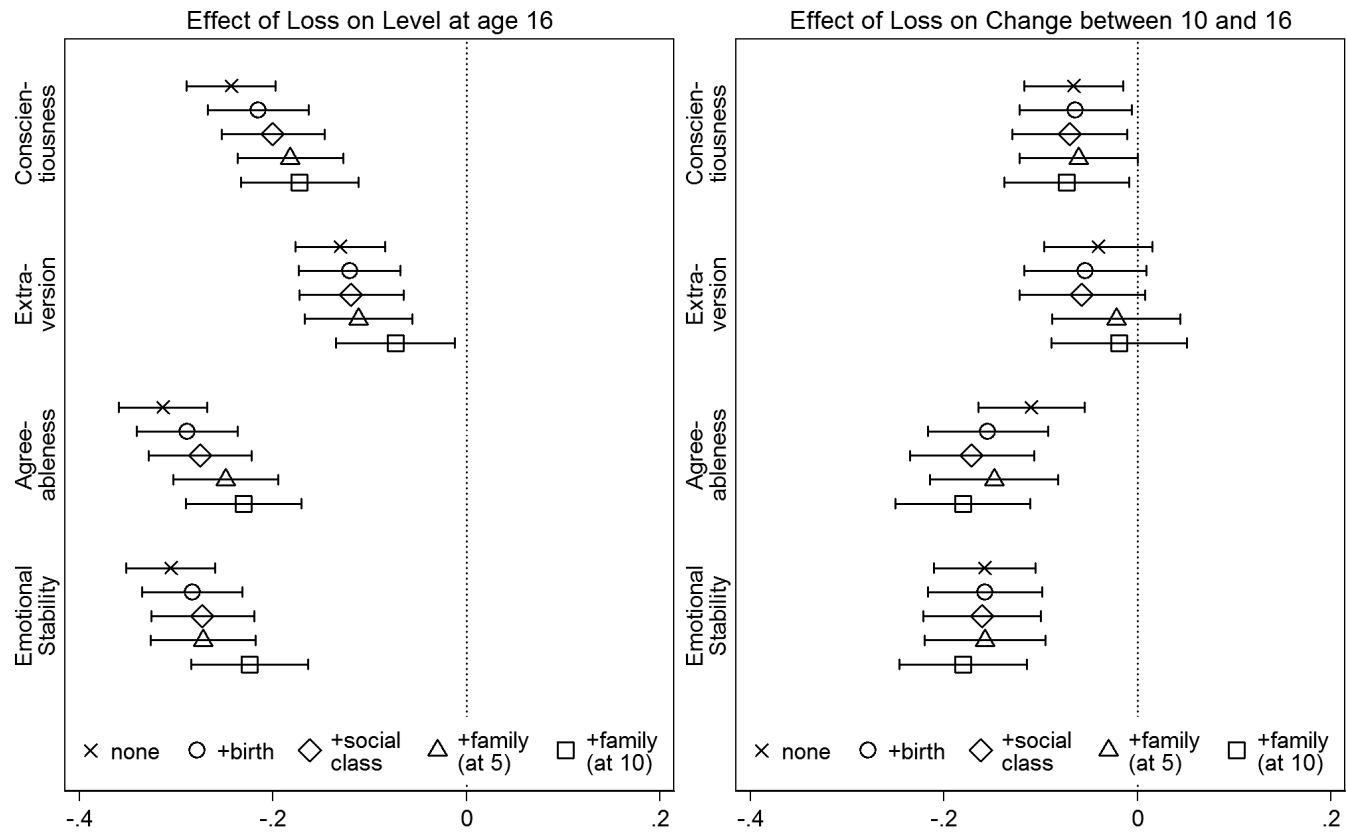

Note: OLS regression coefficients and $90 \%$ confidence intervals for loss of parent (horizontal axis), separately for each personality trait (vertical axis), and for different sets of controls: birth conditions include mother's age at birth, low birthweight, breastfeeding and mother's smoking during pregnancy; social class indicators include years of schooling of both mother and father, and whether the parents hold a skilled or professional job; family (at 5) includes the number of older and the number of younger siblings, and a dummy indicating whether or not the five-year old was read to every day; family (at 10) includes family income and strength of family ties. Full specifications available on request.

\footnotetext{
${ }^{21}$ Although not reported or shown in Figure 4.B.1, the full specifications, including the controls, are available on request.
} 


\section{B.2 Heterogeneous effects}

Figures 4.B.2 and 4.B.3 show results that demonstrate the heterogeneity of the correlations between parental loss and personality. To estimate the results by reason of loss, the Lost Parent dummy in equations (4.B.1) and (4.B.2) is replaced by three dummies: one for separation, one for divorce, and one for death. To determine the role of age at loss of parent, the Lost Parent dummy in equations (4.B.1) and (4.B.2) is replaced by four dummies, splitting the sample of children who experienced parental loss by the age at which the change occurred: at birth, between birth and age 5, between 5 and 10, or between ages 10 and 16 . The results by reason of loss are presented in the top panel of Figure 4.B.2, whereas those by age at loss are shown in the bottom panel of Figure 4.B.2. Finally, the effects are considered separately for boys and girls (Figure 4.B.3).

As was the case in the analyses presented in Section 4.4, experiencing death of a parent is not significantly associated with lower personality or less favorable personality development. The strongest effects are seen for divorce of parents. The effect sizes (in standard deviations) for the age-16 traits are as following: -.21 for conscientiousness, (an insignificant) -.06 for extraversion, -.21 for agreeableness, and -.27 for emotional stability. Divorce also significantly effects the changes in the distribution of these traits between 10 and 16 . Relative to children from intact families, those experiencing divorce drop in the distribution by 11 standard deviations for conscientiousness, and by .15 standard deviations for agreeableness and emotional stability. Looking at the role of age of the child at the time of parental loss, being born into a single-parent household is particularly detrimental for personality levels at age-16, as well as personality development between ages 10 and 16. For agreeableness and emotional stability, these effect sizes are around four tenths of a standard deviation, both for age-16 levels and changes between 10 and 16. The effect of being born into a singleparent household is smaller for extraversion, and not significantly different from zero for conscientiousness. Generally, the correlations between parental loss and personality levels and changes are smaller when the child was older at the time of family breakdown.

The results are presented for boys and girls separately in Figure 4.B.3. The top panel shows the main specification with the most extensive set of controls (as in equations (4.B.1) and (4.B.2)), whereas the bottom panel distinguishes between the reasons for parental loss. Regarding the overall effects of parental loss, boys seem to suffer more than girls, although the differences are only significant for extraversion and emotional stability, indicating that boys act out more than girls when one of their natural parents leaves the household. Splitting parental loss into death, divorce and separation, the same conclusion appears as in Section 4.4. Boys suffer more when experiencing the death of a parent, whereas girls are more strongly affected by the divorce of parents than boys are. 
Figure 4.B.2: Point estimates of Reasons for Loss of Parent on Big Five Traits
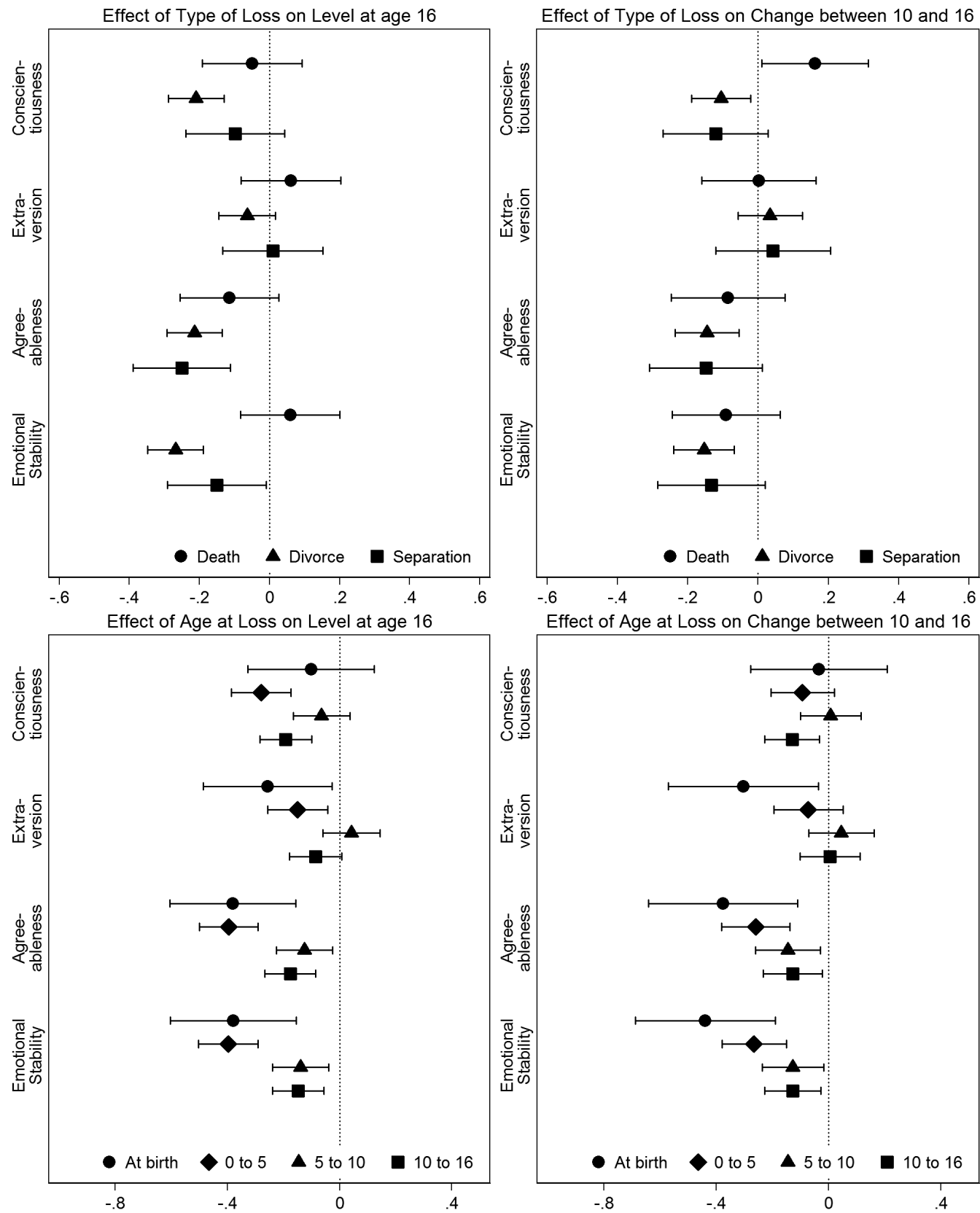

Note: OLS regression coefficients and $90 \%$ confidence intervals for reasons of loss of parent (horizontal axis), separately for each personality trait (vertical axis). All specifications include a full set of controls, including birth conditions, social class at birth, and family characteristics at age 5 and at age 10 . Additionally, the specifications in the top panel (left and right) include three dummies for reason of loss of parent (death, divorce, or separation), whereas the specifications in the bottom panel include four dummies for age at loss of parent (at birth, 0to5, 5to10, 10to16). Full specifications available on request. 
Figure 4.B.3: Point estimates of Loss of Parent on Big Five Traits, by Gender
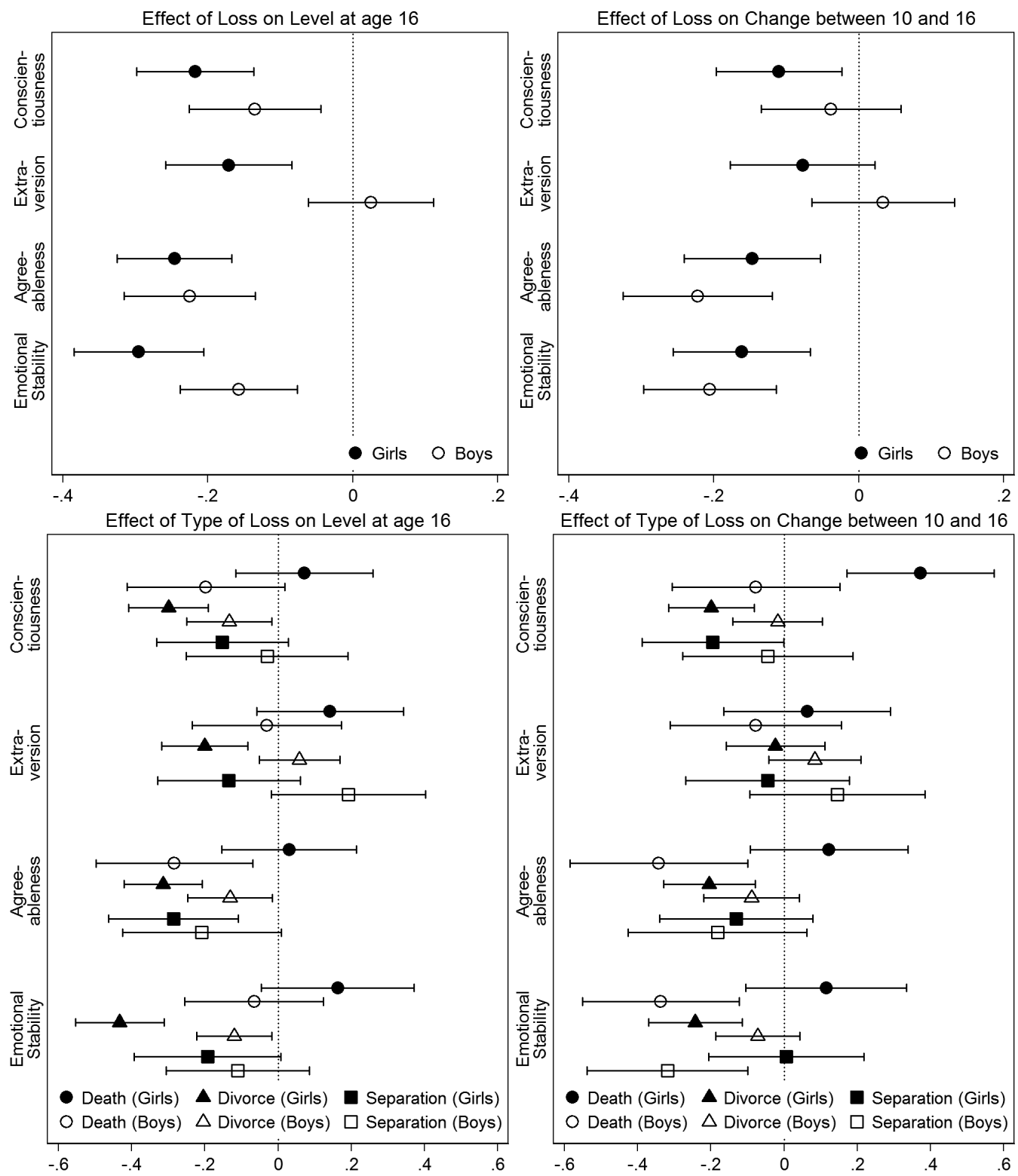

Note: OLS regression coefficients and $90 \%$ confidence intervals for overall loss of parent (top panel), as well as for various reasons of loss of parent (bottom panel), separately for each personality trait (vertical axis). Separate regressions were run for girls and boys. The specifications shown in the top panel include a dummy indicating the child lost a parent between birth and age 16, as well as a full set of controls, including birth conditions, social class at birth, and family characteristics at age 5 and at age 10 . The specifications in the bottom panel replaced the parental loss dummy with three dummies for reason of loss of parent (death, divorce, or separation). Full specifications available on request. 



\title{
Stimulating Effective Habits in Teenagers Community Service and Skills Education ${ }^{1}$
}

\begin{abstract}
Using data from a Dutch high school, we investigate the impact of changes in the curriculum of a high school on its students' academic achievements and social development. As of 2006, students had to complete 40 hours of community service, and a new course was introduced, aimed at developing and improving students' study and social skills. Comparing treated and untreated students, we show that these changes are not significantly associated with better performance on national high school exit exams. Students in the treatment group report higher satisfaction with chosen tertiary education and experience less regret over the choice made. Treatment is positively associated with better academic performance after high school, especially for boys. However, this effect is not statistically significant. Regarding personality, boys in the treatment group report higher scores on Big Five traits conscientiousness, agreeableness, and emotional stability than boys in the control group. Treated boys also differ in self-reported attribution style, attributing positive events more to internal and stable causes. These associations between treatment and personality are much lower for girls, and not significantly different from zero.
\end{abstract}

${ }^{1}$ This chapter is based on joint work with Lex Borghans. 


\subsection{Introduction}

There is growing evidence that success in life does not only depend on cognitive skills but also on noncognitive skills. Success at school requires intelligence but also motivation, study skills, taking homework seriously, concentration at exams and making the right choices for courses and field of study. These noncognitive skills also matter later in life. Improving relevant noncognitive skills could improve success in school, and both directly and indirectly have an impact on outcomes later in life. The question is whether education is able to foster these personal and social skills in the same way as it improves cognitive skills such as math.

The main contribution of this study is to the literature about the impact of universal, school-based programs aimed at stimulating pupils' noncognitive skills. Since many early childhood intervention programs, such as the Perry Preschool Program and Abecedarian, are targeted at specific groups of disadvantaged children and youth, the treatment effects they are associated with are difficult to generalize to larger populations or more generic settings. It is therefore important to evaluate programs of a less intense nature, but that can be applied to a broader audience and in a wider range of settings and circumstances. In these lines, Durlak et al. (2011) evaluate the impact of universal, school-based programs designed to foster social and emotional learning, and generally also find strong and positive impacts of such programs. Another example of a school-based program was applied at a Dutch high school in 2006.

The aim of this study is to investigate the impact of a high school program introducing mandatory community service and a course designed to foster study and social skills. Using administrative and questionnaire data on 1,172 Dutch high school students, we investigate these effects by comparing cohorts of students before and after the introduction of the program. Mandatory community service involved 40 hours of service, the skills course involved weekly one-hour meetings, for a period of three years. The program was found not to have any significant impact on the academic performance of students. Using survey data for a subsample of students, we find that students who received the program report less regret about the career/study choice they make at the end of high school, and report to be more satisfied with the chosen path. Treated students also report higher scores on Big Five personality traits conscientiousness, agreeableness, and emotional stability, as well as on stable and internal attribution of positive events, which in themselves are predictive of a range of later life outcomes (see e.g. Borghans et al., 2008a; Heckman et al., 2006; Mueller \& Plug, 2006).

Regarding the importance of such noncognitive skills for academic success, Robbins, Lauver, Le, Davis, Langley \& Carlstrom (2004) examine the relationship between psychosocial and study skill factors (PSFs) and college outcomes by meta-analyzing 109 studies. Of the nine skill factors found, the best predictors for GPA were academic self-efficacy and achievement motivation. An interesting result is the very low correlation between general self-concept and GPA or retention. One's general beliefs and perceptions about oneself are not significantly correlated with GPA and grade retention, yet these beliefs are predictive of a range of other socio-economic outcomes (e.g. Heckman et al., 2006). Should evaluations of school programs be based on GPA scores, then positive effects of these programs on noncognitive skills unrelated to GPA, such as self-concept, will go unnoticed. This points to the importance of moving beyond using school performance as a measure of quality. 
With the exception of self-concept, Robbins et al. (2004) found all noncognitive skill factors to be significantly related to GPA. Similarly, (Poropat, 2009) shows that conscientiousness - facets of which include achievement motivation - shows correlations with GPA in the same order of magnitude as does intelligence. This again points to the need for evaluating programs on dimensions other than IQ and school performance. This is further illustrated by example of results obtained from the Perry Preschool Program.

The Perry Preschool Program is one of the oldest early childhood intervention programs, starting at age 3 . During the two years of intervention, children who received the treatment showed much faster growth in terms of IQ than their counterparts in the control group (e.g. Heckman et al., 2010, 2008, 2012). However, these initial effects on IQ faded away after the end of the program. At the same time, significant long-term effects of the intervention were observed when the subjects were re-interviewed at ages 27 and 40 . The treatment group scored better in terms of educational performance and income, while also reporting lower rates of being on welfare and reporting lower rates of arrests. The mechanism driving the association between treatment and better life outcomes is the changes in noncognitive skills resulting from the treatment, as demonstrated by higher scores on traits obtained from using items from the Pupil Behavior Inventory (e.g. Heckman et al., 2012). This example illustrate the possible mediating role of noncognitive skills in the effectiveness of intervention programs.

One of the dimensions of the treatment under analysis here, is performing community service, which was intended to improve pupils' motivation and enhance their social engagement. This chapter adds to the literature on the effects of school-mandated community service. To battle the lack of social cohesion and social engagement among youth, the Dutch government mandated that, as of 2011, all students have to perform community service for a minimum of 30 hours during secondary education. Qualitative evaluations of these civic internships within early-adopting schools revealed that students who had participated in civic internships scored higher on various domains of citizenship, such as altruistic values, empathy, social support behavior and civic attitudes (Bekkers \& Karr, 2008; Bekkers, Spenkelink, Ooms \& Immerzeel, 2010). Widening the focus to include academic performance as well as a wider range of social or personality skills, we show that - with mixed effects on high school grades - the main effect of community service lies in its impact on pupil's social skills and civic engagement.

Another aspect of the curriculum change involves teaching students the necessary skills, as well as the accompanying mentality, to effectively choose and succeed in their studies after high school. This study contributes to the current debate on dropouts and study delay in higher education. After high school, four out of five Dutch students continue in higher education, either in higher vocational education, or at university level. Eighteen months after the start of higher education, some 16 percent of students have already dropped out (The Research Centre for Education and the Labour Market, 2012). Of those surviving the first year of their chosen study, well over a quarter of students fail to complete the study ${ }^{2}$. While we do not observe completion rates of both control and treatment groups, we find that treated students indicate they are more satisfied with their chosen studies.

\footnotetext{
${ }^{2}$ For a four-year study at higher vocational education, the share of students completing the study after five years ranges from 61 to 74 percent, depending on the chosen institution. For a three-year bachelor study at university, the share of students completing the study after four years ranges from 39 to 78 percent, depending on the chosen university (Belleman, 2012).
} 
Given the findings that not all noncognitive skills are associated with better school performance, and that long-term effects of treatment in terms of cognitive skills may be limited, it is important to assess a range of student outcomes in evaluating the curriculum change. The following section describes the treatment and the associated hypotheses. Section 5.3 describes the data and it's limitations, as well as the estimation used to test the hypotheses. Section 5.4 presents the results, separately for each of the four outcome domains and associated hypotheses; followed by a set of robustness checks. Finally, Section 5.5 concludes.

\subsection{Treatment and Hypotheses}

In the 2006-2007 academic year, one high school in Maastricht, the Netherlands, introduced community service and a new course Skills Education in the 2006-2007 academic year. The new skills course became part of the curriculum of students in upper secondary education. Over the course of three years, from starting around the age of 15, students received this course for an average of 1 hour per week. The mandatory service project was to cover 40 hours of community service, to be fulfilled outside regular school hours. Community service is intended to improve self-awareness and citizenship among students, while the skills course emphasizes the development of personal, study and social skills. Now, several years after the introduction of these changes, we are interested in the impact of this treatment on students.

The most obvious outcome to measure treatment effects is academic performance. In the Netherlands, completion of high school is dependent on one's performance in school exams and national exams. The school exams are administered by each school independently, throughout the last years of secondary education, while subject specific national exams are taken by all Dutch graduates simultaneously at the end of secondary education. One's final grade on a subject is then the average of the grades on the school and national exams. The skills course teaches students how to plan ahead and how to work independently and securely, which are skills that are arguably beneficial to successfully prepare for exams. At the same time, the hours spent on the new course and on community service, cannot be spent on studying for exams. These two channels have opposite effects. We will therefore investigate the effects on academic performance without a hypothesis about the direction of the effect.

Since the treatment targets a much broader range of skills than ability to perform well on exams, we would like to compare the treated and untreated on measures that capture the aims of the treatment more precisely. In addition to performance in high school, we therefore consider outcomes in three other domains: satisfaction with study choice, performance in tertiary education, and personality traits.

The choice of which study to pursue after completion of high school is an important one. In hindsight, many students drop-out or change field after one or two years in college, or indicate after their study that they would have preferred another field of study of they could choose again (Borghans \& Golsteyn, 2007). Dropout and study switching is both a burden to individuals, and to society. Given that the treatment involves both a focus on self-awareness and improved guidance in the study-career-choice of students, the treated are expected to be more satisfied with their chosen follow-up studies than the students who graduated prior to the introduction of community service and Skills Education. 


\section{Hypothesis 1 Treated Students ARE MORE SATISFIEd With Their STUdy Choice}

Students who continue with the chosen study, are still faced with the challenge to do so in an efficient manner. Although government funds are made available, so that all students have the option to pursue tertiary education, the pressure on students to complete their studies on time is increasing. Many students take more than the scheduled three (four) years to complete a Bachelor's (Master's) degree, and a large share of these costs are born by society, rather than the students themselves. The literature shows that personal and social skills are associated with performance in education. ${ }^{3}$ The course Skills Education tries to provide students with tools on how to plan ahead and how to work thoroughly and independently, while emphasizing the importance of always working towards a goal, and keeping that goal in mind. If students adopt these tools, the treated are expected to be more productive and efficient in their chosen studies, leading us to our second hypothesis:

\section{Hypothesis 2 Treated students Perform BetTer in tertiary EDUCATion}

While academic performance or ability has been shown to be a strong predictor of success in various domains, the predictive power of social skills and personality traits in these domains is almost just as strong. In a meta-analysis of personality-academic performance relationships, Poropat (2009) shows that correlations between conscientiousness and GPA are almost as large as those between grades and intelligence. When these noncognitive skills are investigated alongside cognitive skills such as intelligence, both are shown to be relevant for success. Heckman et al. (2006) demonstrate that both higher cognitive skills and higher noncognitive skills are significantly associated with a higher probability of graduating from college, but also with higher adult wages and a lower probability of smoking tobacco and marijuana.

One of the main sources in Skills Education is the book The Seven Habits of Highly Effective Teens by Sean Covey, which demonstrates the importance of certain habits in being able to respond to and manage changes in life. Given the aim and contents of Skills Education, we expect students who followed this course to score higher on valuable personality traits than students who graduated before the course was introduced.

\section{Hypothesis 3 Treated Students score higher on VAluable Personality traits}

The expectations regarding the third hypothesis are also based on findings from the literature on the effects of programs falling under the umbrella of Social and Emotional Learning (SEL). Durlak et al. (2011) present findings from a meta-analysis of 213 SEL programs, aimed at improving the noncognitive skills of students. The authors find significant effects of SEL programs on a range of noncognitive skills, but also on academic achievement. Rather than constructing a set of instruments designed to measure the seven habits articulated in the course book, we evaluate noncognitive skills using a more common and widely used set of noncognitive skills, namely the Big Five personality traits, covering a wide variety of personality. In addition to Big Five taxonomy of personality, we measure students attribution styles, a concept related to self-concept, as described above.

\footnotetext{
${ }^{3}$ See e.g. Poropat (2009) for a meta-analysis on the relationship between personality and academic performance.
} 
We use the following indicators to test the above-mentioned hypotheses:

- High School Performance

Average report card grade one year prior to graduation

Average grade on school and national exit exams

Course specific grade on school and national exit exams (Dutch, English, Mathematics)

- Satisfaction with Study Choice

Extent of doubt in making choice

Extent of regret in made choice

- Performance in Tertiary Education

Percentage of first year exams completed in first year (0-100)

Self-rated chance to complete current study (in percentage points)

Hours spent on studying per week

- Personality Traits

Big Five: openness, conscientiousness, extraversion, agreeableness, emotional stability

Attribution style to positive and negative events

\subsection{Data and Approach}

Our data contains information on 1,172 students who graduated from high school between 2006 and 2010. The treatment was introduced in 2006, for all students in the fourth and fifth years of high school. As mentioned above, we consider four outcome domains to measure the effect of treatment: high school performance, satisfaction with study choice, performance in tertiary education, and personality traits. Data from the school administration provides information on high school performance, as well as individual scores on a primary school exit test (CITO, taken at age 12), and indicators for gender, date of birth, and track in high school. Information on the other three outcome domains are obtained from questionnaire data. Questionnaires were sent out to all cohorts in mid-2010, and after two rounds of sending out reminders to non-responders, a third of the students $(n=398)$ responded to our questionnaire. Although this is a selective sample of students, as demonstrated below, the non-response does not influence the estimation results, given that non-response applies equally to the control and treatment groups.

High school performance can be measured for all former graduates, since all the information is readily available from school administrative data. When moving to the other outcome domains, we only have information from graduates that completed the questionnaire. The 398 responders might not be representative for the entire population of graduates, and any conclusions drawn from the questionnaire data might not reflect the true treatment effects. Table 5.1 compares responders to non-responders in terms of high school performance, and other information obtained from the administrative data. Students who participated in the survey have significantly higher grades than those who chose not to participate. However, this might be the result of the fact that the highest track is overrepresented in the group of 
Table 5.1: Bias in Questionnaire Response

\begin{tabular}{lll}
\hline \hline & \multicolumn{2}{l}{ Responded? } \\
& No & Yes \\
\hline Average Exam Grades & & \\
Report Grade (year before graduation) & 6.60 & $6.78^{* *}$ \\
School Exam & 6.58 & $6.73^{* *}$ \\
National Exam & 6.51 & $6.65^{* *}$ \\
National Exam (1st attempt only) & 6.49 & $6.62^{* *}$ \\
Final Grade & 6.57 & $6.72^{* *}$ \\
& & \\
School Exam Grades & & \\
English & 6.91 & 6.92 \\
Dutch & 6.38 & $6.59^{* *}$ \\
Math & 6.40 & $6.60^{* *}$ \\
National Exam Grades & & \\
English & 6.71 & 6.75 \\
Dutch & 6.30 & 6.34 \\
Math & 6.61 & $6.84^{* *}$ \\
Age at graduation & & \\
Male (share) & 18.06 & 17.99 \\
High Track (share) & 0.51 & $0.41^{* *}$ \\
Primary school exit test & 0.47 & $0.55^{* *}$ \\
At least one Dutch parent (share) & 543.21 & 543.54 \\
Two Dutch parents (share) & 0.95 & 0.97 \\
Year of graduation (share) & 0.85 & 0.88 \\
2006 & & \\
2007 & & \\
2008 & 0.24 & 0.24 \\
2010 & 0.18 & 0.22 \\
\hline \hline & 0.23 & 0.24 \\
& 0.21 & 0.20 \\
& 0.14 & $0.10^{*}$ \\
\hline
\end{tabular}

Note: Stars indicate averages are significantly different: ${ }^{* *}$ at the $5 \%$ level, $*$ at the $10 \%$ level.

responders (55 vs 47 percent). On average, vwo students have higher report card grades and score higher on school exit exams than HAVO students do. The share of girls is also larger among students responding to the questionnaire (59 vs. 49 percent). This could also account for part of the observed differences in high school performance, since, on average, girls score higher on exams and have a higher GPA than boys. Given these significant differences, it is therefore crucial to account for gender and track when estimating the effects of the curriculum changes.

Our results are based on a comparison of different cohorts of students, which might influence the estimated treatment effect. Differences between the cohorts of students before and after treatment along dimensions other than treatment, could potentially bias the estimates . While Table 5.1 does not show significant differences in the distribution of cohorts (year of graduation) between the responders and non-responders, we adjust for potential cohort effects by incorporating information on year of graduation and academic ability measured before high school.

A potential confounding factor are some changes that occurred countrywide in the education system for the second half of secondary education, the so-called Second Stage (Tweede Fase). In the academic year 2007-2008, a renewed version of this Second Stage was introduced, 
redefining the content of and requirements for certain subjects. The changes in the subjects English and Dutch were only minimal, with no changes in terms of education time/hours, whereas the changes in mathematics courses were quite substantial. The changes apply to all students who have not yet entered upper secondary education by academic year 2007-2008, and thus applies to VwO students graduating in 2010 and to HAVO students graduating in 2009 and 2010. We therefore have to look at the math results with care.

Our estimates could further be biased if the answers to the questionnaire are dependent on age and current position in education or career. The questionnaire was answered by former graduates of the high school in the same period (the second quarter of 2010), whereas the respondents vary substantially in age and year of graduation. Respondents who graduated from high school in 2006 were much older when answering the survey, than those graduating in the spring of 2010. In general, the control group contains older respondents who have already been away from high school for several years, whereas the treatment group is on average younger, a large share of which have only recently started tertiary education or entered the job market. This might also lead to reporting bias. When asking respondents to report back on how they experienced the choice of what to do after high school, it might matter how long ago this was. A related potential problem could be the relationship between personality and age. Roberts et al. (2006) show that all Big Five personality traits are increasing throughout adolescence and young adulthood. Based on this pattern of increasing personality traits, we would assume that our control group scores higher on these traits, because they are older. Including the year of graduation as a control is intended to capture this problem.

This brings us to the measurement of the indicators of the domains other than high school performance. Firstly, Hypothesis 1 concerns satisfaction with study choice. The respondents where asked to think about what they did in high school to prepare for their choice of study or career following high school. They were then asked to indicate, on a scale from 1 "completely disagree" to 5 "completely agree," to what extent they had strong doubt or were uncertain about their study choice (doubt) or that in hindsight, they would have preferred a different choice (regret). Third, general satisfaction with their study was measured by simply asking respondents to indicate their satisfaction with their current study, on a scale from 1 to 10 .

Three indicators of success in tertiary education are used to assess the second hypothesis. Respondents had to indicate their belief about their chances of completing the current study, as well as reporting the share of exams passed in their first year of tertiary education. These items are reported in percentages. The third indicator relating to tertiary education is the amount of hours per week the respondents report to spend on their studies (including classes, lectures, as well as hours spent studying at home or elsewhere).

Finally, personality is measured using items that capture the Big Five personality traits and the Attribution Style of respondents. The Big Five traits openness to experience, conscientiousness, extraversion, and emotional stability (neuroticism) are measured using a set of items obtained from the International Personality Item Pool (IPIP). There are a number of IPIP measures designed to measure constructs similar to Costa and Mcrae's Five Factor Model (Costa \& McCrae, 2008). ${ }^{4}$ We used 22 items from the 50-item IPIP representation of Costa and McCrae's five NEO domains, all measured on a scale from

\footnotetext{
${ }^{4}$ Most IPIP scales were developed by identifying IPIP items, that, when summed into a single scale, correlate highly with the existing measure. See Goldberg, Johnson, Eber, Hogan, Ashton, Cloninger \& Gough (2006) for a description of how the IPIP scales are constructed.
} 
1 "completely disagree" to 5 "completely agree." Appendix 5.A provides details on the items used. Despite the use of a subset of the full list of 50 items, the reliability of the resulting constructs is still sufficient, with Cronbach's alphas of .57 for openness, .77 for conscientiousness, .72 for extraversion, .67 for agreeableness, and .69 for emotional stability.

Attribution theory is concerned with an individual's perception of the causes of events. Attribution style consists of three dimensions: internality versus externality, stability versus instability, and globality versus specificity (e.g. Cohen, van den Bout, Kramer \& van Vliet, 1986; Peterson, Semmel, von Baeyer, Abramson, Metalsky \& Seligman, 1982). Rather than applying the full range of questions on twelve events, ${ }^{5}$ the student questionnaires contain a set of questions pertaining to two good and two bad hypothetical events and allows us to capture the stability and internality of attribution of both positive and negative events. Appendix 5.B provides details on the questions and events. Even with only four items each for the total score on attribution of positive events and of negative events, the Cronbach's alphas of .61 and .55, respectively, indicate that this subset of questions was sufficient to provide a reasonably reliable measure for attribution style.

\section{Estimation}

For each outcome measure in all four domains, we estimated the following relationship:

$$
Y_{i}=\alpha+\beta T_{i}+\gamma \mathbf{X}_{\mathbf{i}}+\epsilon_{i}
$$

for each individual $i$, and for each outcome $Y$. The coefficient on the treatment dummy $T$ measures the difference in the outcome measures between the treated and untreated students, while controlling for a set of covariates $\mathbf{X}$, which includes high school track, performance on the primary school exit test (CITO), gender, and year of graduation from high school.

There are two tracks within this high school, a pre-university track (VWO) that gives direct access to university after completion, and a general secondary education track (HAVO) that allows entry into university after completion of a transition year. Students select into the two tracks either before or at the end of the first year of secondary education, partly based on their performance on the primary school exit test. For students with a missing score on the CITO test, we added a dummy to the model, indicating whether or not the student had a valid score. Besides the difference in average CITO score of students, the two education tracks differ in length, as well as in content. The pre-university track takes six years; the general education track only five. Students in both tracks take similar courses, yet the contents and number of instruction hours per course may differ by track. Given that the sample of students as well as the educational content differs by track, educational track is also likely to be correlated with our outcome measures.

Many outcome variables vary between men and women and between students at HAVO and vwo. To reduce the variance of the error term we add gender and track as controls. Furthermore, it is possible that characteristics of the students change gradually over time. We therefore also include the year of graduation as a linear continuous control variable, to exclude that our comparison of outcomes before and after the introduction of the new programme is just picking up this gradual change in student characteristics.

\footnotetext{
${ }^{5}$ See Peterson et al. (1982) for the full Attribution Style Questionnaire.
} 


\subsection{Results}

This section describes the results of estimating equation (5.1) for the four outcome domains: high school performance, satisfaction with study choice, performance in tertiary education, and personality traits. The point estimates of the treatment dummy are shown graphically in Figures 5.1-5.5, along with 90\% confidence intervals. Given that outcomes generally vary by gender and high school track, the results are not only shown for the total sample, but also for four subsamples: for boys and girls separately (open and solid triangle, respectively), and for HAVO and VWO graduates separately (open and closed circle, respectively). The full regression tables are presented in Appendix 5.C.

\subsubsection{High School Performance}

Figures 5.1 and 5.2 show the estimated effect of the programme on high school performance. A short glance at Figure 5.1 reveals no significant effects of the addition of community service and Skills Education on average grades in high school. Whether GPA is measured by average report card grades the year prior to graduation, average grades on school exams, average grades on national exams, or final grades, the point estimates on the treatment dummy are neither economically, nor statistically significant. Grades range from 0 to 10, with students averaging around 6.6 (Table 5.1). All point estimates are insignificantly different from zero at the ten percent level, and, with the exception of national exam for girls, all point estimates fall below a tenth of a grade point.

Figure 5.2 shows the results for grades on the school exam (left panel), and on the national exam (right panel), for the specific subjects English, Dutch, and Math. Regarding performance on school exams taken throughout the school years, treated students score a quarter of a grade point lower on Dutch and Math. For mathematics, this effect is stronger for girls, than for boys, but also for HAVO graduates, compared to VwO graduates, with a significant effect of almost four tenths of a grade point (Table 5.C.2). This result could be explained by the fact that hours spent on the new course and on community service, which fall outside the standard curriculum, cannot and are not spent on studying for exams.

During the period in which students take the national exams, there are no other classes or school projects. Thus, is this reasoning were to be true, one would not find this negative association between treatment and grades on national exams. The right panel of Figure 5.2 indeed shows no significant association between treatment on grades on national exams for English, Dutch, or Math. While for the total sample all point estimates are positive, they are very small in magnitude, and not significantly different from zero. For the analyses by gender and by school track, the results are somewhat inconclusive. For boys, the estimates are positive, though insignificant, for all three courses, and for girls they are close to zero. Looking at school track, for HAVO students, treatment is associated with almost 0.6 higher grades for English and Math, yet with 0.23 lower grades on Dutch. The association between Dutch and treatment is however not significant. The reverse pattern is shown for vwo students, with treatment being associated with 0.3 higher grades for Dutch, and (insignificantly) lower grades for English and Math. 
Figure 5.1: Point estimates of Treatment on Grade Averages

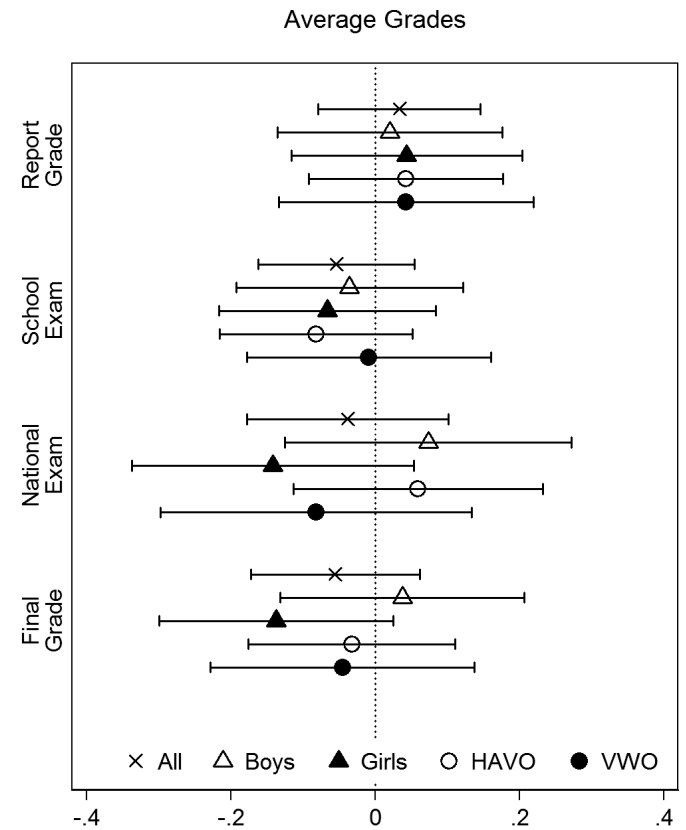

Note: OLS regression coefficients and $90 \%$ confidence intervals for treatment dummy (horizontal axis), separately for each outcome (vertical axis), and for different samples. Controls include gender, academic track, year of graduation, and score on primary school exit exam.

Figure 5.2: Point estimates of Treatment on Grades on School and National Exams

School Exams

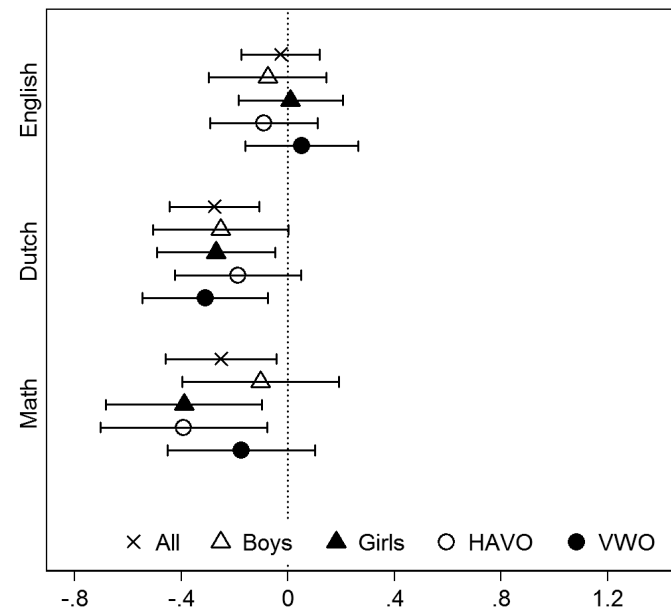

National Exams

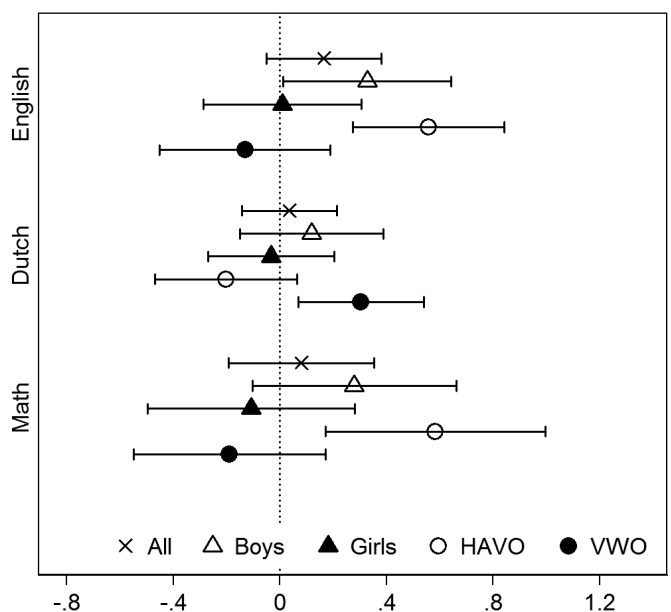

Note: OLS regression coefficients and $90 \%$ confidence intervals for treatment dummy (horizontal axis), separately for each outcome (vertical axis), and for different samples. Controls include gender, academic track, year of graduation, and score on primary school exit exam. 
All in all, while the skills course teaches skills that are arguably beneficial to successfully prepare for exams, the effects are mixed, at best. The hours spent on the new course and on community service seem to hurt performance on school exams. The impact of treatment on the performance on national exams is generally insignificant, but the subsample analyses indicate that this might be hiding a more nuanced picture, one in which the size and even the direction of effects of treatment depend on gender and high school track. ${ }^{6}$

\subsubsection{Satisfaction with Study Choice}

One of the aims of the course Skills Education is to help students prepare for, and guide them in, their choice of study after high school. Hypothesis 1 therefore stipulates that treated students will be more satisfied with their chosen study. The left panel of Figure 5.3 shows the point estimates and associated confidence intervals for the three measures of satisfaction with study choice. ${ }^{7}$ The results provide support for Hypothesis 1.

There is a positive, albeit insignificant, association between treatment and reported doubts about study choice, which might indicate that the increased focus on the importance of making a well-informed choice also lead to more uncertainty surrounding the choice. However, treated students do not regret their choice. Treatment is negatively associated with reported regret about the chosen study, indicating larger satisfaction with study choice for the treated. These associations are, however, mostly insignificant, or only marginally significant. When looking at self-reported overall satisfaction with the current study, treated students report to be significantly more satisfied than students who did not follow the skills course or complete community service. Overall, the responders rate their satisfaction at 7.7, on a scale from 1 to 10 , which indicates the effect size of close to 1 is quite substantial.

\subsubsection{Performance in Tertiary Education}

Given that treatment is positively associated with satisfaction with tertiary education, a related question concerns it's association with performance in tertiary education. The right panel of Figure 5.3 shows the point estimates for the treatment dummy for our three measures of success in tertiary education. ${ }^{8}$

The point estimates for the full sample (denoted by an $\mathbf{x}$ ) are all positive, indicating that treated students spend more time on their studies, and report to have passed more of their first year exams than non-treated students. The same holds for self-reported chances of completing the current study. These effects are however not significantly different from zero. The same holds for all subsamples. While the point estimates are generally larger for boys than for girls, none of the effects are significant at the $5 \%$ level (see Table 5.C.3). The

\footnotetext{
${ }^{6}$ The estimates depicted in Figures 5.1 and 5.2, and reported in Tables 5.C.1 and 5.C.2, are based on the total sample of students graduating between 2006 and 2010. However, the results for the other domains are based on the subsample of students who responded to our questionnaire. Estimates for high school performance obtained from this subsample are not significantly different from those using the full sample. Generally, the point estimates are larger for the sample of responders, although the confidence intervals are much larger. Where the full sample revealed a significant and negative association between treatment and performance on school exams, the treatment effects are closer to zero for the subsample, and not significantly different from zero. For performance on national exams, the point estimates are similar for both samples.

${ }^{7}$ The first three columns of Table 5.C.3 in the Appendix report the full regression results.

${ }^{8}$ The last three columns of Table 5.C.3 in the Appendix report the full regression results.
} 
Figure 5.3: Point estimates of Treatment on Tertiary Education
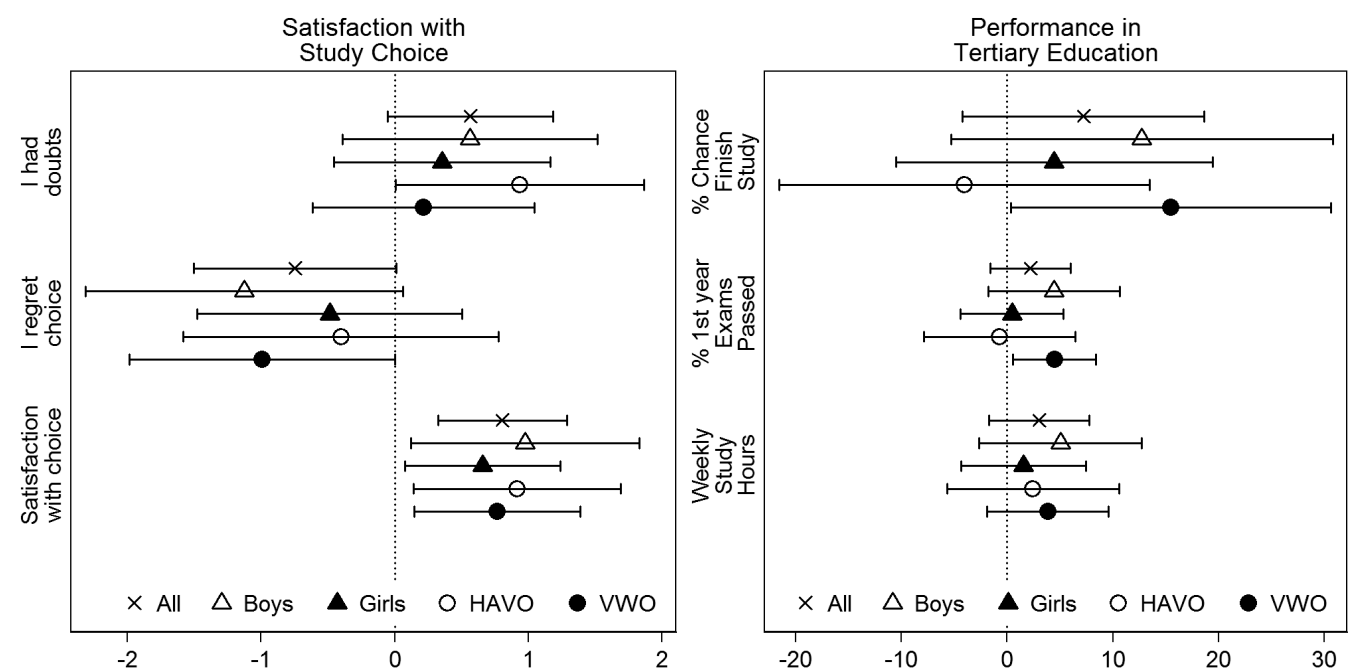

Note: Point estimates and $90 \%$ confidence intervals for treatment dummy (horizontal axis), separately for each outcome (vertical axis), and for different samples. Controls include gender, academic track, year of graduation, and score on primary school exit exam. Results from ordered logistic regressions for I had doubts and I regret choice, and coefficients from ordinary least squared regressions for other outcomes.

magnitude of the effects are quite substantial, yet so are the confidence intervals, providing only weak support for Hypothesis 2. With an average report of 30 hours of study per week, a point estimate of over 3 hours for the full sample, and as large as 5 hours for boys, is quite substantial. Regarding passing rate of first-year exams, a point estimate of 9 for the full sample, and even 17 for boys, is again very large, given an overall reported average of 82 percent.

Overall, Figure 5.3 lends support for Hypothesis 1, that the introduction of the skills course and mandatory community service in high school has improved the tertiary study choice of students, but only weak support for Hypothesis 2, that the introduction of the skills course and mandatory community service in high school has improved the performance of students in tertiary education.

\subsubsection{Personality}

Chapters 2 and 3 discuss and demonstrate the relevance of Big Five traits in predicting a wide range of socio-economic outcomes. ${ }^{9}$ Figure 5.4 shows to what extent the treatment is associated with self-reported scores in Big Five personality traits. Figure 5.5 shows the point estimates of treatment on overall, as well as internality and stability of, attribution of positive and negative events. ${ }^{10}$

With the exception of openness to experience, the association between treatment and the Big Five personality traits is positive, with point estimates - for the full sample - ranging from .13 standard deviations for extraversion to 0.4 standard deviations for agreeableness

\footnotetext{
${ }^{9}$ See also Borghans et al. (2008a) and Almlund et al. (2011) for reviews.

${ }^{10}$ Tables 5.C.4 and 5.C.5 in the Appendix report the full regression results.
} 
(see Table 5.C.4). However, the estimated effect of treatment is only statistically significant for boys. On our measures for emotional stability, boys who performed community service and followed the skills course score three quarters of a standard deviation higher than boys who graduated before these changes in the curriculum. They also score more than half a standard deviation higher in terms of conscientiousness and agreeableness, although these effects are not significant at conventional levels, with p-values just exceeding ten percent.

\section{Figure 5.4: Point estimates of Treatment on Big Five Personality Traits}

Big Five Traits

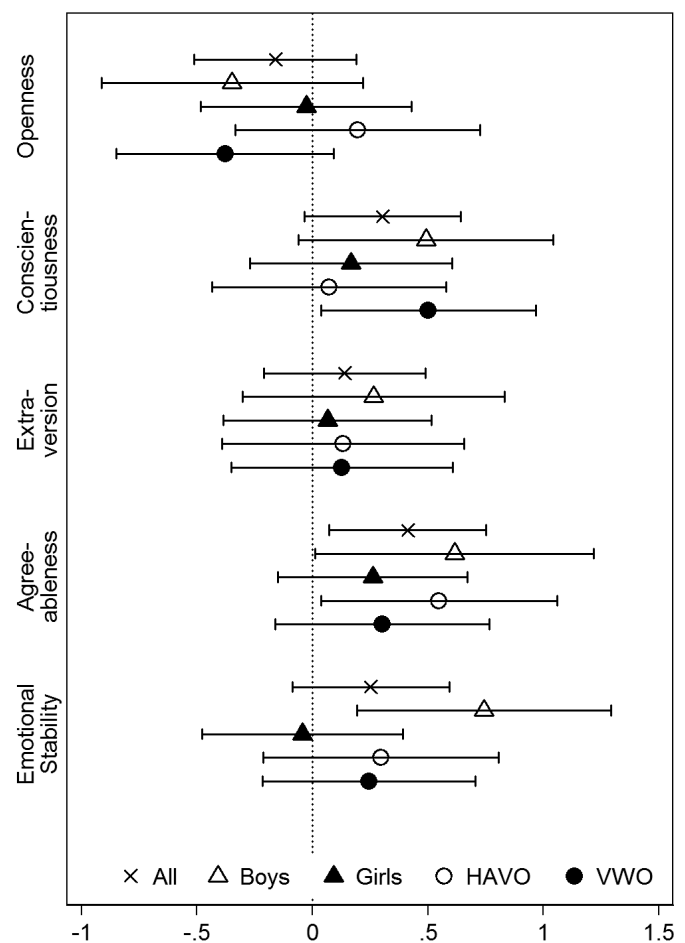

Note: OLS regression coefficients and $90 \%$ confidence intervals for treatment dummy (horizontal axis), separately for each outcome (vertical axis), and for different samples. Controls include gender, academic track, year of graduation, and score on primary school exit exam.

Regarding attribution style (Figure 5.5), the results for the full sample demonstrate that treatment is associated with significantly higher attribution of positive events, indicating that treated students attribute positive events more to stable internal causes than nontreated students. They score about a quarter of a standard deviation higher on the three measures of attribution of positive events. Regarding the attribution styles of causes for negative events, there is no significant difference between students who did and who did not follow the skills course and completed community service. Turning to the results of subsample analyses, it seems that these results are driven by the effects of treatment on boys. Whereas treated boys score over a third of a standard deviation higher on the attribution scales for positive events - compared to boys who did not receive treatment -, the associations between treatment and attribution of positive events is much smaller for girls, and not significantly different from zero. 
Figure 5.5: Point estimates of Treatment on Attribution Style
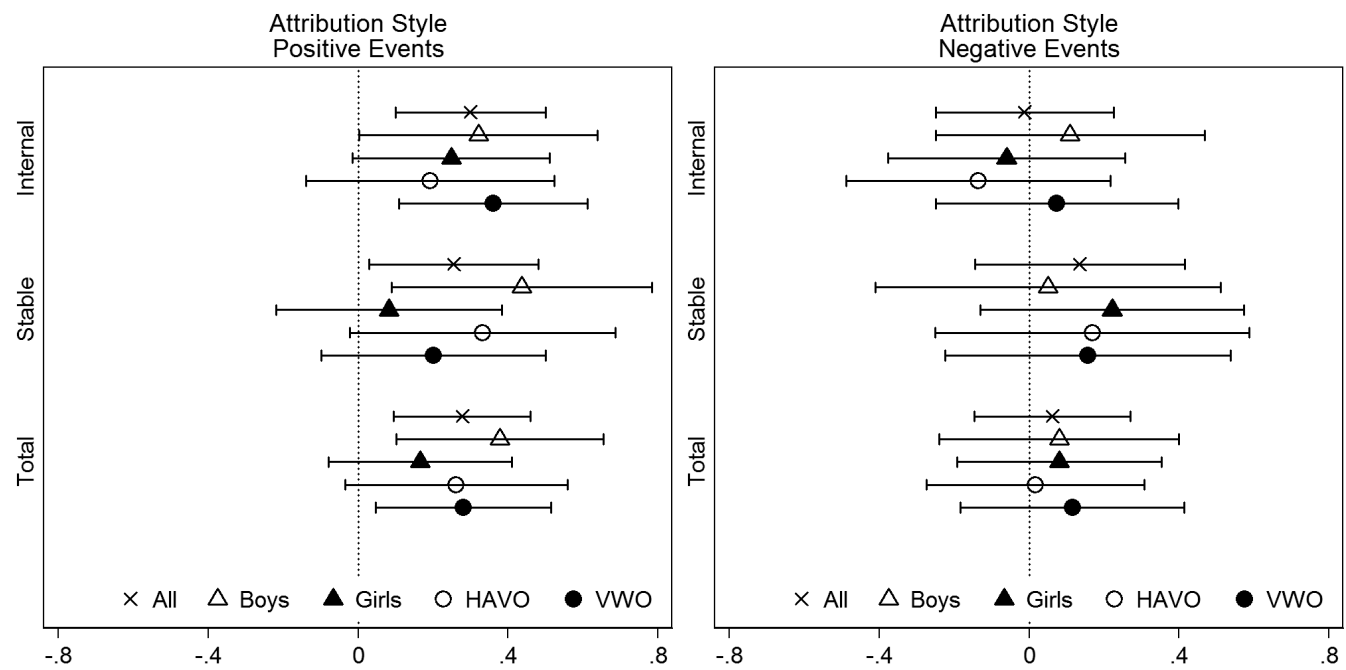

Note: OLS regression coefficients and $90 \%$ confidence intervals for treatment dummy (horizontal axis), separately for each outcome (vertical axis), and for different samples. Controls include gender, academic track, year of graduation, and score on primary school exit exam.

These effect sizes are in line with those found by Durlak et al. (2011) in their meta-analysis on the effects of SEL programs. For emotional emotional stability, they find a mean effect size of .24 standard deviations. The same effect size is found for positive social behavior, which is related to Big Five trait agreeableness. Of the outcomes evaluated by Durlak et al. (2011), attitudes toward self - including self-esteem, self-concept, and self-efficacy - is closely related to attribution style. SEL programs are found to be associated with a quarter of a standard deviation higher scores on attitudes toward self.

Overall, Figures 5.4 and 5.5 lend partial support for Hypothesis 3, that the introduction of the skills course and mandatory community service in high school is associated with higher scores on desirable personality traits. While treated boys seem to score higher on emotional stability, and to a lesser extent also on conscientiousness and agreeableness, these effects are not present for girls. The same holds for attribution style. Treated boys score significantly higher on internal and stable attribution of positive events compared to untreated boys, yet there is no significant difference in attributions styles of treated and untreated girls.

One should, however, be cautious to interpret these patterns as causal. It might also be the case that the program simply increased awareness about important personality characteristics, without actually improving the skills significantly. Our measures of noncognitive skills are based on self-reports, and if students are prone to respond in socially desirable ways, or wish to be seen in a positive light, students from the treatment group may score higher simply because of the fact that they know which traits are deemed desirable. For this reason, the aim of the program to stimulate the development and improvement of noncognitive skills cannot definitely be said to have been accomplished. Nevertheless, the message portrayed in the teachings still seems to have been remembered, which is important in its own right. 


\subsubsection{Robustness Checks}

To test whether the results and conclusions are robust to changes in the model and sample, we make several adjustments to the model and sample. Given that cohorts my differ along dimensions other than treatment, and also on dimensions not controlled, we estimate the effects for different set of cohorts. While questionnaire data is only available for students graduating between 2006 and 2010, exam results are also available for those graduating in 2005, providing information on an additional control cohort. The regression sample then increases by almost thirty percent. Results for high school performance (Figures 5.1 and 5.2) do not change much when adding this additional cohort. ${ }^{11}$ Rather than extending the sample, we could limit the sample to fewer cohorts. The results remain qualitatively the same if those graduating in 2006 are removed from the sample, leaving only 2007 graduates as control group, and those graduating between 2008 and 2010 as treatment group.

With a few exceptions, the same is true should the 2010 graduates be removed from the sample, thus removing graduates who had not yet started tertiary education. The treatment effect on satisfaction with chosen study is much smaller and no longer significantly different from zero. This suggests that our estimated effect on satisfaction with study choice might be driven by students who have not yet experienced the chosen study, and are therefore understandably very satisfied with their choice. However, the raw averages by year of graduation show that 2010 grades were on average less happy with their chosen study than those graduating earlier. In terms of estimated treatment effects on personality, removing the latest cohort does not alter the pattern of effects, yet with slightly larger standard errors. The negative association between school exams and treatment is no longer present once the 2010 cohort is removed from the sample, while also showing no significant relationship with national exams either. ${ }^{12}$

Second, we explore variations in our control for cognitive ability. We attempt to control for cognitive ability by using the score on a national primary school exit test (CITO). This score is missing for about a third of the sample. For those with missing CITO scores, we use the average of others to impute academic ability at the end of primary school, while also adding a missing indicator dummy. While this dummy variable might not fully capture the differences between those with missing CITO scores, the results do not change if we only use the sample of students for whom we have valid CITO scores. An alternative measure for ability might be to use report card grades before the start of treatment. We can do this by adding average report card grade as an additional control to equation (5.1). For HAVO students we add average grade at the end of the third year of high school, and for vwo students we add average grade at the end of the fourth year of high school. However, end of year grades are only available from 2005 onwards, meaning that we do not have early grades information for those graduating in 2006. Additionally, for the 2007 HAVO graduates, there are a lot of missing values for grades in the third year. Of the initial sample of 161 HAVO graduates for the main model, only 69 remain when adding pre-treatment report grades. The reduction for vwo students is also substantial (from 213 to 157), albeit less restrictive. Despite the reduced samples and larger standard errors, the results from replacing CITO with report card grades are qualitatively the same.

\footnotetext{
${ }^{11}$ For average report grade year before graduation, there is no information for those graduating in 2005. Report grades are only available from 2005 onwards.

${ }^{12}$ Except for results on the national Math exam, when academic track is considered. Treatment is associated with 0.8 higher grades on the national Math exam for HAVO students, 0.5 lower grades for VwO students; much higher than the original estimates of 0.6 and -0.2 , respectively.
} 
Finally, we investigate whether the association between treatment and tertiary education (satisfaction and performance) is spurious or not. If it is the case that all effects of community service and the skills course saturate in high school, any effects found for post-high school outcomes might be the result of omitted variable bias. What we consider to be posthigh school effects, might just be a reflection of correlations between high school outcomes and later outcomes. In other words, high school outcomes might be mediators in the relationship between treatment and outcomes in tertiary education. To adjust for this potential spurious effect, we need to control for intermediate high school outcomes. Controlling for average report card grades the year before graduation, which for most students is still after treatment, does not affect our results. An alternative would be to control for average exam grades, which is definitely measured after treatment for all students. Adding average grades on both school exams and national exams also does not affect the results, which provides additional support for hypotheses 1 and 2 .

All in all, the conclusions are not sensitive to changes in the sample or model specification. The results lend support to all three hypotheses, indicating that the changes in the curriculum have improved both satisfaction with and performance in chosen tertiary education, while also having contributed to the development of desirable personality traits.

\subsection{Conclusion}

The aim of this chapter was to investigate the impact of changes in the curriculum of a Dutch high school on its students' academic achievements and social development. As of 2006, students had to complete 40 hours of community service, and a new course was introduced, aimed at developing and improving students' study and social skills. We evaluate three hypotheses, regarding the satisfaction with the chosen tertiary education, performance in that chosen study, and development of desirable personality traits.

The results are not sensitive to changes in the sample or model specification. The results lend support to all three hypotheses, indicating that the changes in the curriculum have improved both satisfaction with and performance in chosen tertiary education, while also having contributed to the development of desirable personality traits. The results further indicate the importance of looking into heterogeneous treatment effects, with results differing by gender and high school track.

Figure 5.3 lends support for Hypothesis 1, that the introduction of the skills course and mandatory community service in high school has improved the tertiary study choice of students, but only weak support for Hypothesis 2, that the introduction of the skills course and mandatory community service in high school has improved the performance of students in tertiary education. Figures 5.4 and 5.5 lend partial support for Hypothesis 3, that the introduction of the skills course and mandatory community service in high school has improved the development of desirable personality traits. While treated boys seem to score higher on emotional stability, and to a lesser extent also on conscientiousness and agreeableness, these effects are not present for girls. The same holds for attribution style. Treated boys score significantly higher on internal and stable attribution of positive events compared to untreated boys, yet there is no significant difference in attributions styles of treated and untreated girls. 
While the findings are in line with the stated hypotheses, and therefore indicative of a meaningful addition to the school curriculum, the sample size is rather small, and therefore also the power of the analysis and precision of the estimates. Several sizeable point estimates are not statistically significant, which reduces the strength of the conclusions postulated above. The lack of pretests on our outcomes measures is also a shortcoming, specifically because the treated and untreated cohorts differ in terms of when they attended high school, and when they graduated. At the same time, the estimates presented in this study are based on the first cohorts of students subjected to these curriculum changes. Since 2006, the course has developed further, and the community service project has also become more structured and now covers more hours. Possible problems during the introduction of the new program might have had a negative impact on its performance. Future research is necessary to replicate and further test these findings. 


\section{Appendix 5.A Big Five Traits}

To measure the Big Five personality traits, we use a subset of items from the International Personality Item Pool (http://ipip.ori.org/) that capture the five domains in Costa and McCrae's taxonomy of personality. Rather than questioning our respondents on the full set of items, we use 22 of the 50 items used in the 10-item IPIP scales corresponding to the five domains of the NEO personality inventory (McCrae \& John, 1992). Table 5.A.1 shows the grouping of these items into the Big Five personality traits, the inter-item correlations or covariances for the five sets of items, and the Cronbach's alpha statistic for the resulting scales. The items are scored on a 5-point scale, ranging from 1, indicating "does not apply at all to me," to 5, indicating "applies very much to me." The scoring on the negatively formulated items is reversed (see first column of Table 5.A.1), and then the average of the items is used as our measure of the relevant construct. For the regression models, these scores are then standardized (mean zero, standard deviation one), as to make the effect of treatment interpretable in terms of standard deviation effects. The reliability of the resulting constructs is sufficiently high, with Cronbrach's alphas of .57 for openness, .77 for conscientiousness, .72 for extraversion, .67 for agreeableness, and .69 for emotional stability.

The questionnaire contained more items from the IPIP than the 22 listed in Table 5.A.1, and allows us to construct alternative Big Five taxonomies. The IPIP contains 10-item and 20item scales that are associated with Goldberg's Big Five domains (Goldberg, 1992), as well as 10-item and 20-item scales for Costa and McCrae's NEO-PI-R domains. Lastly, there are also 10-item scales for each of the 30 NEO-PI-R facets. Using a subset of the items related to those scales, we can thus construct five alternative Big Five taxonomies. Table 5.A.2 lists all personality items available in the questionnaire, and to which scales they belong. For each Big Five trait, for each of the five scales, the Cronbach's alpha of the relevant trait is reported. While the results in Figure 5.4 are based on the constructs resulting from using the items related to the 10-item scales related to the NEO-PI-R domains, the results do not qualitatively change when using the other, either smaller or larger, sets of items. 
Table 5.A.1: Inter-item Correlations and Covariances of Big Five Items

\begin{tabular}{|c|c|c|c|c|c|}
\hline & & 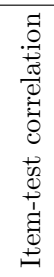 & 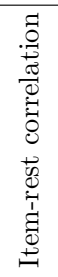 & 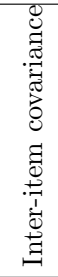 & $\frac{\overparen{\pi}}{\frac{\pi}{4}}$ \\
\hline & Openness & & & .38 & .57 \\
\hline+ & Have a vivid imagination & .69 & .37 & .45 & .49 \\
\hline- & Avoid philosophical discussions & .74 & .39 & .36 & .45 \\
\hline \multirow{2}{*}{+} & Believe in the importance of art & .77 & .38 & .34 & .46 \\
\hline & Conscientiousness & & & .57 & .77 \\
\hline+ & Get chores done right away & .67 & .46 & .70 & .76 \\
\hline- & Find it difficult to get down to work & .85 & .65 & .44 & .65 \\
\hline- & Waste my time & .81 & .65 & .52 & .67 \\
\hline \multirow[t]{2}{*}{-} & Do just enough work to get by & .73 & .49 & .62 & .75 \\
\hline & Extraversion & & & .32 & .72 \\
\hline- & Don't like to draw attention to myself & .77 & .50 & .29 & .67 \\
\hline+ & Feel comfortable around people & .69 & .49 & .36 & .67 \\
\hline- & Keep in the background & .80 & .59 & .26 & .60 \\
\hline \multirow[t]{2}{*}{-} & Have little to say & .70 & .48 & .35 & .67 \\
\hline & Agreeableness & & & .25 & .67 \\
\hline- & Insult people & .69 & .50 & .24 & .58 \\
\hline+ & Have a good word for everyone & .57 & .31 & .29 & .66 \\
\hline & Get back at others & .78 & .57 & .18 & .53 \\
\hline- & Have a sharp tongue & .70 & .41 & .23 & .63 \\
\hline \multirow[t]{2}{*}{+} & Believe that others have good intentions & .53 & .34 & .30 & .65 \\
\hline & Emotional Stability & & & .24 & .69 \\
\hline+ & Seldom feel blue & .67 & .45 & .22 & .64 \\
\hline+ & Am not easily bothered by things & .65 & .44 & .23 & .64 \\
\hline+ & Rarely get irritated & .59 & .37 & .25 & .67 \\
\hline & Panic easily & .66 & .44 & .22 & .64 \\
\hline & Feel comfortable with myself & .63 & .46 & .25 & .64 \\
\hline- & Dislike myself & .56 & .38 & .27 & .66 \\
\hline
\end{tabular}


Table 5.A.2: Selected IPIP Items and Corresponding Scales

\begin{tabular}{|c|c|c|c|c|c|}
\hline Item & 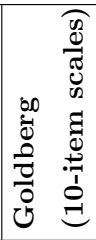 & 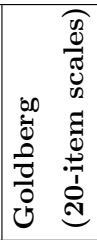 & 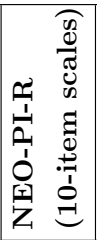 & 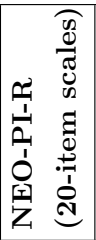 & 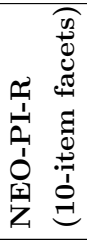 \\
\hline Openness & .43 & .43 & .57 & .64 & .77 \\
\hline+ Have a vivid imagination & $\mathrm{x}$ & $\mathrm{x}$ & $\mathrm{x}$ & $\mathrm{x}$ & $\mathrm{x}$ \\
\hline - Avoid philosophical discussions & & & $\mathrm{x}$ & $\mathrm{x}$ & $\mathrm{x}$ \\
\hline+ Believe in the importance of art & & & $\mathrm{x}$ & $\mathrm{x}$ & $\mathrm{x}$ \\
\hline+ Have a rich vocabulary & $\mathrm{x}$ & $\mathrm{x}$ & & $\mathrm{x}$ & $\mathrm{x}$ \\
\hline+ Enjoy thinking about things & & & & $\mathrm{x}$ & $\mathrm{x}$ \\
\hline+ Spend time reflecting on things & $\mathrm{x}$ & $\mathrm{x}$ & & & $\mathrm{x}$ \\
\hline - Dislike changes & & & & & $\mathrm{x}$ \\
\hline+ Like to get lost in thought & & & & & $\mathrm{x}$ \\
\hline+ Enjoy examining myself and my life & & & & & $\mathrm{x}$ \\
\hline+ Try to understand myself & & & & & $\mathrm{x}$ \\
\hline Conscientiousness & - & .75 & .77 & .76 & .78 \\
\hline+ Get chores done right away & $\mathrm{x}$ & $\mathrm{x}$ & $\mathrm{x}$ & $\mathrm{x}$ & $\mathrm{x}$ \\
\hline - Find it difficult to get down to work & & $\mathrm{x}$ & $\mathrm{x}$ & $\mathrm{x}$ & $\mathrm{x}$ \\
\hline - Waste my time & & $\mathrm{x}$ & $\mathrm{x}$ & $\mathrm{x}$ & $\mathrm{x}$ \\
\hline - Do just enough work to get by & & & $\mathrm{x}$ & $\mathrm{x}$ & $\mathrm{x}$ \\
\hline+ Complete tasks successfully & & & & $\mathrm{x}$ & $\mathrm{x}$ \\
\hline+ Excel in what I do & & & & & $\mathrm{x}$ \\
\hline+ Am sure of my ground & & & & & $\mathrm{x}$ \\
\hline+ Plunge into tasks with all my heart & & & & & $\mathrm{x}$ \\
\hline + Listen to my conscience & & & & & $\mathrm{x}$ \\
\hline + Want everything to be "just right" & & & & & $\mathrm{x}$ \\
\hline+ Go straight for the goal & & & & & $\mathrm{x}$ \\
\hline - Am not bothered by messy people & & & & & $\mathrm{x}$ \\
\hline - Am not bothered by disorder & & & & & $\mathrm{x}$ \\
\hline - Make rash decisions & & & & & $\mathrm{x}$ \\
\hline Extraversion & .75 & .80 & .72 & .80 & .72 \\
\hline - Don't like to draw attention to myself & $\mathrm{x}$ & $\mathrm{x}$ & $\mathrm{x}$ & $\mathrm{x}$ & $\mathrm{x}$ \\
\hline+ Feel comfortable around people & $\mathrm{x}$ & $\mathrm{x}$ & $\mathrm{x}$ & $\mathrm{x}$ & $\mathrm{x}$ \\
\hline - $\quad$ Keep in the background & $\mathrm{x}$ & $\mathrm{x}$ & $\mathrm{x}$ & $\mathrm{x}$ & $\mathrm{x}$ \\
\hline - Have little to say & $\mathrm{x}$ & $\mathrm{x}$ & $\mathrm{x}$ & $\mathrm{x}$ & $\mathrm{x}$ \\
\hline+ Talk to a lot of different people at parties & $\mathrm{x}$ & $\mathrm{x}$ & & $\mathrm{x}$ & $\mathrm{x}$ \\
\hline - Find it difficult to approach others & & $\mathrm{x}$ & & $\mathrm{x}$ & $x^{13}$ \\
\hline+ Have a lot of fun & & & & & $\mathrm{x}$ \\
\hline+ Am always busy & & & & & $\mathrm{x}$ \\
\hline+ Enjoy being reckless & & & & & $\mathrm{x}$ \\
\hline+ Enjoy being part of a group & & & & & $\mathrm{x}$ \\
\hline Agreeableness & .41 & .51 & .67 & .67 & .69 \\
\hline - Insult people & $\mathrm{x}$ & $\mathrm{x}$ & $\mathrm{x}$ & $\mathrm{x}$ & $\mathrm{x}$ \\
\hline+ Have a good word for everyone & & $\mathrm{x}$ & $\mathrm{x}$ & $\mathrm{x}$ & $\mathrm{x}$ \\
\hline - Get back at others & & & $\mathrm{x}$ & $\mathrm{x}$ & $\mathrm{x}$ \\
\hline - Have a sharp tongue & & & $\mathrm{x}$ & $\mathrm{x}$ & $\mathrm{x}$ \\
\hline+ Believe that others have good intentions & & & $\mathrm{x}$ & $\mathrm{x}$ & $\mathrm{x}$ \\
\hline+ Trust what people say & & & & $\mathrm{x}$ & $\mathrm{x}$ \\
\hline + Feel others' emotions & $\mathrm{x}$ & $\mathrm{x}$ & & & $\mathrm{x}^{14}$ \\
\hline - Am not interested in other people's problems & $\mathrm{x}$ & $\mathrm{x}$ & & & $\mathrm{x}$ \\
\hline
\end{tabular}

\footnotetext{
${ }^{13}$ in Emotional Stability scale

${ }^{14}$ in Openness scale
} 
Table 5.A.2: (continued)

\begin{tabular}{|c|c|c|c|c|c|}
\hline Item & 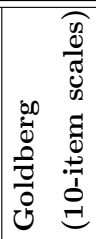 & 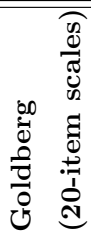 & 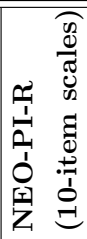 & 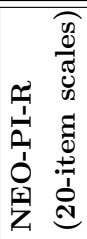 & 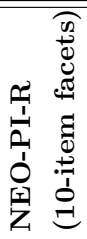 \\
\hline $\begin{array}{ll} & \text { Think highly of myself } \\
+ & \text { Would never cheat on my taxes } \\
+ & \text { Feel sympathy for those who are worse off than myself } \\
- & \text { Believe people should fend for themselves }\end{array}$ & & & & & $\begin{array}{l}\mathrm{x} \\
\mathrm{x} \\
\mathrm{x} \\
\mathrm{x}\end{array}$ \\
\hline Emotional Stability & - & .68 & .69 & .73 & .77 \\
\hline 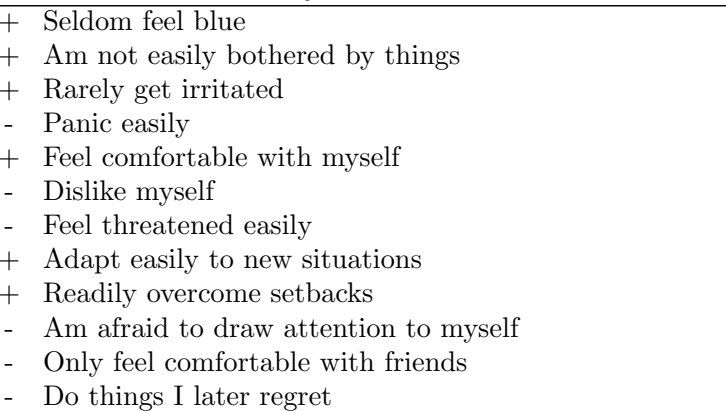 & $\mathrm{x}$ & $\begin{array}{l}\mathrm{x} \\
\mathrm{x} \\
\mathrm{x} \\
\mathrm{x}\end{array}$ & $\begin{array}{l}\mathrm{x} \\
\mathrm{x} \\
\mathrm{x} \\
\mathrm{x} \\
\mathrm{x} \\
\mathrm{x}\end{array}$ & $\begin{array}{l}x \\
x \\
x \\
x \\
x \\
x \\
x\end{array}$ & $\begin{array}{l}\mathrm{x} \\
\mathrm{x} \\
\mathrm{x} \\
\mathrm{x} \\
\mathrm{x} \\
\mathrm{x} \\
\mathrm{x} \\
\mathrm{x} \\
\mathrm{x} \\
\mathrm{x} \\
\mathrm{x}\end{array}$ \\
\hline
\end{tabular}




\section{Appendix 5.B Attribution Style}

The items used to determine students' attribution style towards positive and negative events stem from the Attribution Style Questionnaire, designed by Peterson and co-authors (Peterson et al., 1982), which measures individual differences in the attribution of positive and negative events to internal (versus external), and stable (versus unstable) causes. We ask respondents to think about a positive or negative hypothetical event. To increase the likelihood of response by students, we kept the questionnaire as brief as possible, and only asked a subset of questions, and only for four events, rather than the twelve mentioned in the original questionnaire. The events considered are the following:

- You apply for a position you want very badly (e.g. an internship or job), and you get it. (positive)

- You meet a friend who compliments you on your appearance. (positive)

- You give an important talk in front of a group and the audience reacts negatively. (negative)

- You ask someone to go out with you and he/she says no. (negative)

For each hypothetical event, respondents answer two questions, one indicating the extent of internal (external) attribution, and the other indicating stable (unstable) attribution: Regarding the main cause you would associate with the event, answer the following questions:

- Is the cause of the event due to something about you or to something about other people or circumstances? (internal)

Totally due to other circumstances $\square \square \square \square \square$ Totally due to me

- In the future when in a similar situation, will this cause again be present? (stable)

Will never again be present $\square \square \square \square \square$ Will always be present

Each question is answered on a scale from 1 to 5 . With the resulting 8 answers (4 events: 2 positive, 2 negative; 2 questions for each event: 1 on internal attribution, 1 on stable attribution) we calculate scores by averaging over the attribution dimensions. Overall attribution of positive events is the average of the four questions concerning the first two events listed above, whereas the overall attribution of negative events is the average of the four questions concerning the last two events. For internal (stable) attribution of positive (negative) events, the scores on internal (stable) question on the two positive (negative) events is averaged. Figure 5.5 shows the point estimates of treatment on the scores on the various attribution styles. Alpha coefficients of .61 and .55 are achieved for the attribution style scales for positive and negative events, respectively, which are, given the smaller number of items, lower than the coefficients .75 and .72 reported by Peterson and co-authors (1982). The subscales for positive (negative) events are less reliable, since they are only based on two items each, and have Cronbach's alphas of .27 (.36) and .53 (.56) for internality and stability, respectively. 



\section{Appendix 5.C Regression Tables}

The following tables report the complete regression results belonging to Figures 5.1-5.5, resulting from estimating equation (5.1) on varying sets of outcomes. Table 5.C.1 presents the results for average high school grades, whereas Table 5.C.2 shows the results for grades on the school and national exit exams, for the subjects Dutch, English, and Mathematics. Table 5.C.1 contains one additional measure for GPA, which is not presented in Figure 5.1. Students are allowed to retake national exit exams if they do not do well on their first attempt. Table 5.C.3 lists the results for outcomes pertaining to tertiary education, allowing an evaluation of the first and second hypotheses, postulating that treated students are both more satisfied with and more successful in their chosen tertiary education. Finally, Tables 5.C.4 and 5.5 present the results in which the Big Five personality traits and Attribution Styles are used as outcome measures to evaluate the third hypothesis, that students who received treatment score higher on valuable personality traits.

Table 5.C.1: High School Performance: Average Exam Grades

\begin{tabular}{|c|c|c|c|c|}
\hline & 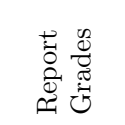 & 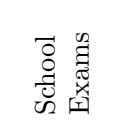 & 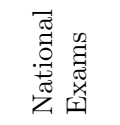 & 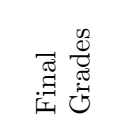 \\
\hline \multicolumn{5}{|l|}{ All } \\
\hline Treated & $\begin{array}{c}.051 \\
(0.75)\end{array}$ & $\begin{array}{c}-.051 \\
(-0.77)\end{array}$ & $\begin{array}{c}-.049 \\
(-0.58)\end{array}$ & $\begin{array}{c}-.059 \\
(-0.83)\end{array}$ \\
\hline Graduation year & $\begin{array}{c}-.037 \\
(-1.45)\end{array}$ & $\begin{array}{c}-.013 \\
(-0.52)\end{array}$ & $\begin{array}{c}-.007 \\
(-0.23)\end{array}$ & $\begin{array}{c}-.009 \\
(-0.35)\end{array}$ \\
\hline Male & $\begin{array}{c}-.209 * * * \\
(-6.35)\end{array}$ & $\begin{array}{c}-.185^{* * *} \\
(-5.70)\end{array}$ & $\begin{array}{c}.041 \\
(0.98)\end{array}$ & $\begin{array}{c}-.0656^{*} \\
(-1.87)\end{array}$ \\
\hline VWO & $\begin{array}{c}.242^{* * *} \\
(6.62)\end{array}$ & $\begin{array}{c}.235^{* * *} \\
(6.56)\end{array}$ & $\begin{array}{c}.050 \\
(1.08)\end{array}$ & $\begin{array}{c}163^{* * *} \\
(4.20)\end{array}$ \\
\hline CITO & $\begin{array}{c}.0227^{* * *} \\
(5.01)\end{array}$ & $\begin{array}{c}.0206^{* * *} \\
(4.61)\end{array}$ & $\begin{array}{c}.0401^{* * *} \\
(7.00)\end{array}$ & $\begin{array}{c}.0289^{* * *} \\
(6.01)\end{array}$ \\
\hline CITO missing & $\begin{array}{c}-.113^{* * *} \\
(-3.16)\end{array}$ & $\begin{array}{c}-.0814^{* *} \\
(-2.32)\end{array}$ & $\begin{array}{c}-.147^{* * *} \\
(-3.24)\end{array}$ & $\begin{array}{c}-.108^{* * *} \\
(-2.84)\end{array}$ \\
\hline$n$ & 1,148 & 1,145 & 1,145 & 1,145 \\
\hline \multicolumn{5}{|l|}{ Boys } \\
\hline Treated & $\begin{array}{c}.042 \\
(0.43)\end{array}$ & $\begin{array}{c}-.029 \\
(-0.31)\end{array}$ & $\begin{array}{c}.061 \\
(0.50)\end{array}$ & $\begin{array}{c}.033 \\
(0.32)\end{array}$ \\
\hline $\begin{array}{l}n \\
\text { Girls }\end{array}$ & 538 & 536 & 536 & 536 \\
\hline Treated & $\begin{array}{c}.064 \\
(0.68)\end{array}$ & $\begin{array}{c}-.064 \\
(-0.70)\end{array}$ & $\begin{array}{c}-.146 \\
(-1.23)\end{array}$ & $\begin{array}{c}-.137 \\
(-1.38)\end{array}$ \\
\hline $\begin{array}{l}n \\
\text { HAVO }\end{array}$ & 610 & 609 & 609 & 609 \\
\hline Treated & $\begin{array}{c}.098 \\
(1.15)\end{array}$ & $\begin{array}{c}-.073 \\
(-0.89)\end{array}$ & $\begin{array}{c}.044 \\
(0.42)\end{array}$ & $\begin{array}{c}-.036 \\
(-0.41)\end{array}$ \\
\hline $\begin{array}{l}n \\
\mathbf{V W O}\end{array}$ & 573 & 569 & 569 & 569 \\
\hline Treated & $\begin{array}{c}.044 \\
(0.42)\end{array}$ & $\begin{array}{c}-.008 \\
(-0.08)\end{array}$ & $\begin{array}{c}-.082 \\
(-0.63)\end{array}$ & $\begin{array}{c}-.045 \\
(-0.40)\end{array}$ \\
\hline$n$ & 575 & 576 & 576 & 576 \\
\hline
\end{tabular}

Note: OLS regression coefficients. T-statistics reported in parentheses. Stars indicate significance of coefficients: ${ }^{* * *}$ at $1 \%,{ }^{* *}$ at $5 \%, *$ at $10 \%$. Top panel for complete sample, lower panels results for subsamples, using same set of controls (coefficients on controls omitted). 
Table 5.C.2: High School Performance: Subject Specific Exam Grades

\begin{tabular}{|c|c|c|c|c|c|c|}
\hline & \multicolumn{3}{|c|}{ School Exam Grades } & \multicolumn{3}{|c|}{ National Exam Grades } \\
\hline & 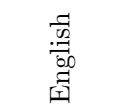 & $\begin{array}{l}\frac{0}{0} \\
\stackrel{+}{*} \\
0\end{array}$ & 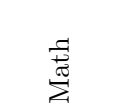 & 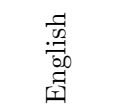 & $\begin{array}{l}\frac{9}{0} \\
\stackrel{+}{*} \\
0\end{array}$ & $\sum_{i}^{\frac{\pi}{ \pm}}$ \\
\hline \multicolumn{7}{|l|}{ All } \\
\hline Treated & $\begin{array}{c}-.027 \\
(-0.30)\end{array}$ & $\begin{array}{c}-.270^{* * *} \\
(-2.64)\end{array}$ & $\begin{array}{l}-.248^{*} \\
(-1.95)\end{array}$ & $\begin{array}{c}.162 \\
(1.23)\end{array}$ & $\begin{array}{c}.024 \\
(0.22)\end{array}$ & $\begin{array}{c}.076 \\
(0.46)\end{array}$ \\
\hline Graduation year & $\begin{array}{l}.0640^{*} \\
(1.91)\end{array}$ & $\begin{array}{c}.043 \\
(1.12)\end{array}$ & $\begin{array}{c}-.049 \\
(-1.03)\end{array}$ & $\begin{array}{c}-.038 \\
(-0.77)\end{array}$ & $\begin{array}{c}-.0714^{*} \\
(-1.76)\end{array}$ & $\begin{array}{c}-.154^{* *} \\
(-2.49)\end{array}$ \\
\hline Male & $\begin{array}{c}.044 \\
(1.01)\end{array}$ & $\begin{array}{c}-.581^{* * *} \\
(-11.58)\end{array}$ & $\begin{array}{c}-.208^{* * *} * \\
(-3.31)\end{array}$ & $\begin{array}{c}.249^{* * *} \\
(3.87)\end{array}$ & $\begin{array}{c}-.240^{* * *} \\
(-4.52)\end{array}$ & $\begin{array}{c}-.013 \\
(-0.16)\end{array}$ \\
\hline VWO & $\begin{array}{c}.054 \\
(1.11)\end{array}$ & $\begin{array}{c}.204^{* * *} \\
(3.67)\end{array}$ & $\begin{array}{c}.025 \\
(0.35)\end{array}$ & $\begin{array}{l}-.045 \\
(-0.64)\end{array}$ & $\begin{array}{l}.148^{* *} \\
(2.52)\end{array}$ & $\begin{array}{c}-.024 \\
(-0.26)\end{array}$ \\
\hline СITO & $\begin{array}{c}.0297^{* * *} \\
(4.93)\end{array}$ & $\begin{array}{c}.009 \\
(1.37)\end{array}$ & $\begin{array}{c}.0293^{* * *} \\
(3.30)\end{array}$ & $\begin{array}{c}.0485^{* * * *} \\
(5.48)\end{array}$ & $\begin{array}{c}.0313^{* * *} \\
(4.29)\end{array}$ & $\begin{array}{c}.0693^{* * *} \\
(5.96)\end{array}$ \\
\hline CITO missing & $\begin{array}{l}-.006 \\
(-0.13)\end{array}$ & $\begin{array}{c}-.134^{* *} \\
(-2.46)\end{array}$ & $\begin{array}{c}-.011 \\
(-0.17)\end{array}$ & $\begin{array}{l}-.102 \\
(-1.46)\end{array}$ & $\begin{array}{c}-.057 \\
(-0.99)\end{array}$ & $\begin{array}{l}-.150^{*} \\
(-1.66)\end{array}$ \\
\hline$n$ & 1,145 & 1,145 & 974 & 1,145 & 1,145 & 974 \\
\hline Boys & & & & & & \\
\hline Treated & $\begin{array}{c}-.081 \\
(-0.60)\end{array}$ & $\begin{array}{c}-.234 \\
(-1.50)\end{array}$ & $\begin{array}{c}-.095 \\
(-0.53)\end{array}$ & $\begin{array}{c}.313 \\
(1.62)\end{array}$ & $\begin{array}{c}.118 \\
(0.71)\end{array}$ & $\begin{array}{c}.278 \\
(1.19)\end{array}$ \\
\hline $\begin{array}{l}n \\
\text { Girls }\end{array}$ & 536 & 536 & 494 & 536 & 536 & 494 \\
\hline Treated & $\begin{array}{c}.016 \\
(0.13)\end{array}$ & $\begin{array}{c}-.275^{* *} \\
(-2.04)\end{array}$ & $\begin{array}{c}-.383^{* *} \\
(-2.15)\end{array}$ & $\begin{array}{c}.020 \\
(0.11)\end{array}$ & $\begin{array}{c}-.050 \\
(-0.35)\end{array}$ & $\begin{array}{c}-.105 \\
(-0.44)\end{array}$ \\
\hline $\begin{array}{l}n \\
\text { HAVO }\end{array}$ & 609 & 609 & 480 & 609 & 609 & 480 \\
\hline Treated & $\begin{array}{c}-.088 \\
(-0.71)\end{array}$ & $\begin{array}{c}-.173 \\
(-1.19)\end{array}$ & $\begin{array}{c}-.378^{* *} \\
(-1.97)\end{array}$ & $\begin{array}{c}.560 * * * \\
(3.22)\end{array}$ & $\begin{array}{c}-.225 \\
(-1.38)\end{array}$ & $\begin{array}{l}.591^{* *} \\
(2.34)\end{array}$ \\
\hline $\begin{array}{l}n \\
\mathbf{V W O}\end{array}$ & 569 & 569 & 398 & 569 & 569 & 398 \\
\hline Treated & $\begin{array}{c}.053 \\
(0.41)\end{array}$ & $\begin{array}{c}-.311^{* *} \\
(-2.17)\end{array}$ & $\begin{array}{c}-.174 \\
(-1.04)\end{array}$ & $\begin{array}{c}-.131 \\
(-0.68)\end{array}$ & $\begin{array}{c}.302^{* *} \\
(2.12)\end{array}$ & $\begin{array}{c}-.187 \\
(-0.86)\end{array}$ \\
\hline$n$ & 576 & 576 & 576 & 576 & 576 & 576 \\
\hline
\end{tabular}

Note: $\overline{\overline{\text { OLS regression coefficients. T-statistics reported in parentheses. Stars indicate significance }}}$ of coefficients: $* * *$ at $1 \%,{ }^{* *}$ at $5 \%, *$ at $10 \%$. Top panel for complete sample, lower panels results for subsamples, using same set of controls (coefficients on controls omitted). 
Table 5.C.3: Study Choice and Performance in Tertiary Education

\begin{tabular}{|c|c|c|c|c|c|c|}
\hline & \multicolumn{3}{|c|}{ Study Choice } & \multicolumn{3}{|c|}{ Performance in Tertiary Education } \\
\hline & 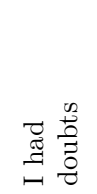 & 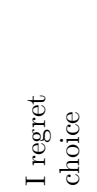 & 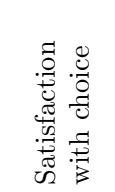 & 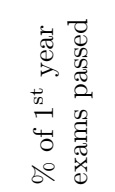 & 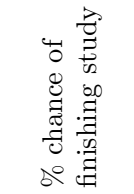 & 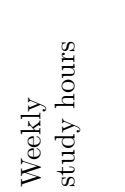 \\
\hline \multicolumn{7}{|l|}{ All } \\
\hline Treated & $\begin{array}{c}.527 \\
(1.40)\end{array}$ & $\begin{array}{l}-.829^{*} \\
(-1.79)\end{array}$ & $\begin{array}{c}.847^{* * *} \\
(2.88)\end{array}$ & $\begin{array}{l}9.432 \\
(1.37)\end{array}$ & $\begin{array}{c}2.089 \\
(0.90)\end{array}$ & $\begin{array}{l}3.318 \\
(1.15)\end{array}$ \\
\hline Graduation year & $\begin{array}{l}-.262^{*} \\
(-1.79)\end{array}$ & $\begin{array}{c}.031 \\
(0.15)\end{array}$ & $\begin{array}{c}-.393^{* * *} \\
-(3.42)\end{array}$ & $\begin{array}{l}-2.149 \\
(-0.68)\end{array}$ & $\begin{array}{c}-4.186^{* * *} \\
(-4.62)\end{array}$ & $\begin{array}{l}-1.353 \\
(-1.01)\end{array}$ \\
\hline Male & $\begin{array}{c}-.285 \\
(-1.53)\end{array}$ & $\begin{array}{c}.070 \\
(0.34)\end{array}$ & $\begin{array}{c}-.019 \\
-(0.13)\end{array}$ & $\begin{array}{l}-3.821 \\
(-1.23)\end{array}$ & $\begin{array}{l}1.203 \\
(1.04)\end{array}$ & $\begin{array}{l}-1.555 \\
(-1.19)\end{array}$ \\
\hline VWO & $\begin{array}{c}.211 \\
(0.98)\end{array}$ & $\begin{array}{c}-.151 \\
(-0.64)\end{array}$ & $\begin{array}{c}.484^{* * *} \\
(2.87)\end{array}$ & $\begin{array}{l}-1.582 \\
(-0.45)\end{array}$ & $\begin{array}{c}4.280^{* * *} \\
(3.22)\end{array}$ & $\begin{array}{l}-1.262 \\
(-0.86)\end{array}$ \\
\hline CITO & $\begin{array}{c}.011 \\
(0.45)\end{array}$ & $\begin{array}{c}-.003 \\
(-0.09)\end{array}$ & $\begin{array}{c}-.008 \\
-(0.44)\end{array}$ & $\begin{array}{c}-.347 \\
(-0.85)\end{array}$ & $\begin{array}{c}-.033 \\
(-0.23)\end{array}$ & $\begin{array}{c}-.068 \\
(-0.40)\end{array}$ \\
\hline CITO missing & $\begin{array}{c}.341 \\
(1.62)\end{array}$ & $\begin{array}{l}.514^{* *} \\
(2.29)\end{array}$ & $\begin{array}{c}-.148 \\
-(0.91)\end{array}$ & $\begin{array}{c}-8.439^{* *} \\
(-2.50)\end{array}$ & $\begin{array}{l}-1.974 \\
(-1.50)\end{array}$ & $\begin{array}{c}.637 \\
(0.45)\end{array}$ \\
\hline$n$ & 379 & 340 & 367 & 333 & 367 & 328 \\
\hline Boys & & & & & & \\
\hline Treated & $\begin{array}{c}.450 \\
(0.77)\end{array}$ & $\begin{array}{c}-1.317^{*} \\
(-1.80)\end{array}$ & $\begin{array}{c}1.047^{* *} \\
(2.01)\end{array}$ & $\begin{array}{c}17.94^{*} \\
(1.71)\end{array}$ & $\begin{array}{l}4.226 \\
(1.11)\end{array}$ & $\begin{array}{l}5.231 \\
(1.11)\end{array}$ \\
\hline $\begin{array}{l}n \\
\text { Girls }\end{array}$ & 153 & 137 & 148 & 136 & 149 & 135 \\
\hline Treated & $\begin{array}{c}.387 \\
(0.78)\end{array}$ & $\begin{array}{c}-.499 \\
(-0.82)\end{array}$ & $\begin{array}{l}.692^{*} \\
(1.97)\end{array}$ & $\begin{array}{l}4.875 \\
(0.54)\end{array}$ & $\begin{array}{c}.571 \\
(0.19)\end{array}$ & $\begin{array}{l}1.617 \\
(0.45)\end{array}$ \\
\hline $\begin{array}{l}n \\
\text { HAVO }\end{array}$ & 226 & 203 & 219 & 197 & 218 & 193 \\
\hline Treated & $\begin{array}{c}.852 \\
(1.49)\end{array}$ & $\begin{array}{c}-.612 \\
(-0.84)\end{array}$ & $\begin{array}{c}1.023^{* *} \\
(2.14)\end{array}$ & $\begin{array}{c}.769 \\
(0.07)\end{array}$ & $\begin{array}{c}-.931 \\
(-0.21)\end{array}$ & $\begin{array}{l}3.061 \\
(0.61)\end{array}$ \\
\hline $\begin{array}{l}n \\
\text { VWO }\end{array}$ & 166 & 145 & 158 & 143 & 158 & 137 \\
\hline Treated & $\begin{array}{c}.216 \\
(0.43)\end{array}$ & $\begin{array}{c}-.992 \\
(-1.64)\end{array}$ & $\begin{array}{l}.767^{* *} \\
(2.04)\end{array}$ & $\begin{array}{c}15.49^{*} \\
(1.69)\end{array}$ & $\begin{array}{c}4.476^{*} \\
(1.89)\end{array}$ & $\begin{array}{l}3.853 \\
(1.11)\end{array}$ \\
\hline$n$ & 213 & 195 & 209 & 190 & 209 & 191 \\
\hline
\end{tabular}

Note: Results from ordered logit regressions for first two columns, OLS regression coefficients for remaining four columns. T-statistics reported in parentheses. Stars indicate significance of coefficients: ${ }^{* * *}$ at $1 \%, * *$ at $5 \%,{ }^{*}$ at $10 \%$. Top panel for complete sample, lower panels results for subsamples, using same set of controls (coefficients on controls omitted). 
Table 5.C.4: Big 5 Personality Traits

\begin{tabular}{|c|c|c|c|c|c|}
\hline & 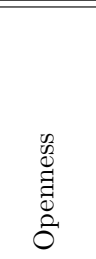 & 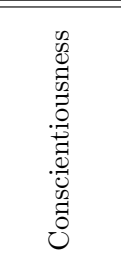 & 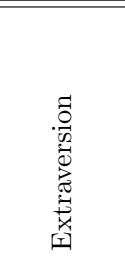 & 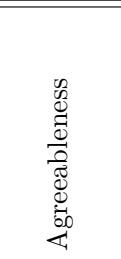 & 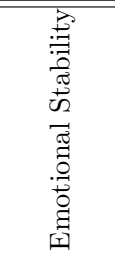 \\
\hline \multicolumn{6}{|l|}{ All } \\
\hline Treated & $\begin{array}{c}-.153 \\
(-0.71)\end{array}$ & $\begin{array}{c}.328 \\
(1.59)\end{array}$ & $\begin{array}{c}.130 \\
(0.61)\end{array}$ & $\begin{array}{c}.394^{*} \\
(1.90)\end{array}$ & $\begin{array}{c}.262 \\
(1.26)\end{array}$ \\
\hline Graduation year & $\begin{array}{c}.063 \\
(0.75)\end{array}$ & $\begin{array}{l}-.178^{* *} \\
-(2.21)\end{array}$ & $\begin{array}{c}-.091 \\
(-1.10)\end{array}$ & $\begin{array}{c}-.114 \\
(-1.41)\end{array}$ & $\begin{array}{c}-.113 \\
(-1.41)\end{array}$ \\
\hline Male & $\begin{array}{l}.191^{*} \\
(1.79)\end{array}$ & $\begin{array}{c}-.442^{* * *} \\
-(4.31)\end{array}$ & $\begin{array}{l}.176^{*} \\
(1.66)\end{array}$ & $\begin{array}{c}-.410^{* * *} \\
(-3.99)\end{array}$ & $\begin{array}{c}.570 * * * \\
(5.57)\end{array}$ \\
\hline VWO & $\begin{array}{l}.263^{* *} \\
(2.15)\end{array}$ & $\begin{array}{c}-.022 \\
-(0.19)\end{array}$ & $\begin{array}{c}.170 \\
(1.40)\end{array}$ & $\begin{array}{c}.024 \\
(0.20)\end{array}$ & $\begin{array}{c}.028 \\
(0.24)\end{array}$ \\
\hline CITO & $\begin{array}{c}-.005 \\
(-0.39)\end{array}$ & $\begin{array}{l}-.0233^{*} \\
-(1.82)\end{array}$ & $\begin{array}{c}-.0271^{* *} \\
(-2.05)\end{array}$ & $\begin{array}{c}-.008 \\
(-0.64)\end{array}$ & $\begin{array}{c}.000 \\
(-0.01)\end{array}$ \\
\hline CITO missing & $\begin{array}{l}.246^{* *} \\
(2.06)\end{array}$ & $\begin{array}{c}-.079 \\
-(0.69)\end{array}$ & $\begin{array}{c}-.091 \\
(-0.77)\end{array}$ & $\begin{array}{c}-.158 \\
(-1.38)\end{array}$ & $\begin{array}{c}-.317^{* * *} \\
(-2.78)\end{array}$ \\
\hline$n$ & 369 & 378 & 378 & 378 & 376 \\
\hline \multicolumn{6}{|l|}{ Boys } \\
\hline Treated & $\begin{array}{c}-.342 \\
(-0.99)\end{array}$ & $\begin{array}{c}.535 \\
(1.59)\end{array}$ & $\begin{array}{c}.289 \\
(0.83)\end{array}$ & $\begin{array}{c}.596 \\
(1.62)\end{array}$ & $\begin{array}{l}.771^{* *} \\
(2.29)\end{array}$ \\
\hline $\begin{array}{l}n \\
\text { Girls }\end{array}$ & 149 & 151 & 151 & 151 & 151 \\
\hline Treated & $\begin{array}{c}-.033 \\
(-0.12)\end{array}$ & $\begin{array}{c}.184 \\
(0.69)\end{array}$ & $\begin{array}{c}.037 \\
(0.14)\end{array}$ & $\begin{array}{c}.240 \\
(0.97)\end{array}$ & $\begin{array}{c}-.051 \\
(-0.19)\end{array}$ \\
\hline $\begin{array}{l}n \\
\text { HAVO }\end{array}$ & 220 & 227 & 227 & 227 & 225 \\
\hline Treated & $\begin{array}{c}.241 \\
(0.74)\end{array}$ & $\begin{array}{c}.120 \\
(0.38)\end{array}$ & $\begin{array}{c}.114 \\
(0.35)\end{array}$ & $\begin{array}{c}.515 \\
(1.64)\end{array}$ & $\begin{array}{c}.325 \\
(1.03)\end{array}$ \\
\hline $\begin{array}{l}n \\
\mathbf{V W O}\end{array}$ & 158 & 164 & 164 & 164 & 162 \\
\hline Treated & $\begin{array}{c}-.379 \\
(-1.33)\end{array}$ & $\begin{array}{l}.502^{*} \\
(1.78)\end{array}$ & $\begin{array}{c}.127 \\
(0.44)\end{array}$ & $\begin{array}{c}.303 \\
(1.08)\end{array}$ & $\begin{array}{c}.245 \\
(0.88)\end{array}$ \\
\hline$n$ & 211 & 214 & 214 & 214 & 214 \\
\hline
\end{tabular}

Note: OLS regression coefficients. T-statistics reported in parentheses. Stars indicate significance of coefficients: ${ }^{* * *}$ at $1 \%,{ }^{* *}$ at $5 \%,{ }^{*}$ at $10 \%$. Top panel for complete sample, lower panels results for subsamples, using same set of controls (coefficients on controls omitted). 
Table 5.C.5: Attribution Style: Positive and Negative Events

\begin{tabular}{|c|c|c|c|c|c|c|}
\hline & \multicolumn{3}{|c|}{ Positive Events } & \multicolumn{3}{|c|}{ Negative Events } \\
\hline & $\begin{array}{l}\underset{\pi}{\pi} \\
\stackrel{0}{0} \\
\stackrel{1}{1}\end{array}$ & 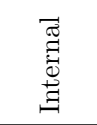 & $\begin{array}{l}\frac{0}{0} \\
\frac{\pi}{\pi} \\
\text { in }\end{array}$ & 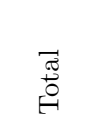 & 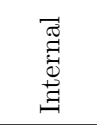 & $\begin{array}{l}\frac{0}{0} \\
\frac{\pi}{\pi} \\
i n\end{array}$ \\
\hline \multicolumn{7}{|l|}{ All } \\
\hline \multirow[t]{2}{*}{ Treated } & $.263^{* *}$ & $.285^{* *}$ & $.241^{*}$ & .071 & -.020 & .162 \\
\hline & $(2.37)$ & $(2.33)$ & $(1.75)$ & $(0.56)$ & $(-0.14)$ & $(0.95)$ \\
\hline \multirow[t]{2}{*}{ Graduation year } & $-.0900^{* *}$ & -.078 & $-.102^{*}$ & -.007 & .037 & -.051 \\
\hline & $(-2.08)$ & $(-1.64)$ & $(-1.90)$ & $(-0.14)$ & $(0.66)$ & $(-0.77)$ \\
\hline \multirow[t]{2}{*}{ Male } & .001 & -.050 & .052 & -.042 & -.055 & -.028 \\
\hline & $(0.01)$ & $(-0.83)$ & $(0.76)$ & $(-0.66)$ & $(-0.77)$ & $(-0.33)$ \\
\hline \multirow[t]{2}{*}{ VWO } & .046 & -.005 & .097 & .031 & .025 & .038 \\
\hline & $(0.73)$ & $(-0.07)$ & $(1.24)$ & $(0.44)$ & $(0.30)$ & $(0.40)$ \\
\hline \multirow[t]{2}{*}{ CITO } & .001 & .006 & -.003 & .005 & .006 & .004 \\
\hline & $(0.21)$ & $(0.80)$ & $(-0.38)$ & $(0.62)$ & $(0.67)$ & $(0.36)$ \\
\hline \multirow[t]{2}{*}{ CITO missing } & -.088 & -.077 & -.100 & .027 & .072 & -.018 \\
\hline & $(-1.44)$ & $(-1.14)$ & $(-1.31)$ & $(0.38)$ & $(0.89)$ & $(-0.19)$ \\
\hline$n$ & 374 & 374 & 374 & 373 & 373 & 373 \\
\hline \multicolumn{7}{|l|}{ Boys } \\
\hline \multirow[t]{2}{*}{ Treated } & $.384^{* *}$ & .312 & $.457^{* *}$ & .084 & .079 & .089 \\
\hline & $(2.27)$ & (1.61) & $(2.15)$ & $(0.43)$ & $(0.36)$ & $(0.32)$ \\
\hline$n$ & 150 & 150 & 150 & 150 & 150 & 150 \\
\hline \multicolumn{7}{|l|}{ Girls } \\
\hline \multirow[t]{2}{*}{ Treated } & .148 & .236 & .060 & .066 & -.075 & .207 \\
\hline & $(1.00)$ & (1.48) & $(0.33)$ & $(0.40)$ & $(-0.39)$ & $(0.97)$ \\
\hline$n$ & 224 & 224 & 224 & 223 & 223 & 223 \\
\hline \multicolumn{7}{|l|}{ HAVO } \\
\hline \multirow[t]{2}{*}{ Treated } & .228 & .147 & .309 & .042 & -.168 & .251 \\
\hline & $(1.25)$ & $(0.72)$ & (1.42) & $(0.24)$ & $(-0.77)$ & $(0.99)$ \\
\hline$n$ & 161 & 161 & 161 & 161 & 161 & 161 \\
\hline \multicolumn{7}{|l|}{ VWO } \\
\hline \multirow[t]{2}{*}{ Treated } & $.281^{* *}$ & $.361^{* *}$ & .201 & .115 & .074 & .157 \\
\hline & (1.99) & $(2.38)$ & (1.11) & $(0.64)$ & $(0.38)$ & $(0.68)$ \\
\hline$n$ & 213 & 213 & 213 & 212 & 212 & 212 \\
\hline
\end{tabular}

Note: OLS regression coefficients. T-statistics reported in parentheses. Stars indicate significance of coefficients: $* * *$ at $1 \%, * *$ at $5 \%, *$ at $10 \%$. Top panel for complete sample, lower panels results for subsamples, using same set of controls (coefficients on controls omitted). 



\section{Bibliography}

Almlund, M., Duckworth, A. L., Heckman, J. J., \& Kautz, T. D. (2011). Personality psychology and economics. IZA Discussion Paper No. 5500.

Amato, P. \& Keith, B. (1991). Parental divorce and the well-being of children: A metaanalysis. Psychological Bulletin, 110(1), 26-46.

Amato, P. R. (2001). Children of divorce in the 1990s: An update of the Amato and Keith (1991) meta-analysis. Journal of Family Psychology, 15(3), 355 - 370.

Andersson, G. (2002). Children's experience of family disruption and family formation: Evidence from 16 FFS countries. Demographic Research, 7, $343-364$.

Baumeister, R. \& Tierney, J. (2012). Willpower: Rediscovering the Greatest Human Strength. Penguin Books.

Becker, A., Deckers, T., Dohmen, T., Falk, A., \& Kosse, F. (2012). The relationship between economic preferences and psychological personality measures. Annual Review of Economics, 4(1), $453-478$.

Becker, G. S. (1964). Human Capital: A Theoretical and Empirical Analysis, with Special Reference to Education. Chicago: University of Chicago Press.

Bekkers, R. \& Karr, L. B. (2008). Evaluatieonderzoek maatschappelijke stage. Technical report, Universiteit Utrecht, Faculteit Sociale Wetenschappen.

Bekkers, R., Spenkelink, S., Ooms, M., \& Immerzeel, T. (2010). Maatschappelijke stage en burgerschap: Rapportage schooljaar 2008/2009. Technical report, Universiteit Utrecht, Faculteit Sociale Wetenschappen.

Belleman, B. (2012). Prestatieafspraken: instellingen durven weinig te beloven. In Onderwijs Innovatie. Open Universiteit.

Benson, H. (2010). Family breakdown in the UK: It's not about divorce. Report, Bristol Community Family Trust.

Bierman, K. L., Coie, J. D., Dodge, K. A., Greenberg, M. T., Lochman, J. E., McMahon, R. J., \& Pinderhughes, E. (2010). The effects of a multiyear universal social-emotional learning program: The role of student and school characteristics. Journal of Consulting and Clinical Psychology, 78(2), 156 - 168.

Björklund, A., Ginther, D. K., \& Sundström, M. (2007). Family structure and child outcomes in the USA and Sweden. Journal of Population Economics, 20(1), 183 - 201.

Björklund, A. \& Sundström, M. (2006). Parental separation and children's educational attainment: A siblings analysis on Swedish register data. Economica, 73(292), 605 - 624 .

Borghans, L., Diris, R., Heckman, J. J., Kautz, T., , \& Ter Weel, B. (2012). Fostering non-cognitive traits to promote lifetime success. Technical report, OECD. 
Borghans, L., Duckworth, A. L., Heckman, J. J., \& Ter Weel, B. (2008a). The economics and psychology of personality traits. Journal of Human Resources, 43(4), 972 - 1059.

Borghans, L. \& Golsteyn, B. H. H. (2007). Skill transferability, regret and mobility. Applied Economics, 39(13-15), 1663 - 1677.

Borghans, L., Meijers, H., \& Ter Weel, B. (2008b). The role of noncognitive skills in explaining cognitive test scores. Economic Inquiry, 46(1), 2 - 12.

Borghans, L., Ter Weel, B., \& Weinberg, B. A. (2006). People people: Social capital and the labor-market outcomes of underrepresented groups. NBER Working Paper No. 11985.

Borghans, L., Ter Weel, B., \& Weinberg, B. A. (2008c). Interpersonal styles and labor market outcomes. Journal of Human Resources, 43(4), 815 - 858.

Brunello, G. \& Schlotter, M. (2011). Non cognitive skills and personality traits: Labour market relevance and their development in education and training systems. IZA Discussion Paper No. 5743.

Buchsbaum, D. G., Buchanan, R. G., Centor, R. M., Schnoll, S. H., \& Lawton, M. J. (1991). Screening for alcohol abuse using CAGE scores and likelihood ratios. Annals Of Internal Medicine, $115(10), 774-777$.

Chen, S. H., Chen, Y.-C., \& Liu, J.-T. (2009). The impact of unexpected maternal death on education: First evidence from three national administrative data links. American Economic Review, 99(2), 149 - 153.

Cobb-Clark, D. A. \& Schurer, S. (2012). The stability of big-five personality traits. Economics Letters, $115(1), 11-15$.

Cobb-Clark, D. A. \& Tan, M. (2011). Noncognitive skills, occupational attainment, and relative wages. Labour Economics, 18(1), 1 - 13.

Cohen, L., van den Bout, J., Kramer, W., \& van Vliet, T. (1986). A Dutch Attributional Style Questionnaire: Psychometric properties and findings of some Dutch-American differences. Cognitive Therapy and Research, 10(6), 665 - 669.

Coneus, K., Laucht, M., \& Reuss, K. (2012). The role of parental investments for cognitive and noncognitive skill formation-evidence for the first 11 years of life. Economics and Human Biology, 10(2), 189 - 209.

Conti, G., Hansman, C., Heckman, J. J., Novak, M. F. X., Ruggiero, A., \& Suomi, S. J. (2012). Primate evidence on the late health effects of early-life adversity. PNAS Proceedings of the National Academy of Sciences of the United States of America, 109(23), 8866 -8871 .

Conti, G., Heckman, J. J., \& Urzua, S. (2010). Early endowments, education, and health. Working Papers 2011-001, Human Capital and Economic Opportunity Working Group.

Corak, M. (2001). Death and divorce: The long-term consequences of parental loss on adolescents. Journal of Labor Economics, 19(3), $682-715$.

Costa, P. T. J. \& McCrae, R. R. (2008). The Revised NEO Personality Inventory (NEOPI-R), (pp. 179 - 198). Sage Publications, Inc.

Cunha, F. \& Heckman, J. J. (2007). The technology of skill formation. American Economic Review, $97(2), 31-47$.

Cunha, F. \& Heckman, J. J. (2008). Formulating, identifying and estimating the technology of cognitive and noncognitive skill formation. Journal of Human Resources, 43(4), 738 782 .

Cunha, F., Heckman, J. J., Lochner, L., \& Masterov, D. V. (2006). Interpreting the evidence on life cycle skill formation. In E. Hanushek \& F. Welch (Eds.), Handbook of the Economics of Education (pp. 697-812).

Cunha, F., Heckman, J. J., \& Schennach, S. M. (2010). Estimating the technology of cognitive and noncognitive skill formation. Econometrica, 78(3), 883 - 931. 
Currie, J. \& Stabile, M. (2006). Child mental health and human capital accumulation: The case of ADHD. Journal Of Health Economics, 25(6), 1094 - 1118.

Daly, M., Harmon, C. P., \& Delaney, L. (2009). Psychological and biological foundations of time preference. Journal of the European Economic Association, 7(2/3), 659 - 669.

Dohmen, T., Falk, A., Huffman, D., \& Sunde, U. (2010). Are risk aversion and impatience related to cognitive ability? American Economic Review, $100(3), 1238$ - 1260.

Durlak, J. A., Weissberg, R. P., Dymnicki, A. B., Taylor, R. D., \& Schellinger, K. B. (2011). The impact of enhancing students' social and emotional learning: A meta-analysis of school-based universal interventions. Child Development, 82(1), 405 - 432.

Ermisch, J., Francesconi, M., \& Pevalin, D. J. (2004). Parental partnership and joblessness in childhood and their influence on young people's outcomes. Journal of the Royal Statistical Society: Series A (Statistics in Society), 167(1), $69-101$.

Ermisch, J. F. \& Francesconi, M. (2001). Family structure and children's achievements. Journal of Population Economics, 14(2), 249.

Fehr, E. (2009). On the economics and biology of trust. Journal of the European Economic Association, 7(2/3), $235-266$.

Feinstein, L. (2000). The relative economic importance of academic, psychological and behavioural attributes developed on childhood. Discussion paper 443, Centre for Economic Performance, London School of Economics and Political Science, London, UK.

Filer, R. K. (1983). Sexual differences in earnings: The role of individual personalities and tastes. Journal of Human Resources, 18(1), 82 - 99.

Flouri, E. \& Buchanan, A. (2004). Early father's and mother's involvement and child's later educational outcomes. British Journal of Educational Psychology, 74, 141 - 153.

Francesconi, M., Jenkins, S. P., \& Siedler, T. (2010). Childhood family structure and schooling outcomes: Evidence for Germany. Journal of Population Economics, 23(3), 1073 - 1103.

Frederick, S., Loewenstein, G., \& O’Donoghue, T. (2002). Time discounting and time preference: A critical review. Journal of Economic Literature, 40(2), 351 - 401.

Gammage, P. (1975). Socialisation, schooling and locus of control. PhD thesis, Bristol University.

Ghera, M. M., Marshall, P. J., Fox, N. A., Zeanah, C. H., Nelson, C. A., Smyke, A. T., \& Guthrie, D. (2009). The effects of foster care intervention on socially deprived institutionalized children's attention and positive affect: Results from the BEIP study. Journal of Child Psychology \& Psychiatry, 50(3), 246 - 253.

Ginther, D. K. \& Pollak, R. A. (2004). Family structure and children's educational outcomes: blended families, stylized facts, and descriptive regressions. Demography, 41(4), 671 - 696 .

Gladwell, M. (2008). Outliers: The Story of Success. Little: Brown and Company.

Goldberg, L. R. (1992). The development of markers for the big-five factor structure. Psychological Assessment, 4(1), 26 - 42.

Goldberg, L. R. (1993). The structure of phenotypic personality traits. American Psychologist, 48(1), $26-34$.

Goldberg, L. R., Johnson, J. A., Eber, H. W., Hogan, R., Ashton, M. C., Cloninger, C. R., \& Gough, H. G. (2006). The international personality item pool and the future of publicdomain personality measures. Journal of Research in Personality, 40(1), $84-96$.

Goldberg, L. R., Sweeney, D., Merenda, P. F., \& Hughes, J. E. J. (1998). Demographic variables and personality: The effects of gender, age, education, and ethnic/racial status on self-descriptions of personality attributes. Personality and Individual Differences, 24(3), $393-403$.

Gould, E. D., Lavy, V., \& Paserman, M. D. (2011). Sixty years after the magic carpet ride: 
The long-run effect of the early childhood environment on social and economic outcomes. Review of Economic Studies, 78(3), 938 - 973.

Gould, E. D. \& Simhon, A. (2011). Does quality time produce quality children? Evidence on the intergenerational transmission of human capital using parental deaths. CEPR Discussion Papers: 8258.

Gronau, R. (1974). Wage comparisons - a selectivity bias. Journal of Political Economy, 82(6), $1119-1143$.

Grove, W. A., Hussey, A., \& Jetter, M. (2011). The gender pay gap beyond human capital: Heterogeneity in noncognitive skills and in labor market tastes. Journal of Human Resources, 46(4), $827-874$.

Heckman, J. H., Moon, S. H., Pinto, R. R., Savelyev, P., \& Yavitz, A. (2010). Analyzing social experiments as implemented: A reexamination of the evidence from the HighScope Perry Preschool Program. Quantitative Economics, 1(1), 1 - 46.

Heckman, J. J. (2007). The economics, technology, and neuroscience of human capability formation. Proceedings Of The National Academy Of Sciences Of The United States Of America, 104 (33), 13250 - 13255.

Heckman, J. J., Malofeeva, L., Pinto, R. R., \& Savelyev, P. (2008). The effect of the Perry Preschool Program on cognitive and noncognitive skills: Beyond treatment effects. Unpublished manuscript, University of Chicago, Department of Economics.

Heckman, J. J., Malofeeva, L., Pinto, R. R., \& Savelyev, P. (2012). Understanding the mechanisms through which an influential early childhood program boosted adult outcomes. IZA Discussion Paper No. 7040.

Heckman, J. J., Stixrud, J., \& Urzua, S. (2006). The effects of cognitive and noncognitive abilities on labor market outcomes and social behavior. Journal of Labor Economics, $24(3), 411-482$.

Heller, S., Pollack, H., Ander, R., \& Ludwig, J. (2012). Improving social-cognitive skills among disadvantaged youth: A randomized field experiment. University of Chicago Working Paper.

Herrnstein, R. J. \& Murray, C. A. (1994). The bell curve: Intelligence and class structure in American life. Free Press.

Holmlund, H. \& Silva, O. (2009). Targeting non-cognitive skills to improve cognitive outcomes: Evidence from a remedial education intervention. IZA Discussion Paper No. 4476.

Jackson, J. J., Bogg, T., Walton, K. E., Wood, D., Harms, P. D., Lodi-Smith, J., Edmonds, G. W., \& Roberts, B. W. (2009). Not all conscientiousness scales change alike: A multimethod, multisample study of age differences in the facets of conscientiousness. Journal of Personality and Social Psychology, 96(2), 446 - 459.

John, O. P. \& Srivastava, S. (1999). The Big Five Trait taxonomy: History, measurement, and theoretical perspectives., (pp. $102-138$ ). Guilford Press.

King, M. (1986). At risk drinking among general practice attenders: validation of the cage questionnaire. Psychological Medicine, 16(1), 213 - 217.

Knudsen, E. I., Heckman, J. J., Cameron, J. L., \& Shonkoff, J. P. (2006). Economic, neurobiological, and behavioral perspectives on building America's future workforce. Procedings of the National Academy of Sciences of the United States of America, 103(27), $10155-$ 10162.

Krueger, A. B. \& Schkade, D. (2008). Sorting in the labor market. Journal of Human Resources, 43(4), $859-883$.

Lawrence, D. (1981). The development of a self-esteem questionnaire. British Journal of Educational Psychology, 52, 245 - 251.

Lebel, C. \& Beaulieu, C. (2011). Longitudinal development of human brain wiring continues 
from childhood into adulthood. The Journal of Neuroscience, 31 (30), 10937 - 10947.

Lewis, S., Ross, C., \& Mirowsky, J. (1999). Establishing a sense of personal control in the transition to adulthood. Social Forces, 77, 1573 - 1599.

Martins, P. S. (2010). Can targeted, non-cognitive skills programs improve achievement? evidence from Epis. IZA Discussion Paper No. 5266.

McCrae, R. R. \& Costa, P. T. (1994). The stability of personality: Observation and evaluations. Current Directions in Psychological Science, 3(6), 173 - 175.

McCrae, R. R. \& John, O. P. (1992). An introduction to the five-factor model and its applications. Journal of Personality, 60(2), $175-215$.

Moffitt, T. E., Arseneault, L., Belsky, D., Dickson, N., Hancox, R. J., Harrington, H., Houts, R., Poulton, R., Roberts, B. W., Ross, S., Sears, M. R., Thomson, W. M., \& Caspi, A. (2011). A gradient of childhood self-control predicts health, wealth, and public safety. Proceedings Of The National Academy Of Sciences Of The United States Of America, $108(7), 2693-2698$.

Mueller, G. \& Plug, E. (2006). Estimating the effect of personality on male and female earnings. Industrial and Labor Relations Review, 60(1), 3 - 22.

Murasko, J. E. (2007). A lifecourse study on education and health: The relationship between childhood psychosocial resources and outcomes in adolescence and young adulthood. Social Science Research, 36, 1348 - 1370.

Nyhus, E. K. \& Pons, E. (2005). The effects of personality on earnings. Journal of Economic Psychology, 26(3), $363-384$.

Office for National Statistics (2010). Table 1. summary of key birth statistics, 1938-2010. In Birth summary tables, England and Wales, 2010.

Persico, N., Postlewaite, A., \& Silverman, D. (2004). The effect of adolescent experience on labor market outcomes: The case of height. Journal of Political Economy, 112(5), 1019 $-1053$.

Peterson, C., Semmel, A., von Baeyer, C., Abramson, L. Y., Metalsky, G. I., \& Seligman, M. E. P. (1982). The Attributional Style Questionnaire. Cognitive Therapy and Research, $6(3), 287-300$.

Poropat, A. E. (2009). A meta-analysis of the five-factor model of personality and academic performance. Psychological Bulletin, 135(2), 322 - 338.

Robbins, S. B., Lauver, K., Le, H., Davis, D., Langley, R., \& Carlstrom, A. (2004). Do psychosocial and study skill factors predict college outcomes?: A meta-analysis. Psychological Bulletin, 130, $261-288$.

Roberts, B., Robins, R., Trzesniewski, K., \& Caspi, A. (2003). Personality Trait Development in Adulthood, chapter 26, (pp. 579-596). New York: Kluwer Academic/Plenum Publishers.

Roberts, B. W. (2009). Back to the future: Personality and assessment and personality development. Journal of Research in Personality, 43(2), 137 - 145.

Roberts, B. W. \& Bogg, T. (2004). A longitudinal study of the relationships between conscientiousness and the social- environmental factors and substance-use behaviors that influence health. Journal of Personality, 72(2), 325 - 353.

Roberts, B. W., Bogg, T., Walton, K. E., Chernyshenko, O. S., \& Stark, S. E. (2004). A lexical investigation of the lower-order structure of conscientiousness. Journal of Research in Personality, 38(2), $164-178$.

Roberts, B. W. \& DelVecchio, W. F. (2000). The rank-order consistency of personality traits from childhood to old age: A quantitative review of longitudinal studies. Psychological Bulletin, 126(1), 3 - 25.

Roberts, B. W. \& Mroczek, D. (2008). Personality trait change in adulthood. Current 
Directions in Psychological Science, 17, 31 - 35.

Roberts, B. W., Walton, K. E., \& Viechtbauer, W. (2006). Patterns of mean-level change in personality traits across the life course: A meta-analysis of longitudinal studies. Psychological Bulletin, 132(1), 1 - 25.

Roberts, B. W., Wood, D., \& Caspi, A. (2008). The development of personality traits in adulthood., (pp. 375 - 398). Guilford Press.

Robins, R. \& Trzesniewski, K. (2005). Self-esteem development across the lifespan. Current Directions in Psychological Science, 14, 158 - 162.

Rutter, M., Beckett, C., Castle, J., Colvert, E., Kreppner, J., Mehta, M., Stevens, S., \& Sonuga-Barke, E. (2007). Effects of profound early institutional deprivation: An overview of findings from a UK longitudinal study of Romanian adoptees. European Journal of Developmental Psychology, 4(3), 332 - 350.

Rutter, M., Sonuga-barke, E. J., Beckett, C., Castle, J., Kreppner, J., Kumsta, R., Schlotz, W., Stevens, S., \& Bell, C. A. (2010). Deprivation-specific psychological patterns: Effects of institutional deprivation. Monographs of the Society for Research in Child Development, $75(1)$, vii-ix, $1-252$.

Rutter, M., Tizard, J., \& Whitmore, K. (1970). Education, health and behaviour. London: Longman.

Schweinhart, L. J., Montie, J., Xiang, Z., Barnett, W. S., Belfield, C. R., \& Nores, M. (2005). Lifetime effects: The High/Scope Perry Preschool study through age 40. Ypsilanti: High/Scope Press.

Segal, C. (2012). Working when no one is watching: Motivation, test scores, and economic success. Management Science, 58(8), 1438 - 1457.

Shonkoff, J. P. E. \& Phillips, D. A. E. (2000). From neurons to neighborhoods: The science of early childhood development. National Academy Press.

Specht, J., Schmukle, S. C., \& Egloff, B. (2011). Stability and change of personality across the life course: The impact of age and major life events on mean-level and rank-order stability of the Big Five. Journal of Personality ES Social Psychology, 101 (4), 862 - 882.

Sutter, M., Kocher, M. G., Glatzle-Ruetzler, D., \& Trautmann, S. T. (2013). Impatience and uncertainty: Experimental decisions predict adolescents' field behavior. American Economic Review, $103(1), 510$ - 531.

The Research Centre for Education and the Labour Market (2012). Schoolverlaters tussen onderwijs en arbeidsmarkt 2011. Technical Report ROA-R-2012/2, Research Centre for Education and the Labour Market (ROA).

Tough, P. (2012). How Children Succeed: Grit, Curiosity, and the Hidden Power of Character. Houghton Mifflin Harcourt.

Van Eijck, K. \& De Graaf, P. M. (2004). The Big Five at school: The impact of personality on educational attainment. Netherlands' Journal of Social Sciences, 40(1), $24-40$.

Vassend, O. \& Skrondal, A. (1995). Factor analytic studies of the NEO Personality Inventory and the five-factor model: The problem of high structural complexity and conceptual indeterminacy. Personality and Individual Differences, 19(2), 135 - 147.

Von Stumm, S., Gale, C. R., Batty, G. D., \& Deary, I. J. (2009). Childhood intelligence, locus of control and behaviour disturbance as determinants of intergenerational social mobility: British Cohort Study 1970. Intelligence, 329 - 340.

Webb, E. (1915). Character and intelligence. British Journal of Psychology, 1(3).

Zeanah, C., Egger, H., Smyke, A., Nelson, C., Fox, N., Marshall, P., \& Guthrie, D. (2009). Institutional rearing and psychiatric disorders in Romanian preschool children. American Journal of Psychiatry, 166(7), 777 - 785. 


\section{Samenvatting (Summary in Dutch)}

Het is algemeen bekend dat kennis een belangrijke input in het productieproces is, zeker in een kenniseconomie zoals Nederland. Lang werd fysiek kapitaal als voornaamste factor voor economische groei gezien, maar steeds meer wordt duidelijk dat kennis van grotere betekenis is. In de jaren zestig introduceerde Gary Becker (1964) de term menselijk kapitaal, om daarmee de overeenkomst met fysiek kapitaal te benadrukken. Menselijk kapitaal is iets waar je in kunt investeren, maar je zult dit alleen doen wanneer de baten de kosten overstijgen. Hierdoor zien we verschillen in investeringen tussen mensen op basis van verschillen in bijvoorbeeld aangeboren talent.

Beckers oorspronkelijke omschrijving van menselijk kapitaal omvatte een breed scala aan eigenschappen, waaronder cognitief vermogen, gezondheid, en persoonlijkheid. Gedurende lange tijd beperkte de economische literatuur zich voornamelijk tot het bestuderen van cognitieve aspecten van menselijk kapitaal, omdat dit aspect van menselijk kapitaal relatief eenvoudig te meten is. Mede door het gemak van het verzamelen en de beschikbaarheid van toetsresultaten en IQ-scores, hechten tot op heden ook beleidsmakers, scholen, en werkgevers veel waarde aan cognitief vermogen als selectie- en evaluatiecriterium.

Als IQ allesbepalend voor succes zou zijn, dan zouden de mensen met het hoogste IQ ook het meest succesvol zijn. Dit is echter lang niet altijd het geval, zoals blijkt uit de diversiteit in het ledenbestand van Mensa, een internationale organisatie van en voor zeer intelligente mensen. De twee procent best scorenden op een IQ-test komen in aanmerking om lid te worden. Wereldwijd telt Mensa ruim 100.000 leden, onder wie ongeveer 4.300 Nederlanders. Onder de Mensaleden bevinden zich zowel professoren als vrachtwagenchauffeurs, en zowel mensen met meerdere doctortitels, als mensen die vroegtijdig de middelbare school verlaten hebben. ${ }^{1}$ Hoewel vele hoogbegaafden succesvol en gelukkig zijn, eindigt een groot deel ook ongelukkig en vereenzaamd, of zelfs werkloos en fysiek of psychisch ziek. Op het werk hebben hoogbegaafden vaak te kampen met aanpassingsproblemen. Kenmerkende uitspraken vanuit deze medewerkers zelf zijn: "Ik heb een hekel aan social talk" en "Ik ben snel afgeleid," waardoor zij door hun werkgever worden bestempeld als moeilijk benaderbaar en niet sociaal, en als iemand met gebrek aan doorzettingsvermogen en discipline. ${ }^{2}$ Een hoog IQ is dus geen garantie voor succes.

\footnotetext{
${ }^{1}$ Zie www.mensa.nl en www.mensa.org voor meer informatie over Mensa, vragen, en berichten in de pers.

${ }^{2}$ Zie bijvoorbeeld het artikel Hoogbegaafden aan het werk van Noks Nauta en Frans Corten in TBV Voor de praktijk (2002, p.343-346) en het boek Hoogbegaafd, dat zie je zó! van Maud Kooijman.
} 
Uit recent onderzoek blijkt dat de focus op cognitieve vaardigheden kan leiden tot gemiste kansen. Wellicht het meest sprekende voorbeeld wordt beschreven in een serie artikelen van James Heckman over een groep 3-jarige kinderen uit de Verenigde Staten die deel hebben genomen aan het Perry Preschool Program. ${ }^{3}$ Ongeveer de helft van de 123 peuters ontving intensieve begeleiding om hun ontwikkeling te stimuleren, terwijl de andere helft geen extra begeleiding ontving. De experimentele groep met extra begeleiding liet na afloop van het programma een veel grotere stijging in IQ-scores zien dan de controlegroep. Echter, deze snellere ontwikkeling in cognitieve vaardigheden vertraagde met de tijd. Op 8-jarige leeftijd verschilden de twee groepen kinderen niet langer van elkaar qua IQ. Deze kinderen werden herhaaldelijk geënquêteerd, inmiddels tot op hun 40e levensjaar. Hoewel de groepen niet van elkaar verschillen in cognitieve vaardigheden, blijkt de experimentele groep het toch significant beter te doen op het gebied van werk, onderwijs, en criminaliteit. Volgens de onderzoekers worden deze effecten veroorzaakt door verschillen in niet-cognitieve vaardigheden tussen de twee groepen (Heckman et al., 2012). Kinderen uit de experimentele groep scoren hoger op verschillende maten van niet-cognitieve vaardigheden dan kinderen uit de controle groep, die geen extra begeleiding ontvingen.

Deze inzichten hebben bijgedragen aan de ontwikkeling van een onderzoeksveld dat zich richt op het analyseren van de rol van niet-cognitieve vaardigheden in het verklaren van sociaaleconomische uitkomsten. Hoewel het onderscheid tussen cognitieve en niet-cognitieve vaardigheden niet zwart-wit is, wordt de term niet-cognitief over het algemeen gebruikt voor vaardigheden die geen deel uitmaken van wat we zouden omschrijven als cognitief vermogen of pure intelligentie. Het integreren van verschillende wetenschappelijke disciplines heeft geleid tot een enorme groei in kennis over het belang, de veranderingen en de ontwikkeling van niet-cognitieve vaardigheden. ${ }^{4}$ Er wordt lering getrokken uit diverse vakgebieden, van informatie over de werking van de hersenen uit de neurowetenschappen, tot inzichten uit de (persoonlijkheids)psychologie en de economische literatuur, als ook de literatuur over de ontwikkeling van kinderen. Zowel cognitieve als niet-cognitieve vaardigheden hebben hun eigen waarde in het productieproces. Van de Technology of Skill Formation leren we dat de ontwikkeling van beide typen vaardigheden zowel afhangt van aangeboren talent als van investeringen door de jaren heen. ${ }^{5}$

Hoewel het belang van niet-cognitieve vaardigheden duidelijk begint te worden, roepen de nieuwe bevindingen ook vragen op. De eerste vraag is hoe deze vaardigheden gemeten kunnen worden. Vaak wordt hierbij gekeken naar persoonlijkheid. Van oorsprong zijn persoonlijkheid en de ontwikkeling hiervan het domein van psychologen. Zij hebben een grote verscheidenheid aan vragenlijsten ontwikkeld om persoonlijkheid te meten. De meest erkende en meest gebruikte classificatie voor persoonlijkheid is de Big Five, waarbij de persoonlijkheid van een individu ruwweg wordt beschreven door vijf kenmerken, te weten: openheid (voor nieuwe ervaringen), zorgvuldigheid, extraversie, vriendelijkheid, en emotionele stabiliteit. ${ }^{6} \mathrm{Nu}$ persoonlijkheidsvragen worden opgenomen in vragenlijsten en datasets, worden persoonlijkheidskenmerken steeds vaker meegenomen in onderzoek uit andere vakgebieden, waaronder sociologie, gezondheidswetenschappen, neurowetenschappen, en de economische wetenschappen. Deze persoonlijkheidskenmerken

\footnotetext{
${ }^{3}$ Zie bijvoorbeeld Heckman et al. (2008), Heckman et al. (2010) en Heckman et al. (2012).

${ }^{4}$ Zie Borghans et al. (2008a).

${ }^{5}$ The Technology of Skill Formation: zie Cunha et al. (2006) en Cunha \& Heckman (2007).

${ }^{6}$ De Engelse termen voor de Big Five zijn openness (to experience), conscientiousness, extraversion, agreeableness, en emotional stability. Voor een discussie over de verschillende classificaties van persoonlijkheid, zie Borghans et al. (2008a).
} 
kunnen beschouwd worden als voorspellers voor latere uitkomsten, maar ook als uitkomsten op zich. Om resultaten van verschillende onderzoeken te kunnen vergelijken, is het belangrijk dat vergelijkbare maten gebruikt worden om hetzelfde concept te meten. Vandaar dat nietcognitieve vaardigheden in dit proefschrift vooral zijn gedefinieerd aan de hand van de Big Five classificatie van persoonlijkheid.

In overeenstemming met Beckers theorie over menselijk kapitaal, kan persoonlijkheid als kapitaal worden beschouwd waarin geïnvesteerd kan worden. Om de juiste investeringsbeslissing te nemen, heeft een individu bepaalde informatie nodig. Iemand die zijn loon wil maximaliseren zal willen weten welke persoonlijkheidskenmerken zijn werkgever waardeert. Daarna zal hij moeten achterhalen hoe hij op deze kenmerken scoort en of het mogelijk is om zichzelf op deze punten te ontwikkelen of te verbeteren. Wellicht zijn er bepaalde opleidingen of trainingsprogramma's die hierbij kunnen helpen. Dit voorbeeld illustreert drie nieuwe vragen rondom persoonlijkheid. Ten eerste, is persoonlijkheid relevant en zo ja, zijn alle persoonlijkheidskenmerken even belangrijk voor inkomen, opleiding, gezondheid, en andere sociale uitkomsten? Of zijn bepaald eigenschappen belangrijker dan anderen, of hangt het van de situatie af? Als het gaat om cognitieve vaardigheden, of IQ, stopt de ontwikkeling ergens in de kinderjaren. Is dit ook het geval voor persoonlijkheid? Of zijn persoonlijkheidseigenschappen veranderlijk, ook op latere leeftijd? Tot slot, zijn persoonlijkheidskenmerken in beton gegoten of lonen investeringen, en zijn ze dus te beïnvloeden met onderwijs, training of beleid? Deze drie vragen vormen het onderwerp van deze dissertatie.

Hoofdstuk 2 presenteert de huidige stand van zaken in de academische literatuur over deze vragen. Daarin is ook een poging gedaan om resultaten te repliceren, door gebruik te maken van data verzameld bij representatieve steekproeven van de Nederlandse en Duitse bevolking. Hierbij komen enkele tegenstrijdigheden naar boven en wordt een aantal punten herkenbaar die specifieke aandacht vereisen als het gaat om het analyseren van het belang en de ontwikkeling van niet-cognitieve vaardigheden. De daaropvolgende hoofdstukken gaan elk nader in op één van de drie vragen, waardoor een bijdrage geleverd wordt aan de literatuur over de relevantie van (Hoofdstuk 3), de veranderlijkheid van (Hoofdstuk 4), en rendabele investeringen in (Hoofdstuk 5) persoonlijkheidskenmerken.

\section{Persoonlijkheid is relevant}

De relevantie van persoonlijk is terug te zien in de resultaten van diverse studies die aantonen dat persoonlijkheidskenmerken significante voorspellers zijn voor een groot aantal sociaaleconomische uitkomsten. Van de Big Five kenmerken, heeft zorgvuldigheid de grootste voorspellende kracht. Eigen resultaten op basis van de Nederlandse en Duitse steekproeven laten zien dat ook openheid en emotionele stabiliteit sterk correleren met diverse uitkomsten, zoals onderwijs, loon, gezondheid, en algehele tevredenheid of levensgeluk. Het probleem met het bestuderen van correlaties tussen persoonlijkheid en uitkomsten is dat bij veel studies beide gelijktijdig gemeten zijn, wat het moeilijk maakt om te concluderen of het nu de persoonlijkheid is die de uitkomsten beïnvloedt, of dat persoonlijkheid het gevolg is van het succes dat iemand heeft. In de eigen analyses in Hoofdstuk 2 is een poging gedan om hiervoor te corrigeren door persoonlijkheid gemeten in 2005 te gebruiken om uitkomsten gemeten in 2009 te voorspellen. Er bestaat dan echter wel nog het probleem dat vele uitkomsten sterk gecorreleerd zijn over deze korte tijdspanne. Iemand die in 2009 goed verdiende, gelukkig was, of overgewicht had, zat 
waarschijnlijk enkele jaren eerder waarschijnlijk in een vergelijkbare situatie. Daarnaast ontwikkelt persoonlijkheid zich veel minder op latere leeftijd dan gedurende de kinderjaren. In Hoofdstuk 3 wordt deze problematiek opgelost door persoonlijkheid gemeten in de tienerjaren te correleren met uitkomsten op 34-jarige leeftijd aan de hand van de British Cohort Study.

De British Cohort Study van 1970 bevat data over alle kinderen die in één bepaalde week van April 1970 geboren zijn. Deze kinderen en hun ouders worden ongeveer elke vijf jaar opnieuw geïnterviewd. Als de kinderen 10 en 16 jaar oud zijn, wordt ouders gevraagd het gedrag en de persoonlijkheid van hun kind te beoordelen. De antwoorden hierop worden gebruikt om, in termen van de Big Five, elk kind een score te geven voor zorgvuldigheid, extraversie, vriendelijkheid, en emotionele stabiliteit. Deze data bevat daarnaast ook veel informatie over de omgeving waarin het kind opgroeit. Het is cruciaal om deze achtergronden omgevingskenmerken in de analyse mee te nemen, omdat deze zowel samenhangen met persoonlijk als met de gemeten uitkomsten. Door te corrigeren voor de effecten van deze kenmerken op de gemeten correlatie tussen persoonlijkheid en uitkomsten komen we dichterbij het causale verband tussen persoonlijkheid en sociaaleconomische uitkomsten.

De resultaten laten zowel economisch relevante als statistisch significante verbanden zien tussen persoonlijkheid gemeten op 16-jarige leeftijd, en uitkomsten als mensen 34 zijn. De sterkste voorspeller is zorgvuldigheid. Een één standaarddeviatie hogere score op zorgvuldigheid op 16-jarige leeftijd is geassocieerd met een $4 \%$ hoger uurloon op 34-jarige leeftijd, een $3,2 \%$ hogere kans dat men dan een deel van het loon spaart, een $4,2 \%$ lagere kans dat men dan rookt, en een 3,2\% lagere kans dat men dan verslaafd is aan alcohol. De significantie en grootte van deze effecten blijven vrijwel onveranderd als we corrigeren voor eerdere gedragsproblemen of sociaal gedrag, de thuissituatie, of andere maten voor persoonlijkheid, zoals zelfvertrouwen en gevoel voor controle over de dingen in je leven (locus of control). Het corrigeren voor meetfout in de maten voor persoonlijkheid heeft ook geen significante effecten op de resultaten. Deze resultaten laten zien dat er een gradiënt van zorgvuldigheid bestaat die het onderzoeken waard is. Vergeleken met kinderen die weinig veranderen in zorgvuldigheid, scoren kinderen die tussen leeftijd 10 en 16 dalen in de verdeling van zorgvuldigheid minder goed op onze sociaaleconomische uitkomsten op volwassen leeftijd. Deze resultaten laten zien dat bepaalde persoonlijkheidskenmerken waardevol zijn voor een reeks uitkomsten. De volgende vraag is dan of deze eigenschappen binnen een persoon kunnen veranderen, of dat deze genetisch en/of op vroege leeftijd bepaald worden en dus niet met interventies te beïnvloeden zijn.

\section{Persoonlijkheid verandert}

Hoe persoonlijkheid met leeftijd samenhangt, is onderzocht in een groot aantal studies. Deze resultaten zijn door Roberts en coauteurs gecombineerd in metastudies, die aantonen dat de verschillende Big Five kenmerken zich over de levensjaren heen anders ontwikkelen. ${ }^{7}$ Tot in (vroege) volwassenheid ontwikkelen de meeste eigenschappen zich positief, met een stijging in zorgvuldigheid en emotionele stabiliteit. Deze ontwikkeling is ook terug te zien in de resultaten gebaseerd op de Nederlandse en Duitse data. De resultaten over de ontwikkeling van de overige kenmerken zijn minder eenduidig. De conclusies over de groei van persoonlijkheid over de levensjaren hangen samen met de steekproef die gebruikt is, maar ook met de grootte van die steekproef en met hoe persoonlijkheid gemeten is. Hetzelfde geldt

\footnotetext{
${ }^{7}$ Zie Roberts \& DelVecchio (2000) en Roberts et al. (2006).
} 
voor de vraag op welke leeftijd persoonlijkheid stabiliseert, of niet meer verandert. Hoewel er geen conclusie mogelijk is wat betreft de leeftijd waarop persoonlijkheid vrijwel stabiel is, is het wel duidelijk dat persoonlijkheid zich tot een latere leeftijd blijft ontwikkelen dan $\mathrm{IQ}$, en ook op latere leeftijd nog gevoelig is voor veranderingen in de omgeving.

De invloed van de omgeving op persoonlijkheid wordt onderzocht in de literatuur over het effect van ingrijpende gebeurtenissen. Veranderingen in gezondheid, familiesituatie, en werk worden in dat onderzoek gerelateerd aan veranderingen in Big Five persoonlijkheidskenmerken bij volwassenen. Cobb-Clark en Schurer (2012) maken gebruik van Australische data en concluderen dat deze ingrijpende gebeurtenissen tussen 2005 en 2009 geen goede verklaring zijn voor de persoonlijkheidsontwikkeling tussen deze twee jaren. Dezelfde verbanden worden onderzocht door Specht, Schmukle en Egloff (2011), met gebruik van Duitse data. Zij laten zien dat als verschillende gebeurtenissen samengenomen worden, het effect van de specifieke gebeurtenissen over het hoofd gezien kan worden. Daarnaast worden specifieke gebeurtenissen zowel voorafgegaan als gevolgd door veranderingen in bepaalde persoonlijkheidseigenschappen. De invloed van werken, trouwen, scheiden, en ervaren van sterfgevallen is verschillend voor de afzonderlijke kenmerken, en is ook verschillend voor mannen en vrouwen.

Gegeven dat persoonlijkheid grotere veranderingen kent in de kinderjaren, zullen ingrijpende gebeurtenissen gedurende deze periode waarschijnlijk ook een grotere impact op persoonlijkheid hebben. Kinderen die opgroeien in een minder bevoorrechte omgeving worden blootgesteld aan risicofactoren die weer samenhangen met een lagere kans op economisch succes en een lagere kwaliteit van leven. ${ }^{8}$ Het gaat hierbij vooral om het verband tussen ouderlijke investeringen en de ontwikkeling van hun kinderen. Coneus en coauteurs (2012) laten het verband zien tussen ouderlijke investeringen en de ontwikkeling van cognitieve en niet-cognitieve vaardigheden van hun kinderen. Persoonlijkheidsmaten gerelateerd aan zorgvuldigheid lijken het sterkst beïnvloed te worden door ouderlijke investeringen. Daarnaast zijn de effecten verschillend voor jongens en meisjes. Daarnaast is ook duidelijk dat de impact van investeringen groter is op jongere leeftijd. Studies over het effect van sterfte van een ouder of scheiding van ouders vinden hetzelfde patroon. Hoe jonger het kind, hoe groter het effect van de verandering. Meta-studies laten een significant verband zien tussen het ervaren van een echtscheiding en sociaal-wenselijk gedrag en psychologische ontwikkeling. ${ }^{9}$ De conclusies over de grootte van het effect hangen echter sterk samen met de methodologie die in de verschillende studies zijn toegepast. Hierbij gaat het vooral om de grootte van de steekproef en welke variabelen wel of niet meegenomen zijn in het onderzoek.

Hoofdstuk 4 draagt bij aan deze literatuur door de invloed van het wegvallen van een ouder op de ontwikkeling van de persoonlijkheid van het kind te analyseren. Hierbij wordt gebruik gemaakt van data van het al genoemde Britse cohort uit 1970. Er is een verscheidenheid aan persoonlijkheidsmaten beschikbaar op leeftijden 10 en 16 . Kinderen krijgen een gestandaardiseerde score voor zelfvertrouwen, locus of control, en gedragsproblemen. Deze kinderen worden vervolgens ingedeeld in twee groepen. De eerste groep heeft tot en met leeftijd 16 met beide ouders samengewoond. De tweede groep heeft ergens tussen geboorte en leeftijd 16 één ouder zien wegvallen uit het huishouden. Omdat kinderen een positieve ontwikkeling doormaken in termen van persoonlijkheid, is gekeken naar het effect van deze gezinsverstoring op de positie op leeftijd 16, maar ook naar de verandering in positie tussen 10 en 16 op de verschillende persoonlijkheidsmaten.

\footnotetext{
${ }^{8}$ Zie bijvoorbeeld Knudsen et al. (2006) en Cunha et al. (2006).

${ }^{9}$ Zie Amato \& Keith (1991) en Amato (2001).
} 
De kinderen die een verstoring in de gezinssituatie hebben meegemaakt, scoren op 16-jarige leeftijd lager in zelfvertrouwen en in het geloof de eigen situatie te kunnen beïnvloeden (internal locus of control). Zij scoren ook significant hoger op de maat voor gedragsproblemen. De correlaties nemen af naarmate meer omgevingsfactoren aan het model worden toegevoegd, maar zelfs in het meest uitgebreide model zijn de effecten in de orde van grootte van een kwart standaardafwijking voor de persoonlijkheid op 16-jarige leeftijd. De analyses zijn ook uitgevoerd op de Big Five persoonlijkheidskenmerken, met ook hier gemiddelde effecten van een kwart standaardafwijking. Naast dit niveau-effect, is ook de persoonsontwikkeling tussen 10 en 16 slechter voor kinderen die een ouder hebben verloren.

De effecten van het wegvallen van een ouder zijn echter heterogeen. De reden voor het wegvallen is belangrijk, als ook het geslacht van het kind en de leeftijd waarop de verandering plaatsvindt. Als ouders scheiden, is het effect op de persoonlijkheidsontwikkeling van hun kinderen groter dan wanneer één van de ouders komt te overlijden. In termen van persoonlijkheid beïnvloedt de dood van een ouder jongens sterker dan meisjes, terwijl meisjes juist meer last hebben van het uit elkaar gaan of scheiden van ouders. Tot slot zijn de effecten groter wanneer het kind jonger is ten tijde van de gezinsverstoring.

De correlaties tussen het wegvallen van een ouder en de ontwikkeling van persoonlijkheid zijn deels gedreven door selectie. Dit is terug te zien in het feit dat de correlaties afnemen naarmate meer achtergrondkenmerken in de analyse worden meegenomen. Resultaten van een placebo-analyse bevestigen dit probleem en laten zien dat persoonlijkheid op leeftijd 10 significant gecorreleerd is met het wegvallen van een ouder uit het huishouden tussen 10 en 16. Dit laat zien dat de gemeten gezinsverstoring niet exogeen is. Een deel van dit probleem wordt opgelost door het toevoegen van achtergrondkenmerken. Hoewel een causale interpretatie niet mogelijk is, laten de resultaten duidelijk zien dat de ontwikkeling van persoonlijkheid afhankelijk is van de omgeving. Hieruit volgt vervolgens de vraag of de omgeving zodanig ingericht kan worden om waardevolle eigenschappen te stimuleren.

\section{Investeringen in persoonlijkheid lonen}

Als het aankomt op rendabele investeringen in persoonlijkheid, komt het meeste bewijs voort uit interventieprogramma's die plaatsvinden in de vroege kinderjaren. Het beste voorbeeld is hierboven al beschreven: het Perry Preschool Program. Peuters die onderworpen werden aan de interventie waren als volwassenen meer succesvol. Zij waren beter opgeleid, vonden vaker een baan, en raakten minder vaak in aanraking met politie, in vergelijking met de controlegroep van peuters die geen extra begeleiding ontvingen. Dit verband tussen deelname aan het programma en betere uitkomsten wijst op een positieve invloed van de interventie op waardevolle niet-cognitieve vaardigheden.

De resultaten van verschillende interventieprogramma's zijn moeilijk te vergelijken, vanwege het specifieke karakter van het programma en van de doelgroep. Deze studies kunnen informatie bieden over welke ingrediënten cruciaal zijn voor het succes van een interventie, maar er is ook behoefte aan informatie over programma's die voor de gehele populatie ingevoerd kunnen worden, en niet slechts een bepaalde risicogroep betreffen. Hoofdstuk 5 analyseert een dergelijk generiek programma.

Veranderingen in het curriculum van een middelbare school worden gebruikt om te kijken in hoeverre de lichtingen studenten vóór en ná de introductie van de veranderingen van elkaar verschillen. In 2006 werden op de school een maatschappelijke stage en een extra vak 
over studie- en sociale vaardigheden geïntroduceerd. De stage moest minimaal 40 uur in beslag nemen, en het extra vak werd gedurende de bovenbouw van HAVO en vwo gevolgd voor gemiddeld één uur per week. Door gebruik te maken van het administratiesysteem van de school is het mogelijk het verschil in schoolprestaties te meten tussen de leerlingen die de stage hebben moeten doen en het extra vak hebben doorlopen (de interventiegroep) en de leerlingen die al voor de introductie afstudeerden (de controlegroep). Hoewel er voor sommige vakken een indicatie is dat de prestaties op schoolexamens lager zijn door de toevoegingen aan het curriculum, zijn de gemiddelde cijfers op de schoolexamens en centraal examens niet significant verschillend tussen de twee groepen leerlingen. Toch illustreert dit resultaat dat een aanpassing aan het curriculum ten koste kan gaan van ontwikkeling of prestaties op andere gebieden. Tijd en energie die besteed wordt aan de stage en het extra vak zouden ten koste kunnen gaan van lestijd of studietijd voor andere vakken.

De stage en het vak werden gë̈ntroduceerd met het doel de studievaardigheden en sociale vaardigheden van leerlingen te stimuleren en hen het belang ervan te laten inzien. Om deze effecten te kunnen meten, hebben we vragenlijsten naar oud-leerlingen gestuurd, waarmee onder meer de studiekeuze en persoonlijkheid van oud-leerlingen gemeten kan worden. Wat studiekeuze betreft scoort de interventiegroep hoger op de vraag "Ik heb sterk getwijfeld over mijn studie- en beroepskeuze." Aan de andere kant scoort deze groep lager op de vraag "Achteraf had ik graag een andere opleiding willen kiezen." Ook geven oud-leerlingen uit deze groep aan meer tevreden te zijn over hun gekozen studie dan oud-leerlingen uit de controlegroep. Dit wijst erop dat leerlingen de studiekeuze serieus nemen, en dat de extra aandacht aan die keuze wellicht tot minder uitval zou kunnen lijden. Voor persoonlijkheid wordt naast de Big Five ook de Attribution Style bevraagd. Dit laatste heeft betrekking op de oorzaken voor succes en falen, en meet in hoeverre oud-leerlingen succes en falen aan zichzelf of aan externe factoren toeschrijven. Het is daarmee een maat voor zelfvertrouwen en motivatie. Jongens uit de interventiegroep scoren hoger op zorgvuldigheid, vriendelijkheid, en emotionele stabiliteit dan jongens uit de controlegroep. Datzelfde geldt voor attribution van succes, wat duidt op hoger zelfvertrouwen en motivatie. De positieve associatie tussen de veranderingen in het curriculum en persoonlijkheid is minder groot voor meisjes, en statistisch gezien niet significant. Deze resultaten tonen aan dat een globale interventie de beoogde doelen kan bereiken, maar dat de interventie niet over de gehele populatie succesvol hoeft te zijn.

Bewijs over het belang van persoonlijkheid groeit, en is terug te zien in de relevantie ervan voor een hele reeks uitkomsten. De problemen waar hoogbegaafden mee te kampen hebben laten zien dat je er met intelligentie alleen niet komt. Als loopbaancoach helpt Frans Corten - zelf ook hoogbegaafd - werknemers met een hoog IQ die vastlopen in hun werk. Volgens hem is motivatie allesbepalend. Hoogbegaafden moeten niet vanuit hun competenties benaderd worden. Zij kunnen in principe heel veel, maar als die taken hun geen voldoening geven, worden ze ongelukkig en liggen ze waarschijnlijk ook niet goed in het team. ${ }^{10}$ Nader onderzoek, met variaties in steekproeven, methoden, en contexten, zal meer inzicht bieden in de situaties waarin bepaalde persoonlijkheidskenmerken een belangrijke rol spelen en welke investeringen in persoonlijkheid lonen.

\footnotetext{
${ }^{10}$ Hoog IQ geen succesgarantie, Het Financieele Dagblad, 17 Oktober 2008.
} 



\section{Curriculum Vitae}

Tyas Prevoo was born on March 6, 1984 in Heerlen, The Netherlands. He started studying economics at Maastricht University in 2002, obtaining a Master of Science in International Economics in September 2007, with a major in Behavioral Economics. The following year he conducted research as a visiting research scholar at the University of Chicago (October 2007 - October 2008).

In November of 2008, Tyas returned to Maastricht University as a $\mathrm{PhD}$ candidate at the Department of Economics of the School of Business and Economics. The results of his work as a doctoral candidate are collected in this dissertation. His research has been presented at various international conferences, including annual meetings of the European Society of Population Economics (June 2012), the European Economic Association (August 2012), and the Society of Labor Economists (May 2013).

As of January 2013, Tyas holds the position of postdoctoral researcher at the Department of Economics and the Centre for Education Research Kaans.nl at Maastricht University. 


